\title{
TMI-2 Nozzle Examinations Performed at the Idaho National Engineering Laboratory
}

Manuscript Completed: February 1994

Date Published: March 1994

Prepared by D. W. Akers, B. K. Schuetz

Idaho National Engineering Laboratory

Managed by the U.S. Department of Energy

EG\&G Idaho, Inc.

Idaho Falls, ID 83415

\section{Prepared for}

Division of Systems Research

Office of Nuclear Regulatory Research

U.S. Nuclear Regulatory Commission

Washington, DC 20555-0001

NRC FIN L1004

Under DOE Contract No. DE-AC07-76D01570 


\begin{abstract}
As part of the Three Mile Island Unit 2 (TMI-2) Vessel Investigation Project, under the auspices of the Organization for Economic Cooperation and Development, examinations were performed at the Idaho National Engineering Laboratory on eight nozzles and one guide tube from the TMI-2 reactor vessel. This document describes the examination methodology, summarizes the examination results, and presents interpretations of the results as they relate to the damage to the reactor vessel and to the development of a core relocation scenario. Not all examinations originally proposed as part of this program were completed due to facility problems at the INEL. Consequently, only the results of completed aspects of the examination program are presented.
\end{abstract}

FIN No. L1004-TMI-2 VIP Metallography and Integration 


\section{CONTENTS}

ABSTRACT $\ldots \ldots \ldots \ldots \ldots \ldots \ldots \ldots \ldots \ldots \ldots \ldots \ldots \ldots \ldots \ldots \ldots \ldots \ldots \ldots \ldots \ldots$

LIST OF FIGURES $\ldots \ldots \ldots \ldots \ldots \ldots \ldots \ldots \ldots \ldots \ldots \ldots \ldots \ldots \ldots$

LIST OF TABLES $\ldots \ldots \ldots \ldots \ldots \ldots \ldots \ldots \ldots \ldots \ldots \ldots \ldots \ldots \ldots \ldots$

EXECUTIVE SUMMARY $\ldots \ldots \ldots \ldots \ldots \ldots \ldots \ldots \ldots \ldots \ldots \ldots \ldots$ vii

FOREWORD $\ldots \ldots \ldots \ldots \ldots \ldots \ldots \ldots \ldots \ldots \ldots \ldots \ldots \ldots \ldots \ldots \ldots \ldots$

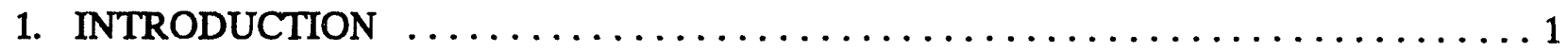

2. SAMPLE PREPARATION AND EXAMINATION METHODOLOGY $\ldots \ldots \ldots \ldots . .2$

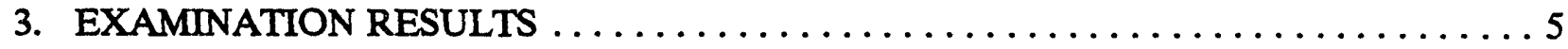

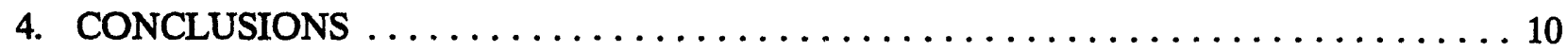

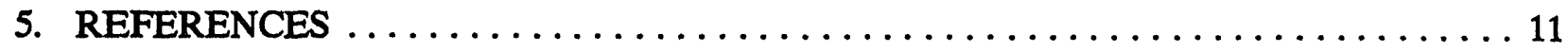

Appendix A-Examination Techniques $\ldots \ldots \ldots \ldots \ldots \ldots \ldots \ldots \ldots \ldots \ldots \ldots \ldots \ldots \ldots$

Appendix B-Visual and Gamma Spectrometry $\ldots \ldots \ldots \ldots \ldots \ldots \ldots \ldots \ldots$

Appendix C-Microstructural Examination Results $\ldots \ldots \ldots \ldots \ldots \ldots \ldots \ldots \ldots \ldots$

Appendix D-SEM and WDX Examination Results $\ldots \ldots \ldots \ldots \ldots \ldots \ldots \ldots \ldots \ldots$ 


\section{LIST OF FIGURES}

1. TMI-2 grid locations showing the positions of the lower head nozzles $\ldots \ldots \ldots . \ldots$

2. Schematic of a TMI-2 lower head nozzle $\ldots \ldots \ldots \ldots \ldots \ldots \ldots \ldots \ldots \ldots$

3. $\mathbf{R}-7$ nozzle sample $\ldots \ldots \ldots \ldots \ldots \ldots \ldots \ldots \ldots \ldots \ldots \ldots \ldots \ldots \ldots \ldots$

4. $\mathrm{K}-11$ nozzle sample $\ldots \ldots \ldots \ldots \ldots \ldots \ldots \ldots \ldots \ldots \ldots \ldots \ldots \ldots \ldots \ldots \ldots$

5. E-7 nozzle sample $\ldots \ldots \ldots \ldots \ldots \ldots \ldots \ldots \ldots \ldots \ldots \ldots \ldots \ldots \ldots \ldots$

6. K-5 guide tube sample $\ldots \ldots \ldots \ldots \ldots \ldots \ldots \ldots \ldots \ldots \ldots \ldots \ldots \ldots \ldots \ldots \ldots$

\section{LIST OF TABLES}

1. Summary of the nozzle and guide tube examinations $\ldots \ldots \ldots \ldots \ldots \ldots$ 


\section{EXECUTIVE SUMMARY}

The accident at the Three Mile Island Unit 2 (TMI-2) reactor resulted in the relocation of about $19,000 \mathrm{~kg}$ of molten core material to the lower head of the reactor vessel. The Vessel Investigation Project (VIP) was formed as a cooperative effort by the Organization for Economic Cooperation and Development (OECD) to assess potential damage to the lower head of the reactor vessel. As part of this project, 14 nozzles and two guide tube segments were removed from the TMI-2 lower head for detailed inspection and microstructural evaluation. The objectives of these examinations were to assess the peak nozzle temperatures near the lower head and to define the mechanisms and extent of nozzle degradation needed to evaluate the challenge to the lower head of the reactor vessel.

Six nozzles were examined at Argonne National Laboratory-East (ANL-E), and eight nozzles and a guide tube were examined at the Idaho National Engineering Laboratory (INEL). The remaining guide tube segment was undamaged and was not examined. In addition, several sections of the INEL nozzles were shipped to CEA-CEN in Saclay, France for examination. Examinations performed at the INEL included visual characterization, gamma spectrometry, sectioning, and optical metallography. Due to facility problems, the examination program was not as extensive as originally planned.

Conclusions of the completed examinations are that some nozzles were melted off, whereas others were only thermally affected by contact with the molten debris. The elevations at which the nozzles were melted off suggests that the molten core debris was on top of a crust of solidified material that apparently insulated the reactor vessel from the hottest debris. The pattern of nozzle degradation was consistent with the location of a hot spot in the TMI-2 vessel at the E7-8/F7-8 location as determined by metallurgical examination of the vessel steel samples.

Evidence of the interaction of molten fuel and the stainless steel and Inconel core structures was found. Interaction phases contained $\mathrm{U}, \mathrm{Zr}, \mathrm{Fe}$, and other structural materials. Both thermal and chemical interaction products were identified. The finding of significant quantities of control assembly materials ( $\mathrm{Ag}, \mathrm{Cd}, \mathrm{In}, \mathrm{Zr}, \mathrm{Fe}$, and $\mathrm{Cr}$ without $\mathrm{U}$ ) in the nozzle material and on nozzle surfaces indicates their presence on the lower head prior to the massive relocation of core debris 226 minutes into the accident. This relocation probably occurred as loose debris, which relocated after fuel failure in the upper core region and before the fuel relocation event. 


\section{FOREWORD}

The contents of this report were developed as part of the Three Mile Island Unit 2 Vessel Investigation Project. This project is jointly sponsored by eleven countries under the auspices of the Nuclear Energy Agency of the Organization for Economic Cooperation and Development. The twelve sponsoring organizations are:

* The Centre d'Etudes d'Energie Nucléaires of Belgium,

* The Säteilyturvakeskus of Finland,

* The Institute de Protection et de Sûreté Nucléaire of the Commissariat à l'Energie Atomique of France,

* The Gesellschaft für Reaktorsicherheit mbH of Germany,

* The Comitato Nazionale per La Ricerca e per Lo Sviluppo Dell' Energia Nucleare e Delle Energie Alternative of Italy,

* The Japan Atomic Energy Research Institute,

* The Consejo de Seguridad Nuclear of Spain,

* The Statens Kärnkraftinspektion of Sweden,

* The Office Fédéral de l'Energie of Switzerland,

* AEA Technology of the United Kingdom,

* The United States Nuclear Regulatory Commission, and

* The Electric Power Research Institute.

The primary objectives of the Nuclear Energy Agency (NEA) are to promote cooperation between its Member governments on the safety and regulatory aspects of nuclear development, and on assessing the future role of nuclear energy as a contributor to economic progress.

This is achieved by:

- encouraging harmonisation of governments' regulatory policies and practices in the nuclear field, with particular reference to the safety of nuclear installations, protection of man against ionising radiation and preservation of the environment, radioactive waste management, and nuclear third party liability and insurance;

- keeping under review the technical and economic characteristics of nuclear power growth and of the nuclear fuel cycle, and assessing demand and supply for the different phases of the nuclear fuel cycle and the potential future contribution of nuclear power to overall energy demand;

- developing exchanges of scientific and technical information on nuclear energy, particularly through participation in common services;

- setting up international research and development programmes and undertakings jointly organized and operated by OECD countries.

In these and related tasks, NEA works in close collaboration with the International Atomic Energy Agency in Vienna, with which it has concluded a Cooperation Agreement, as well as with other international organizations in the nuclear field. 


\section{TMl-2 Nozzle Examinations Ferformed at the INEL}

\section{INTRODUCTION}

The accident at the Three Mile Island Unit 2 (TMI-2) reactor resulted in the relocation of about $19,000 \mathrm{~kg}$ of molten core material to the lower head of the reactor vessel. Relocation occurred at about 224 minutes after the reactor scrammed and lasted for about 2 minutes. The Vessel Investigation Project (VIP), a cooperative effort by the Organization for Economic Cooperation and Development (OECD), has the objective of assessing the potential damage to the lower head of the reactor vessel. As part of the VIP, 14 nozzles and two guide tube segments were removed from the lower head for detailed inspection and metallurgical evaluation.

Six nozzles were examined at Argonne National Laboratory-East (ANL-E). ${ }^{1}$ Eight nozzles and a guide tube were examined at the Idaho National Engineering Laboratory (INEL). Samples from several INEL nozzles and a guide tube were also examined by CEA-CEN in Saclay, France. ${ }^{2}$ The distribution of samples between ANL-E and the INEL was selected so that both laboratories had comparable samples from all sections of the lower head. The purpose of this report is to document the results of the examinations of the INEL nozzles; however, the work performed and results from the INEL samples were limited due to the temporary shutdown of the INEL hotcell facility.

The general objectives of the examinations were to (a) determine peak temperatures of the nozzle materials near the lower head, and (b) assess the mechanisms, and extent of nozzle degradation needed to provide information on the challenge to the lower head of the reactor vessel.

Specific objectives of the examinations were to:

- Determine the nature and extent (axial and radial) of fuel/debris ingress into a nozzle

- Evaluate the nature and degree of chemical and thermal interaction between fuel, debris, and nozzles

- Assess thermal-related metallurgical changes in the nozzle as a function of axial position to evaluate the axial temperature distribution and attempt to quantify temperatures near the vessel

- Determine the position and composition of debris adhering to nozzle surfaces to establish the depth of the debris bed.

The following sections discuss the examination methodology, a summary of the examination results, and the interpretation of the results as they relate to the damage to the reactor vessel. 


\section{SAMPLE PREPARATION AND EXAMINATION METHODOLOGY}

After the nozzles and guide tube samples were removed from the TMI- 2 reactor, they were shipped to the INEL, and the nuzzles were divided between the INEL and ANL-E. The locations of the nozzle samples on the lower head of the reactor vessel are shown in Figure 1, and Figure 2 shows a schematic of a TMI-2 in-core nozzle. Six nozzles, located at core locations M-9, L-6, H-5, H-8, D-10, and E-11, were examined at ANL-E, ${ }^{1}$ and eight nozzles, located at core locations M-10, H-9, L-11, R-7, K-11, K-12, G-5, and E-7, and a guide tube (located at K-5) were examined at the INEL. In addition to the INEL examinations, samples from nozzles E-7, G-5, and R-7, and guide tube K-5 were examined by CEA-CEN in Saclay, France. ${ }^{2}$ At both INEL and ANL E, each nozzle was visually examined and photographed to identify notable areas of damage prior to sectioning. Photographs were taken of the entire external surface, including the bottom and top surfaces. Appendix A describes the photographic method.

Following the visual examinations, each nozzle was characterized using gamma spectrometry to determine the location of radionuclides in the nozzles and to identify locations for sectioniri, and microstructural examinations. The experimental arrangement for the gamma spectrometry measurements is shown in Appendix A. Spectra were obtained at 0.6-cm intervals from top to bottom of each nozzle using a collimated intrinsic germanium detector system. The Cs-137 activity profile was measured because this activity is expected to be representative of the distribution of $\mathrm{UO}_{2}$ fuel present in the nozzles. In addition, both $\mathrm{Co}-60$ and gross activity profiles were measured. The Co-60 measurements were performed to determine the location of activated metals that may have relocated from the reactor core to the lower head.

The follow $\mathrm{g}$ criteria were used to determine the sectioning locations for nozzles for destructive an . sis:

- Top and bottom locations to obtain information on the hottest (sometimes molten) and coldest (nearest the vessel) temperature extremes in a nozzle

- Fuel/nozzle interaction areas (to assess nozzle degradation mechanisms)

- Indications from gamma scans of fuel penetration into the nozzle

- Obvious locations of surface layers on a nozzle

- Locations of surface cracking (possible nozzle degradation mechanism).

After the nozzle sectioning diagrams were developed and reviewed, the nozzles were placed in tubes and vacuum-impregnated with cold-setting epoxy resin. This was done to stabilize loose surface debris, fragile solidified masses, and internal components. Additional vacuumimpregnation was performed during sectioning if significant voids were found in the epoxy and if there was a possibility of material falling out. After sectioning, microstructural specimens were placed in Bakelite or other mounts, vacuum-impregnated with epoxy resin, and polished. Appendix A describes the examination techniques used. 


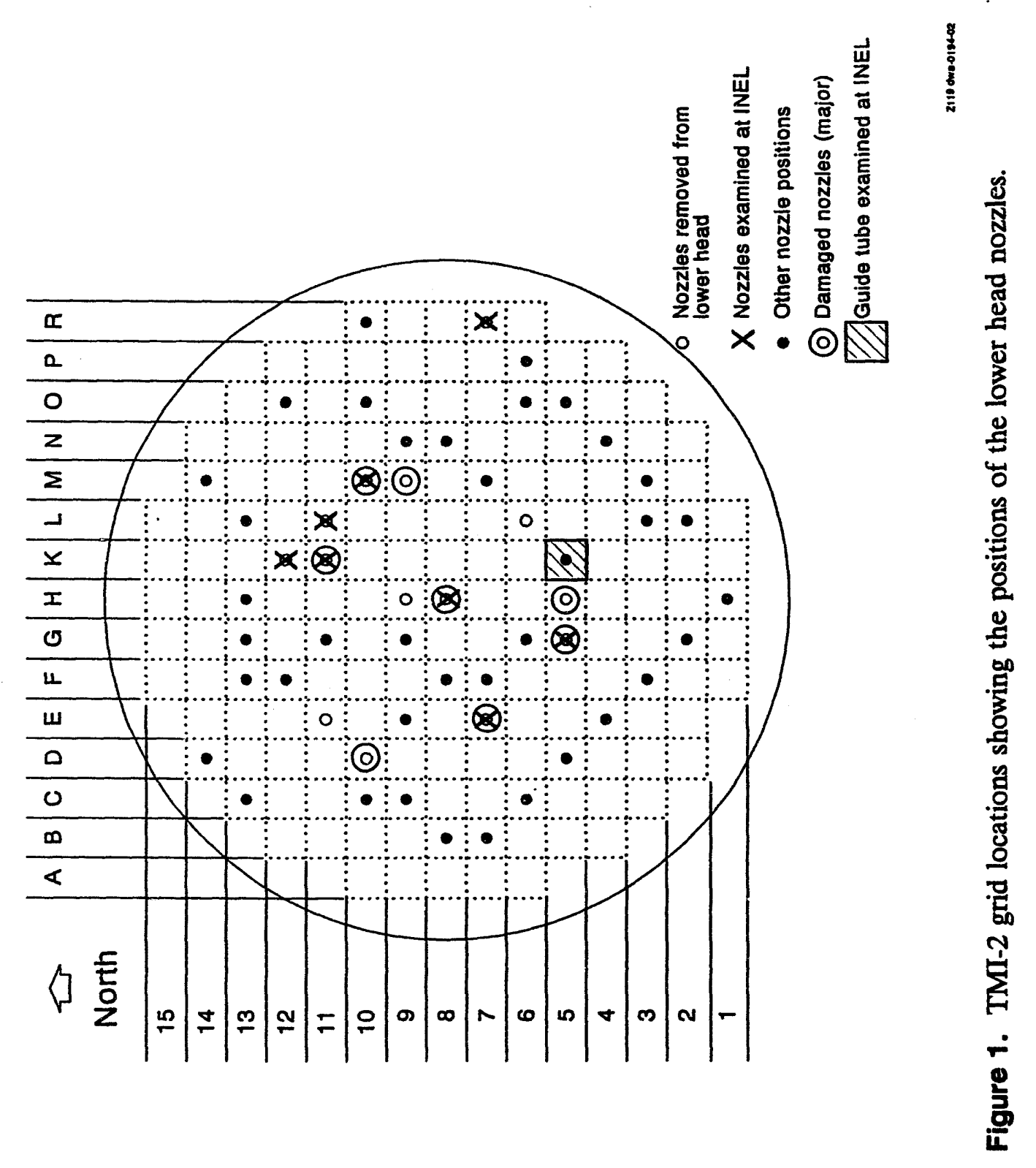




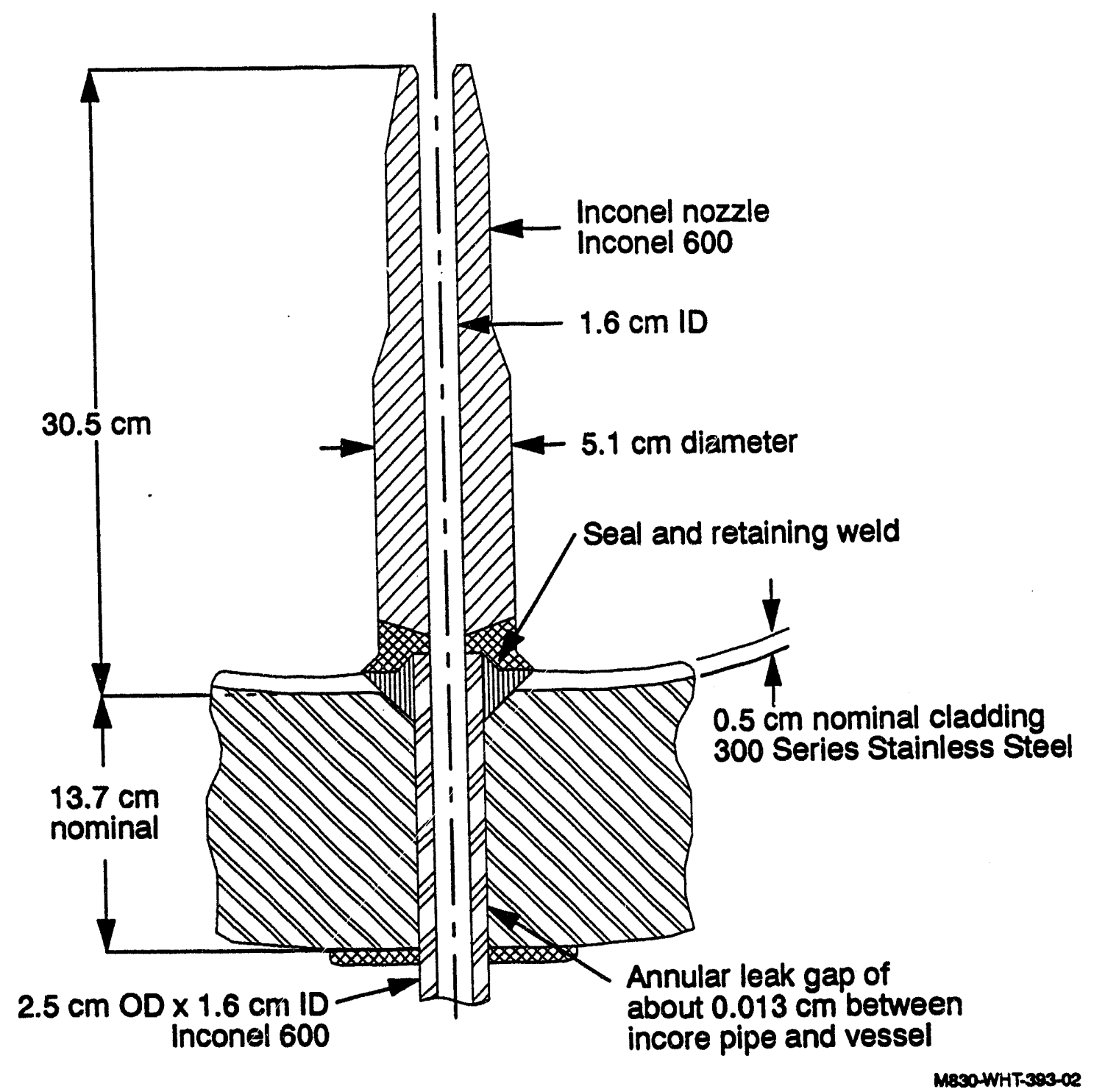

Figure 2. Schematic of a TMI-2 lower head nozzle. 
Following destructive sample preparation, the primary analysis techniques used were optical metallography and scanning electron microscopy (SEM) with energy dispersive $x$-ray (EDS) or wavelength dispersive $\mathrm{x}$-ray (WDS) analyses. The optical metallography analyses were performed to assess the microstructure of deposited fuel debris and the damage to the nozzles. SEM analyses were performed to better assess the microstructure and to determine the distribution of elements and the composition of different phases formed by the interaction of the fuel debris with the nozzle and guide tube material.

\section{EXAMINATION RESULTS}

The TMI-2 nozzle examinations results that were completed include the photographic examinations, radioactive materials distribution, and some microstructural examinations. Table 1 summarizes the observed damage to each nozzle, nozzle segment lengths, and probing results. Each nozzle was probed with a wire to determine the location of blockages. Detailed photographic and radioactivity distribution data for the nozzles are listed in Appendix B. In addition, Appendix B displays the sectioning diagrams for the nozzles.

Because of the extensive amount of information available from the nozzle and guide tube examinations, only representative data are shown and discussed in this report. Photographs of all samples are shown in Appendix B. Photographs of nozzles R-7, K-11, and E-7 are shown in Figures 3 through 5, and are ordered from the least damage to the most. The K-5 guide tube sample is shown in Figure 6.

Figure 3 shows the R-7 nozzle, on which the instrument string was melted off and a bulb of previously molten fuel was found attached to the instrument string. Visual examination of the R-7 nozzle shows little damage except for the top edge. The gamma spectroscopy results for this sample indicate a high-activity region near the top of the nozzle; however, the probing examinations indicated that there were no blockages in the nozzle. As a consequence, only the bulb on the instrument string and the top of the nozzle were sectioned for examination. The top bulb proved to be composed of $\mathrm{U}_{-}, \mathrm{Zr}$-, and Fe-rich interaction phases that are probably representative of the interaction zone between the molten fuel material and the guide tube or instrument string material. A quarter section of the bulb was sent to CEA-CEN for examination. As will be discussed, microstructural examinations of the R-7 bulb indicate apparent interaction between the fuel debris and the instrument string material. Formation of a number of intermediate phases composed of fuel material and constituents of the instrument string are indicated.

Figure 4 shows the K-11 nozzle and the extensive damage to the middle portion with lesser damage to the top and bottom of the nozzle. The nozzle was approximately $235 \mathrm{~mm}(9.3 \mathrm{in}$.) long. The major region of damage extends from about $19 \mathrm{~mm}(0.75 \mathrm{in}$.) from the bottom to within $76 \mathrm{~mm}$ ( $3 \mathrm{in}$.) of the top of the nozzle. Gamma spectroscopy analysis of K-11 indicated the presence of high-activity material (fuel) at several locations near the bottom of the nozzle: $20-63 \mathrm{~mm}(0.8-2.5 \mathrm{in}$.), 70-100 mm (2.8-4 in.), and 200-230 mm (8-9 in.). These data suggest that fuel penetrated through most of the nozzle. A probe of the nozzle was performed from both the top and the bottom. Both probes were able to penetrate to the breach near the center of the nozzle. Sections were removed from the K-11 nozzle from the locations indicated in the gamma 
Table 1. Nozzle and Guide Tube Descriptions.

\begin{tabular}{|c|c|c|}
\hline Location & $\begin{array}{l}\text { Length } \\
\text { (cm) }\end{array}$ & Description \\
\hline \multirow[t]{2}{*}{ E-7 } & $\begin{array}{l}1.3 \text { to } 1.6 \\
\text { (variable) }\end{array}$ & $\begin{array}{l}\text { Nozzle E- } 7 \text { was severely damaged. A thin section of nozzle was } \\
\text { partially molten. In Figure } 5 \text {, it can be seen that a crack extends } \\
\text { all the way through one wall of the nozzle. }\end{array}$ \\
\hline & & Probe results: Not applicable. \\
\hline \multirow[t]{2}{*}{ G-5 } & 4.4 & $\begin{array}{l}\text { Only a short section of the nozzle remained, with melt ingress } \\
\text { into the instrument string hole. Instrument string visible. }\end{array}$ \\
\hline & & $\begin{array}{l}\text { Probe results: The nozzle was completely filled with melt. It } \\
\text { could not be determined if melt penetration ends above or below } \\
\text { the original cut location. }\end{array}$ \\
\hline \multirow[t]{2}{*}{ H-9 } & 23.5 & $\begin{array}{l}\text { The H-9 nozzle exhibits very little damage. The instrument core } \\
\text { string is still intact. }\end{array}$ \\
\hline & & Probe results: No blockage discovered. \\
\hline \multirow[t]{2}{*}{$\mathbf{K}-11$} & 23.5 & $\begin{array}{l}\text { The K-11 nozzle sustained major damage. The entire thickness } \\
\text { of the wall was melted away on one side, and it exhibits slumping } \\
\text { (bending) at about mid-length of the nozzle. It was the only } \\
\text { nozzle found showing undercutting (see Figure B-32). }\end{array}$ \\
\hline & & $\begin{array}{l}\text { Probe results: A wire probe was performed from both ends of } \\
\text { the nozzle section, and although narrowing of the interior } \\
\text { diameter was noted, no blockage was encountered. }\end{array}$ \\
\hline \multirow[t]{2}{*}{$\mathrm{K}-12$} & $\begin{array}{c}24.4 \\
25.7 \\
\text { (w/string) }\end{array}$ & $\begin{array}{l}\text { The } \mathrm{K}-12 \text { nozzle exhibited almost no visible damage. The } \\
\text { activity profile shows that } \mathrm{K}-12 \text { exhibits twice the relative activity } \\
\text { along almost the entire length than does any other nozzle. }\end{array}$ \\
\hline & & Probe results: No blockages were detected. \\
\hline \multirow[t]{2}{*}{$\mathrm{L}-11$} & 22.9 & $\begin{array}{l}\text { Nozzle L-11 was undamaged, except for a } 51-\mathrm{mm}(2 \text {-in.) region } \\
\text { that showed minor damage at the shoulder of the nozzle. }\end{array}$ \\
\hline & & Probe results: No blockages were detected. \\
\hline
\end{tabular}


Table 1. (continued).

\begin{tabular}{|c|c|c|}
\hline Location & $\begin{array}{c}\text { Length } \\
\text { (cm) }\end{array}$ & Description \\
\hline \multirow[t]{2}{*}{ M-10 } & \multirow[t]{2}{*}{17.1} & $\begin{array}{l}\text { The M-10 nozzle exhibited severe melt damage to the top } \\
64 \mathrm{~mm}(2.5 \mathrm{in} \text {.) of the nozzle. The uppermost portion of nozzle } \\
\text { appears to have been sheared off. }\end{array}$ \\
\hline & & $\begin{array}{l}\text { Probe results: An assay of the melt penetration depth } \\
\text { determined the blockage to exist to within } 57 \mathrm{~mm} \text { ( } 2.25 \mathrm{in} \text {.) from } \\
\text { the bottom (butt) end. The base of the melt blockage was of } \\
\text { varying depths. Examination of Figure B- } 8 \text { reveals melt } \\
\text { interaction with the interior wall and the instrument core string } \\
\text { of the nozzle. }\end{array}$ \\
\hline \multirow[t]{2}{*}{ R-7 } & \multirow[t]{2}{*}{$\begin{array}{l}23.2 \\
\text { (with melt bulb } \\
\text { removed) }\end{array}$} & $\begin{array}{l}\text { The initial nozzle condition showed a melt bulb [ } 16-\mathrm{mm} \\
(-0.625 \text {-in.) diameter] attached to the instrument core string and } \\
\text { minor melt damage to the top of the nozzle. }\end{array}$ \\
\hline & & Probe results: No blockages were detected. \\
\hline \multirow[t]{2}{*}{$\begin{array}{l}\text { K-5 } \\
\text { (guide tube) } \\
\text { (MPR-5-24) }\end{array}$} & \multirow[t]{2}{*}{$\begin{array}{c}23.8 \\
\text { (maximum) } \\
14.9 \\
\text { (minimum) }\end{array}$} & $\begin{array}{l}\text { The K-5 guide tube sustained severe bottom end damage. The } \\
\text { edges indicate extensive melt interaction, being deformed } \\
\text { outwards. Guide tube material was much harder than the as- } \\
\text { fabricated stainless steel. }\end{array}$ \\
\hline & & Probe results: Not applicable. \\
\hline
\end{tabular}




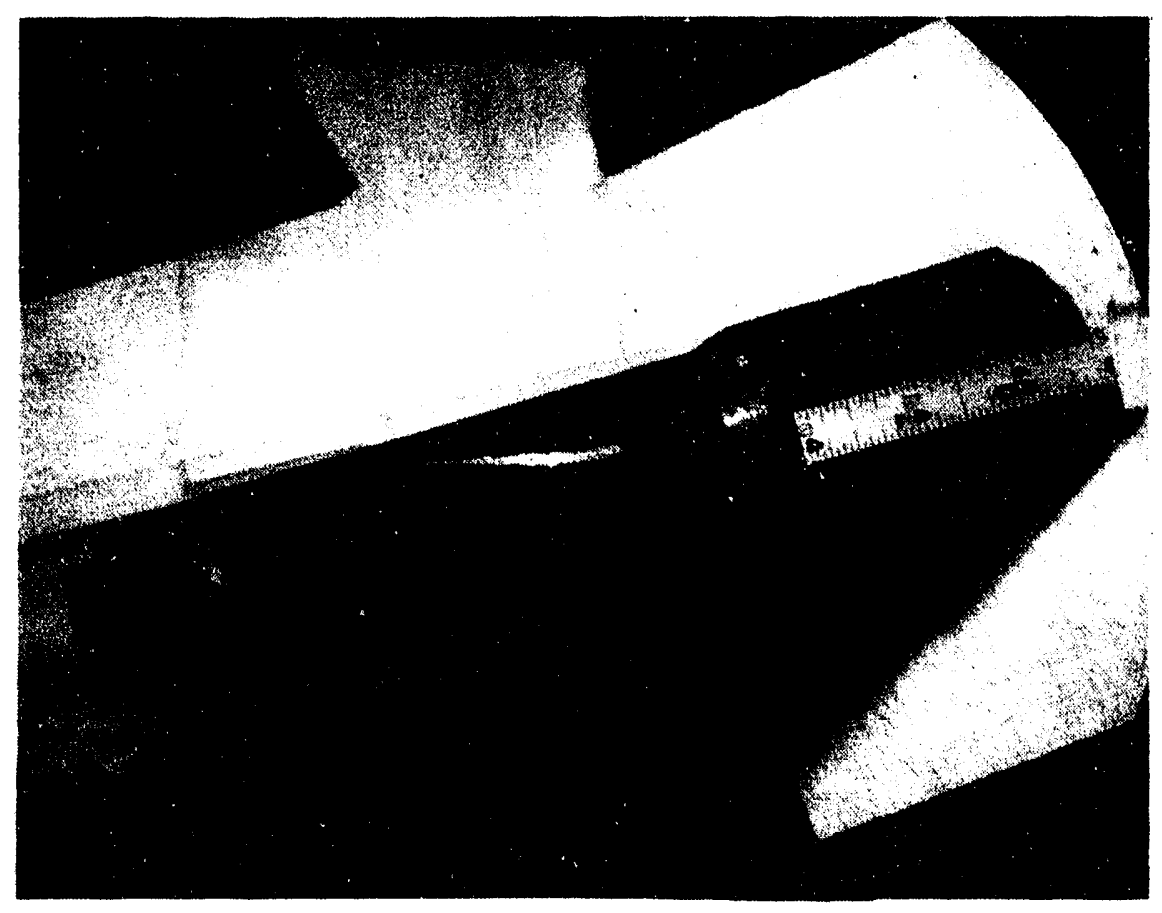

Figure 3. R-7 nozzle sample.

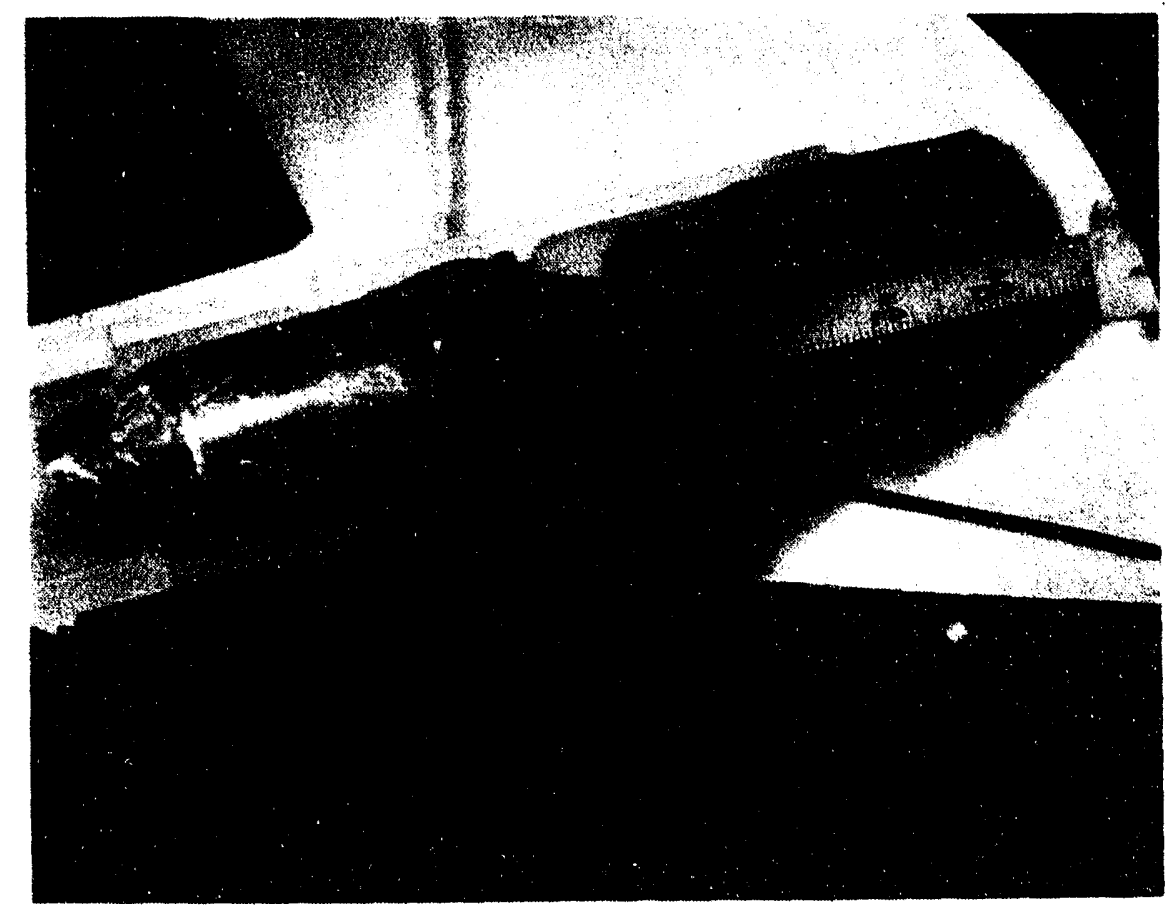

Figure 4. K-11 nozzle sample. 


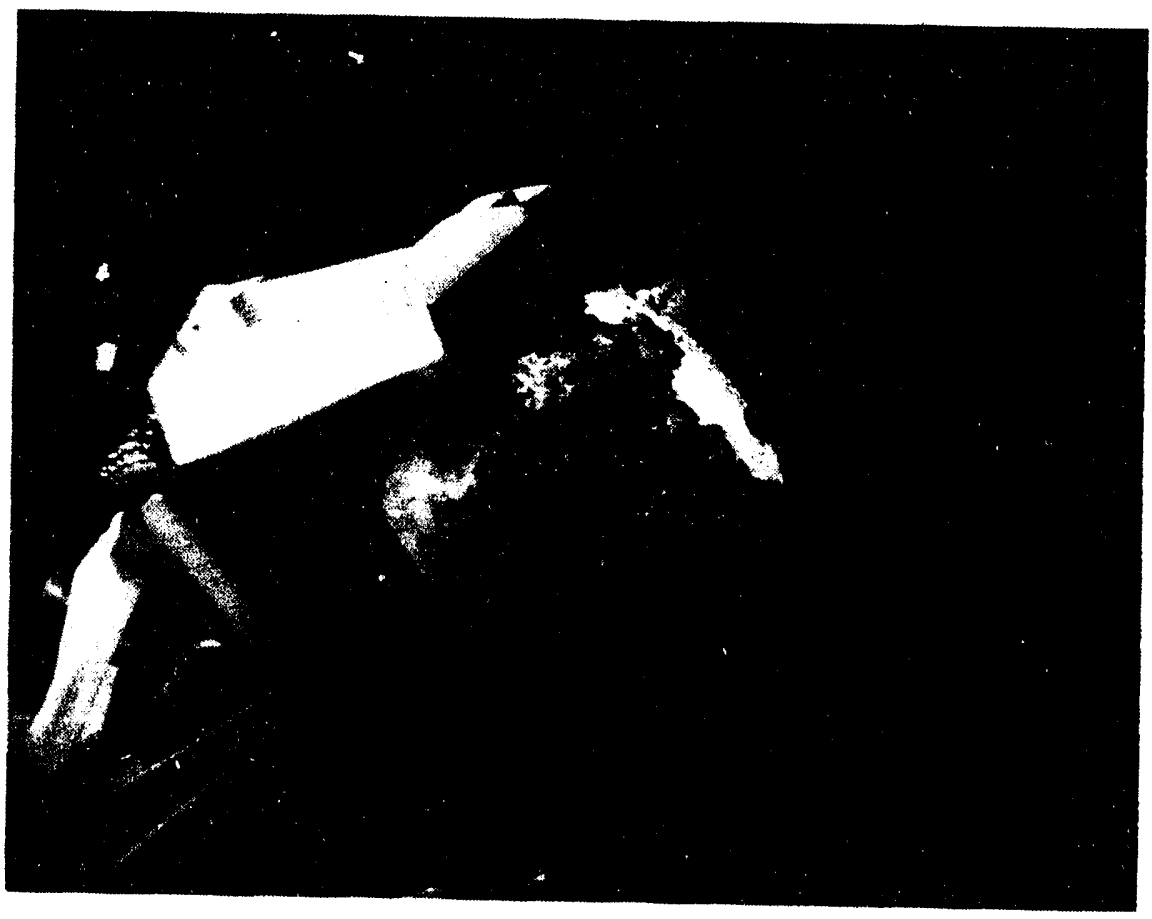

Figure 5. E-7 nozzle sample.

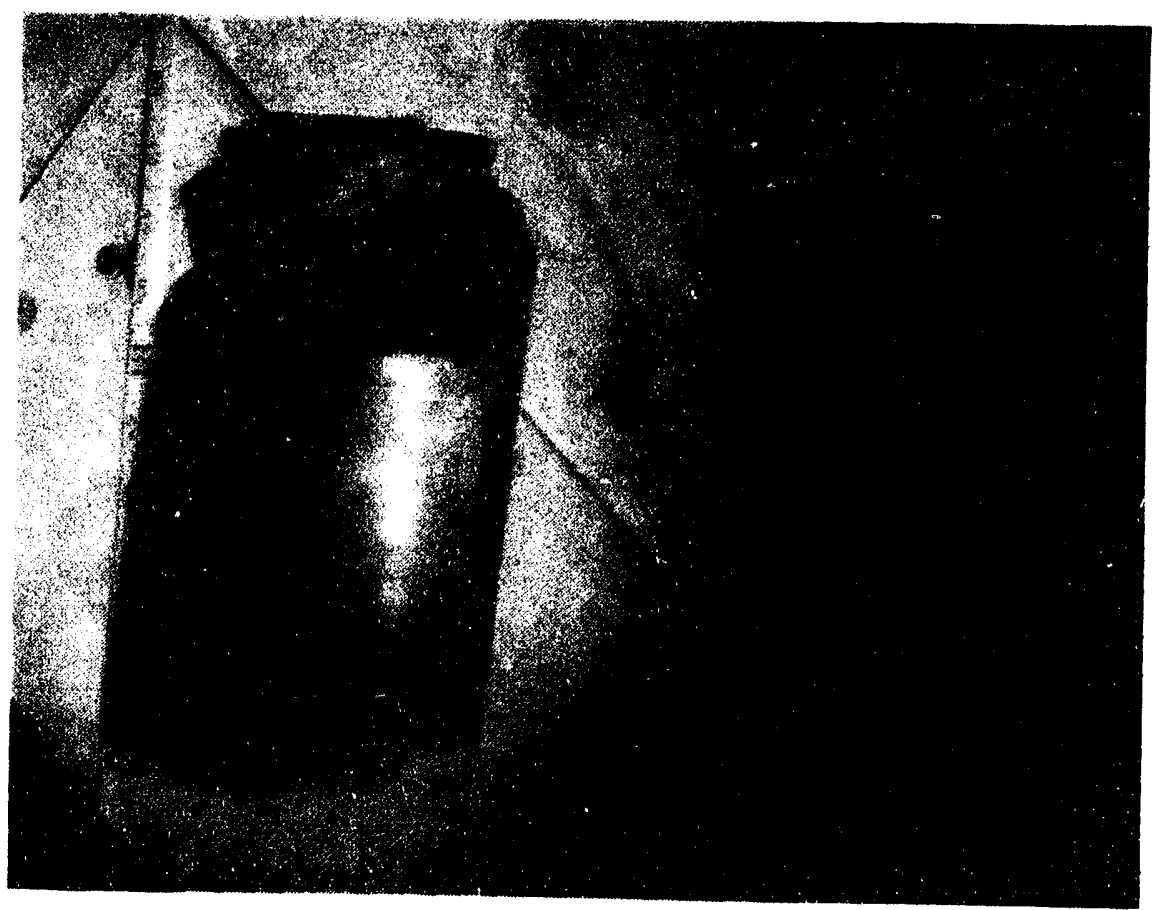

Figure 6. K-5 guide tube sample. 
scan analyses (i.e., near the bottom, the mid-plane, and the top of the nozzle). Fuel probably entered the nozzle through holes near the midplane.

Very little of the E-7 nozzle, as shown in Figure 5, remained after being removed from the lower head. The original length of the nozzle stub was about $51 \mathrm{~mm}(2 \mathrm{in}$.); however, after the stub was cut, it was about $16 \mathrm{~mm}(0.63 \mathrm{in}$.) long. Under close examination, it can be seen that a crack extends entirely through one side of the nozzle. Gamma spectroscopy was not performed on this nozzle because sectioning locations did not need to be determined. One section of this nozzle was sent to CEA-CEN for examination.

As shown in Figure 6, the K-5 guide tube suffered substantial damage at the lower end. The damaged edges created by melt interaction are slightly twisted outward. The original diameter of the guide tube was about $117 \mathrm{~mm}$ (4.6 in.); the remaining length on the longest side was $238 \mathrm{~mm}$ (9.4 in.), while the remaining length on the shortest side was only $149 \mathrm{~mm}$ (5.9 in.). The K-5 guide tube did not need to be gamma scanned or probed because the sample location was determined from visual examination of the nozzle section. As discussed in Appendix C, apparent molten fuel material interacted with the stainless steel of the guide tube and melted into its surface. In most cases, the clear separation between the stainless steel and the fuel material phases suggests that the mechanism for this interaction appears to be melting of the stainless steel with no apparent chemical interaction. However, Figure C-8 shows the presence of an apparent intermediate phase that may be the result of a dissolution of the stainless steel by the fuel debris.

The very bottom of the guide tube was cut transversely, at a depth of approximately $19 \mathrm{~mm}$ ( 0.75 in.). It was very difficult to section this sample, and an MPR Associates technician indicated that the damaged guide tube material was much harder to cut than as-fabricated stainless steel.

In all cases, where nozzle or guide samples were obtained, they were subjected to a series of optical and SEM EDX/WDX examinations. The microstructural data are shown in Appendix C. Observations from these measurements are the following:

- Melt was attached to many surfaces and had interacted with the K-5 guide tube material

- Interactions occurred between liquid fuel material and the R-7 nozzle material.

Only limited SEM/EDX/WDX work was performed. Samples that were examined consisted of surface material from the tops of nozzles R-7, E-7, G-5, and M-10. A wide range of interactions between these materials was observed. Some SEM/WDX dot map data from these samples are shown in Appendix D.

\section{CONCLUSIONS}

The results of the examinations indicate that some nozzles were melted off by interaction with molten core debris, whereas others were only thermally affected by contact with core debris, some of which attached themselves to nozzle surfaces. The elevations at which the nozzles were melted off suggest that the liquid core debris was on top of a crust of solidified material that apparently insulated the reactor vessel from the hottest debris. The pattern of nozzle degradation was consistent with the location of a hot spot in the TMI-2 vessel at the E7-8/F7-8 location as 
determined by metallurgical examination of the vessel steel samples. ${ }^{3}$ The basal crust of the material insulated the vessel and the lower portions of the nozzles. The finding of significant quantities of control assembly materials ( $\mathrm{Ag}, \mathrm{Cd}, \mathrm{In}, \mathrm{Zr}, \mathrm{Fe}$, and $\mathrm{Cr}$ without $\mathrm{U}$ ) in the nozzle material and on nozzle surfaces indicates their presence on the lower head prior to the massive relocation of core debris 226 minutes into the accident.

\section{REFERENCES}

1. L. A. Neimark, T. L. Shearer, A. Purohit, and A. G. Hins, TMI-2 Instrument Nozzle Examinations at Argonne National Laboratory, TMI V(93)AL01, OECD-NEA-TMI-2 Vessel Investigation Project, February 1993.

2. M. Trotabas, M. Perrot, and P. Winter, "TMI-2 Instrument Nozzle and Guide Tube Examinations at Saclay," Presentation to the TMI-2 Project Review Group, Bethesda, MD, November 12-13, 1992, TMI V(92)FO01, OECD-NEA-TMI-2 Vessel Investigation Project, CEA/DRN/DMT 93/479.

3. G. E. Korth, Metallographic and Hardness Examinations of TMI-2 Lower Pressure Vessel Head Samples, TMI V(92)EG01, OECD-NEA-TMI-2 Vessel Investigation Project, January 1992. 


\section{Appendix A}

\section{Examination Techniques}




\section{Appendix A}

\section{Examination Techniques}

This appendix presents a brief overview of techniques used during examination of the TMI-2 nozzle and guide tube samples, including physical, optical metallography, scanning electron microscopy, chemical, and radiochemical examinations.

\section{A.1 Physical Examinations}

Physical examinations included visual/photographic and radiation field examinations, each of which are discussed in this section.

\section{A.1.1 Visual/Photographic}

Each nozzle and guide tube was examined, and its appearance and size were recorded. A 35-mm single lens reflex camera body was attached to a Kollmorgen periscope at the camera port. A "data back" as part of the camera door was used to record a number on the negative, and a camera log was used to track each photograph. A scale was placed alongside each sample to determine the magnification of the photograph. In some cases, the samples were photographed from different orientations to give an overall view of the damage sustained.

\section{A.1.2 Radiation Field}

Beta/gamma and gamma radiation levels on the nozzles and guide tubes were measured with a teletector probe during a transfer from one cell to another. Most of the nozzles exhibited high radiation levels, with initial readings ranging from 1 to $100 \mathrm{R} / \mathrm{hr}$ beta-gamma at contact.

\section{A.2 Microstructural Examinations}

Optical metallography was used and involved viewing highly polished samples with a light microscope at magnifications up to $500 \mathrm{x}$. The samples were often ireated with etchants to highlight grain boundaries and second phases.

Small samples were mounted in 31.8-mm (1.25-in.) brass mounts. A brass holder (shown in Figure A-1) was used to contain each sample in a lead/bismuth alloy. The alloy was melted (melting point $123.9^{\circ} \mathrm{C}$ ) in a metal beaker and then poured into a preheated brass mount. Each sample was positioned so that its examination surface was held level with the lead/bismuth surface and allowed to set up for 24 hours.

Large samples that did not fit in a brass mount were mounted on an aluminum plate with a 127-mm (5-in.) ID aluminum ring (see Figure A-2). The samples were then placed with the examination surface facing the plate. Epoxy resin, mixed with hardener [Jeffamine (polyoxpropulene diamine)], was poured around the samples. The mounts were then inserted into 
a vacuum chamber to impregnate the samples with epoxy. The epoxy was allowed to cure for approximately 72 hours.

The following grinding and polishing sequence was used for the TMI-2 lower head nozzles and guide tubes:

1. Course grind with water-lubricated silicon carbide 120 -grit paper with a whirlamat.

2. Medium grind with 240 - and 400 -grit paper. Wash the sample between grit sizes.

3. Final grind with 600 -grit paper.

4. Initial polish with 6- $\mu \mathrm{m}$ diamond grit in mineral oil-type fluid on a hard paper with a whirlamat.

5. Final polish with 3- $\mu \mathrm{m}$ diamond grit in mineral oil on a short nap nylon cloth.

In general, a swab-etching was used, with the etching time varying, depending on whether a heavy or light etch was appropriate. A fuel etchant of $85 \% \mathrm{H}_{2} \mathrm{O}_{2}$ and $15 \% \mathrm{H}_{2} \mathrm{SO}_{4}$ was used because most of the damage observed from nozzle and guide tube examinations involved a ceramic melt with urania content.

\section{A.3 Scanning Electron Microscopy}

Scanning electron microscopy (SEM) examinations were performed to determine the physical and chemical states of the lower head components. The high-image resolution and small scanning area of the SEM analysis complemented the optical metallography, allowing detailed examination of specific sample areas that were identified from the metallographic analysis to be important. Energy dispersive x-ray (EDS) and wavelength dispersive x-ray (WDS) analyses were used to acquire elemental composition data, which identify core thermodynamic properties (e.g., peak temperatures).

In SEM, a finely focused electron beam is swept in a raster across the surface of a sample. The types of signals include secondary electrons, backscattered electrons, and characteristic $\mathrm{x}$-rays. The primary signal of interest is the variation in secondary electron emission that occurs from differences of the surface topography. The secondary electrons are collected by a scintillatorphotomultiplier system, and the resultant signal is displayed on a cathode-ray tube. The scanning electron beam is synchronized with the scanning of the cathode-ray tube such that images can be presented on a storage oscilloscope or a monitor oscilloscope for photographing.

This procedure was also used for backscattered electron (BSE) images. Backscattered electrons are electrons that undergo elastic collisions within the sample and ultimately escape. A significant portion $(-30 \%)$ of the beam electrons escape, resulting in the backscattered electron signal. These electrons, because of their higher energy, originate from deeper in the material than do secondary electrons. Because the efficiency of the scattering process is dependent on the electron density (atomic number), the primary advantage of BSE images is that they contain information on the relative densities of phases in the examined material. This differentiates 
between elements of low and high atomic numbers by the brightness displayed on the screen. Those phases with high average atomic numbers are displayed as light areas, while phases with low atomic numbers appear as dark areas.

\section{A.3.1 Energy-Dispersive X-Ray Spectroscopy}

Energy-dispersive x-ray spectroscopy (EDS) analysis is performed by measuring characteristic detectable $x$-rays from elements above atomic number 10 that are excited by a scanning electron beam. The beam is typically $1 \mu \mathrm{m}$ in diameter, but scattering produces $\mathrm{x}$-rays over a region up to 10 times wider. SEM/EDS systems are very convenient for quickly surveying areas for elemental content and spectral uniformity, and produce high-quality images and photographic records. Other advantages include the low beam energy and the relatively low operating vacuum, both of which limit the absorption of deposited molecules. However, the usefulness of this instrument is reduced by its susceptibility to background radiation, its inability to detect oxygen and carbon, and its inability to provide binding energy information.

The limit of detection for most elements for the SEM/EDS is between 0.5 and 5 wt\% under ideal conditions; however, radioactivity can drastically affect the signal-to-noise ratio for the SEM analysis, depending on the magnitude of the radiation field present. Therefore, elements that exist in the sample at concentrations of less than 1 to $2 \mathrm{wt} \%$ may not be detected by SEM analysis.

\section{A.3.2 Wavelength-Dispersive X-ray Spectroscopy}

Wavelength-dispersive $x$-ray spectroscopy (WDS) is similar to EDS except that the $x$-rays generated by the electron beam are separated by wavelength through a diffracting crystal, and a gas-filled proportional counter is used as the detector. The detector is physically scanned across the spectrum of diffracted $\mathrm{x}$-rays and generates a signal on a point-by-point basis. Acquisition is slow, but WDS provides a very high resolution spectrum.

WDS was used to provide elemental data of two types: qualitative $\mathrm{x}$-ray dot maps, and spectra for quantitative analysis. Dot maps are produced by tuning the spectrometer to the element signal peak of interest and rastering the electron beam across the area. Spectrometer output is correlated to beam position, and a picture of the area is constructed in which relative brightness corresponds to beam-generated x-ray intensity, and thereby to the concentration of the element. The images show the relative distribution of elements in the area.

WDS can be used to ascertain precise elemental compositions in very small ( $<10 \mu \mathrm{m})$ regions of the sample. The procedure for obtaining quantitative information from WDS spectra consists of comparing, for a given element in a phase of unknown composition, the intensity of the characteristic $x$-ray against a well-characterized standard. However, the atomic processes of electron beam/material and $x$-ray/material interaction are extremely complex, and accurate quantitative analyses can be achieved only by correcting for these effects. This is especially important for material of highly dissimilar constituents such as heavy metal oxides. 


\section{A.4 Gamma Spectrometry Examinations}

Gamma spectrometry was used to scan along the length of six TMI nozzles (H-9, K-11, K-12, L-11, M-10, and R-7) to determine radioactivity profiles and to identify locations of fuel interactions in or on the nozzles. Based on the presence of any high concentrations of radioactivity, sectioning was performed.

The equipment used consisted of an ORTEC intrinsic germanium detector, a Davidson multichannel analyzer, and a lead collimator. The scanning apparatus was completely surrounded by $102 \mathrm{~mm}$ ( $4 \mathrm{in}$.) of lead shielding, reducing the transmission of gamma rays beyond the shield and to the operator to approximately $0.1 \%$ (for Cs-137). The procedure for the TMI-2 nozzle gamma scanning was the following:

1. Establish a Zone III at the rear of Cell \#2.

2. Construct the gamma scanning setup as illustrated in Figure A-3. This setup alleviates the need for any entries into Zone III during the scanning process and reduces or eliminates any radiation/contamination exposure.

3. After the gamma scanning setup is assembled, open the rear port and insert the square aluminum pipe into the cell. With the pipe in place, insert the sample holder into the pipe and push it into the cell using the push rod.

4. From the front of Cell \#2, identify and remotely place the TMI-2 nozzle into the push rod.

5. From outside the cell, pull the pushrod, dragging the sample holder through the square aluminum pipe until it reaches the detector/sample shield. Once in the shield, it may take a few minutes to verify the alignment of the nozzle with the collimator in the detector assembly.

The nozzles were scanned with a germanium detector (PG-3) and a Davidson multichannel analyzer. Regions of interest were selected for the Cs-137 photopeak, the region that includes the two Co-60 photopeaks, and the entire spectrum from approximately 400-1,350 KeV. Each position was scanned for 60 seconds, live time. After scanning each position of each nozzle, the gross counts for each region of interest were tabulated. The tabulated data were then background subtracted and plotted with no decay corrections included. All six nozzles were scanned in the same geometry, from the base (large-diameter end closest to the lower head) to the tip, in 6.4-mm (0.25-in.) increments. The data points associated with the scan position of each nozzle are within $3.2 \mathrm{~mm}(0.125 \mathrm{in}$.) of the actual position. 

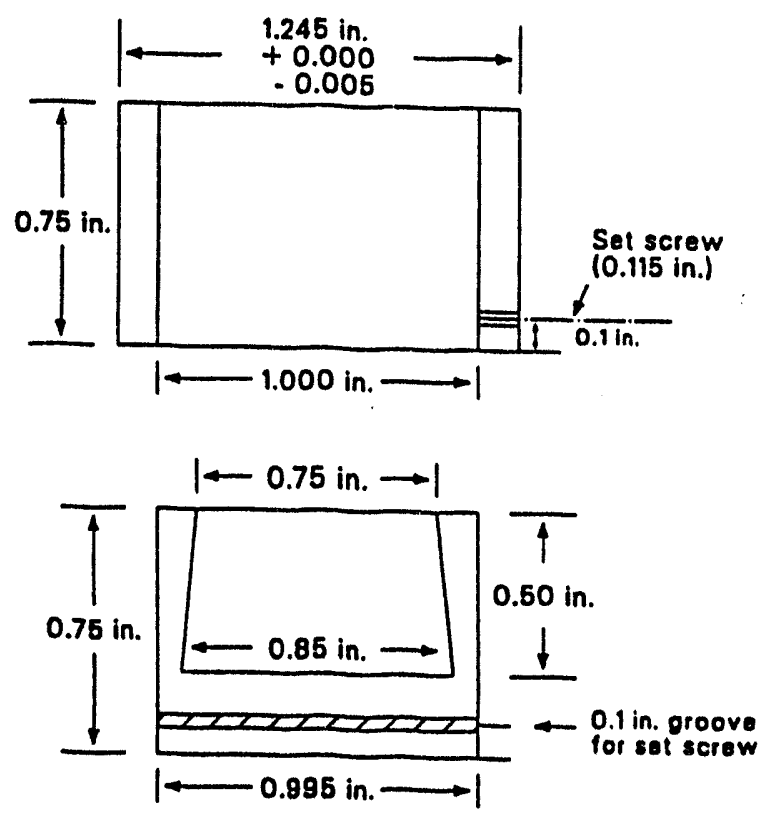

L242-KM278-02

Figure A-1. Schematic drawing of 1-1/4-in. metallographic mount.

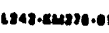
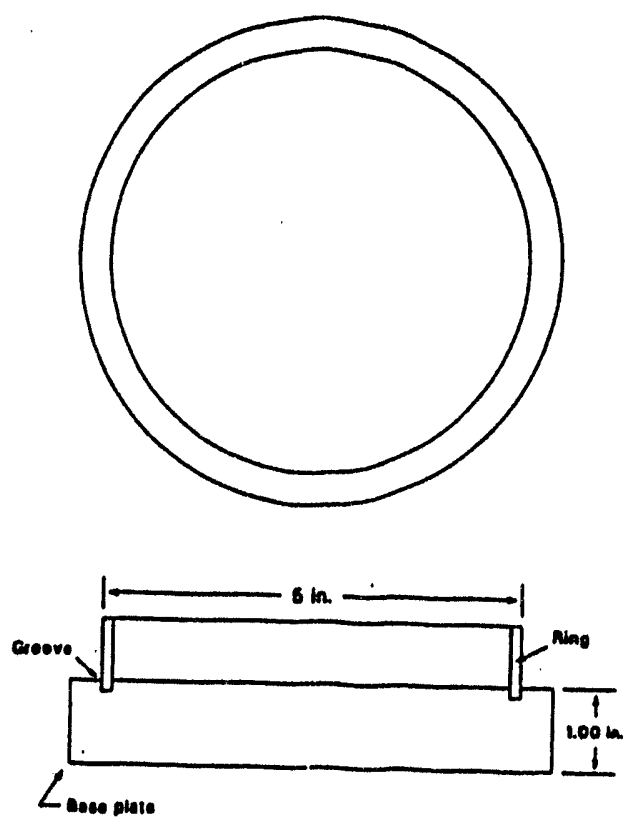

Figure A-2. Schematic drawing of 5-in. metallographic mount. 


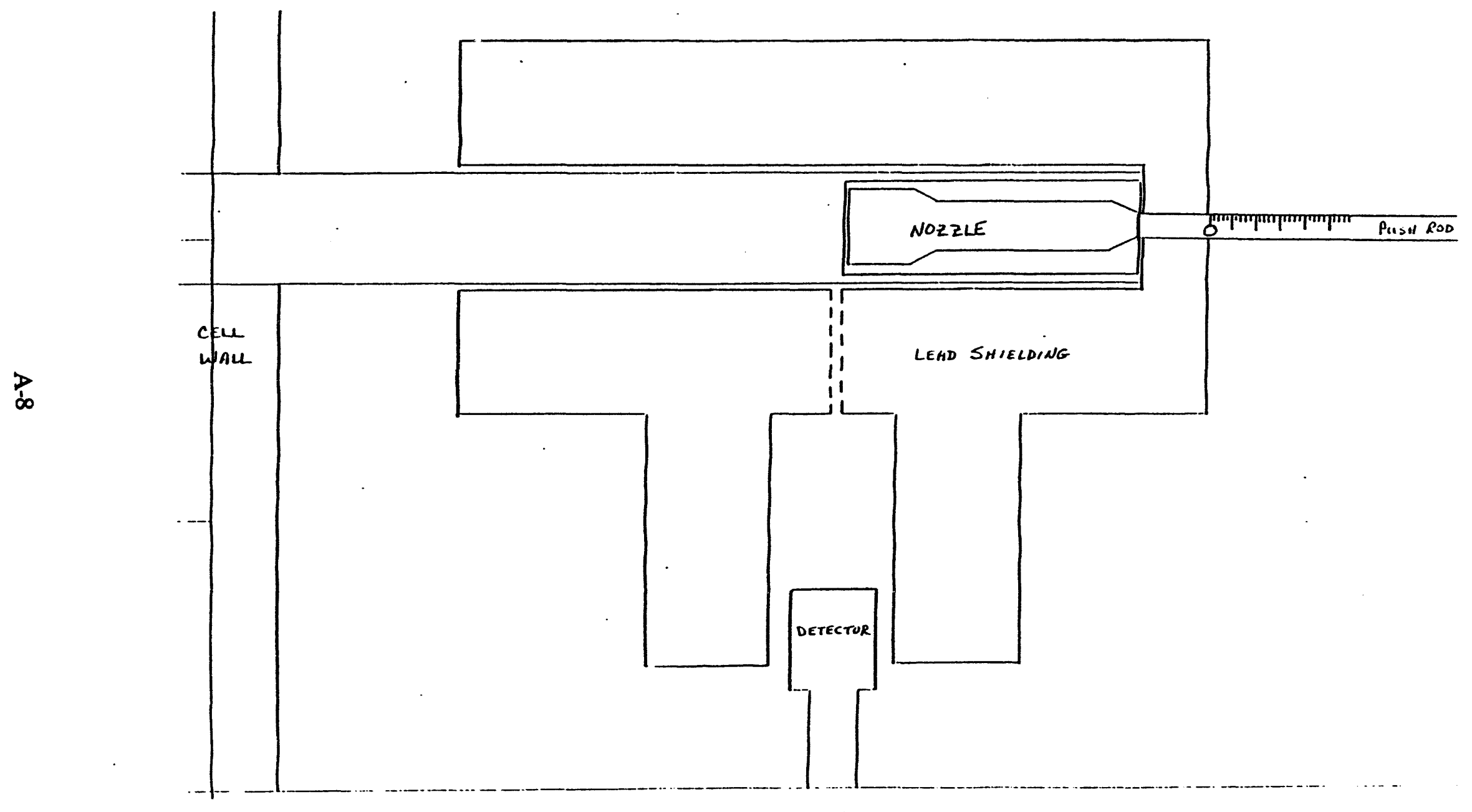

Figure A-3. Sketch of TMI-2 nozzle gamma-scanning apparatus. 


\section{Appendix B}

\section{Visual and Gamma Spectrometry}

B-1 


\section{Appendix B}

\section{Visual and Gamma Spectrometry}

Visual examinations and activity profiles are addressed in this appendix. The TMI-2 nozzles were examined visually to determine the overall damage they sustained, including melt interaction, melt penetration, cracking, and shearing. Various perspectives and angles of rotation were used during macrophotography.

Radioactivity profiles were obtained for six of the TMI-2 nozzles (H-9, K-11, K-12, L-11, M-10, and R-7). Each nozzle was loaded into the detector assembly with its base aligned with the collimator, and was counted in 1.9-cm (0.75-in.) increments for a specified period of time. As each nozzle advanced through the assembly, the gross area counts of the Cs-137, Co-60, and fullspectrum photopeaks were recorded for each position. Activity profiles were developed using the gamma scan data by plotting nozzle position ( $x$-axis) versus the gross area counts ( $y$-axis).

For the sectioning examinations, cutting locations on each nozzle were determined by using the photopeaks of activity profiles and observations of damaged regions and melt interaction zones noted in the visual examinations.

\section{B.1 M-10 Nozzle}

An initial examination of the M-10 nozzle was performed on a small fragment broken from its tip, where the material and melt interaction were greatest. This fragment was mounted in brass and subjected to analysis by SEM. The results from this analysis are reported in Appendix D.

Figure B-1 is a full-length view of the M-10 nozzle. It was measured to be $17.1 \mathrm{~cm}(6.75 \mathrm{in}$.) long. Figure B-2 is a magnified view of the material and melt interaction on the tip of the nozzle.

The activity profiles for the M-10 nozzle, which were obtained by plotting the data found in Table B-1, indicated high activity regions at approximately $5.7 \mathrm{~cm}(2.25 \mathrm{in}$.$) and 15.2 \mathrm{~cm}(6 \mathrm{in}$.) (see Figures B-3 through B-5). It is interesting to note that Cs-137 is high at the lower elevation, whereas Co-60 is high at the upper elevation.

A probe test of $\mathrm{M}-10$ was conducted by inserting a wire into the bottom end of the nozzle. The result of the test indicated that melt had plugged the nozzle to within $5.7 \mathrm{~cm}(2.25 \mathrm{in}$.) of the bottom end. Using the gamma scan data and penetration test information to identify regions of interest, the nozzle was sectioned as shown in Figure B-6. A transverse cut was made at the nozzle tip creating a section $1.9 \mathrm{~cm}(0.75$ in.) thick. This section was then cut longitudinally, creating two samples, $\mathrm{M}-10-1 \mathrm{~A}$ and $\mathrm{M}-10-1 \mathrm{~B}$. The second transverse cut was made in a location $4.8 \mathrm{~cm}(1-7 / 8 \mathrm{in}$.) from the bottom end. After this section was cut from the nozzle, the instrument core string was inspected; it appeared to be undamaged. Interior damage, however, was noted on the upper surface. A third transverse cut was made at a distance of $6.7 \mathrm{~cm}$ 
(2-5/8 in.) from the bottom end. This created a 1.9-cm (0.75-in.) section, sample M-10-2, for which a top and 0-degree reference was maintained.

After examination of these unpolished sample sections, it was determined that both samples M-10-1A (see Figure B-7) and M-10-1B (see Figures B-8 and B-9) would yield more information if they were mounted and polished longitudinally. Section M-10-2 was mounted and polished on the transverse surface (see Figures B-10 and B-11). The results of these examinations are discussed in Appendix C.

\section{B.2 H-9 Nozzle}

A visual examination of the H-9 nozzle (see Figure B-12) showed that it was approximately $241 \mathrm{~mm}(9.5 \mathrm{in}$.) long and had sustained very little obvious damage. Inspection of the top of the nozzle showed that the instrument core string was still intact, as shown in Figure B-13.

Figures B-12 and B-13 show the front (0 degrees) and back surface (180 degrees) of the nozzle, respectively.

The gamma scan data listed in Table B-2 were used to obtain the activity profile plots shown as Figures B-14 through B-16. The differences between the first and last scan positions seen on the full-spectrum plot (Figure B-16) are probably due to improper alignment in the sample holder. Inspection of the activity profiles indicates high activity regions at approximately $5.1 \mathrm{~cm}$ $(2 \mathrm{in}$.$) and 14 \mathrm{~cm}(5.5 \mathrm{in}$.) from the base.

A probe test was performed on the H-9 nozzle, but no blockage was discovered. Using the indications obtained from the gamma scan results, sectioning was performed on the nozzle as shown in Figure B-17. A transverse cut was made $13.3 \mathrm{~cm}$ (5.25 in.) from the bottom of the nozzle. The second transverse cut was located about $15 \mathrm{~cm}(6 \mathrm{in}$.) from the bottom, creating a transverse section approximately $0.75 \mathrm{in}$. $(1.9 \mathrm{~cm})$ thick. A top reference was maintained. This transverse section was then cut longitudinally, producing sample H-9-1, which was mounted to examine the transverse (cross-sectional) surface, and producing sample H-9-2, which was mounted to examine the longitudinal surface with the top reference being maintained.

\section{B.3 Nozzle L-11}

The L-11 nozzle (see Figure B-18) was about $22.9 \mathrm{~cm}(9 \mathrm{in}$.) long and appeared to be undamaged except for a 5.1-cm (2-in.) region at the shoulder of the nozzle. The high activity region extended from $5.1 \mathrm{~cm} \mathrm{(2} \mathrm{in.)} \mathrm{to} 10 \mathrm{~cm} \mathrm{(4} \mathrm{in.)} \mathrm{at} \mathrm{the} \mathrm{bottom} \mathrm{end.}$

The activity profile plots (see Figures B-19 through B-21), which were obtained from the L-11 gamma scan data in Table B-3, indicate a high activity region $5.1 \mathrm{~cm}(2 \mathrm{in}$.) to $10 \mathrm{~cm}(4 \mathrm{in}$.) from the bottom end of the nozzle.

A probe of the nozzle was conducted, but no blockage was found. From a comparison of the gamma scan results and the visual inspection, the cutting locations were determined, as shown in Figure B-22. The first transverse cut was made $7.6 \mathrm{~cm} \mathrm{(3} \mathrm{in.)} \mathrm{from} \mathrm{the} \mathrm{bottom} \mathrm{end} \mathrm{of} \mathrm{the}$ nozzle. The nozzle was cut again to produce a section $1.9 \mathrm{~cm}(0.75 \mathrm{in}$.) thick. While maintaining 
the identification of the top surface, another cut was made longitudinally, producing sample L-11-A, which was mounted to show the longitudinal surface, and sample L-11-B, which was mounted and polished to show the transverse surface (cross section) of the nozzle.

\section{B.4 Nozzle R-7}

Figure B-23 shows a full-length view of the R-7 nozzle with the melt bulb and instrument core string intact. A visual examination of the nozzle indicated that it had sustained little damage except on the top surface of the nozzle as shown in Figure B-24.

Initially, a small sample from the melt bulb at the top of the instrument core string on the R-7 nozzle was submitted for SEM analysis. The results from this analysis can be found in Appendix D. A full-length photo of the nozzle after the bulb had been removed for examination is shown in Figure B-25. The detached melt bulb was submitted for optical metallography and SEM analysis. A one-quarter section of the melt bulb was cut and sent to CEA-CEN in France.

Although the base of the nozzle had an uneven surface, it was $23.2 \mathrm{~cm}(9-1 / 8 \mathrm{in}$.) long (after melt bulb removal). Gamma scan data for the nozzle, listed in Table B-4, were used to plot the activity profiles (Figures B-26 through B-28). These showed high activity regions at approximately $11.4 \mathrm{~cm}$ (4.5 in.) and at 19 to $23 \mathrm{~cm}$ ( 7.5 to 9 in.) from the base.

No blockages were found during the probe of the nozzle. Based on the visual and gamma scan data, the nozzle was sectioned at $1.9 \mathrm{~cm}(0.75 \mathrm{in}$.) from the top surface, as shown in Figure B-29. The resulting 1.9-cm (0.75-in.) sample was then cut longitudinally. The top surface reference was maintained. One-half of the sample was mounted to show the longitudinal surface.

\section{B.5 Nozzle K-11}

A visual examination and measurement of the $\mathrm{K}-11$ nozzle showed that it was $23.5 \mathrm{~cm}$ (9-1/4 in.) long and suffered extensive damage to the majority of its surface. Figures B-30 and B-31 are full-length views of the front (0-degree) and back (180-degree) surface, respectively. They give an overall view of the K-11 nozzle. The major damage extends from about $1.9 \mathrm{~cm}$ $(0.75$ in.) from the bottom end to within $7.6 \mathrm{~cm}$ (3 in.) of the top of the nozzle. A magnified view of the top of the nozzle shows cracking and melt interaction (see Figures B-32 and B-33, which show the 0 - and 180-degree reference views, respectively).

The gamma scan data listed in Table B-5 were used to plot the activity profiles, which are shown in Figures B-34 through B-36. Analysis of these plots indicates regions of interest at locations 1.9 to $5.7 \mathrm{~cm}$ ( 0.75 to $2.25 \mathrm{in}$.), 6.4 to $10 \mathrm{~cm}$ ( 2.5 to $4 \mathrm{in}$.), and 20 to $23 \mathrm{~cm}$ (8 to 9 in.) from the bottom of the nozzle.

The nozzle was probed for blockage from the bottom end. Although narrowing of the interior diameter was noted, the wire could be seen in the exposed center of the nozzle, and no blockage was found. A penetration test was also performed from the top end of the nozzle, and no blockage was found. 
Gamma scan data and visual inspection were used to determine cutting locations on the K-11 nozzle as shown in Figure B-37. A white marker line extending the length of the nozzle was used to maintain a 0-degree reference. The first cut was made $3.2 \mathrm{~cm}(1-1 / 4 \mathrm{in}$.) from the bottom end, and the second cut was made $1.5 \mathrm{~cm}(0.6 \mathrm{in}$.) above the first cut, creating sample K-11-1. A third cut was made $7.6 \mathrm{~cm}$ ( 3 in.) from the bottom, followed by a fourth cut, which produced a 19-mm (0.75-in.) section identified as K-11-2. A fifth cut created sample K-11-3. The remaining nozzle section was rotated, and two more cuts were made approximately $4.1 \mathrm{~cm}(1.6 \mathrm{in}$.) and $5.7 \mathrm{~cm}$ (2.25 in.) from the tip of the nozzle, creating sample K-11-4.

Each of the above samples, K-11-1, $-2,-3$, and -4 , were sectioned longitudinally along the 0-degree reference line. Zero-degree and top-reference orientations were maintained throughout the process by using rough sketches of the sample sections to record cutting details. Sample K-11-1 was cut to produce sample K-11-1A, which was not mounted, and sample $\mathrm{K}-11-1 \mathrm{~B}$, which was mounted and polished to show the longitudinal surface. Sample K-11-2 was cut into sample K-11-2A (see Figure B-38), which was mounted to show the longitudinal surface, and sample K-11-2B (see Figure B-39), which was mounted to show the transverse surface. Sample K-11-3 was cut longitudinally, creating sample K-11-3A (see Figure B-40), which was mounted to show the transverse surface, and sample K-11-3B (see Figure B-41), which was mounted to show the longitudinal surface. One-half of sample K-11-4 was mounted to show the longitudinal surface (sample K-11-4A).

\section{B.6 Nozzle G-5}

The G-5 nozzle (see Figure B-42) was approximately $4.4 \mathrm{~cm}$ (1.75 in.) long and was severely damaged. As shown in Figure B-43, melt was attached to the nozzle and its center was completely plugged with melt.

This nozzle was not subjected to gamma spectroscopy because it was so short. Since the nozzle was completely plugged with melt, any cutting location would have provided melt interaction information. As shown in Figure B-44, the first cut was transverse, approximately 1.9 $\mathrm{cm}(0.75 \mathrm{in}$.) from the top of the sample. The resulting segment was then cut longitudinally. One-half was mounted to show the longitudinal surface; the other half was cut into a rectangularshaped section and shipped to CEA-CEN in France.

\section{B.7 Nozzle E-7}

As shown in Figure B-45, approximately $5.1 \mathrm{~cm}(2$ in.) of the E-7 nozzle was all that remained on the lower head after the shearing that occurred during the accident. The sample section removed was only 0.5 to 0.6 in. $(1.3$ to $16 \mathrm{~cm}$ ) long. A crack extending entirely through one side of the nozzle was also observed.

Gamma spectrometry was not performed on this nozzle because it was so short. After the sample was cut longitudinally, one of the halves split in two because of the crack that extended through the nozzle, leaving three sections. A pie-shaped segment was cut from the second largest of the three portions and shipped to CEA-CEN in France. The largest of the samples was cut twice longitudinally, creating sample E-7-1, which was mounted to show the longitudinal surface, 
and sample E-7-2, which was prepared for examination of the transverse (top) surface. A sectioning diagram for nozzle E-7 is shown in Figure B-46.

\section{B.8 Nozzle K-12}

The K-12 nozzle sustained very little damage, as illustrated in Figures B-47 and B-48, (0- and 180-degree rotation, respectively). An identifying notch can be seen at the base of the nozzle in Figure B-47. The nozzle was $25.7 \mathrm{~cm}(10-1 / 8 \mathrm{in}$.) long with the instrument string and $24.4 \mathrm{~cm}$ (9-5/8 in.) long without the string.

The activity profiles plotted from the gamma scan data in Table B-6 show high levels of activity along the entire length of the K-12 nozzle. Activity peaks at greater than $1,400,000$ counts (see Figures B-49 through B-51) are almost double the relative activity of any other nozzles that were gamma-scanned. The possible explanation for this high activity is that there is a significant amount of surface-deposited activity.

A probe wire was inserted into the bottom end of the nozzle, and no blockages were detected. Since no specific regions of interest were indicated by examination, random sectioning locations were chosen, as seen in Figure B-52. The first transverse cut was made $5.1 \mathrm{~cm}(2 \mathrm{in}$.) from the bottom end of the nozzle. A second cut was made $7.0 \mathrm{~cm}$ ( 2.75 in.) from the bottom, producing sample $\mathrm{K}-12-1$. This sample was then sectioned longitudinally, producing sample $\mathrm{K}-12-1 \mathrm{~A}$, which was mounted to show the transverse surface, and sample $\mathrm{K}-12-1 \mathrm{~B}$, which was mounted to show the longitudinal surface. A top reference was maintained during the cutting process.

\section{B.9 Guide Tube K-5}

The K-5 guide tube, which was damaged by melt interaction, was found to be twisted and slightly misshapen (see Figure B-53). Its approximated diameter was determined to be $117 \mathrm{~mm}$ (4-5/8 in.). Length measurements around the guide tube varied from $23.9 \mathrm{~cm}(9.4 \mathrm{in}$.) to only $15 \mathrm{~cm}$ (5.9 in.).

Gamma spectroscopy was not performed on the K-5 guide tube because there was no visible significant difference in the deposition of material on the nozzle.

The guide tube was sectioned as shown in Figure B-54. Several cutting blades were destroyed in the effort to perform the first transverse cut at approximately $1.9 \mathrm{~cm}(0.75 \mathrm{in}$.) from the bottom of the guide tube. MPR Associates reported this same difficulty during the removal of the guide tube samples from the reactor, stating that the damaged guide tube material was much harder than the as-fabricated stainless steel. A second cut was made longitudinally on one end of the primary section, creating sample K-5-1, which was polished longitudinally after it had been stabilized with sample supports. The same end was cut again longitudinally, and the resulting sample was shipped to France. A fourth cut was made on the opposite end of the primary section, again longitudinally, creating sample K-5-2. It was stabilized against another sample and polished transversely. 
Table B-1. Gamma scan data for nozzle M-10 (from base of cut nozzle)

\begin{tabular}{rrrr}
\hline $\begin{array}{c}\text { Position } \\
\text { (in./cm) }\end{array}$ & $\begin{array}{c}\text { Cs-137 } \\
\text { (ROI \#1) }\end{array}$ & $\begin{array}{r}\text { Co-60 } \\
\text { (ROI \#2) }\end{array}$ & $\begin{array}{r}\text { Spectrum } \\
\text { (ROI \#3) }\end{array}$ \\
\hline $0.00 / 0.0$ & 3973 & 281 & 16337 \\
$0.25 / 0.6$ & 7069 & 282 & 26288 \\
$0.50 / 1.2$ & 9949 & 0 & 35378 \\
$0.75 / 1.9$ & 12598 & 394 & 44168 \\
$1.00 / 2.5$ & 14077 & 0 & 51441 \\
$1.25 / 3.2$ & 17409 & 19 & 65291 \\
$1.50 / 3.8$ & 38498 & 282 & 127205 \\
$1.75 / 4.4$ & 55000 & 0 & 178721 \\
$2.00 / 5.1$ & 71925 & 812 & 232359 \\
$2.25 / 5.7$ & 90693 & 1322 & 283614 \\
$2.50 / 6.4$ & 46051 & 1367 & 160392 \\
$2.75 / 7.0$ & 13298 & 1246 & 69638 \\
$3.00 / 7.5$ & 6826 & 1159 & 47691 \\
$3.25 / 8.2$ & 4898 & 1105 & 39887 \\
$3.50 / 8.9$ & 5468 & 1033 & 45134 \\
$3.75 / 9.5$ & 7151 & 1529 & 56983 \\
$4.00 / 10.2$ & 7071 & 4683 & 79261 \\
$4.25 / 10.8$ & 5906 & 7354 & 99153 \\
$4.50 / 11.4$ & 6899 & 5471 & 89845 \\
$4.75 / 12.1$ & 8817 & 4174 & 88036 \\
$5.00 / 12.7$ & 10651 & 3964 & 95578 \\
$5.25 / 13.3$ & 12302 & 3737 & 99209 \\
$5.50 / 14.0$ & 15973 & 3456 & 116808 \\
$5.75 / 14.6$ & 40098 & 4346 & 200127 \\
$6.00 / 15.2$ & 48075 & 3602 & 200205 \\
$6.25 / 15.9$ & 14983 & 1106 & 63594 \\
\hline
\end{tabular}


Table B-2. Gamma scan data for nozzle H-9 (from base of cut nozzle)

\begin{tabular}{|c|c|c|c|}
\hline $\begin{array}{l}\text { Position } \\
\text { (in./cm) }\end{array}$ & $\begin{array}{c}\text { Cs-137 } \\
\text { (ROI \#1) }\end{array}$ & $\begin{array}{c}\text { Co-60 } \\
\text { (ROI \#2) }\end{array}$ & $\begin{array}{l}\text { Spectrum } \\
\text { (ROI \#3) }\end{array}$ \\
\hline $0.00 / 0.0$ & 278 & 0 & 50950 \\
\hline $0.25 / 0.6$ & 3502 & 517 & 64036 \\
\hline $0.50 / 1.2$ & 6078 & 1336 & 84505 \\
\hline $0.75 / 1.9$ & 6892 & 895 & 88133 \\
\hline $1.00 / 2.5$ & 7477 & 544 & 88719 \\
\hline $1.25 / 3.2$ & 7239 & 490 & 97311 \\
\hline $1.50 / 3.8$ & 8623 & 1600 & 127313 \\
\hline $1.75 / 4.4$ & 9846 & 1412 & 164493 \\
\hline $2.00 / 5.1$ & 105608 & 1075 & 525158 \\
\hline $2.25 / 5.7$ & 153039 & 1011 & 709598 \\
\hline $2.50 / 6.4$ & 27467 & 537 & 247593 \\
\hline $2.75 / 7.0$ & 11573 & 704 & 150678 \\
\hline $3.00 / 7.5$ & 16683 & 1071 & 161245 \\
\hline $3.25 / 8.2$ & 22154 & 1642 & 189771 \\
\hline $3.50 / 8.9$ & 22486 & 2044 & 174764 \\
\hline $3.75 / 9.5$ & 21928 & 1336 & 168268 \\
\hline $4.00 / 10.2$ & 22041 & 1181 & 170899 \\
\hline $4.25 / 10.8$ & 24411 & 1130 & 176717 \\
\hline $4.50 / 11.4$ & 21065 & 758 & 167139 \\
\hline $4.75 / 12.1$ & 15667 & 849 & 163131 \\
\hline $5.00 / 12.7$ & 18414 & 1090 & 194633 \\
\hline $5.25 / 13.3$ & 60335 & 1553 & 370085 \\
\hline $5.50 / 14.0$ & 148972 & 1745 & 704230 \\
\hline $5.75 / 14.6$ & 145853 & 2099 & 734036 \\
\hline $6.00 / 15.2$ & 65678 & 10222 & 519421 \\
\hline $6.25 / 15.9$ & 30966 & 15364 & 413730 \\
\hline $6.50 / 16.5$ & 27509 & 6842 & 301934 \\
\hline $6.75 / 17.1$ & 29942 & 2202 & 256029 \\
\hline $7.00 / 17.8$ & 40365 & 1979 & 289724 \\
\hline $7.25 / 18.4$ & 58496 & 5399 & 375165 \\
\hline $7.50 / 19.0$ & 63477 & 4478 & 383288 \\
\hline $7.75 / 19.7$ & 30536 & 1264 & 223491 \\
\hline $8.00 / 20.3$ & 19212 & 1085 & 159151 \\
\hline $8.25 / 21.0$ & 17820 & 450 & 143022 \\
\hline $8.50 / 21.6$ & 12538 & 803 & 116257 \\
\hline $8.75 / 22.2$ & 11240 & 331 & 104811 \\
\hline $9.00 / 22.9$ & 23287 & 495 & 141968 \\
\hline $9.25 / 23.4$ & 18539 & 135 & 121073 \\
\hline $9.50 / 24.1$ & 18566 & 602 & 120879 \\
\hline $9.75 / 24.8$ & 6003 & 175 & 74091 \\
\hline $110.0 / 25.4$ & 1777 & 0 & 55289 \\
\hline
\end{tabular}


Table B-3. Gamma scan data for nozzle L-11 (from base of cut nozzle)

\begin{tabular}{rrrr}
$\begin{array}{r}\text { Position } \\
\text { (in./cm) }\end{array}$ & $\begin{array}{r}\text { Cs-137 } \\
\text { (ROI \#1) }\end{array}$ & $\begin{array}{r}\text { Co-60 } \\
\text { (ROI \#2) }\end{array}$ & $\begin{array}{r}\text { Spectrum } \\
\text { (ROI \#3) }\end{array}$ \\
\hline $0.00 / 0.0$ & 3586 & 167 & 17375 \\
$0.25 / 0.6$ & 15486 & 83 & 54283 \\
$0.50 / 1.2$ & 19338 & 444 & 69446 \\
$0.75 / 1.9$ & 17991 & 625 & 70900 \\
$1.00 / 2.5$ & 15695 & 380 & 67390 \\
$1.25 / 3.2$ & 14591 & 256 & 63702 \\
$1.50 / 3.8$ & 12550 & 825 & 59743 \\
$1.75 / 4.4$ & 9233 & 349 & 53839 \\
$2.00 / 5.1$ & 8316 & 1382 & 61624 \\
$2.25 / 5.7$ & 15285 & 2440 & 99817 \\
$2.50 / 6.4$ & 51626 & 5050 & 242161 \\
$2.75 / 7.0$ & 89559 & 12291 & 468767 \\
$3.00 / 7.5$ & 130133 & 8367 & 608715 \\
$3.25 / 8.2$ & 188563 & 6991 & 766811 \\
$3.50 / 8.9$ & 156708 & 6289 & 617241 \\
$3.75 / 9.5$ & 88749 & 7534 & 384800 \\
$4.00 / 10.2$ & 41032 & 7759 & 222712 \\
$4.25 / 10.8$ & 14570 & 2473 & 93358 \\
$4.50 / 11.4$ & 11090 & 1266 & 64192 \\
$4.75 / 12.1$ & 11474 & 930 & 59927 \\
$5.00 / 12.7$ & 13680 & 1149 & 64910 \\
$5.25 / 13.3$ & 15562 & 679 & 72125 \\
$5.50 / 14.0$ & 27748 & 1486 & 117119 \\
$5.75 / 14.6$ & 27810 & 1519 & 114370 \\
$6.00 / 15.2$ & 17968 & 85 & 70969 \\
$6.25 / 15.9$ & 18677 & 426 & 68790 \\
$6.50 / 16.5$ & 20654 & 401 & 72013 \\
$6.75 / 17.1$ & 20026 & 63 & 70243 \\
$7.00 / 17.8$ & 20269 & 521 & 7234 \\
$7.25 / 18.4$ & 21149 & 239 & 70084 \\
$7.50 / 19.0$ & 19217 & 0 & 62320 \\
$7.75 / 19.7$ & 14085 & 480 & 47813 \\
$8.00 / 20.3$ & 16420 & 176 & 53609 \\
$8.25 / 21.0$ & 13146 & 518 & 32828 \\
$8.50 / 21.6$ & 11363 & 201 & 37899 \\
$8.75 / 22.2$ & 11066 & 308 & 37147 \\
$9.00 / 22.9$ & 10445 & & 9741 \\
$9.25 / 23.4$ & 2724 & & \\
& & &
\end{tabular}


Table B-4. Gamma scan data for nozzle R-7 (from base of cut nozzle)

\begin{tabular}{|c|c|c|c|}
\hline $\begin{array}{l}\text { Position } \\
\text { (in./cm) }\end{array}$ & $\begin{array}{c}\text { Cs-137 } \\
\text { (ROI \#1) }\end{array}$ & $\begin{array}{c}\text { Co-60 } \\
\text { (ROI \#2) }\end{array}$ & $\begin{array}{l}\text { Spectrum } \\
\text { (ROI \#3) }\end{array}$ \\
\hline $0.00 / 0.0$ & 474 & 0 & 2674 \\
\hline $0.25 / 0.6$ & 563 & 273 & 2969 \\
\hline $0.50 / 1.2$ & 547 & 0 & 3244 \\
\hline $0.75 / 1.9$ & 322 & 284 & 3215 \\
\hline $1.00 / 2.5$ & 266 & 40 & 2348 \\
\hline $1.25 / 3.2$ & 302 & 121 & 2872 \\
\hline $1.50 / 3.8$ & 626 & 417 & 3945 \\
\hline $1.75 / 4.4$ & 750 & 0 & 5232 \\
\hline $2.00 / 5.1$ & 1276 & 310 & 7063 \\
\hline $2.25 / 5.7$ & 1161 & 72 & 7860 \\
\hline $2.50 / 6.4$ & 1474 & 0 & 9864 \\
\hline $2.75 / 7.0$ & 2302 & 183 & 11922 \\
\hline $3.00 / 7.5$ & 3755 & 62 & 16809 \\
\hline $3.25 / 8.2$ & 5346 & 89 & 22360 \\
\hline $3.50 / 8.9$ & 8147 & 429 & 32602 \\
\hline $3.75 / 9.5$ & 12180 & 588 & 44707 \\
\hline $4.00 / 10.2$ & 19205 & 143 & 64206 \\
\hline $4.25 / 10.8$ & 24799 & 313 & 77974 \\
\hline $4.50 / 11.4$ & 22986 & 0 & 72784 \\
\hline $4.75 / 12.1$ & 18715 & 285 & 61234 \\
\hline $5.00 / 12.7$ & 14384 & 220 & 49012 \\
\hline $5.25 / 13.3$ & 11554 & 0 & 40917 \\
\hline $5.50 / 14.0$ & 9458 & 556 & 35700 \\
\hline $5.75 / 14.6$ & 8917 & 523 & 35020 \\
\hline $6.00 / 15.2$ & 8065 & 0 & 32226 \\
\hline $6.25 / 15.9$ & 7814 & 405 & 31792 \\
\hline $6.50 / 16.5$ & 8200 & 371 & 34206 \\
\hline $6.75 / 17.1$ & 13516 & 511 & 51234 \\
\hline $7.00 / 17.8$ & 21623 & 777 & 77528 \\
\hline $7.25 / 18.4$ & 29052 & 229 & 103240 \\
\hline $7.50 / 19.0$ & 33193 & 1348 & 120855 \\
\hline $7.75 / 19.7$ & 57722 & 795 & 209275 \\
\hline $8.00 / 20.3$ & 92136 & 1626 & 310636 \\
\hline $8.25 / 21.0$ & 91205 & 1642 & 303881 \\
\hline $8.50 / 21.6$ & 82096 & 1593 & 275752 \\
\hline $8.75 / 22.2$ & 65962 & 1925 & 222634 \\
\hline $9.00 / 22.9$ & 35006 & 1132 & 120317 \\
\hline $99.25 / 23.0$ & 2372 & 605 & 16291 \\
\hline
\end{tabular}


Table B-5. Gamma scan data for nozzle K-11 (from base of cut nozzle)

\begin{tabular}{rrrr}
\hline $\begin{array}{r}\text { Position } \\
\text { (in./cm) }\end{array}$ & $\begin{array}{r}\text { Cs-137 } \\
\text { (ROI \#1) }\end{array}$ & $\begin{array}{r}\text { Co-60 } \\
\text { (ROI \#2) }\end{array}$ & $\begin{array}{r}\text { Spectrum } \\
\text { (ROI \#3) }\end{array}$ \\
\hline $0.00 / 0.0$ & 213 & 324 & 11150 \\
$0.25 / 0.6$ & 5785 & 142 & 38097 \\
$0.50 / 1.2$ & 12253 & 597 & 97800 \\
$0.75 / 1.9$ & 27643 & 907 & 203175 \\
$1.00 / 2.5$ & 89243 & 1088 & 472481 \\
$1.25 / 3.2$ & 128463 & 1953 & 650506 \\
$1.50 / 3.8$ & 105058 & 2279 & 566874 \\
$1.75 / 4.4$ & 82641 & 1937 & 479256 \\
$2.00 / 5.1$ & 75657 & 3013 & 445515 \\
$2.25 / 5.7$ & 67473 & 3294 & 404138 \\
$2.50 / 6.4$ & 55696 & 3062 & 359474 \\
$2.75 / 7.0$ & 53551 & 3211 & 348205 \\
$3.00 / 7.5$ & 63250 & 3681 & 388749 \\
$3.25 / 8.2$ & 74224 & 3900 & 430172 \\
$3.50 / 8.9$ & 67191 & 4597 & 382262 \\
$3.75 / 9.5$ & 51030 & 3445 & 289803 \\
$4.00 / 10.2$ & 35356 & 1884 & 201844 \\
$4.25 / 10.8$ & 24371 & 1077 & 140340 \\
$4.50 / 11.4$ & 26534 & 1836 & 136121 \\
$4.75 / 12.1$ & 31615 & 1699 & 152175 \\
$5.00 / 12.7$ & 26466 & 2626 & 138202 \\
$5.25 / 13.3$ & 25537 & 2098 & 135753 \\
$5.50 / 14.0$ & 28582 & 2241 & 150533 \\
$5.75 / 14.6$ & 29819 & 2018 & 161135 \\
$6.00 / 15.2$ & 35725 & 1595 & 178035 \\
$6.25 / 15.9$ & 28338 & 2465 & 150174 \\
$6.50 / 16.5$ & 21072 & 1901 & 112842 \\
$6.75 / 17.1$ & 20845 & 1273 & 105688 \\
$7.00 / 17.8$ & 29836 & 1547 & 134394 \\
$7.25 / 18.4$ & 26385 & 1263 & 117408 \\
$7.50 / 19.0$ & 14337 & 613 & 68085 \\
$7.75 / 19.7$ & 10000 & 247 & 49768 \\
$8.00 / 20.3$ & 11022 & 504 & 54884 \\
$8.25 / 21.0$ & 26744 & 959 & 112439 \\
$8.50 / 21.6$ & 33889 & 1037 & 139049 \\
$8.75 / 22.2$ & 21665 & 667 & 87234 \\
$99.00 / 22$. & 12773 & 846 & 49014 \\
$99.25 / 23.4$ & 6243 & 382 & 23393 \\
$9.5 / 24.1$ & 1267 & 0 & 6498 \\
& & & \\
\hline & & & \\
& & & \\
\hline
\end{tabular}


Table B-6. Gamma scan data for nozzle K-12 (from base of cut nozzle)

\begin{tabular}{|c|c|c|c|}
\hline $\begin{array}{l}\text { Position } \\
\text { (in./cm) }\end{array}$ & $\begin{array}{c}\text { Cs-137 } \\
(\mathrm{ROI} \# 1)\end{array}$ & $\begin{array}{c}\text { Co-60 } \\
\text { (ROI \#2) }\end{array}$ & $\begin{array}{l}\text { Spectrum } \\
\text { (ROI \#3) }\end{array}$ \\
\hline $0.00 / 0.0$ & 3073 & 774 & 35992 \\
\hline $0.25 / 0.6$ & 6185 & 676 & 60754 \\
\hline $0.50 / 1.2$ & 8892 & 922 & 86004 \\
\hline $0.75 / 1.9$ & 9404 & 603 & 126221 \\
\hline $1.00 / 2.5$ & 29494 & 1536 & 273328 \\
\hline $1.25 / 3.2$ & 125766 & 2056 & 750672 \\
\hline $1.50 / 3.8$ & 174354 & 3097 & 1100302 \\
\hline $1.75 / 4.4$ & 171651 & 3282 & 1202616 \\
\hline $2.00 / 5.1$ & 170350 & 6810 & 1242939 \\
\hline $2.25 / 5.7$ & 155164 & 9726 & 1256498 \\
\hline $2.50 / 6.4$ & 161628 & 9713 & 1337884 \\
\hline $2.75 / 7.0$ & 150716 & 7790 & 1266698 \\
\hline $3.00 / .5$ & 148602 & 7993 & 1222078 \\
\hline $3.25 / 8.2$ & 135025 & 8115 & 1152459 \\
\hline $3.50 / 8.9$ & 125771 & 11658 & 1144313 \\
\hline $3.75 / 9.5$ & 164194 & 9280 & 1307605 \\
\hline $4.00 / 10.2$ & 178728 & 7823 & 1367460 \\
\hline $4.25 / 10.8$ & 147140 & 7942 & 1214165 \\
\hline $4.50 / 11.4$ & 146224 & 9219 & 1190455 \\
\hline $4.75 / 12.1$ & 155335 & 8655 & 1245091 \\
\hline $5.00 / 12.7$ & 162761 & 10014 & 1289928 \\
\hline $5.25 / 13.3$ & 169861 & 8759 & 1333474 \\
\hline $5.50 / 14.0$ & 172724 & 8481 & 1356308 \\
\hline $5.75 / 14.6$ & 168834 & 9759 & 1325592 \\
\hline $6.00 / 15.2$ & 163305 & 9949 & 1291440 \\
\hline $6.25 / 15.9$ & 163228 & 8329 & 1270380 \\
\hline $6.50 / 16.5$ & 162087 & 10185 & 1264342 \\
\hline $6.75 / 17.1$ & 163130 & 10812 & 1271003 \\
\hline $7.00 / 17.8$ & 164521 & 10804 & 1290088 \\
\hline $7.25 / 18.4$ & 169640 & 12399 & 1314631 \\
\hline $7.50 / 19.0$ & 173156 & 7447 & 1341323 \\
\hline 7.75/19.7 & 169504 & 8325 & 1338725 \\
\hline $8.00 / 20.3$ & 171698 & 11147 & 1331725 \\
\hline $8.25 / 21.0$ & 167810 & 8907 & 1302177 \\
\hline $8.50 / 21.6$ & 176604 & 8997 & 1337375 \\
\hline $8.75 / 22.2$ & 209646 & 9503 & 1438863 \\
\hline $9.00 / 22.9$ & 186166 & 8867 & 1139391 \\
\hline $9.25 / 23.4$ & 86016 & 4919 & 554483 \\
\hline $9.50 / 24.1$ & 12176 & 1845 & 157095 \\
\hline $9.75 / 24.8$ & 7848 & 808 & 82568 \\
\hline $10.0 / 25.4$ & 5372 & 1002 & 52655 \\
\hline $10.3 / 26.0$ & 1133 & 176 & 30983 \\
\hline
\end{tabular}




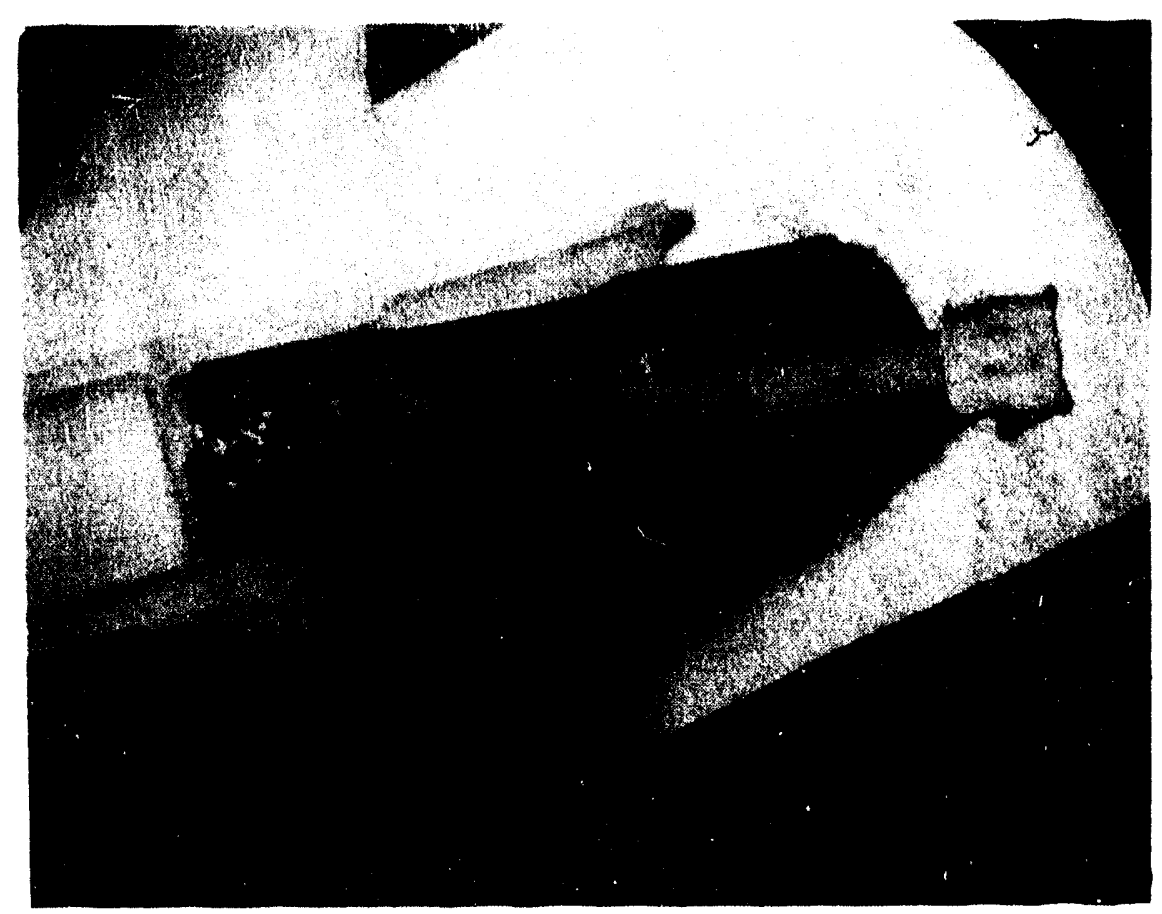

Figure B-1. Photograph of the entire M-10 nozzle (the extrapolated length is 6-3/8 in.).

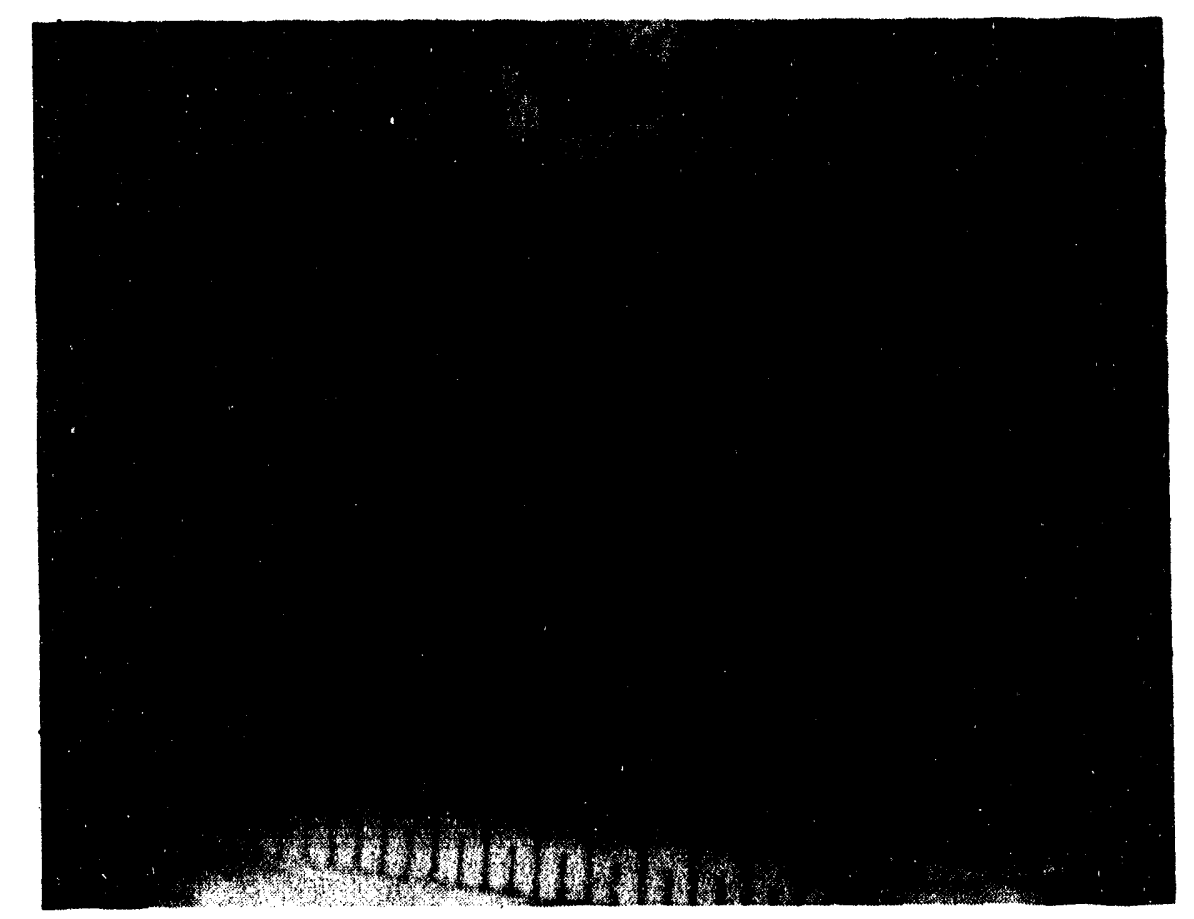

Figure B-2. Closeup view of the melt interaction zone on the top edge (tip) of nozzle M-10. 


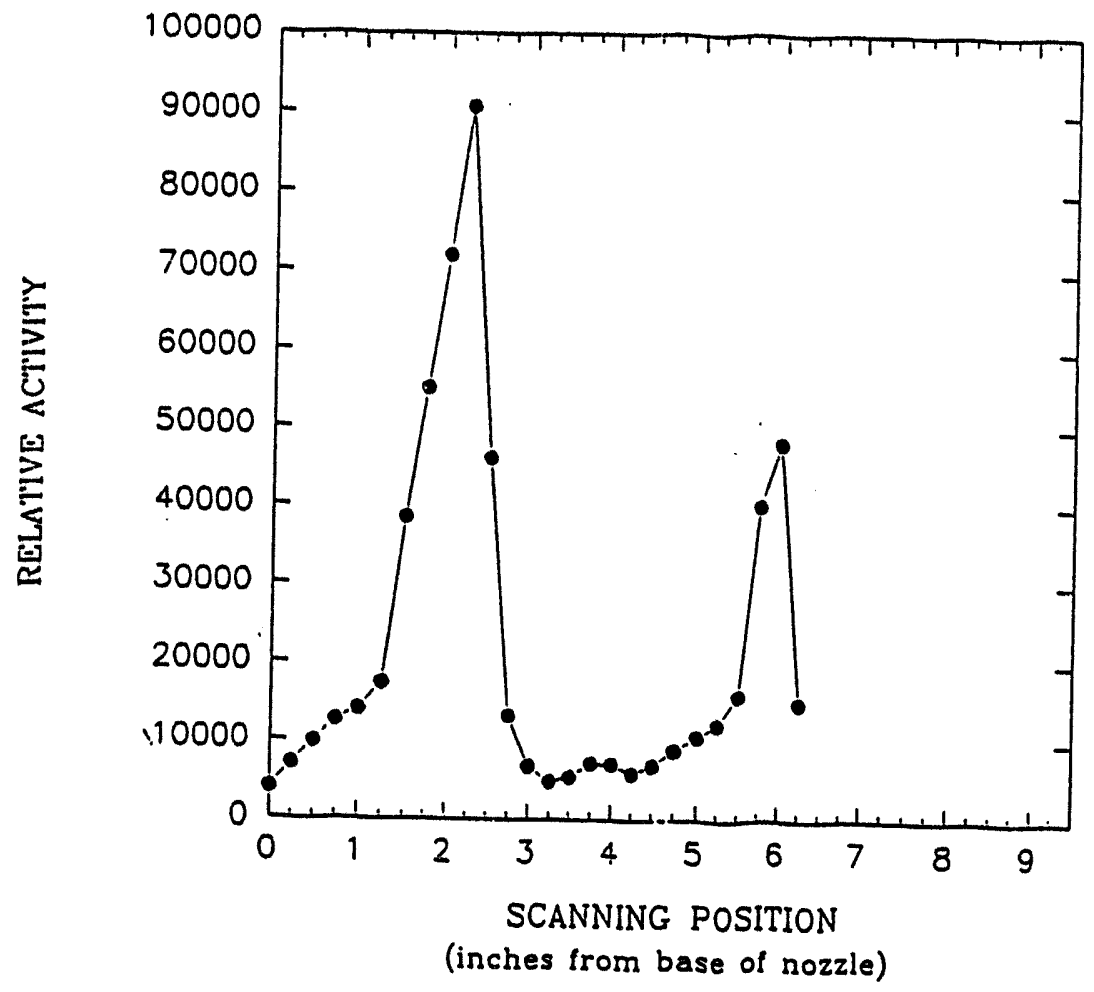

Figure B-3. The Cs-137 activity profile of nozzle M-10.

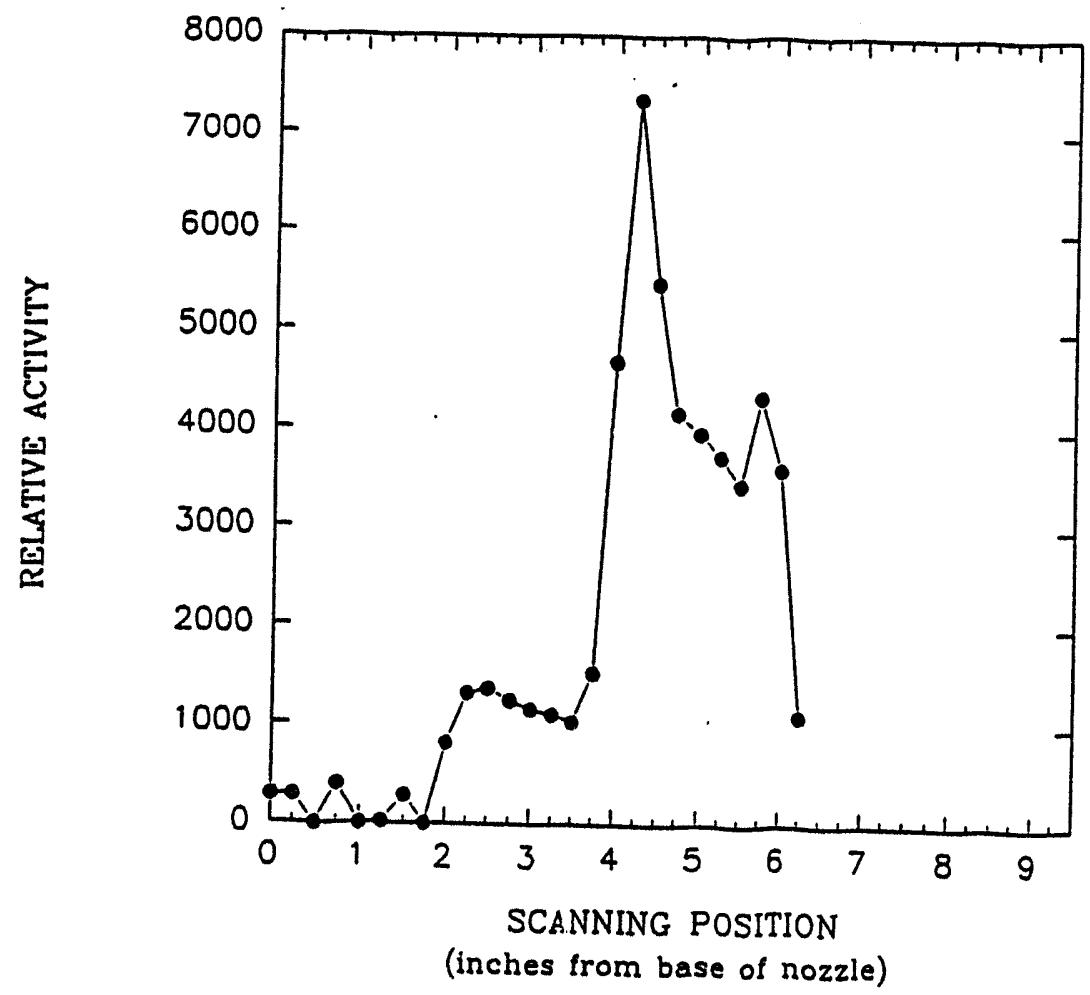

Figure B-4. The Co-60 activity profile of nozzle M-10. 


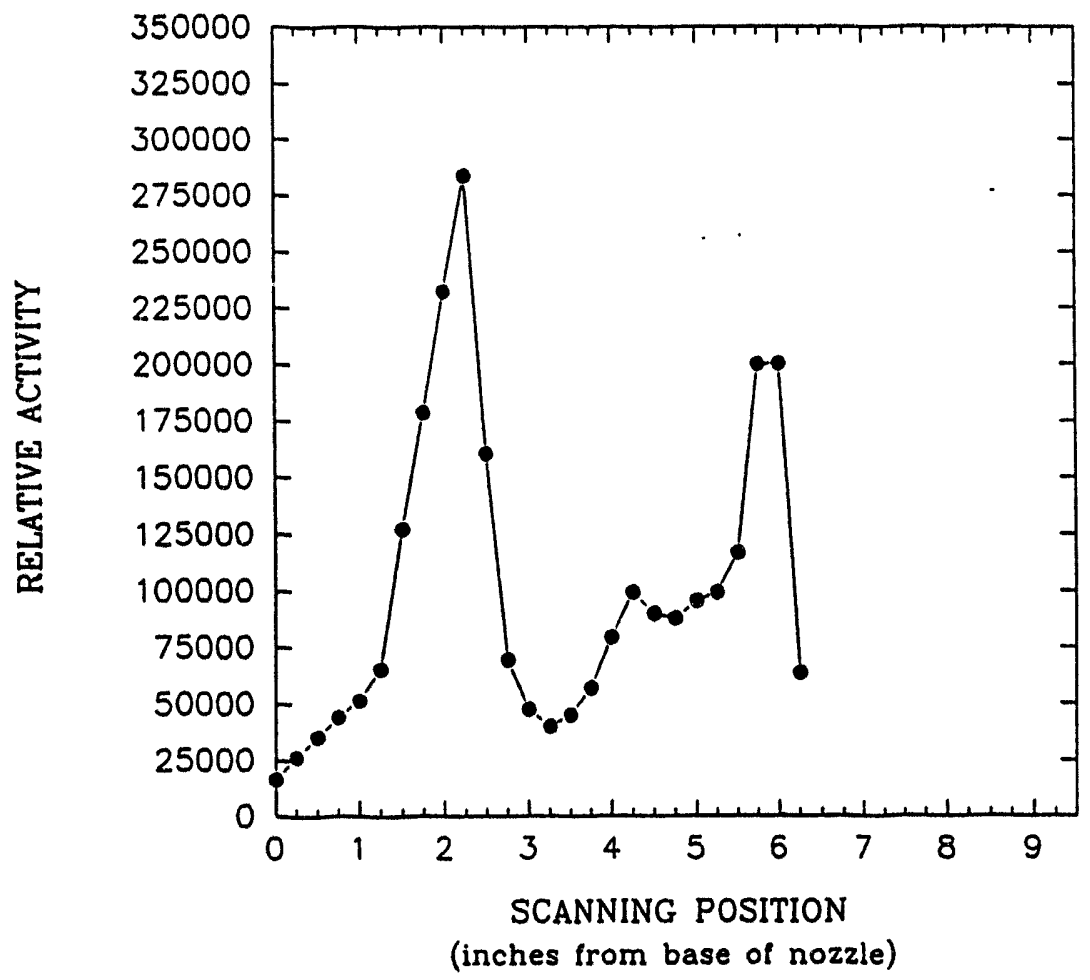

Figure B-5. The full-spectrum activity profile of nozzle M-10.

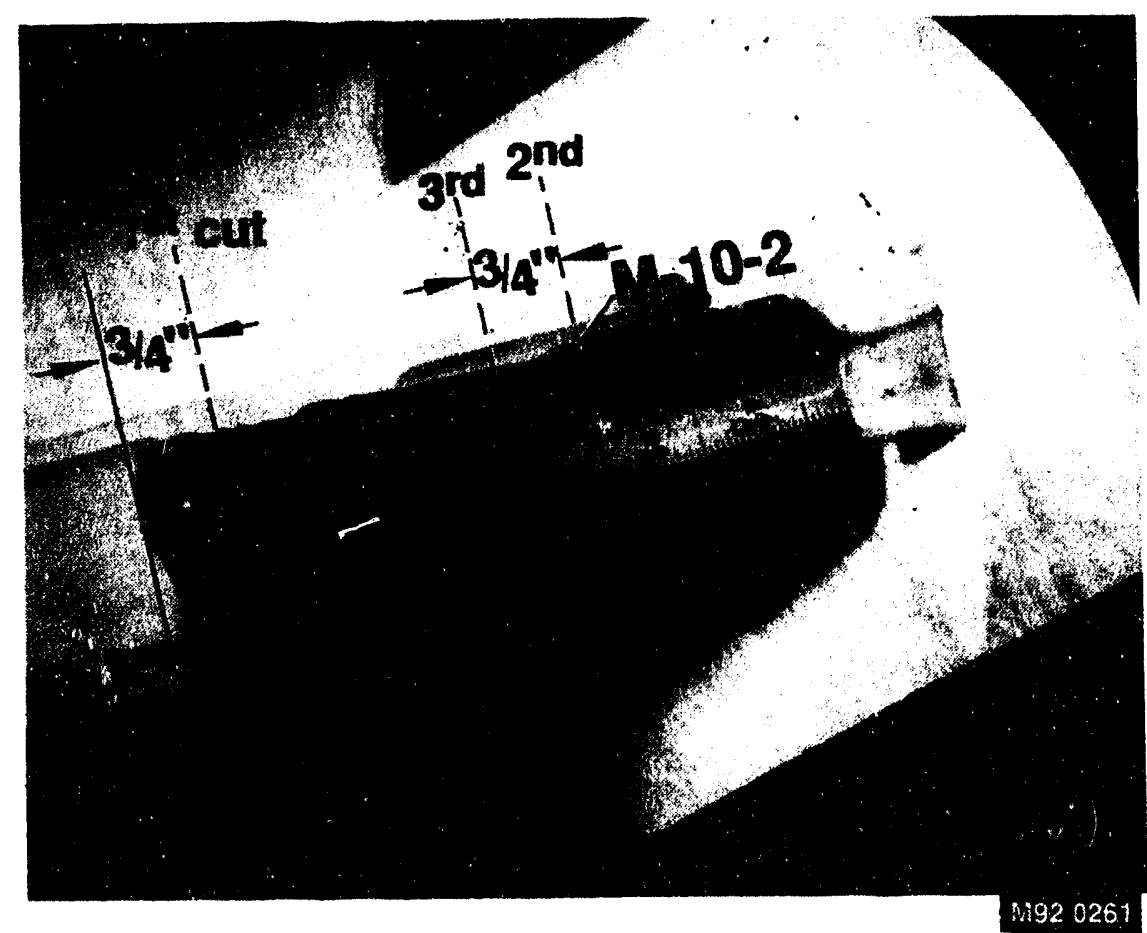

Figure B-6. Sectioning diagram of the M-10 nozzle. 


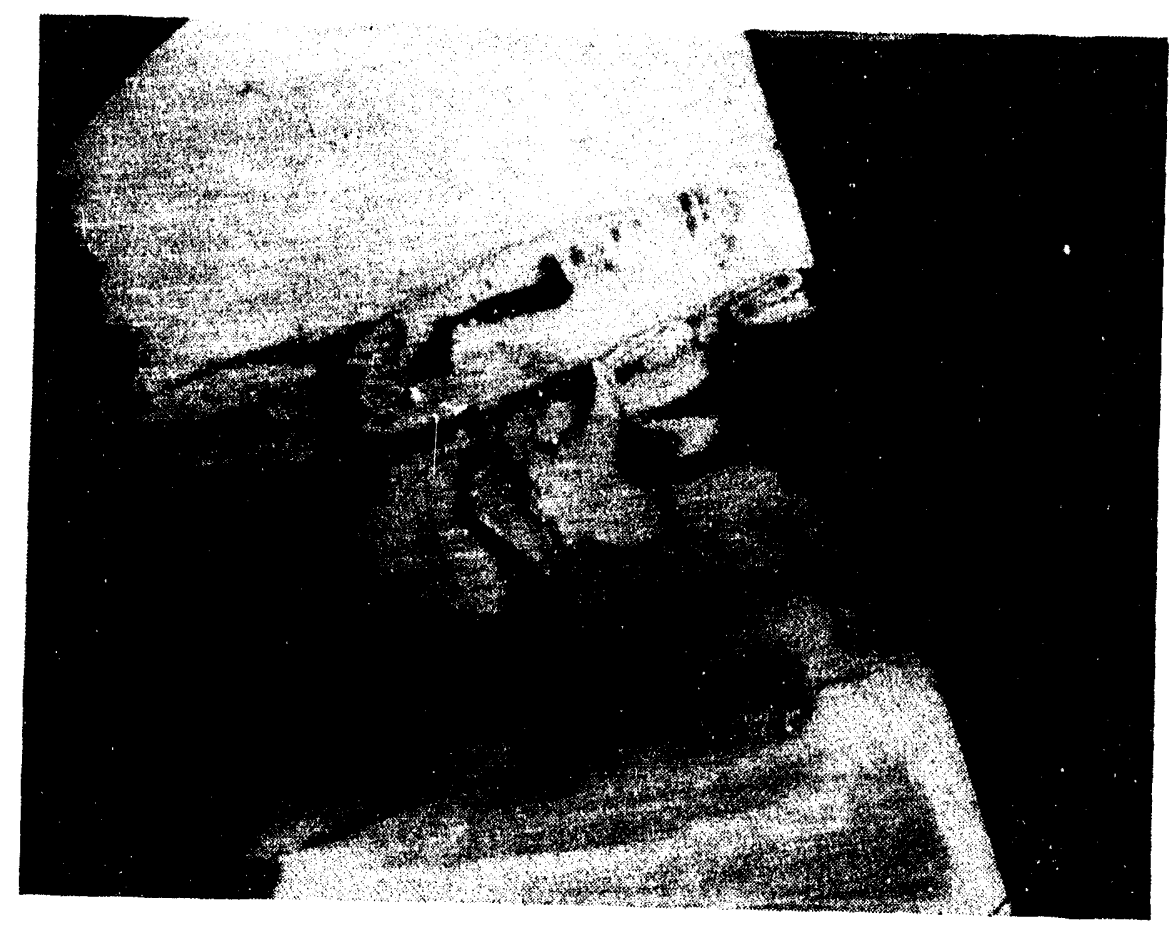

Figure B-7. Sample M-10-1A, from a longitudinal cut of M-10-1.

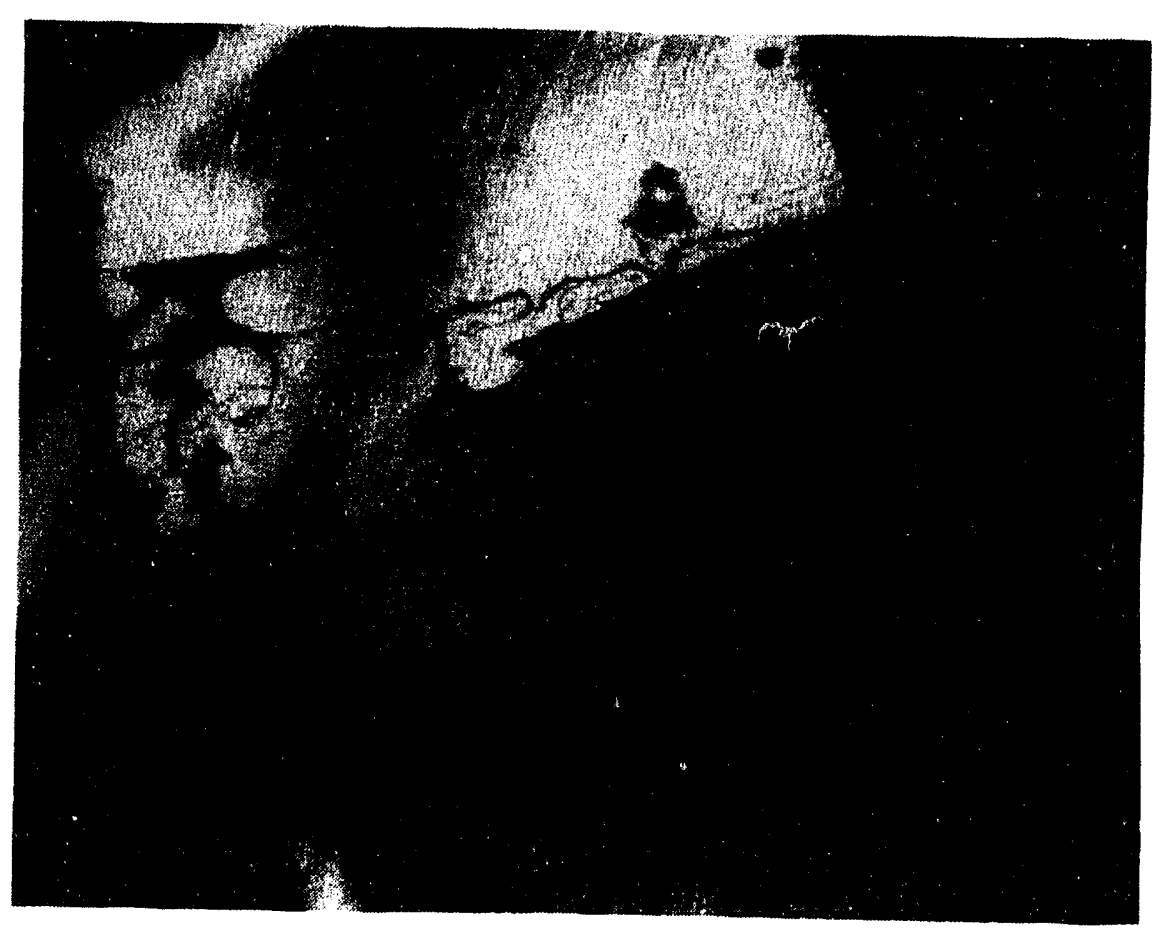

Figure B-8. Sample M-10-1B, showing melt/instrument string interaction. 


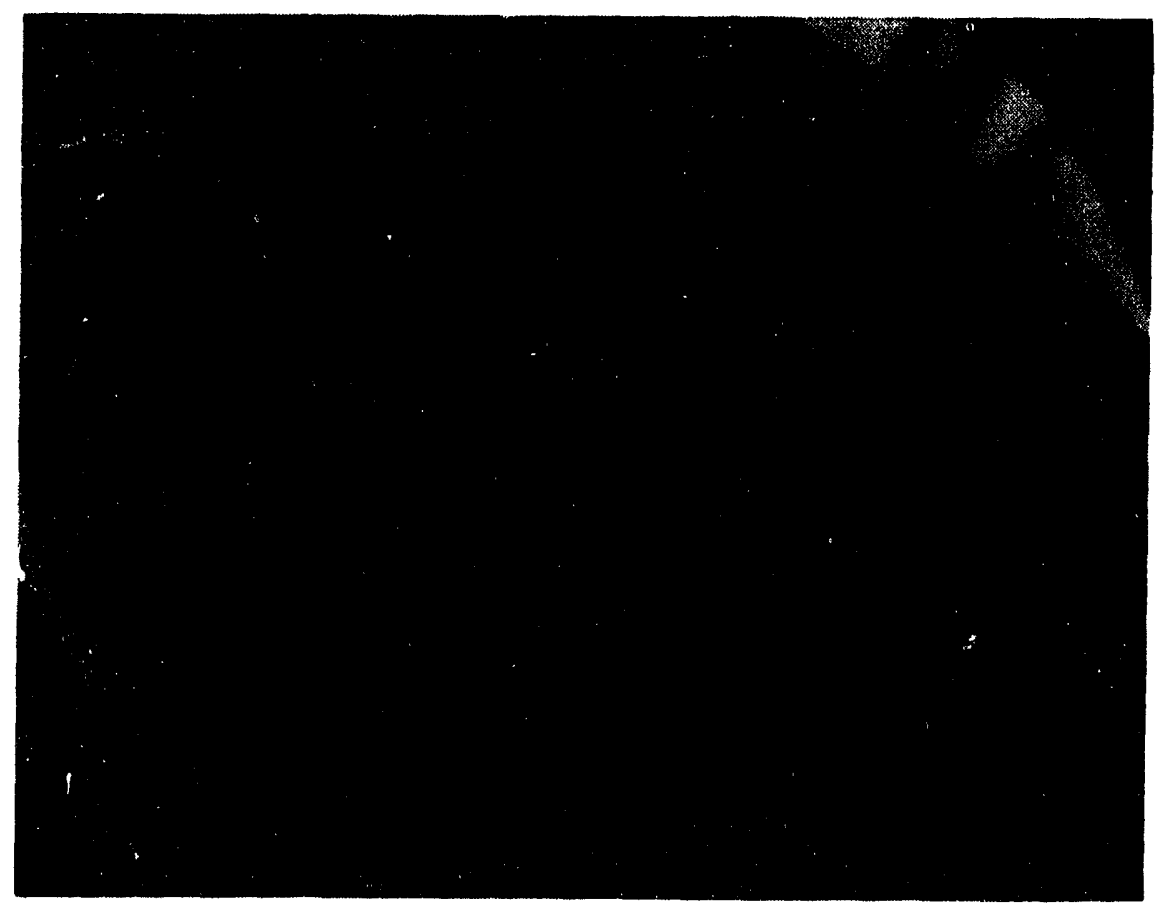

Figure B-9. Macro side view of sample M-10-1B.

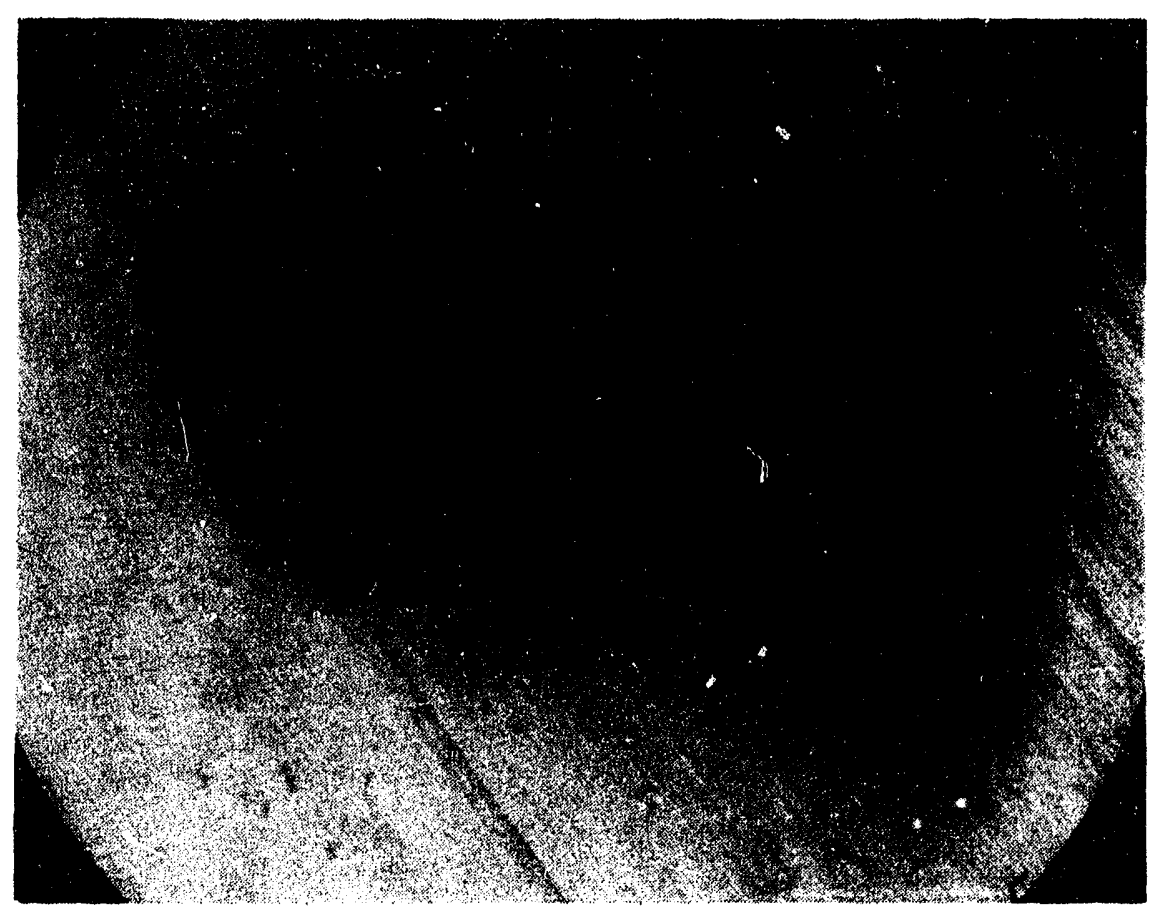

Figure B-10. View of the bottom end of the transverse section, M-10-2, showing the beginning of the melt penetration. 


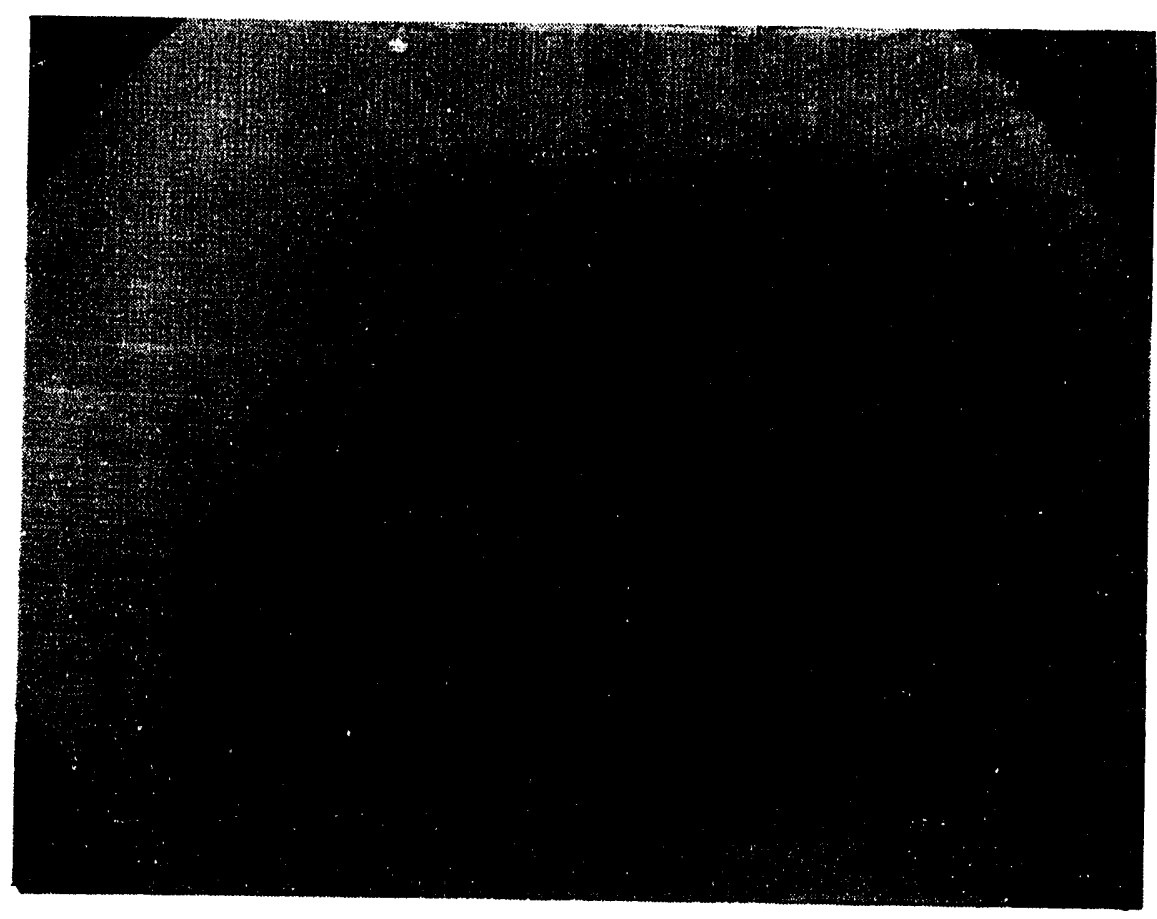
Figure B-11. Top (tip) end perspective of the transverse section, M-10-2, exhibiting extensive
melt interaction.

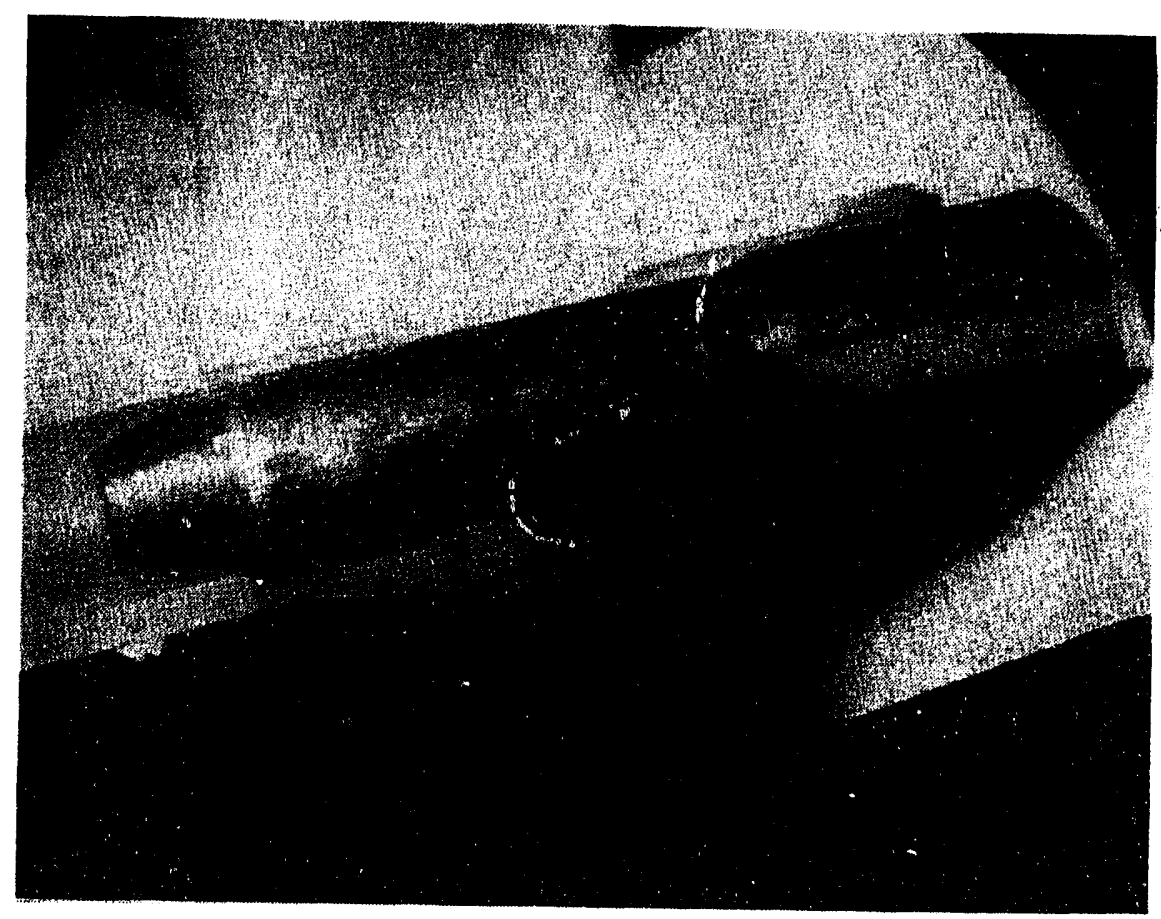

Figure B-12. Full-length (9-1/2 in.) view of the H-9 nozzle. 


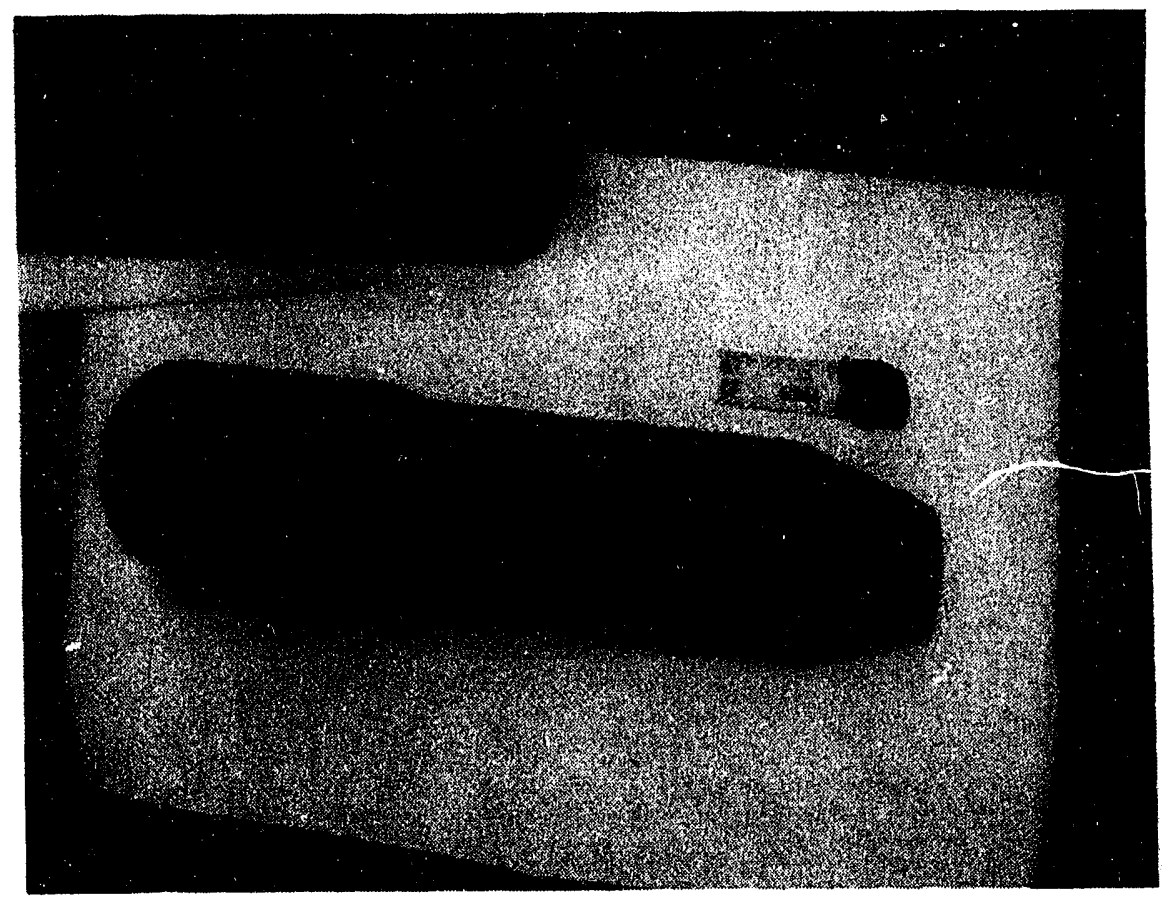

Figure B-13. A side (long) view of nozzle H-9, showing the instrument core string still intact.

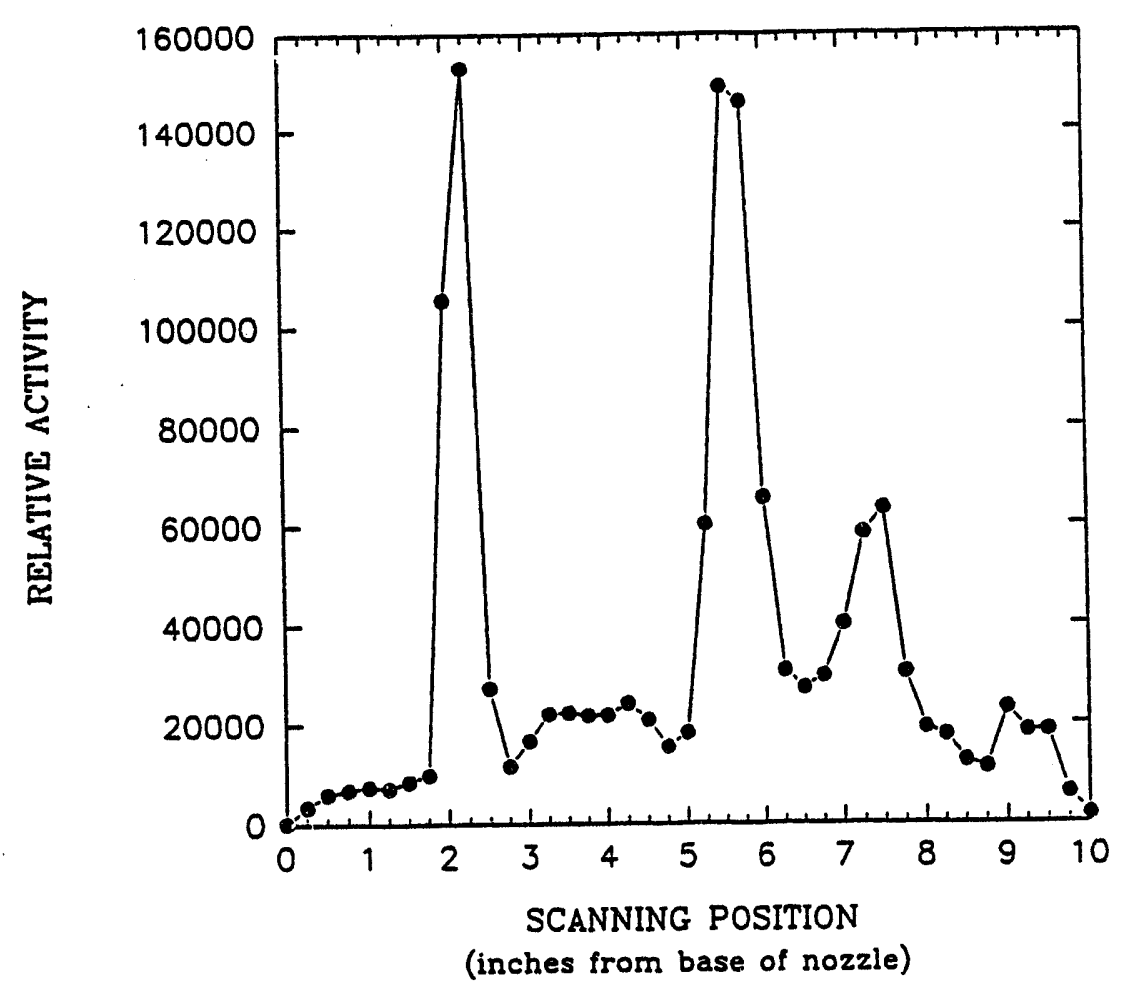

Figure B-14. The Cs-137 activity profile of nozzle H-9. 


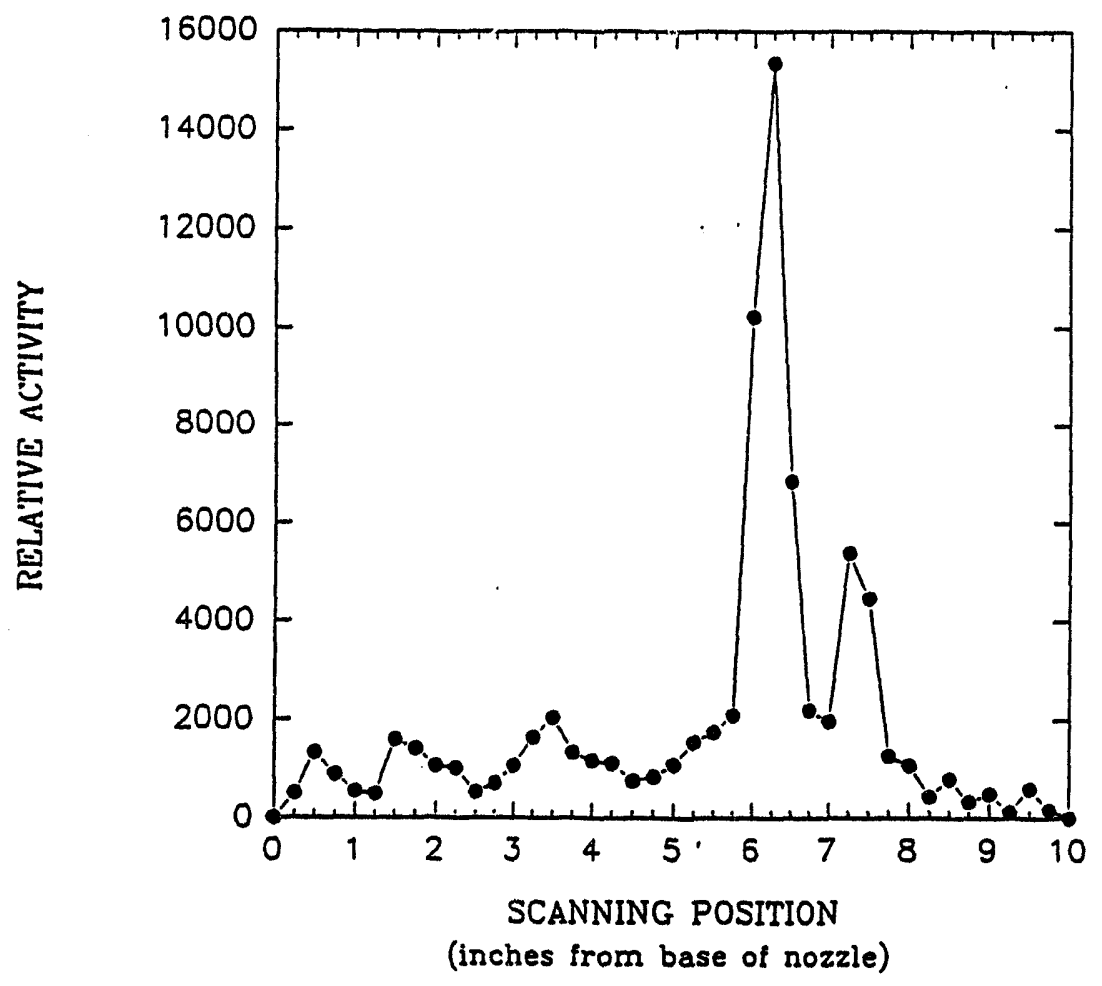

Figure B-15. The Co-60 activity profile of nozzle H-9.

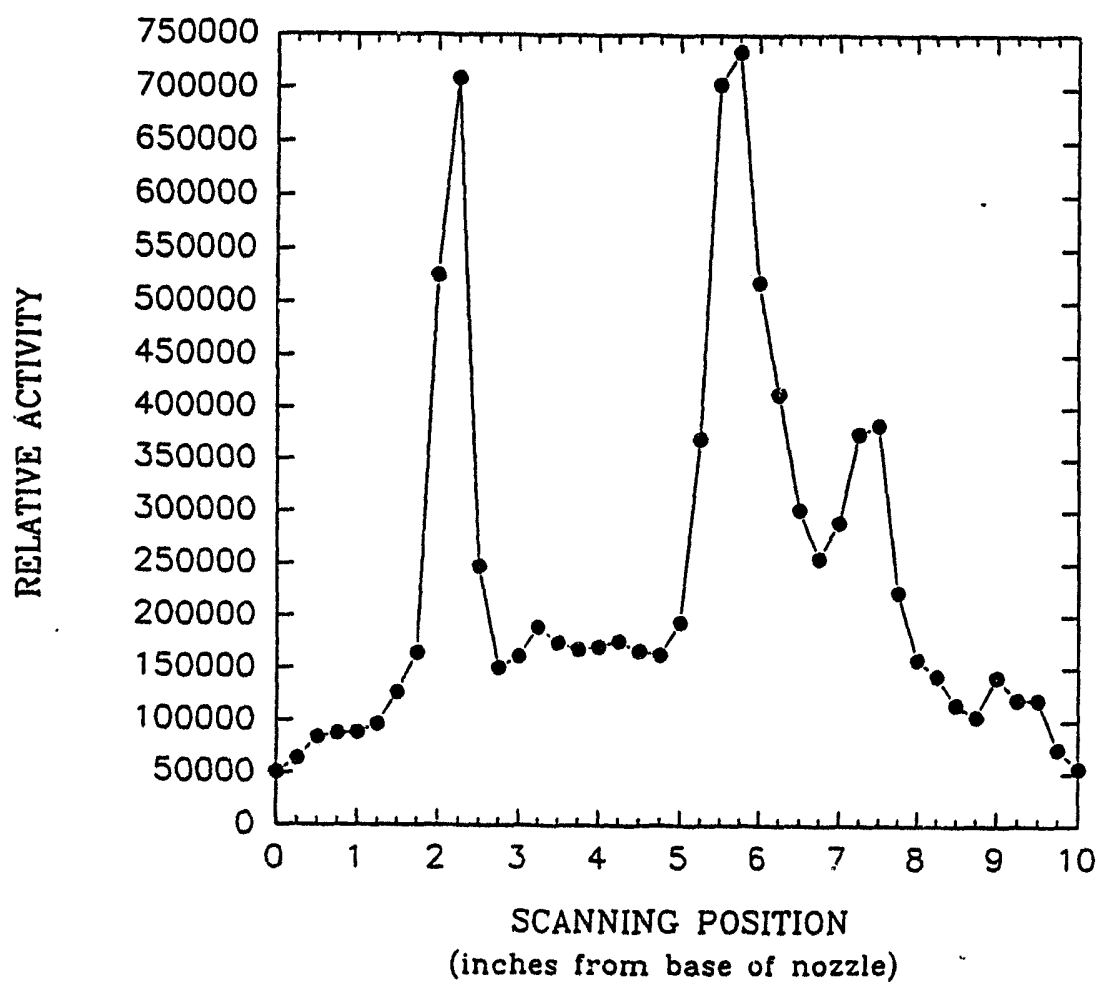

Figure B-16. The iull-spectrum activity profile of nozzle H-9. 


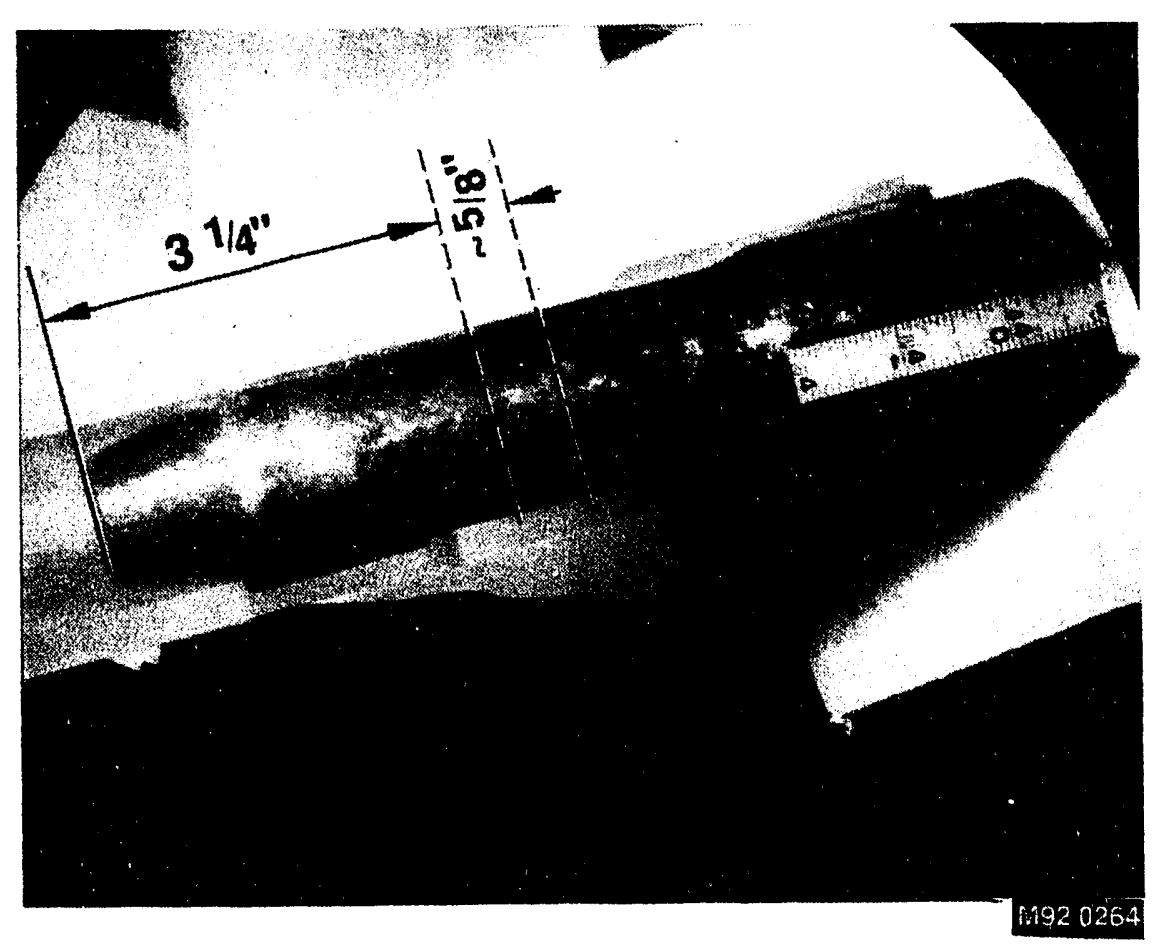

Figure B-17. Sectioning diagram of the H-9 nozzle.

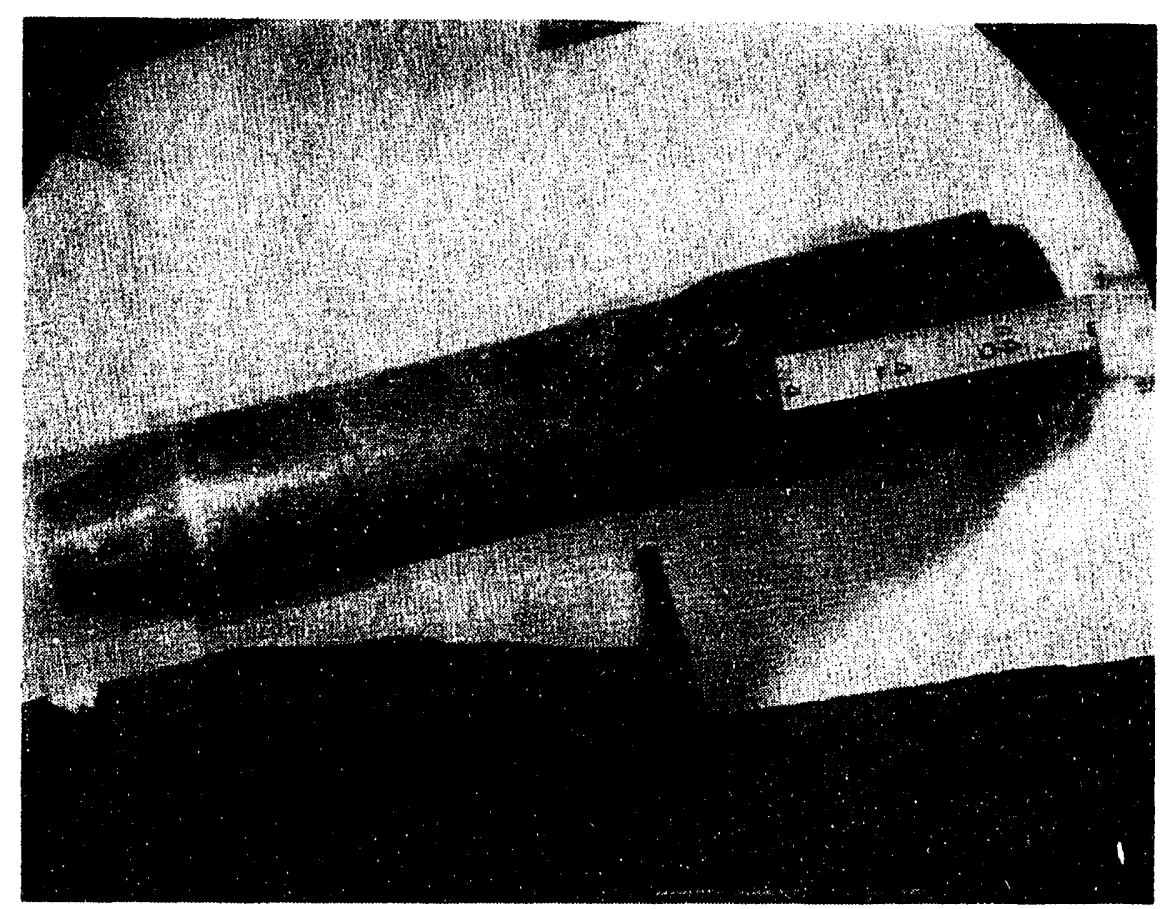

Figure B-18. Full-length (9-in.) view of nozzle L-11. 


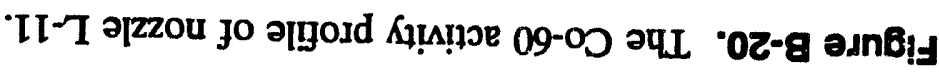
(эzzou jo әseq uroxy sayou!) NOILISOd DNINNHOS

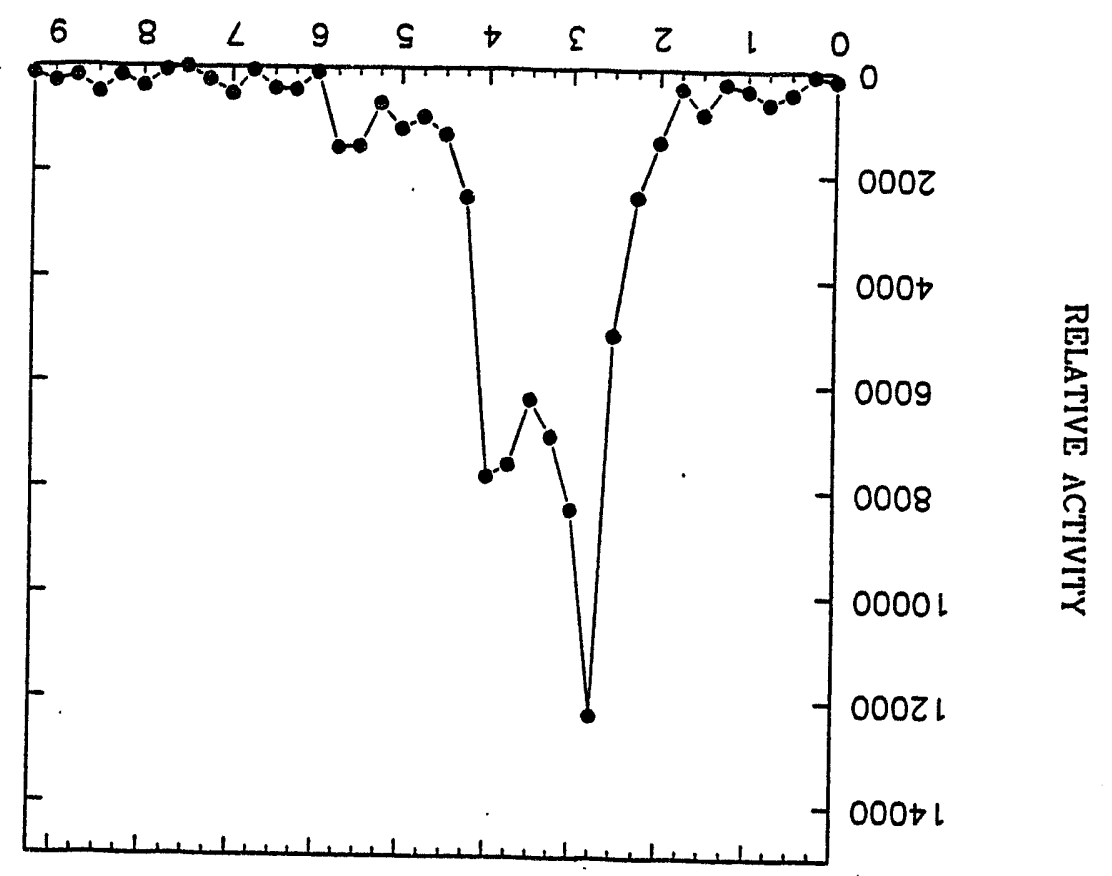

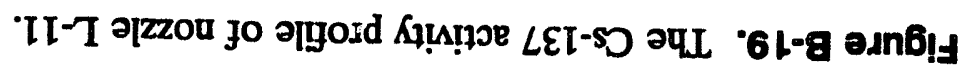

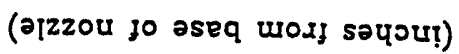
NOILISOd JNINNGJS

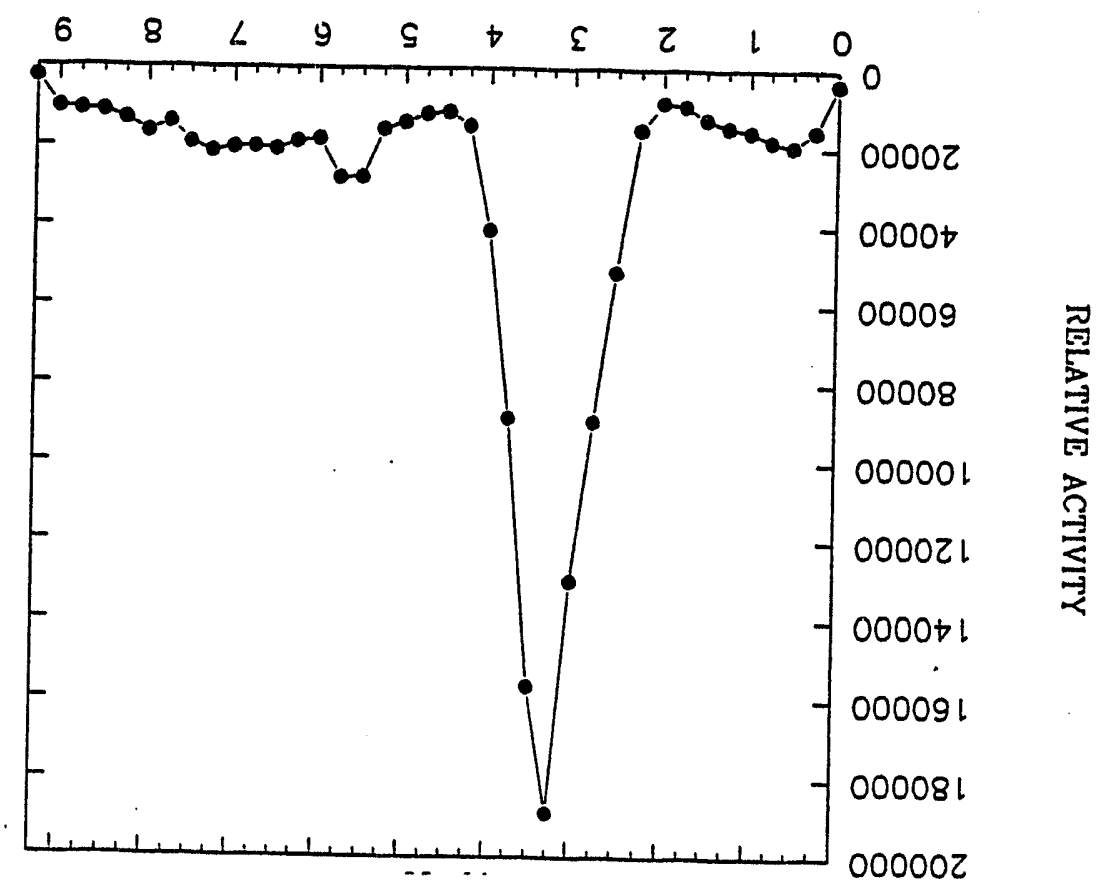




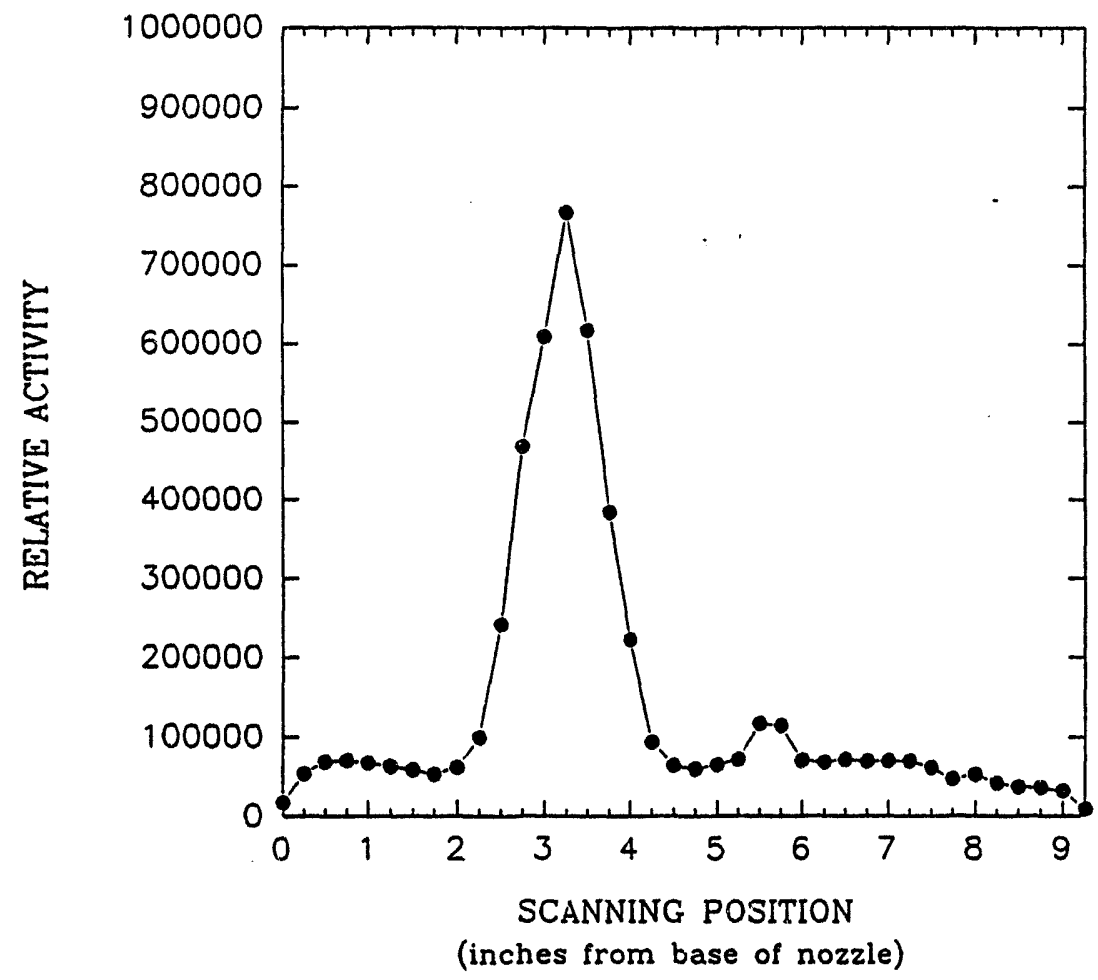

Figure B-21. The full-spectrum activity profile of nozzle L-11.

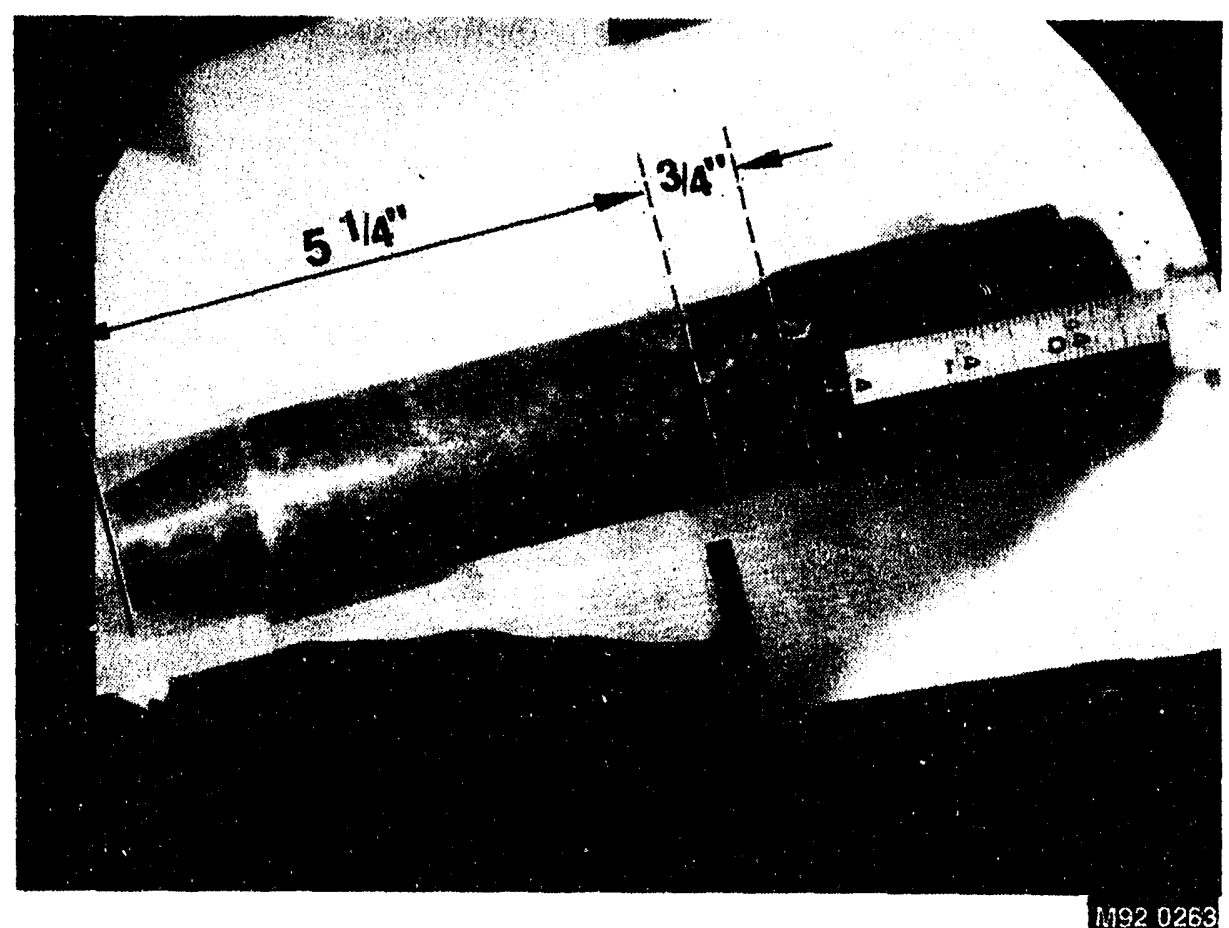

Figure B-22. Sectioning diagram of the $L-11$ nozzle. 


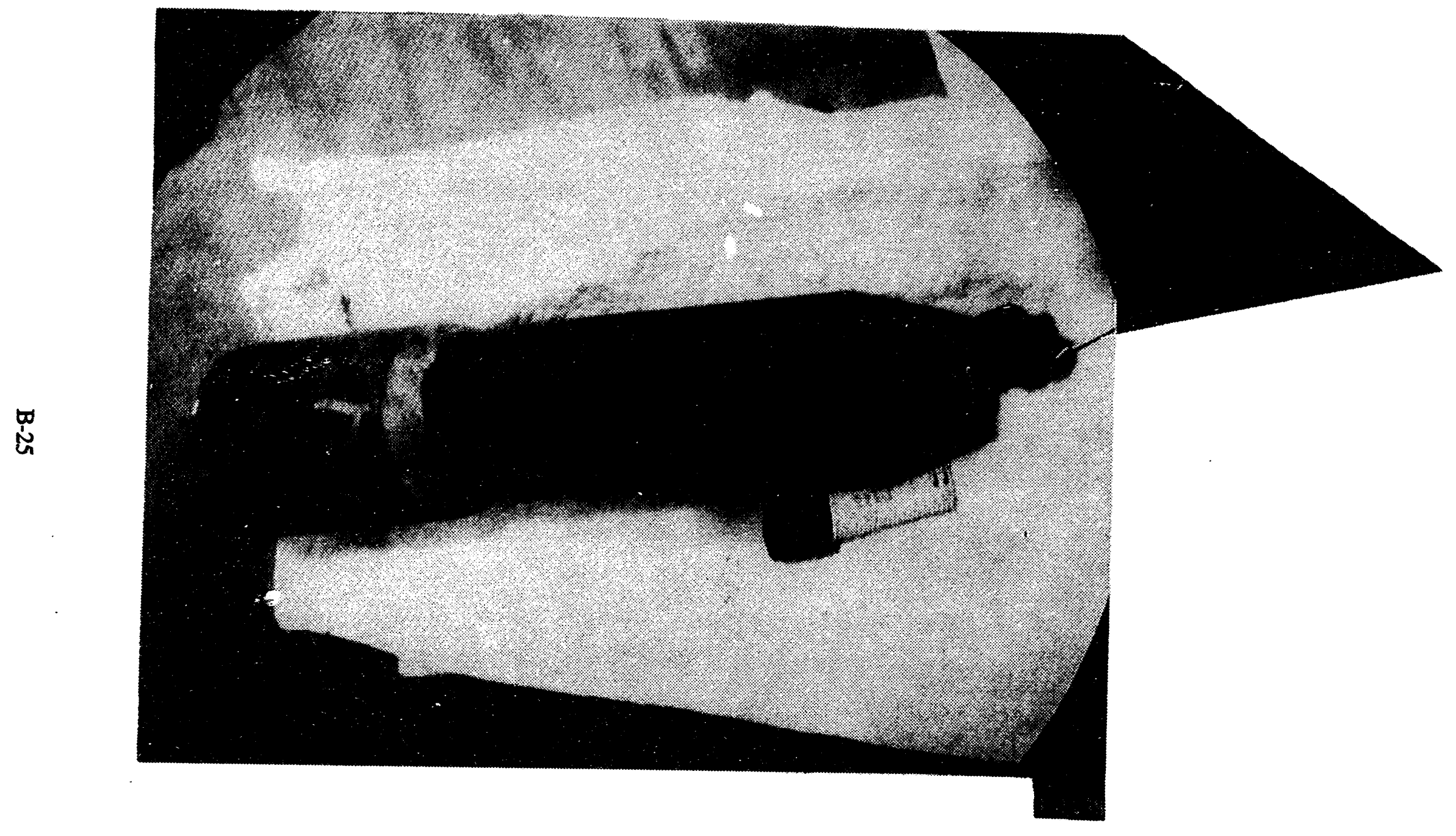

Figure B-23. Full-length view of the R-7 nozzle with the instrument core string and melt bulb still attached. 


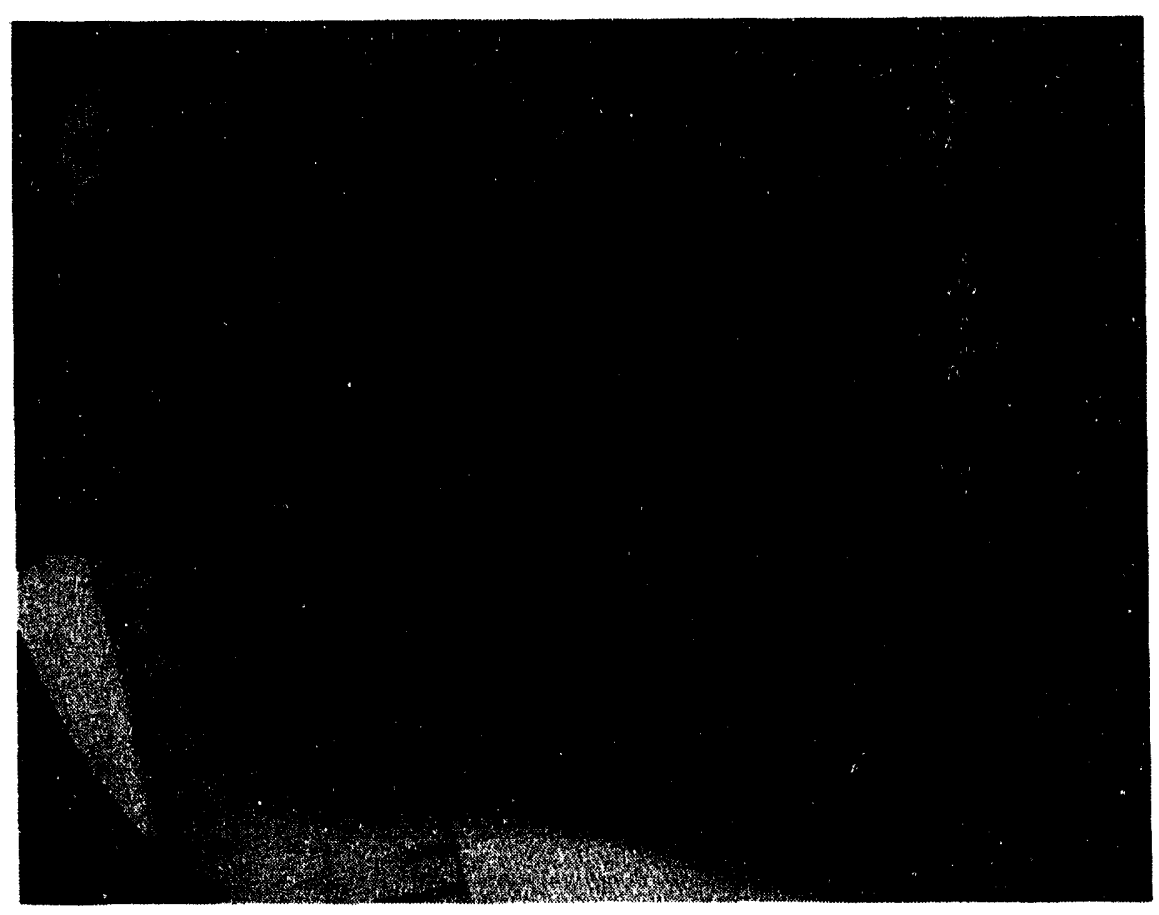

Figure B-24. A closeup perspective of the lip of R-7 with instrument string still intact.

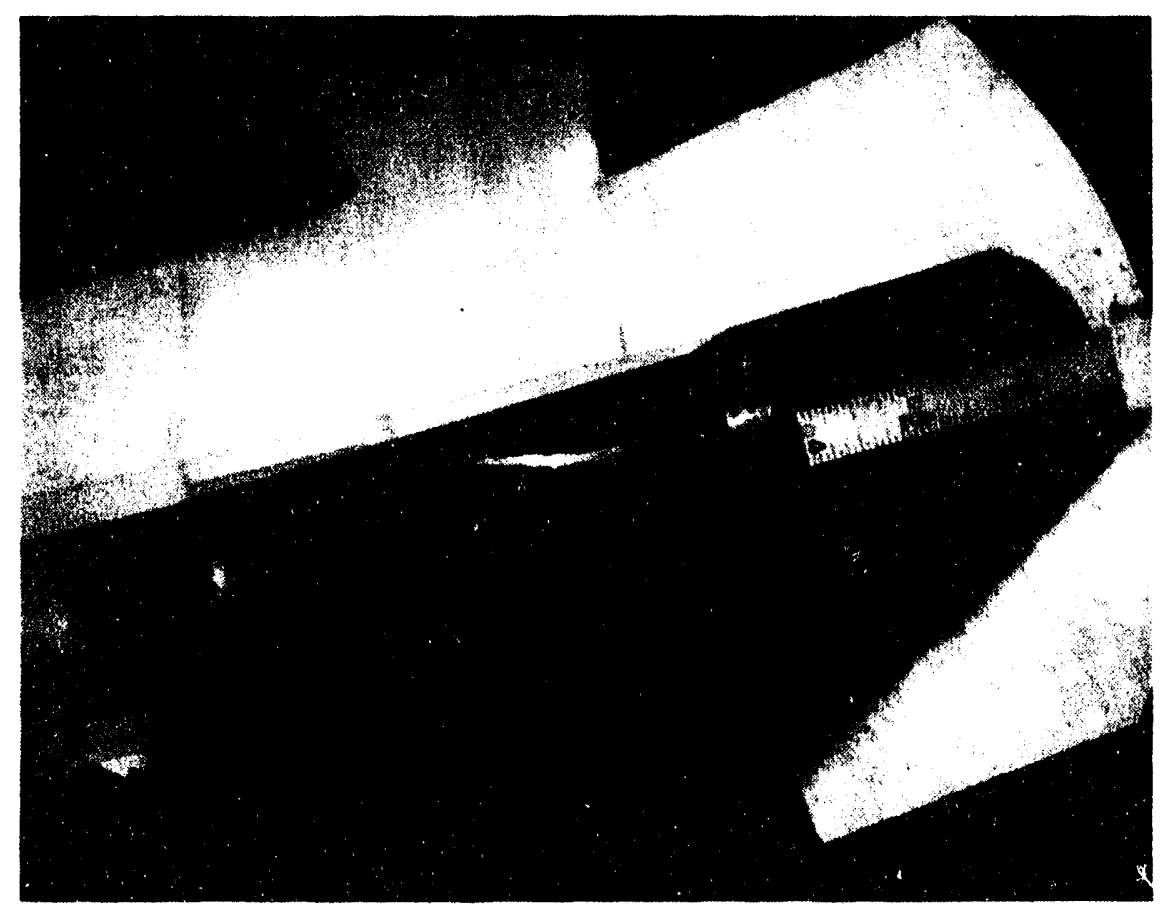

Figure B-25. Full-length (9-1/8 in.) view of the R-7 nozzle after melt bulb removal. 


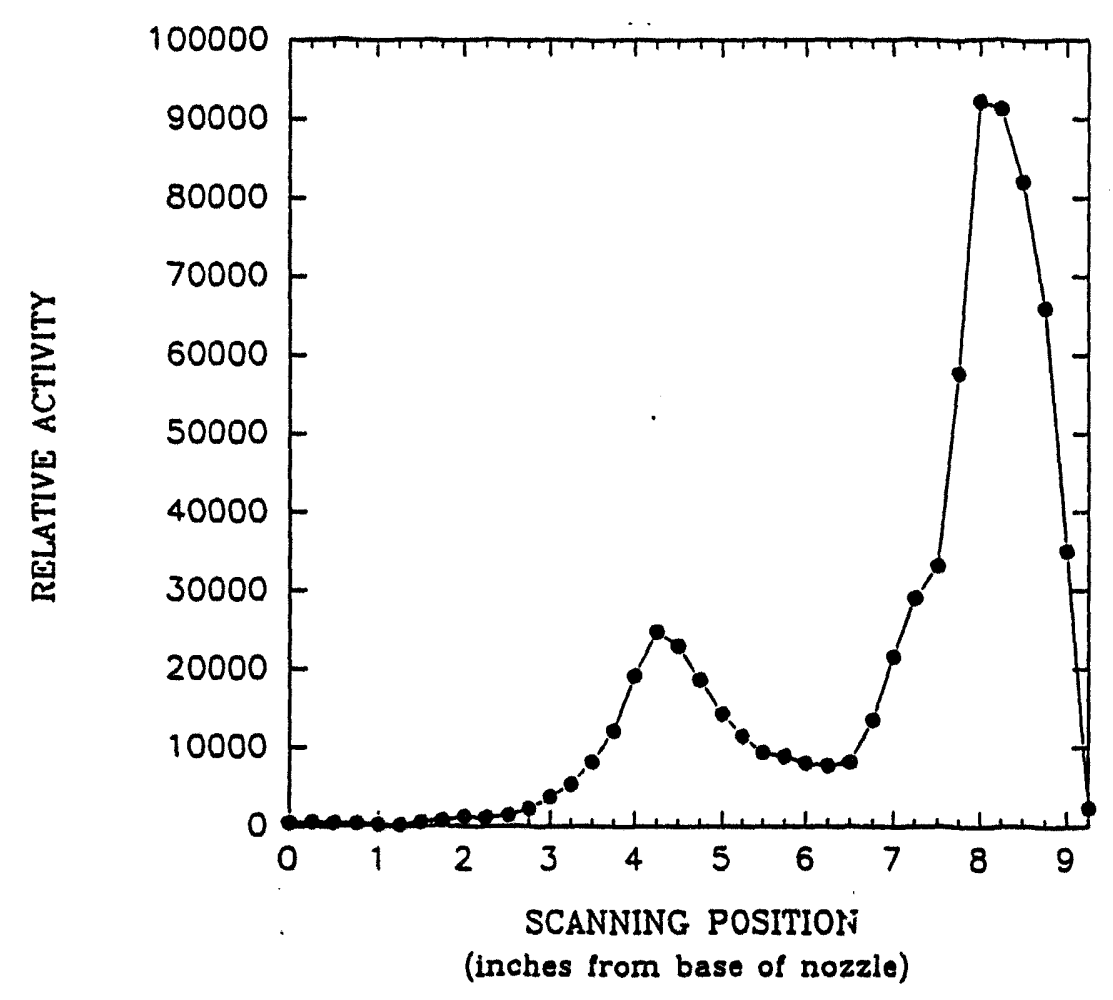

Figure B-26. The Cs-137 activity profile of nozzle R-7.

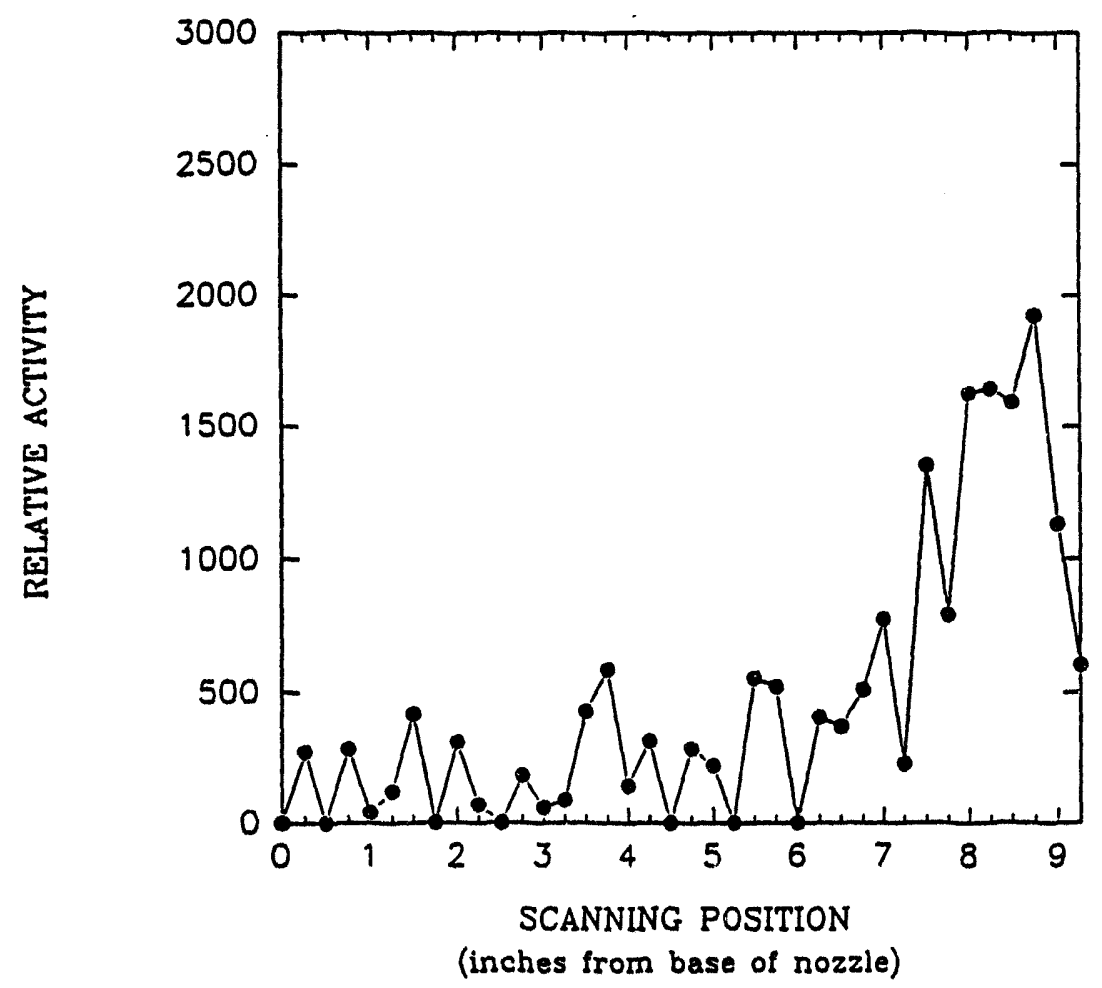

Figure B-27. The Co-60 activity profile of nozzle R-7. 


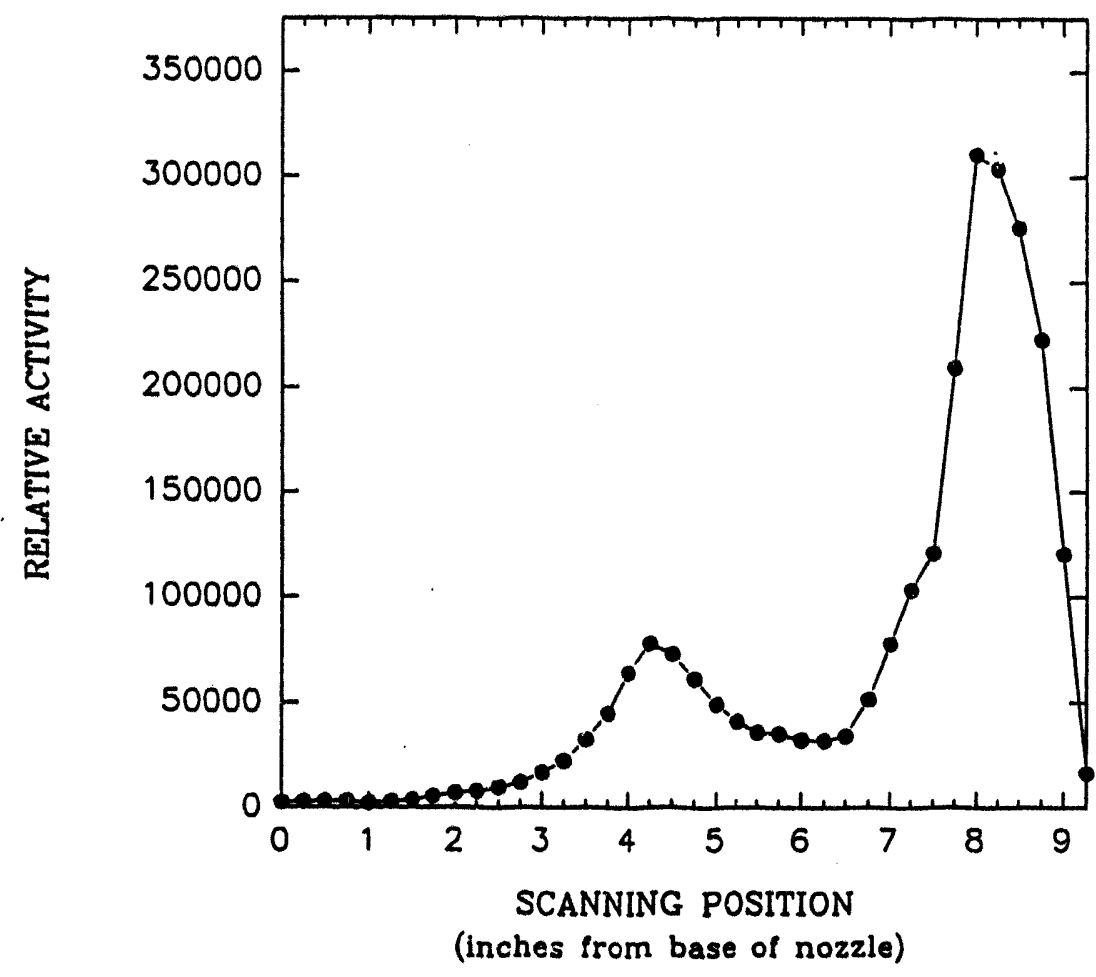

Figure B-28. The full-spectrum activity profile of nozzle R-7.

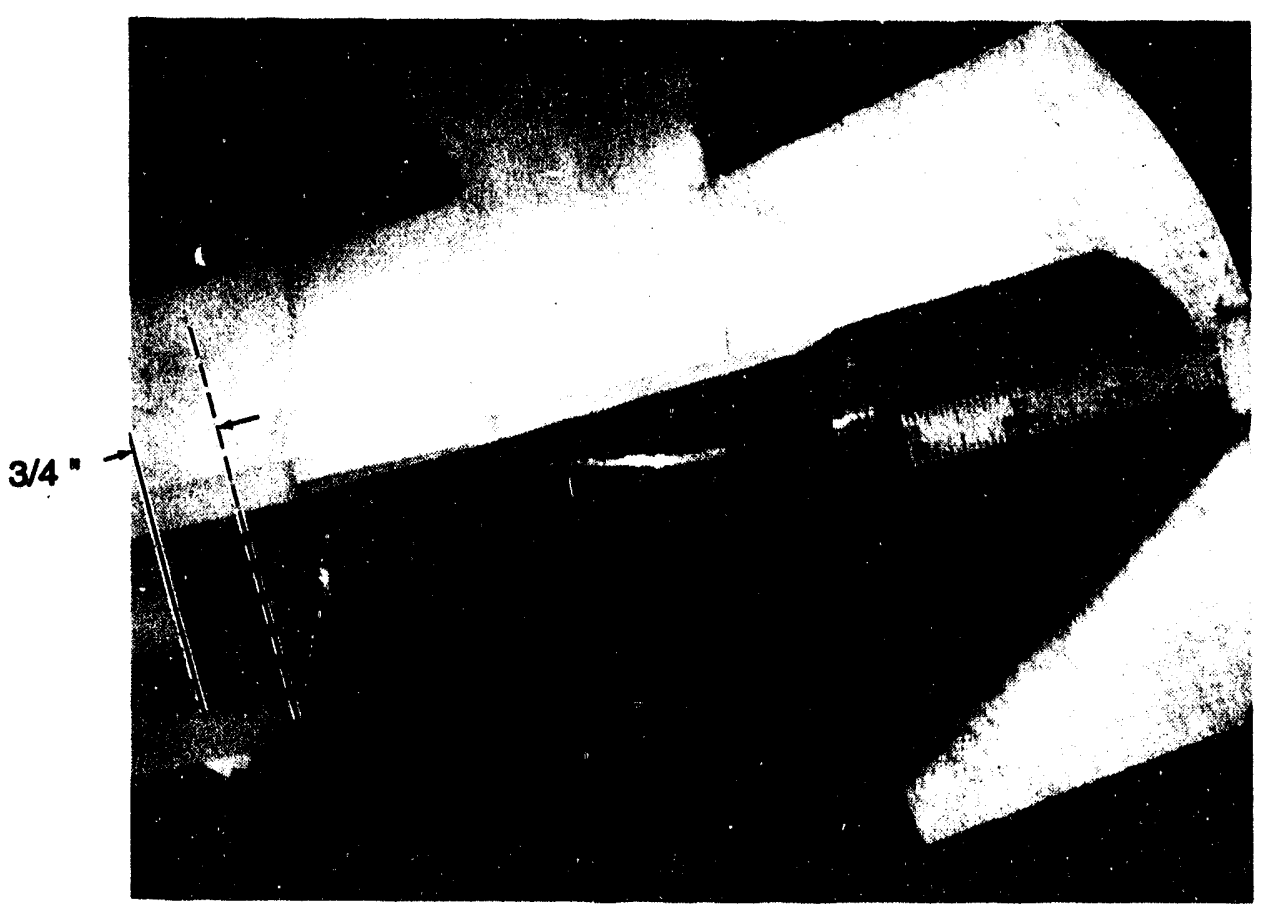

Figure B-29. Sectioning diagram of the R-7 nozzle. 


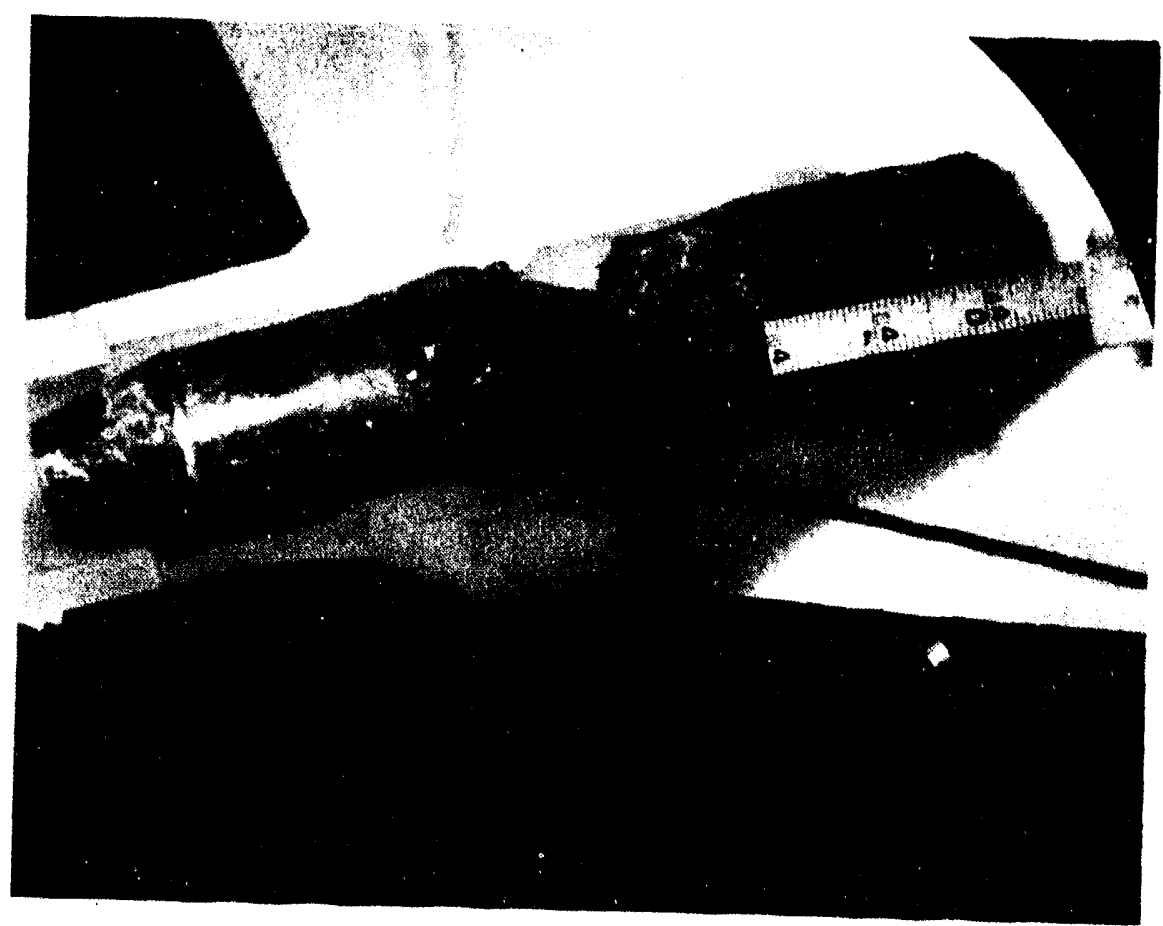

Figure B-30. Full-length (9-1/4 in.) view of K-11 nozzle at a 0-degree reference.

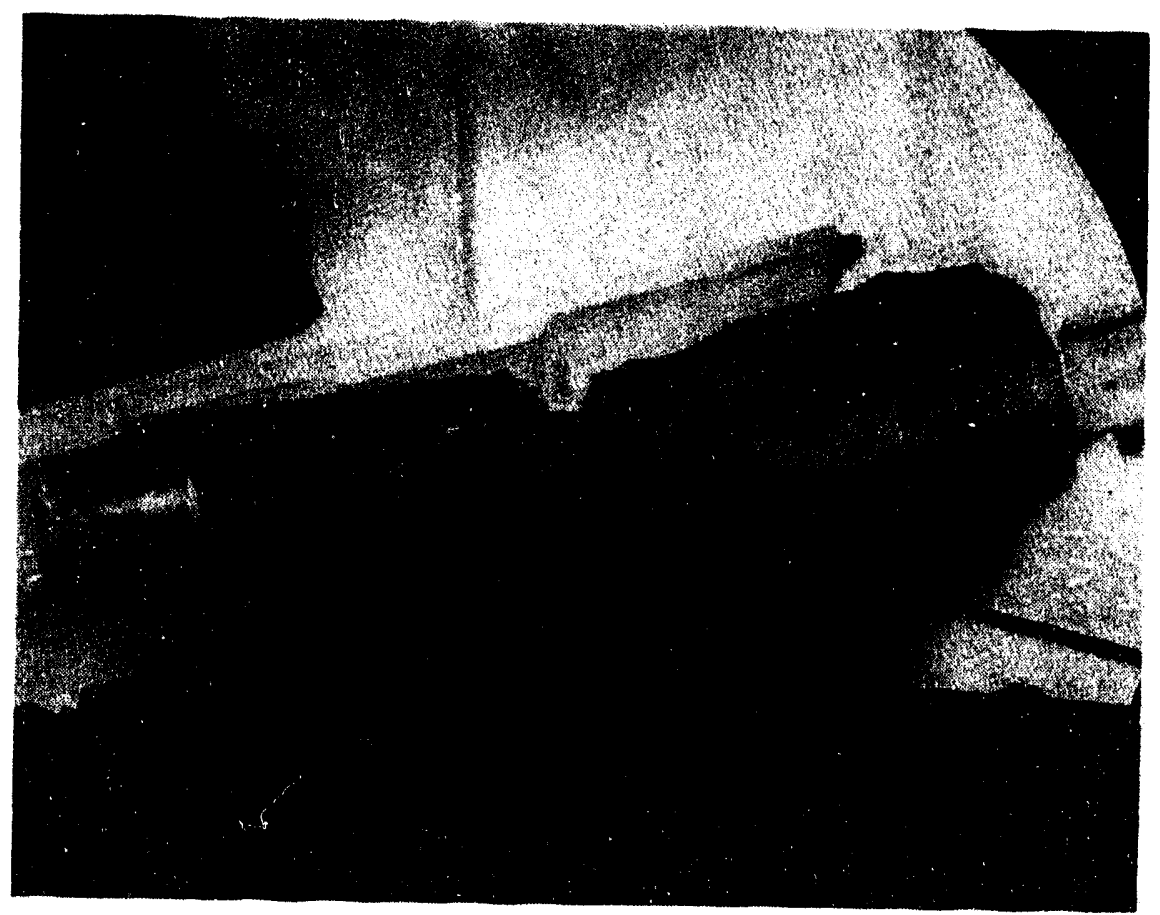

Figure B-31. K-11 nozzle with a 180-degree rotation. 


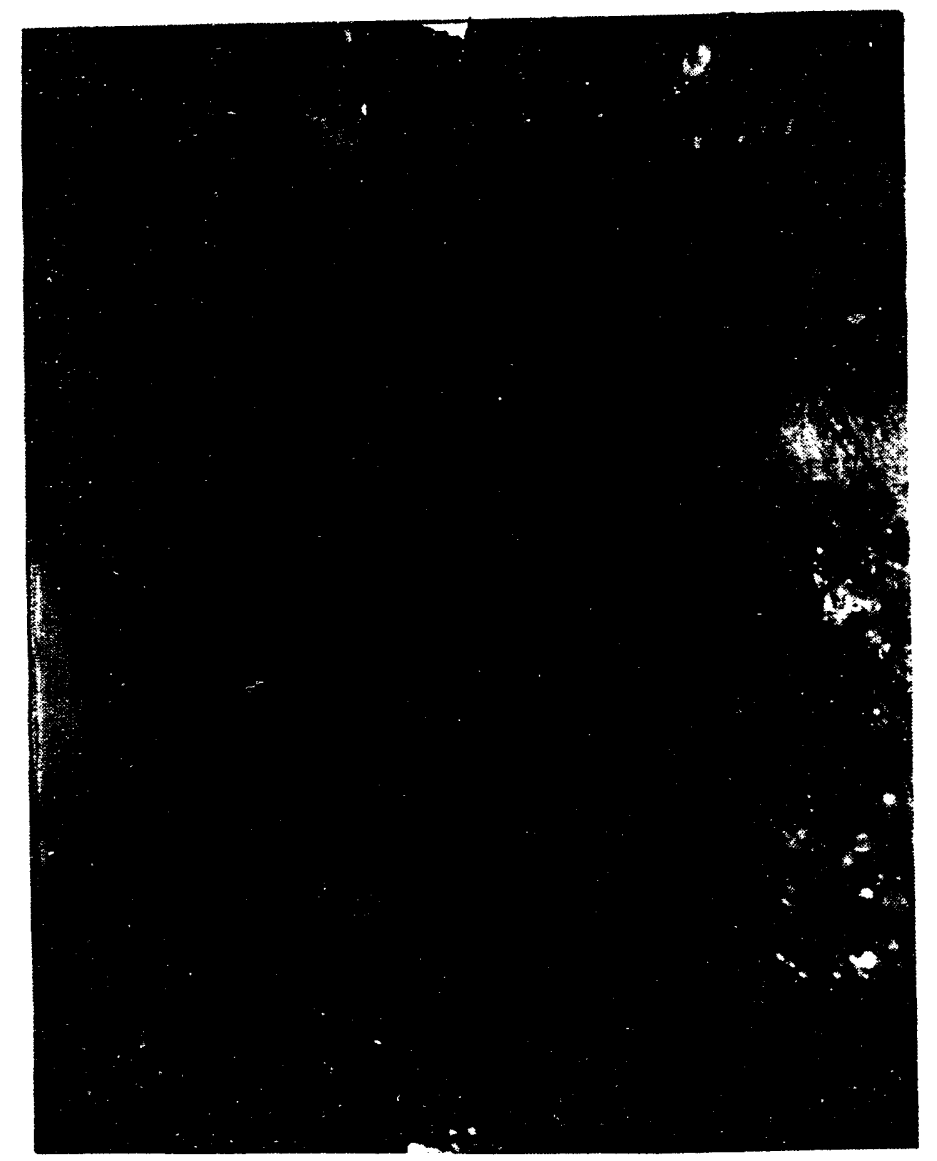

Figure B-32. Closeup perspective of the K-11 nozzle at a 0-degree reference.

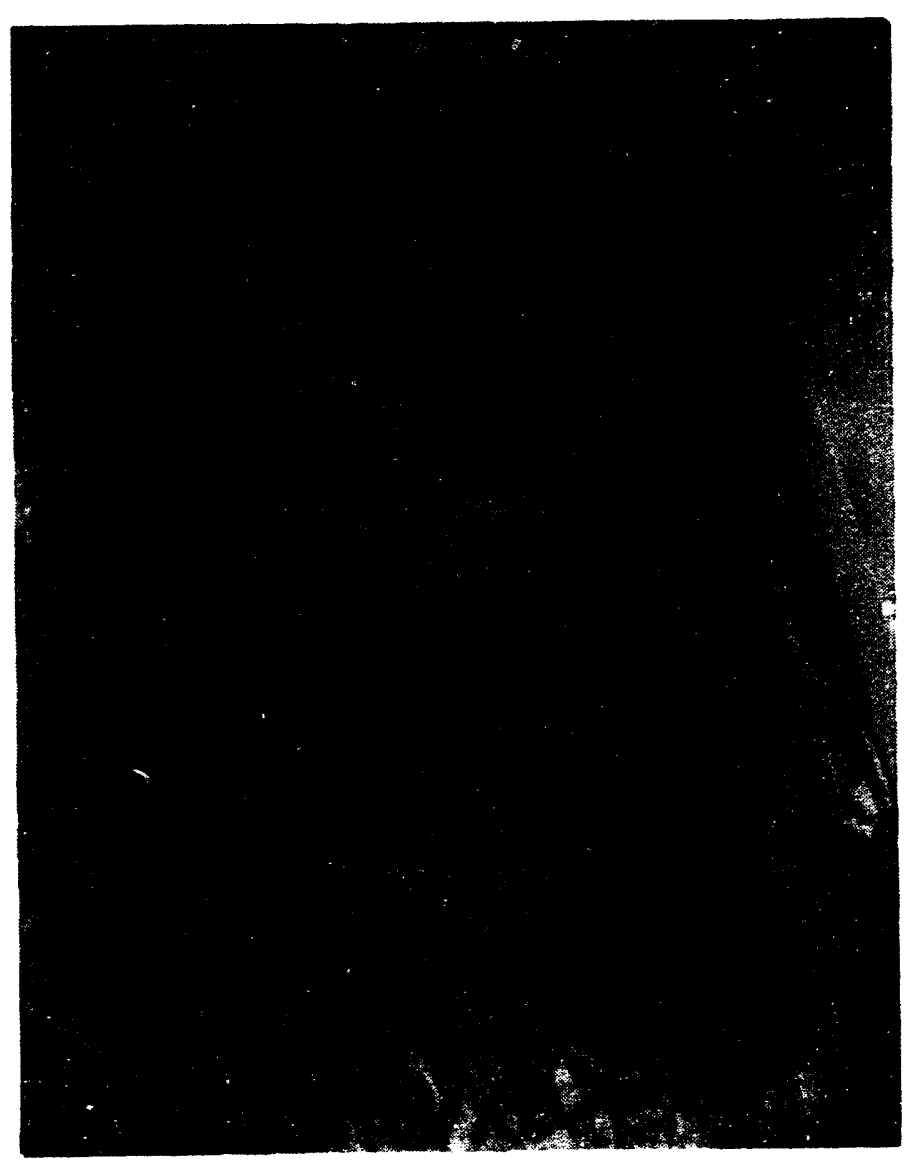

Figure B-33. Magnified view of the K-11 nozzle at a 180-degree reference. 


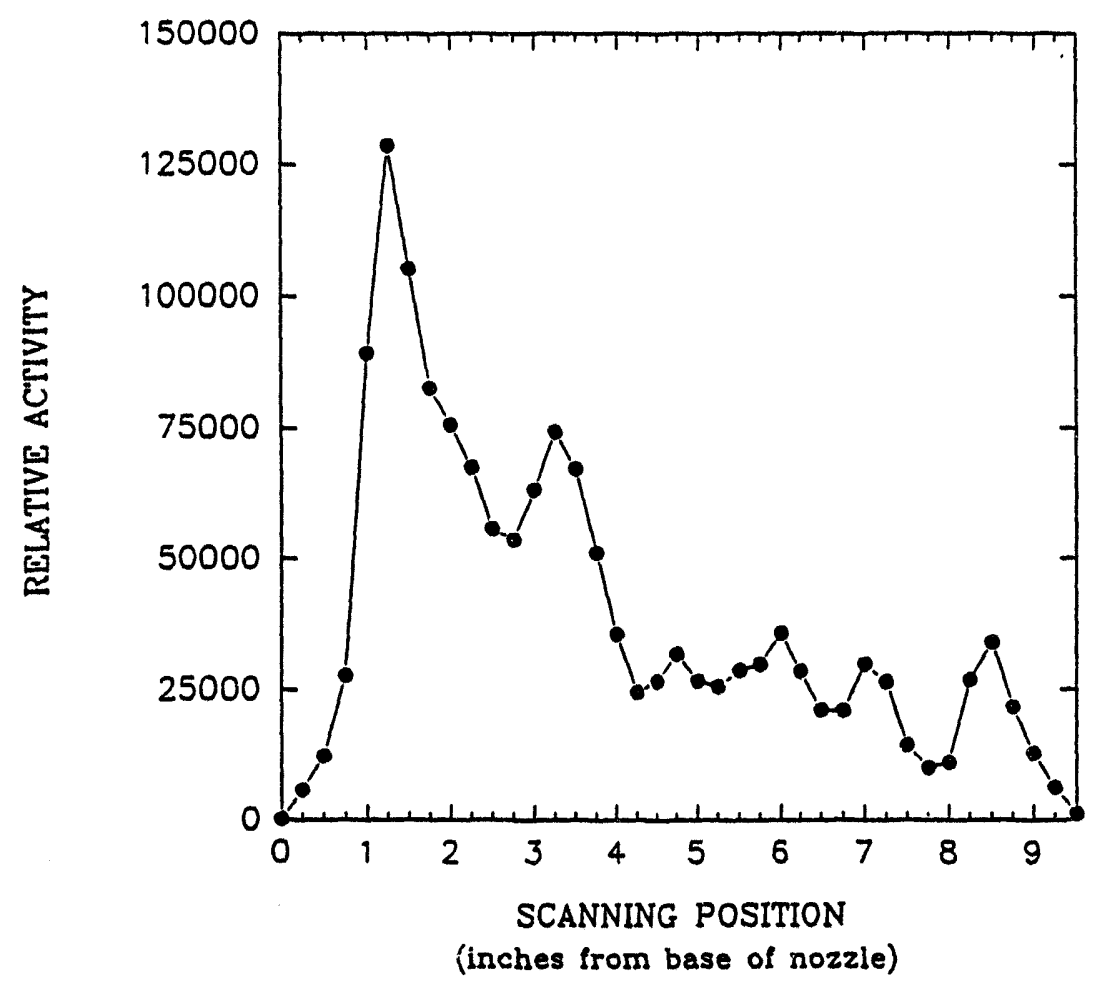

Figure B-34. The Cs-137 activity profile of nozzle K-11.

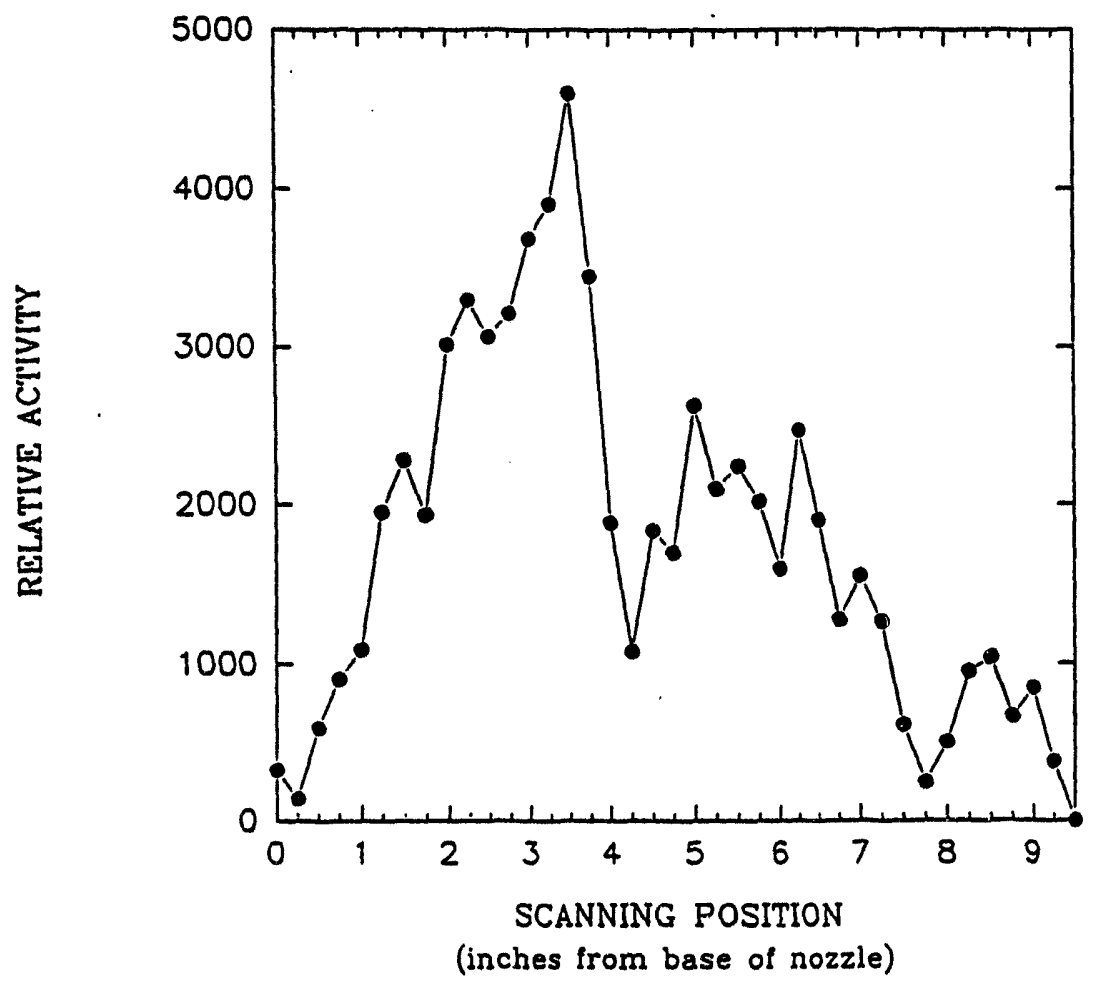

Figure B-35. The Co-60 activity profile of nozzle K-11. 


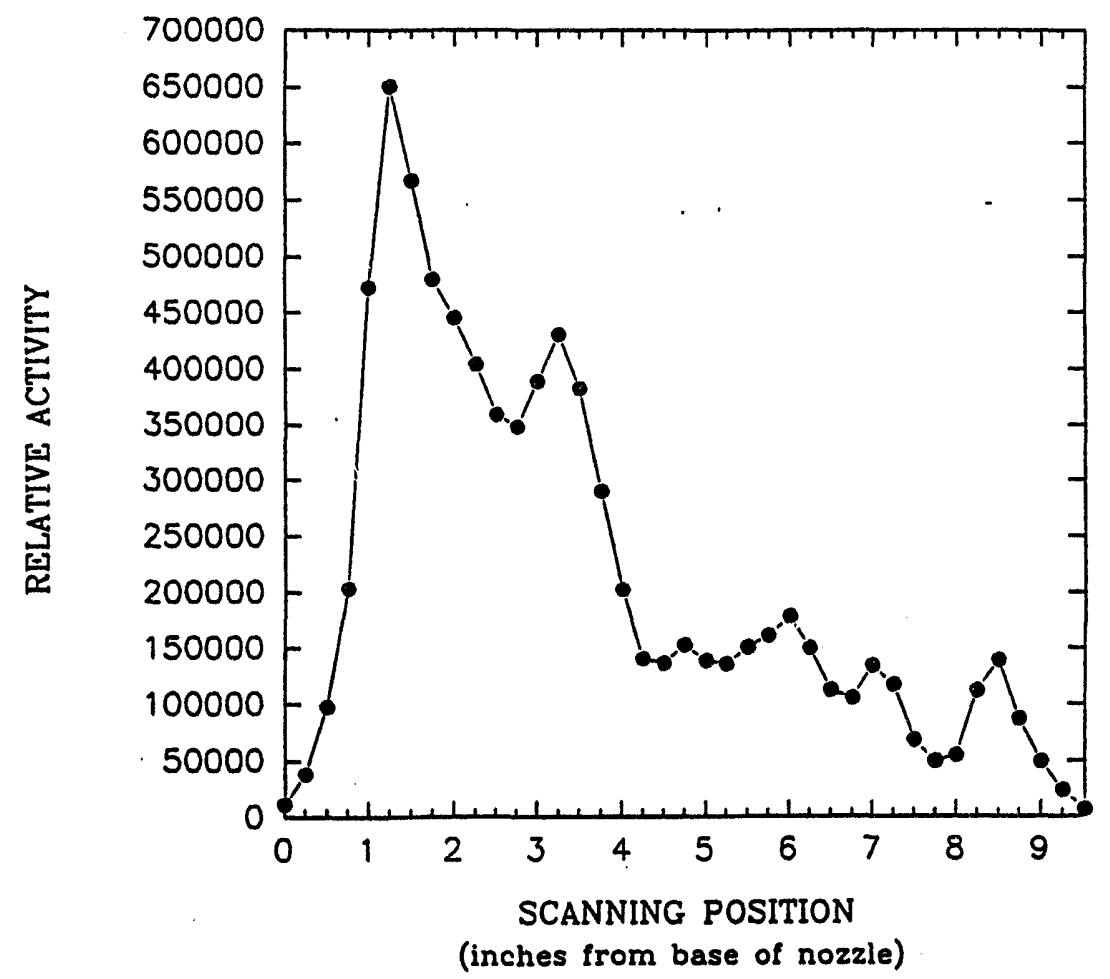

Figure B-36. The full-spectrum activity profile of nozzle K-11.

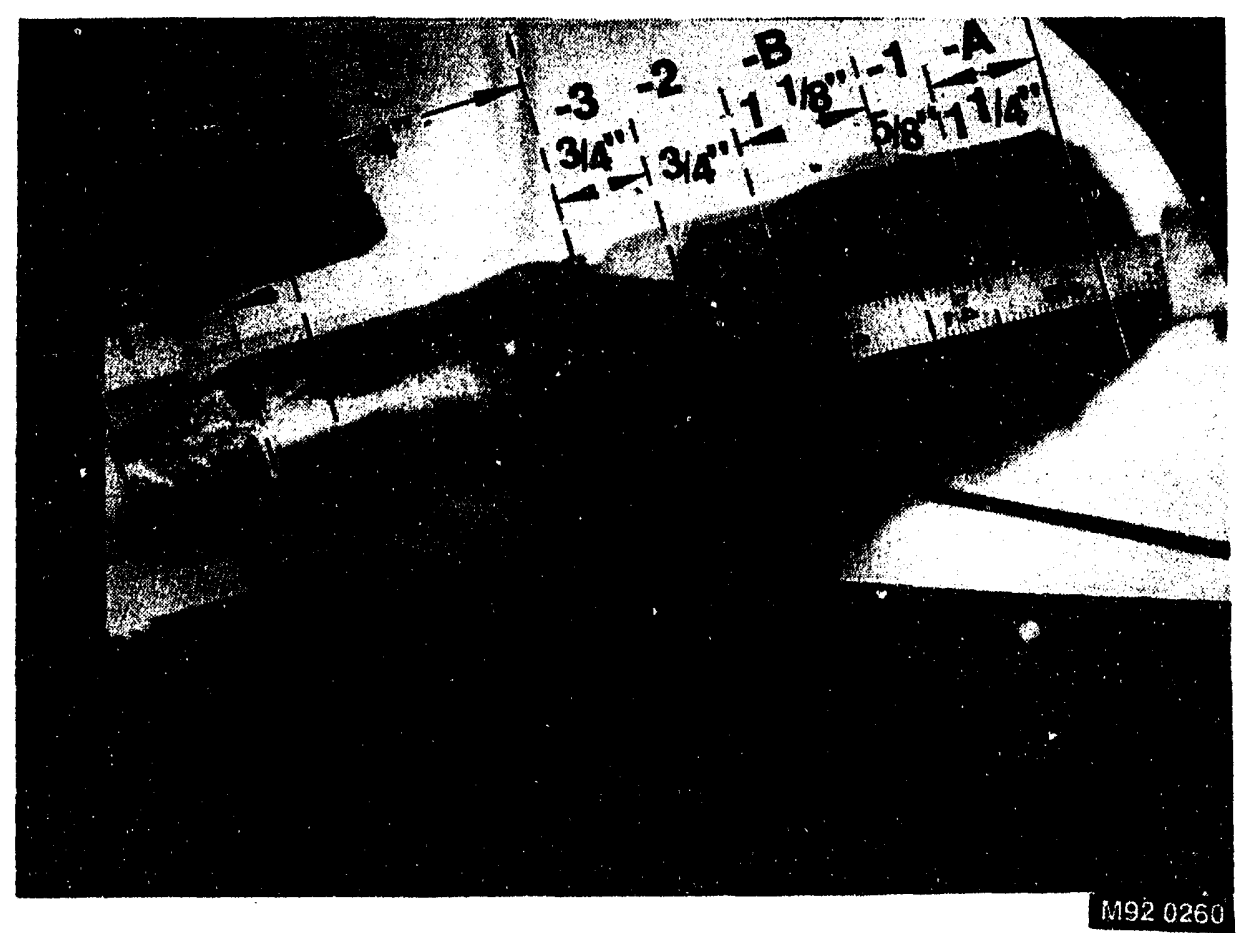

Figure B-37. Sectioning diagram of the K-11 nozzle. 


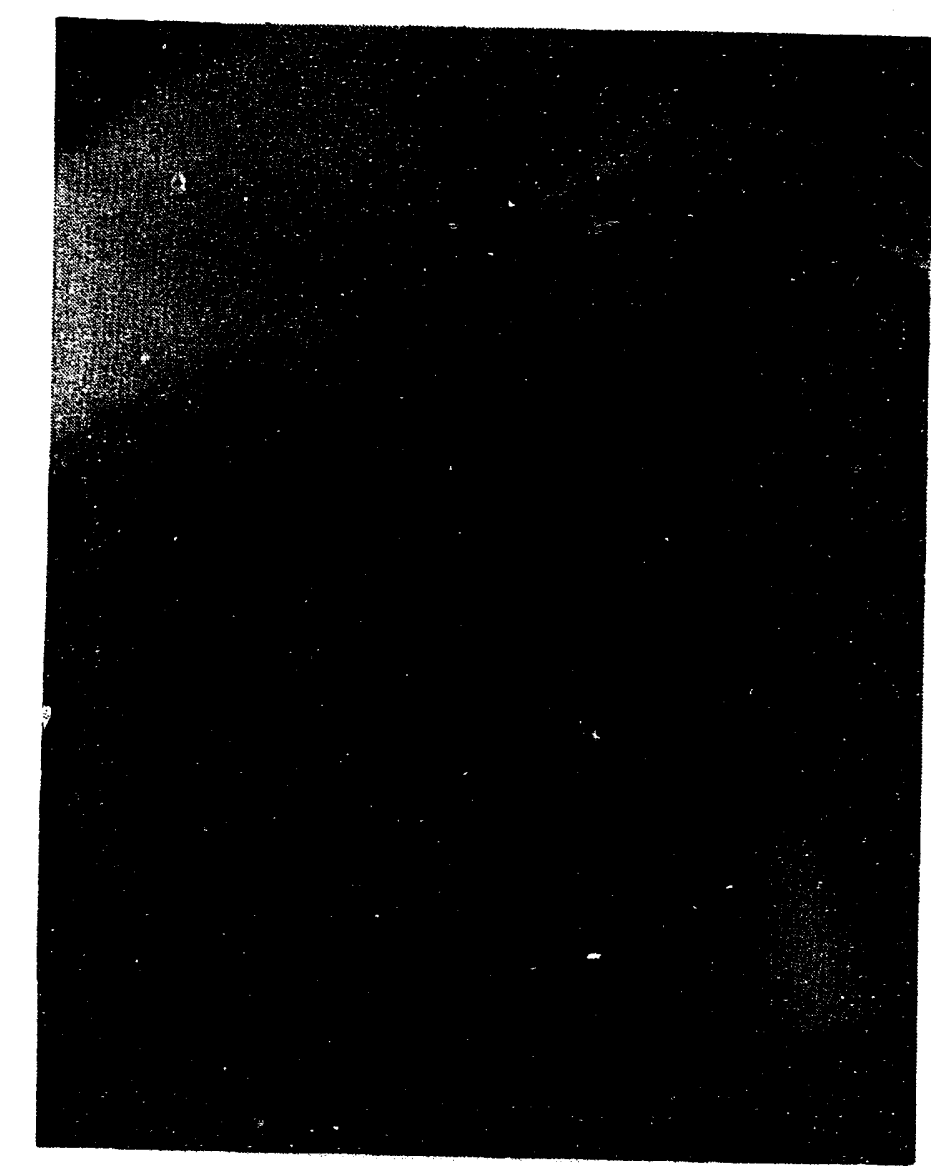

Figure B-38. Side view of sample K-11-2A.

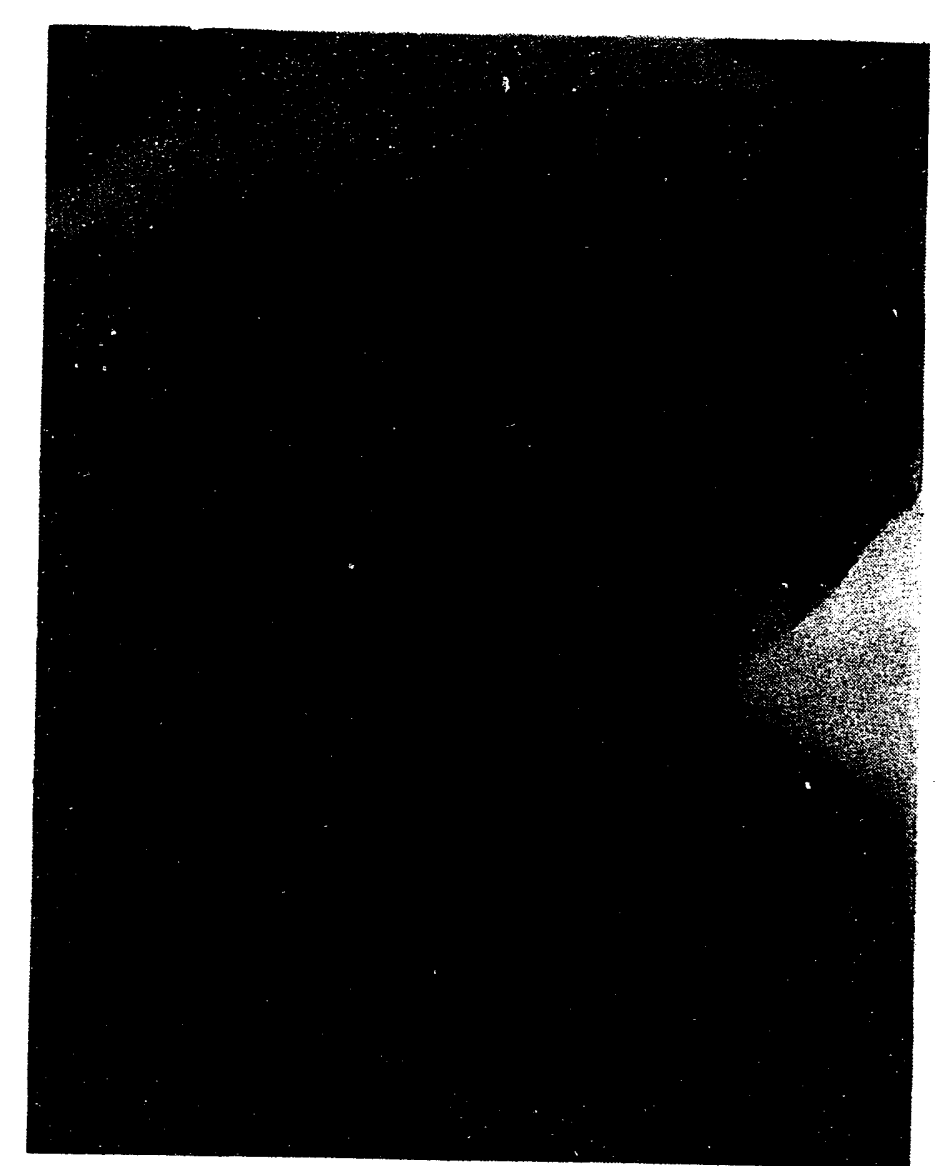

Figure B-39. Side view of sample K-11-2B. 


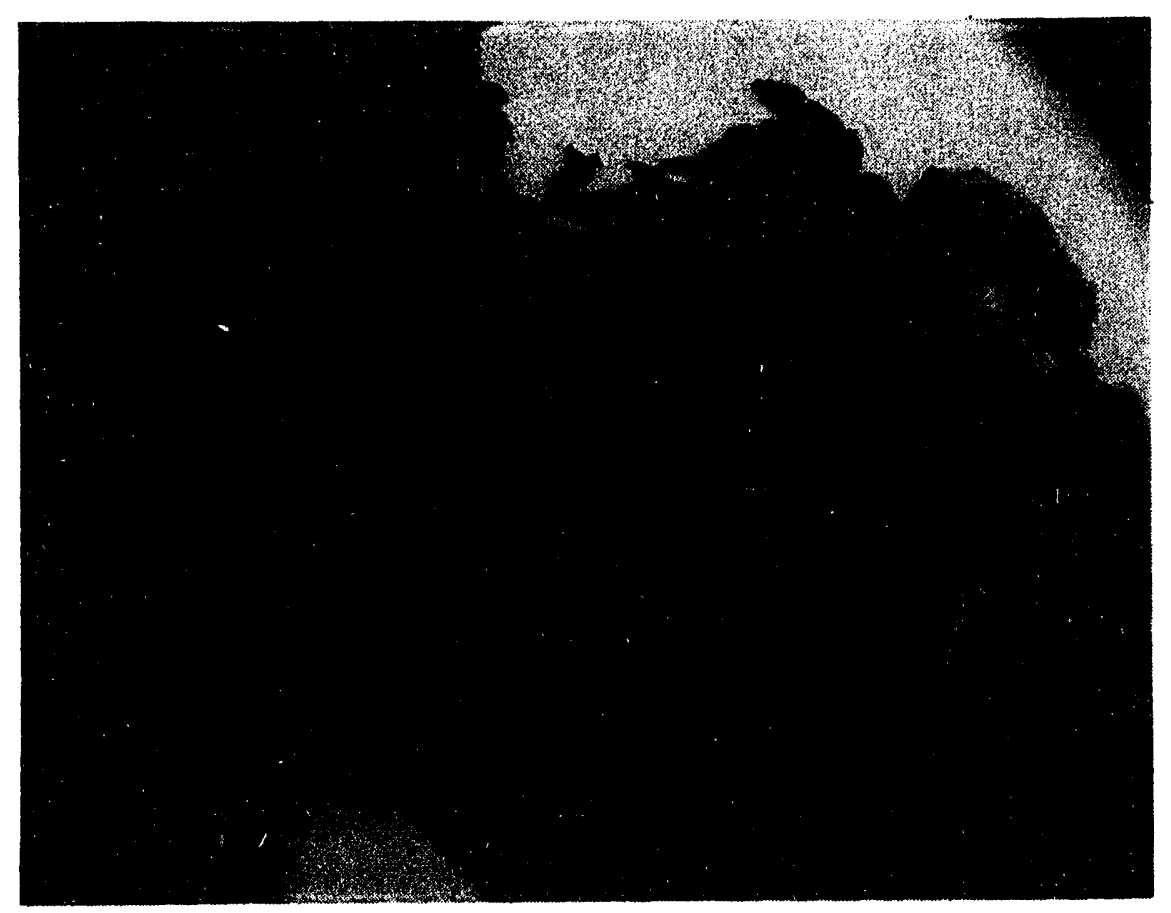

Figure B-40. Post-cutting side view of $\mathrm{K}-11-3 \mathrm{~A}$.

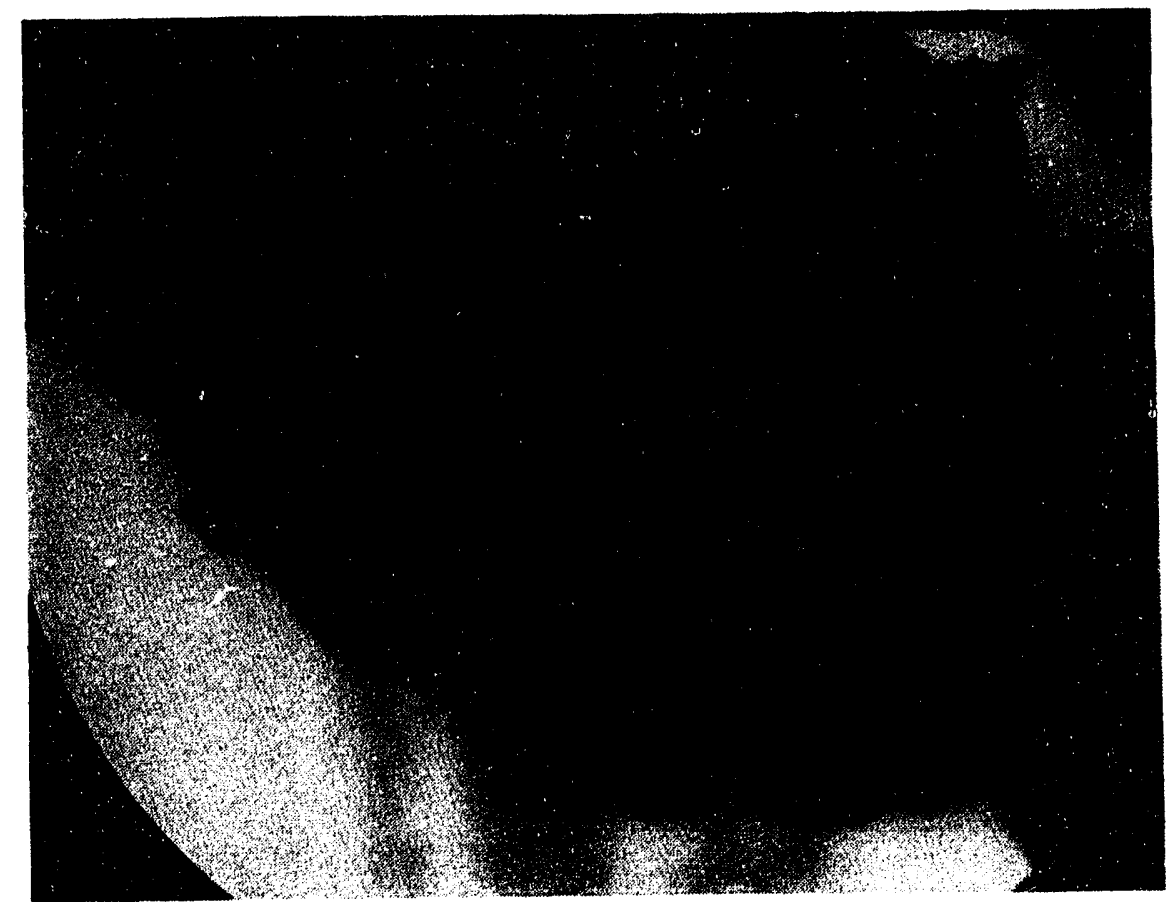

Figure B-41. Post-cutting side view of $\mathrm{K}-11-3 \mathrm{~B}$. 


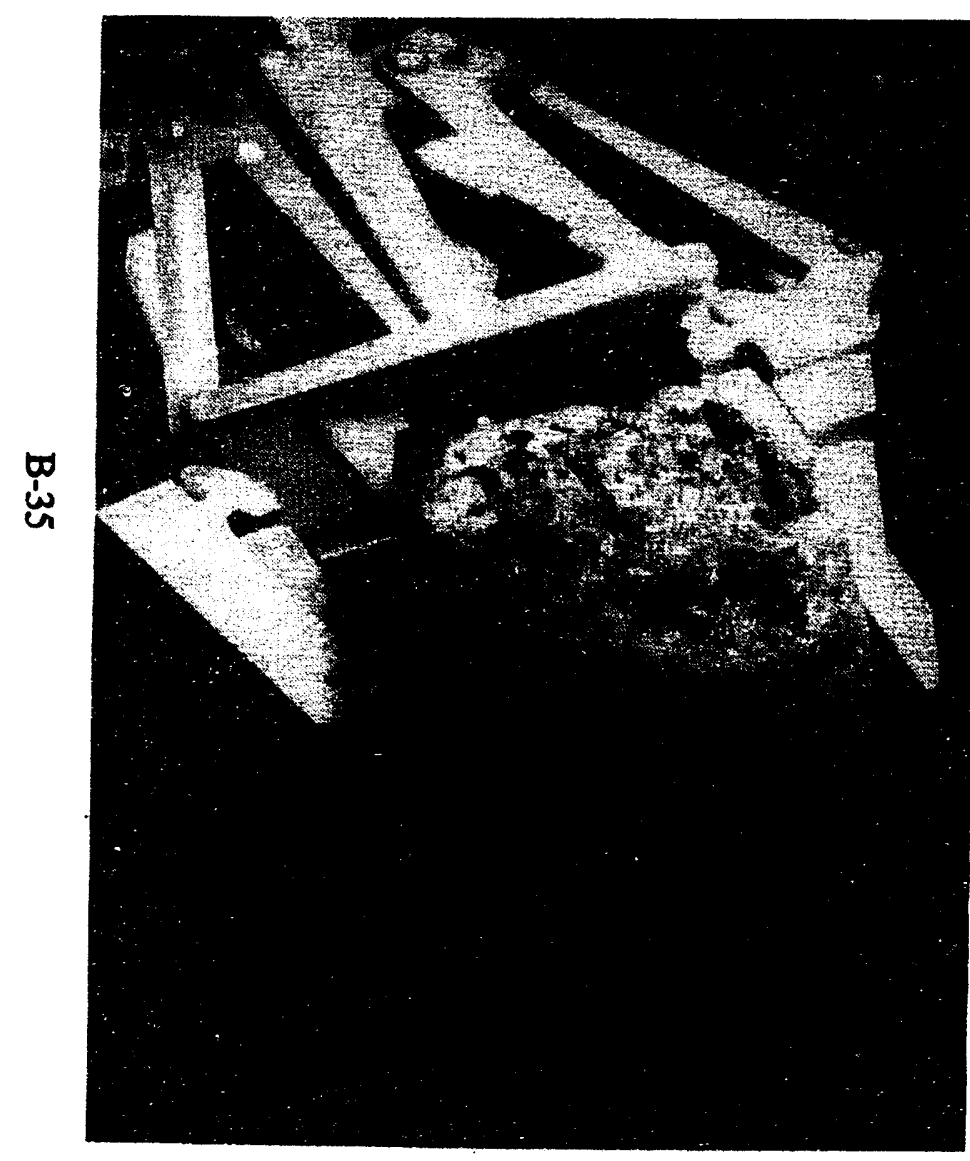

Figure B-42. Side view of the G-5 nozzle.

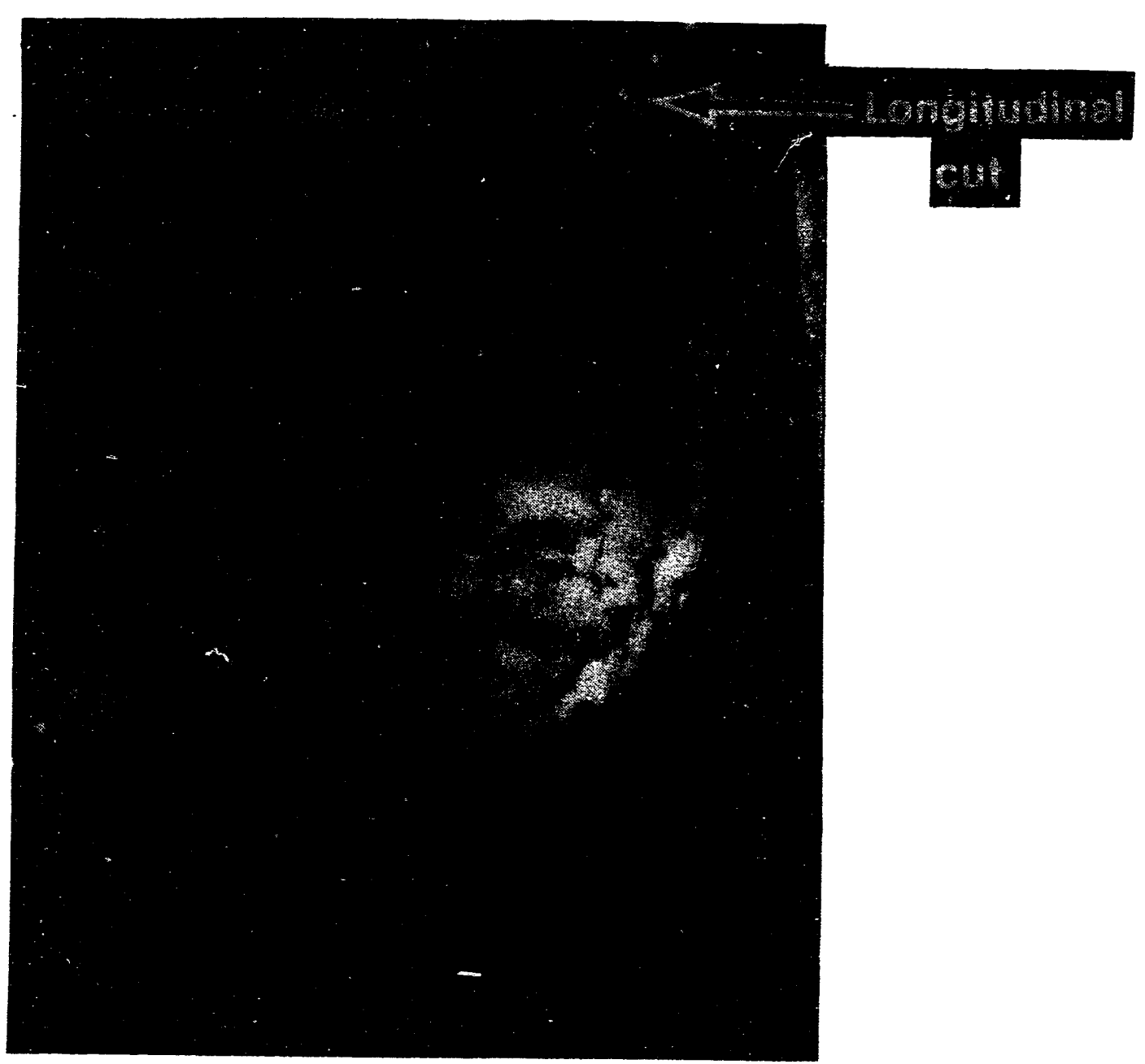

Figure B-43. Magnified view of the top of nozzle G-5 and the proposed sectioning line. 

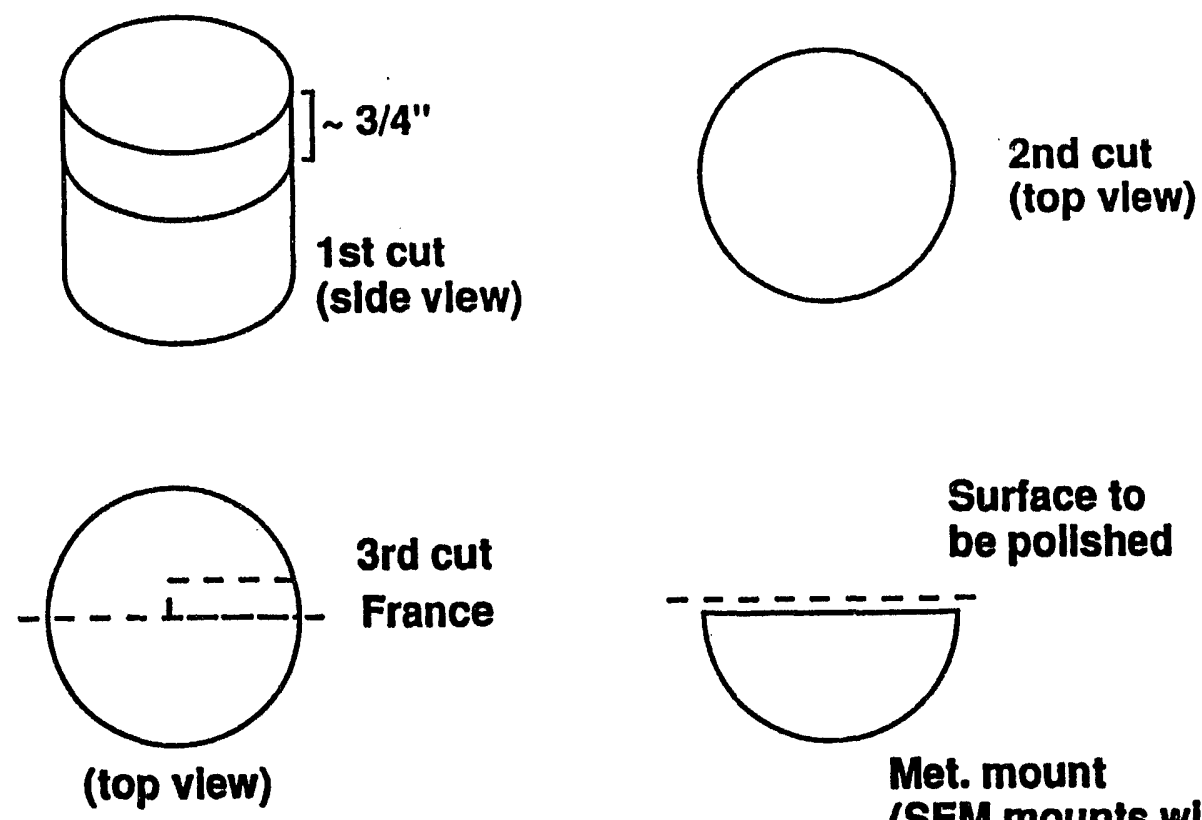

Surface to be polished

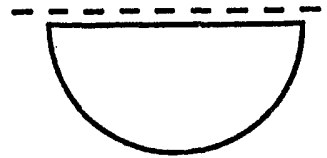

Met. mount

(SEM mounts will be cut from thls at a later date)

Figure B-44. Sectioning diagram of the G-5 nozzle.

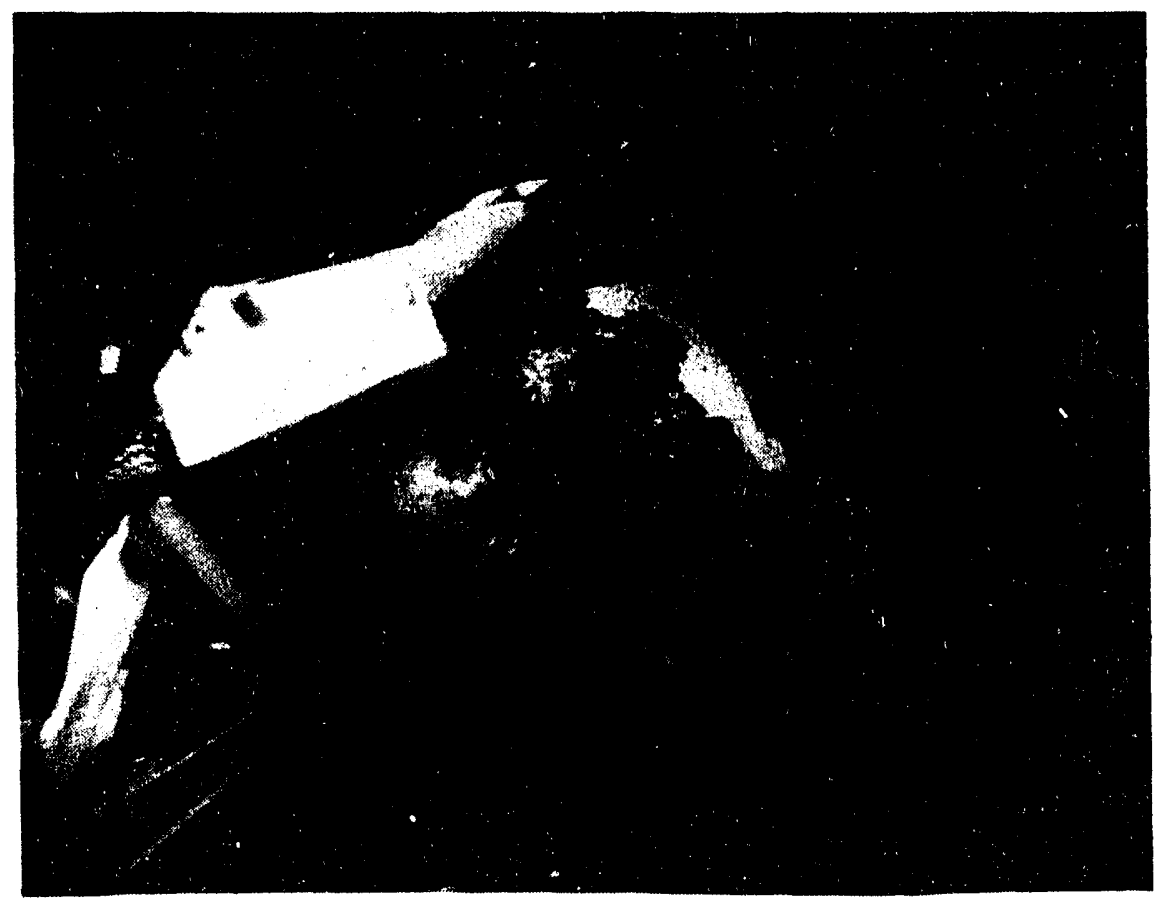

Figure B-45. Top view of nozzle E-7. 


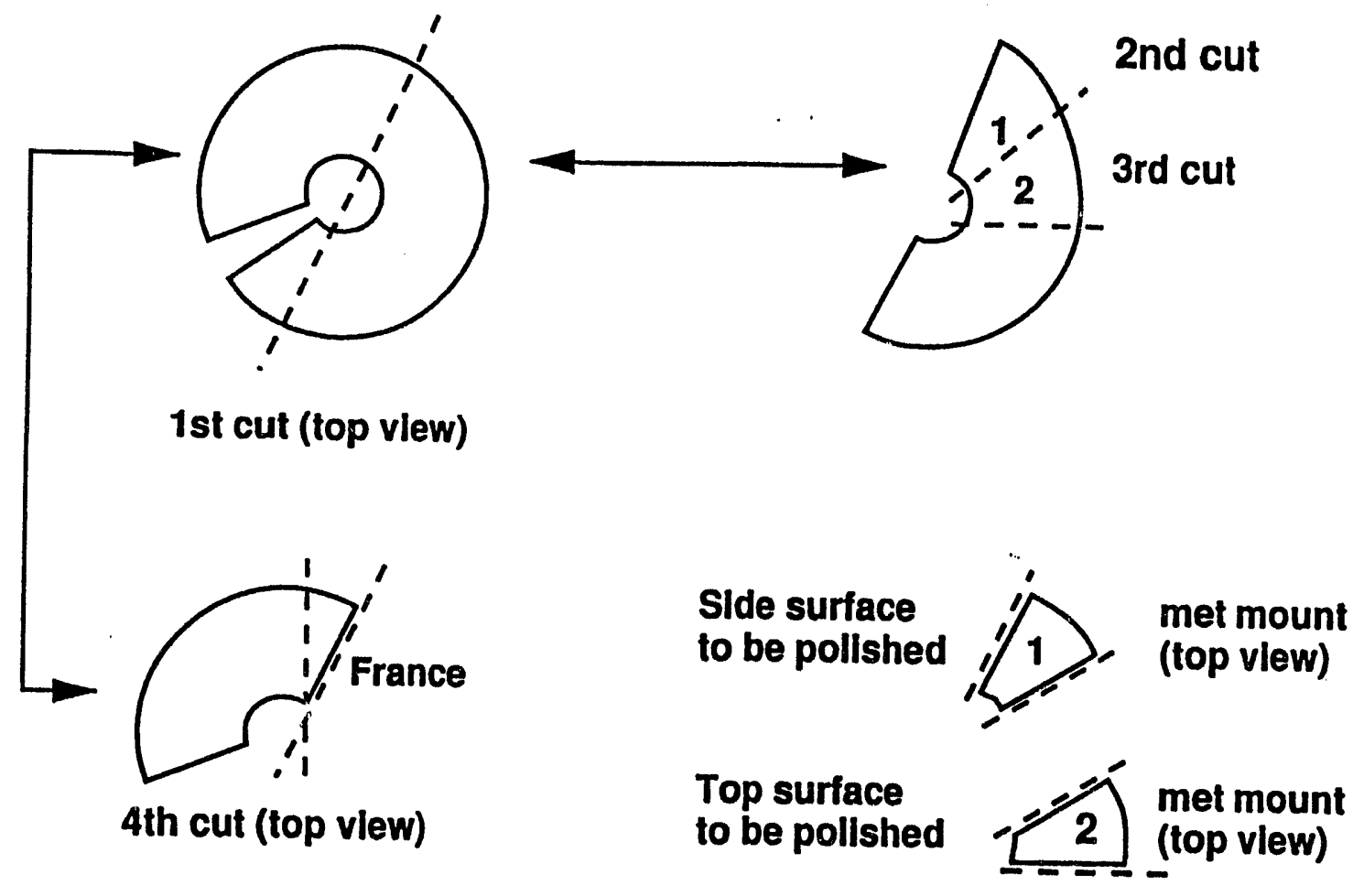

Figure B-46. Cutting diagram of the E-7 nozzle.

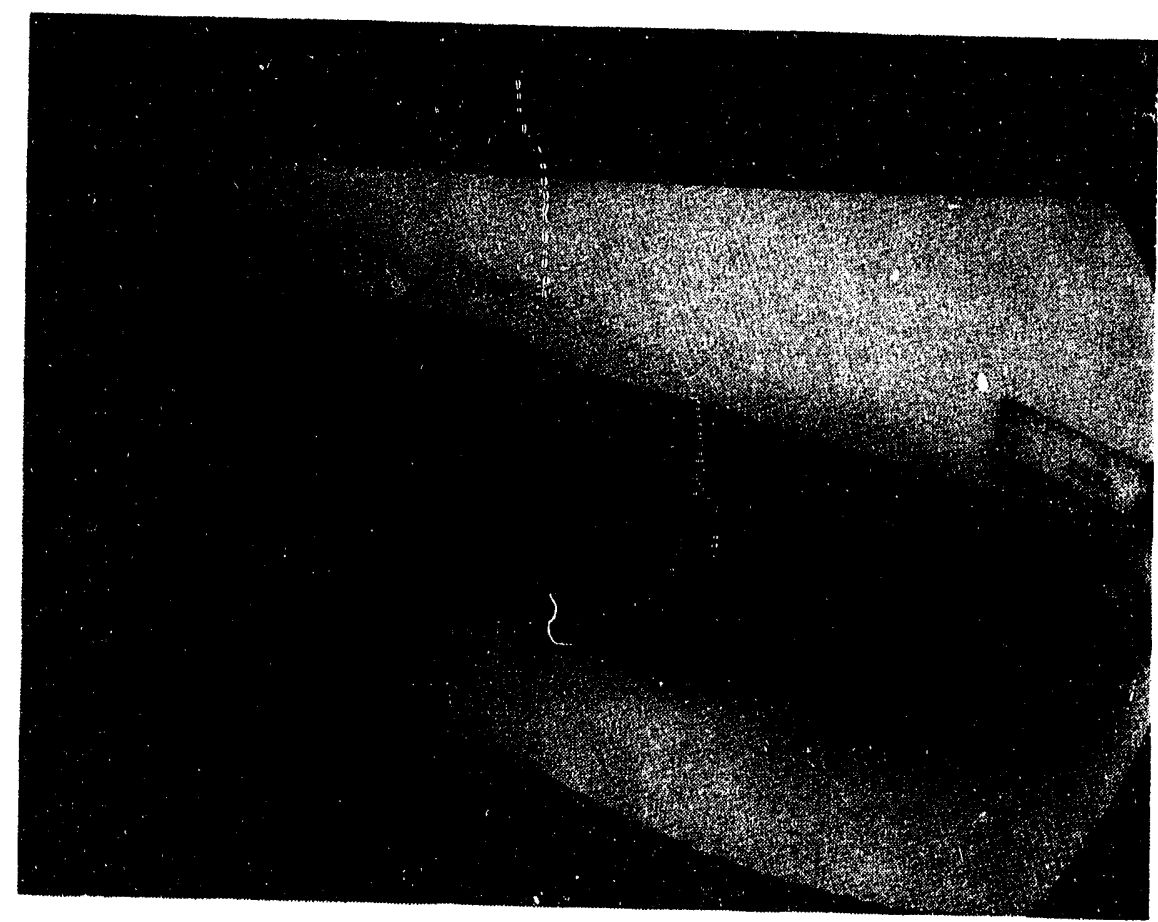

Figure B-47. Full-length view (including instrument string, 10-1/8 in.) of nozzle K-12. 


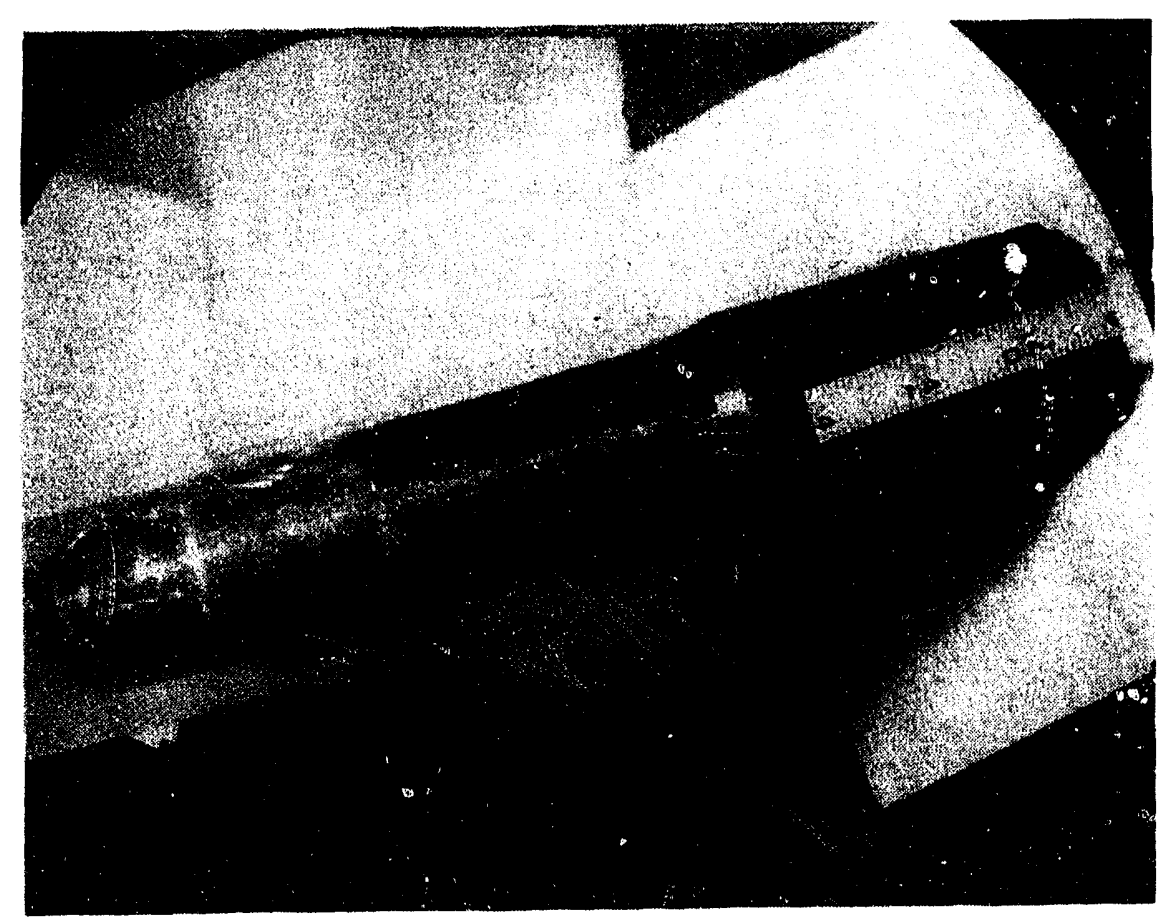

Figure B-48. Full-length view (excluding instrument string, 9-5/8 in.) of nozzle K-12.

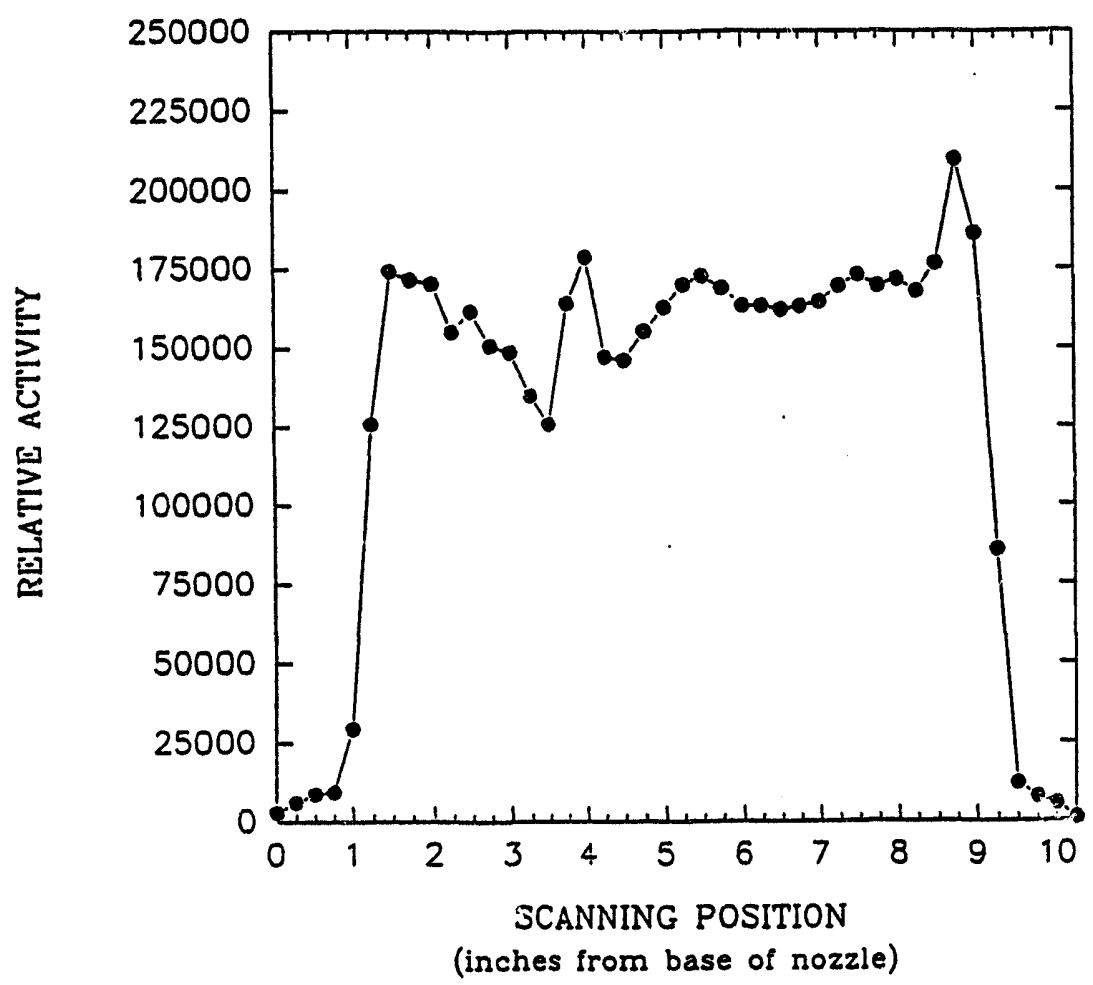

Figure B-49. The Cs-137 activity profile of nozzle $\mathrm{K}-12$. 


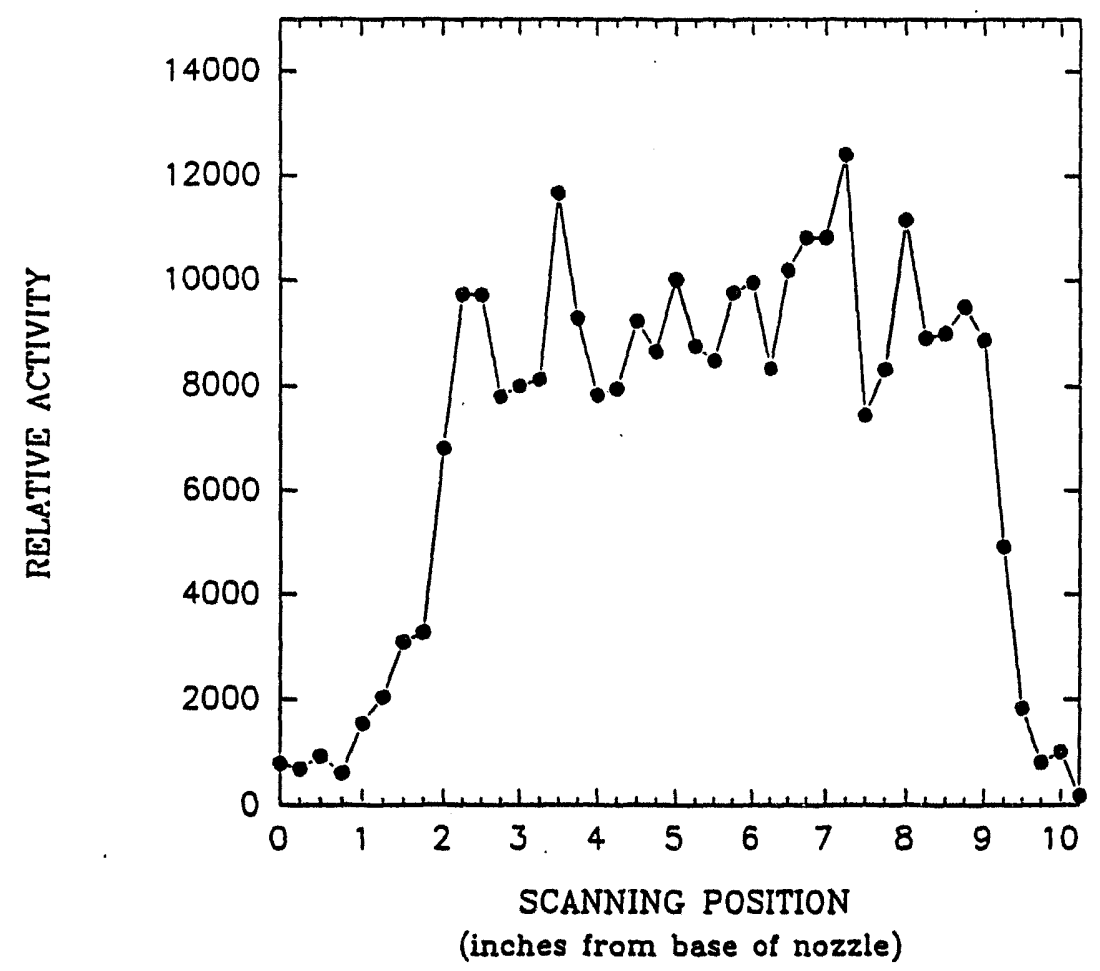

Figure B-50. The Co-60 activity profile of nozzle K-12.

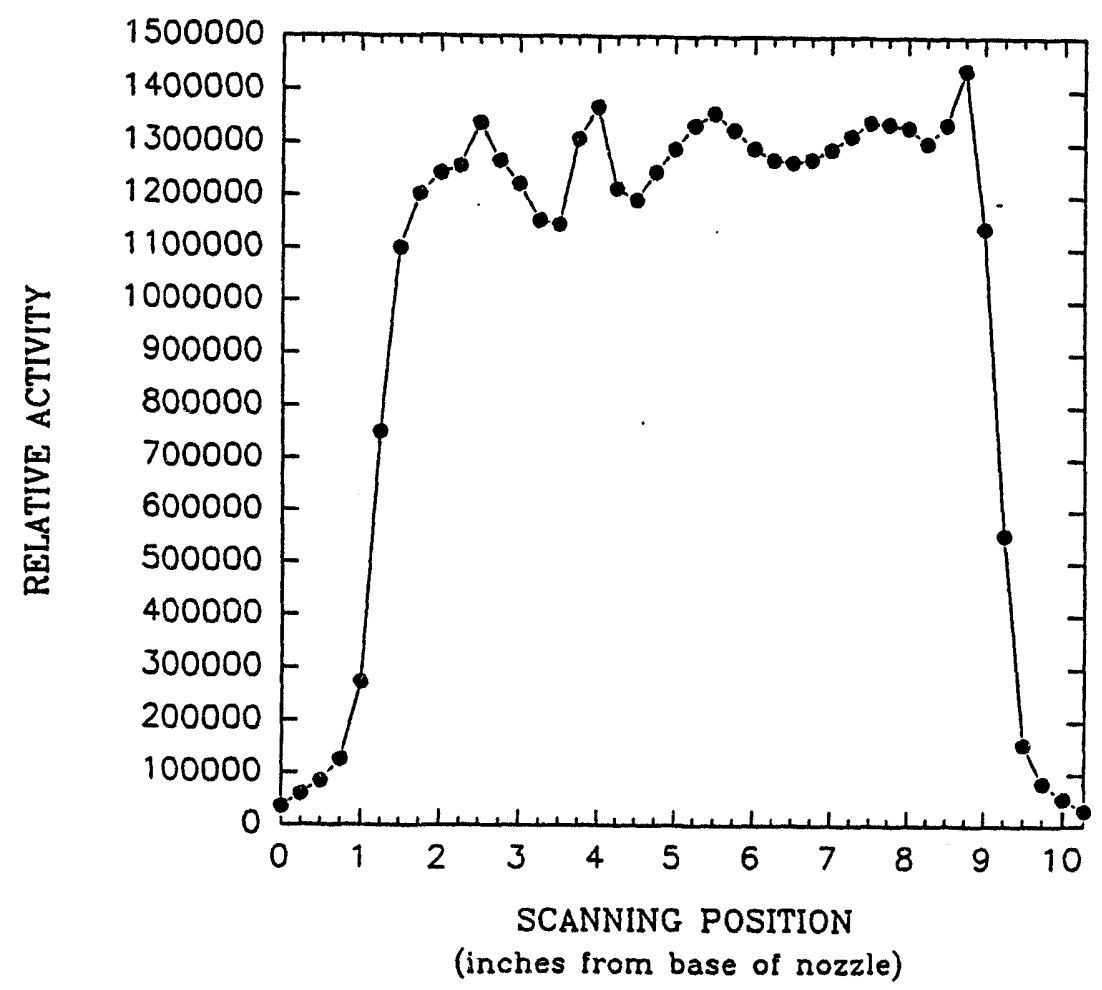

Figure B-51. A full-spectrum activity profile of nozzle K-12. 


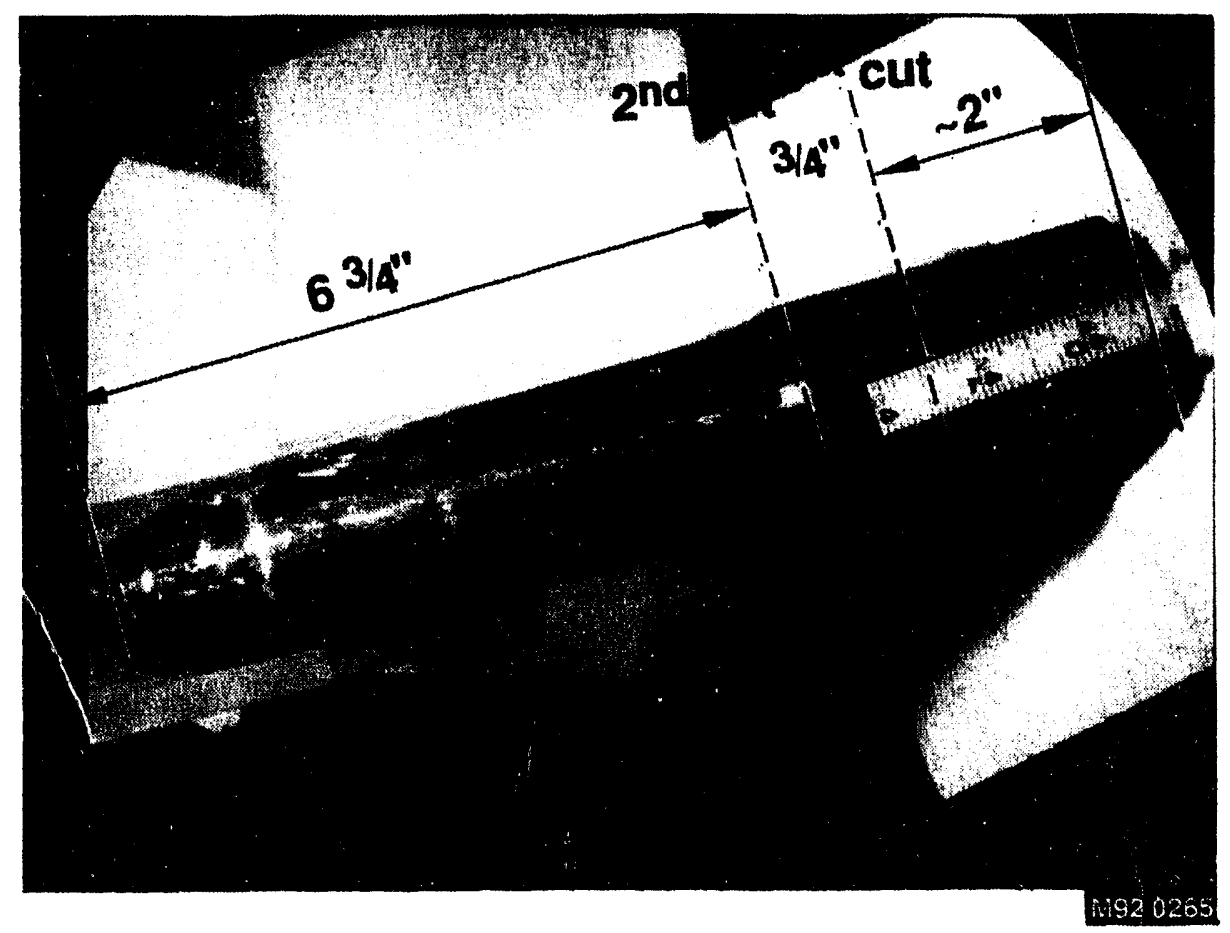

Figure B-52. Sectioning diagram of nozzle K-12.

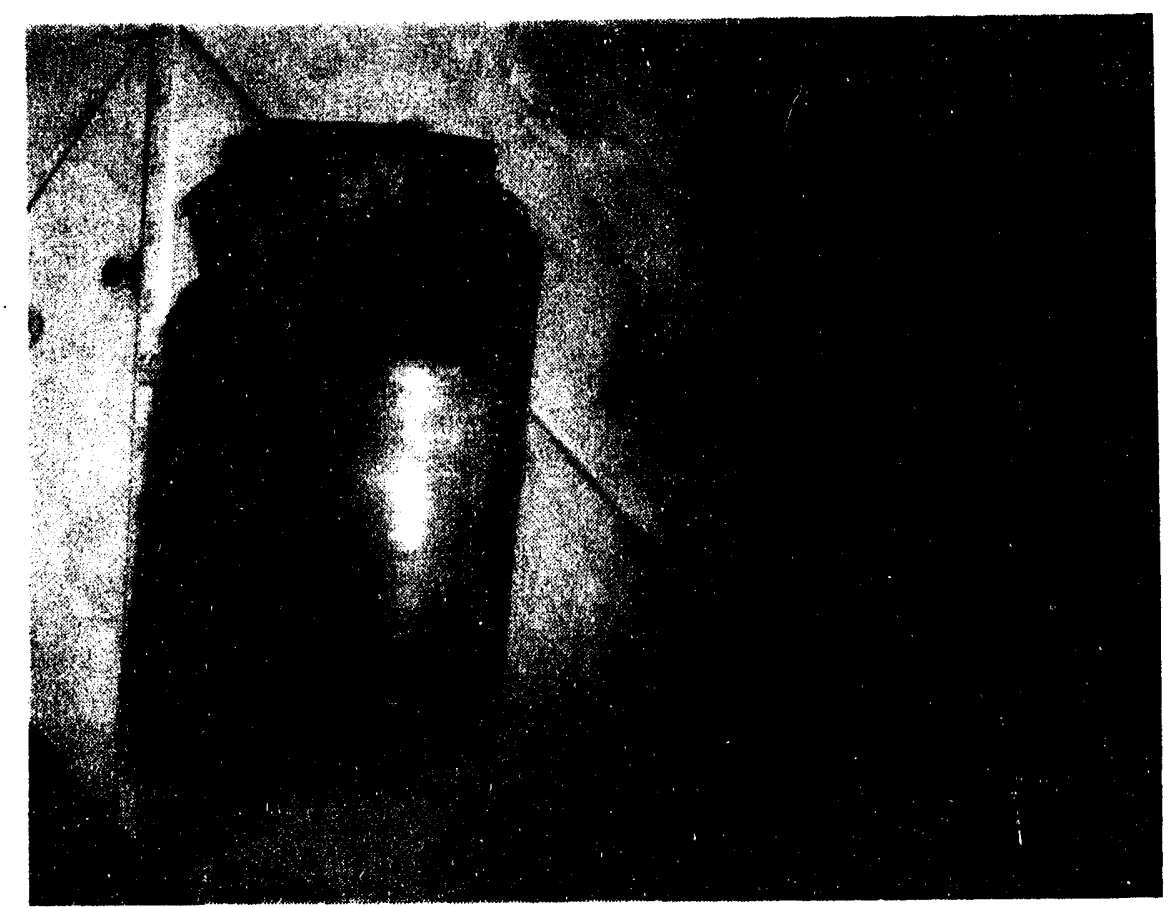

Figure B-53. Full-length side view (-9-3/8 in.) of the K-5 guide tube. 

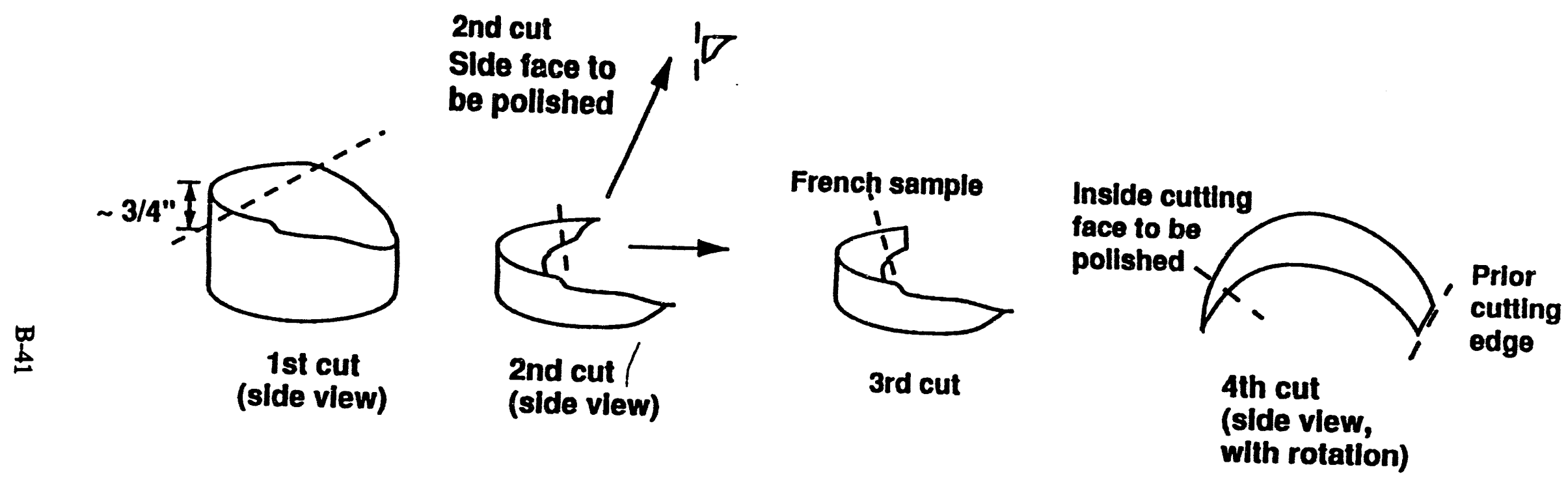

Cutting diagrams determined during meeting with:

D. Akers D. Sparks B. Schuetz

Figure B-54. Sectioning diagram of the K-5 guide tube. 


\section{Appendix C}

\section{Microstructural Examination Results}




\section{Appendix C}

\section{Microstructural Examination Results}

Microstructure samples were obtained from each of the eight nozzles (E-7, G-5, H-9, K-11, $\mathrm{K}-12, \mathrm{~L}-11, \mathrm{M}-10$, and $\mathrm{R}-7$ ) and from one guide tube (K-5). In addition, an initial examination was performed on a sample taken from the melt bulb that was attached to the instrument core string on the R-7 nozzle. Results of the microstructural examinations are described below.

The microstructural sample from the K-5 guide tube was obtained by the cutting sequence shown in Figure C-1. A second cut produced sample K-5-1, which was mounted and polished on the face exposed by the sectioning procedure (see Figure C-2). Sample K-5-1 was divided up into examination locations as shown in Figure C-3. Microstructural examinations were conducted at each of these locations or regions of interest (ROI) (91M209 through 91M214), as shown in Figures C-4 through C-9. These photomicrographs indicate that apparent molten fuel material interacted with the stainless steel of the guide tube and melted into its surface. In most cases, the clear separation between the stainless steel and the fuel material phases suggest that the mechanism for this interaction appears to be melting of the stainless steel with no apparent chemical interaction. However, Figure $\mathrm{C}-8$ shows the presence of an apparent intermediate phase that may be the result of a dissolution of the stainless steel by the fuel debris. Further SEM/WDX analysis would be required to confirm the formation of this intermediate phase.

The R-7 nozzle was sectioned as shown in Figure C-10. Sample R-7-B, as shown in Figure C-11, was produced from cutting the R-7 nozzle. Figure C-12 shows the examination locations that were examined. The photomicrographs of the these ROIs (91M197 through 91M208) are shown in Figures C-13 through C-18. Examination of these photomicrographs indicates apparent interaction between the fuel debris and the instrument string material. Figure C-15 shows the interaction zone between the instrument string and the fuel material and suggests the formation of a number of intermediate phases composed of fuel material and constituents of the instrument string.

The G-5 cutting diagram, Figure C-19, shows how the G-5 nozzle was cut. As shown in Figure C-20, the cut surface was polished; ROIs were then selected, as shown in Figure C-21. Each of these ROIs (91M215 through 91M228) are shown in Figures C-22 through C-27. Evaluation of these photomicrographs indicates the presence of melt interspersed with metallic Inconel sections near the periphery of the nozzle. Further, the presence of what was determined to be silver is shown in Figure C-24. This figure suggests that silver was present on the lower head prior to the relocation of fuel debris to the lower head. Figure C-26 is a series of photographs that show the melt in the center of the nozzle from the top surface to the near the bottom of the melt region. These photomicrographs show a range of interactions from what appears to pure metallic material to a range of intermediate phases with molten material apparently interacting with the instrument string and the nozzle material.

The E-7 nozzle was sectioned as shown in Figure C-28. After samples E-7-1 (Figure C-29) and E-7-2 (Figure C-30) were mounted and polished, ROIs for sample E-7-1 were selected, as 
shown in Figure C-31. Figures C-32 through C-40 show the ROIs (91M175 through 91M188) for sample E-7-1. Figures C-34 and C-35 show melt interaction between the nozzle material and the apparent fuel material. Figure C-35 indicates the presence of an intermediate phase, which suggests that some molten interaction occurred.

The selected ROIs for sample E-7-2 are shown in Figure C-41, and each of these ROIs (91M189 through 91M193) are shown in Figures C-42 through C-46. Typically, the interactions shown here are similar to those shown for sample E-7-1. 


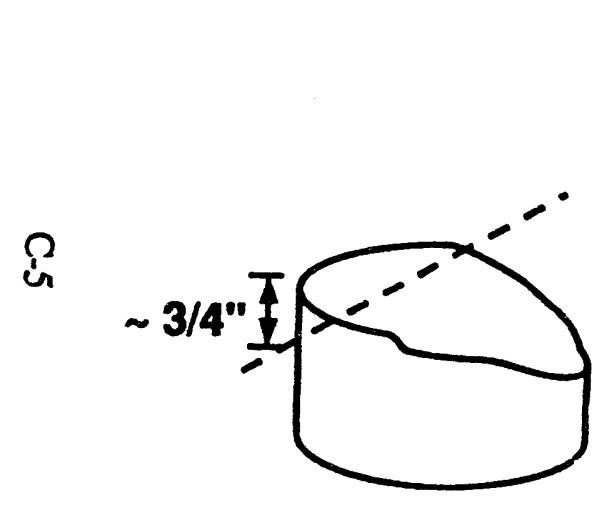

1st cut (side view)

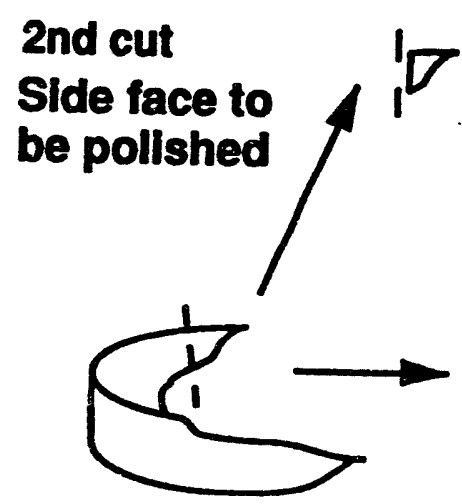

2nd cut (side view)

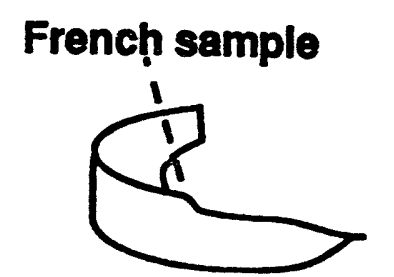

3rd cut

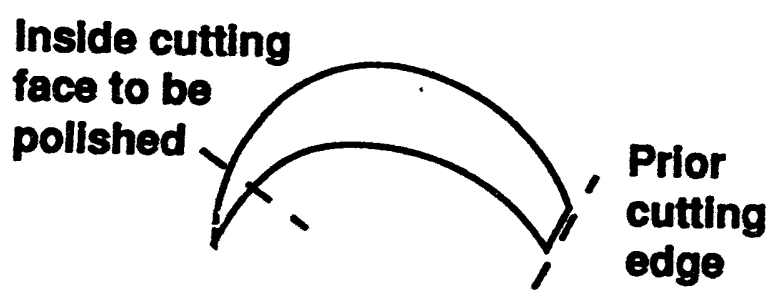

4th cut (side view, with rotation)

Figure C-1. Metallographic section of the K-5 guide tube. 


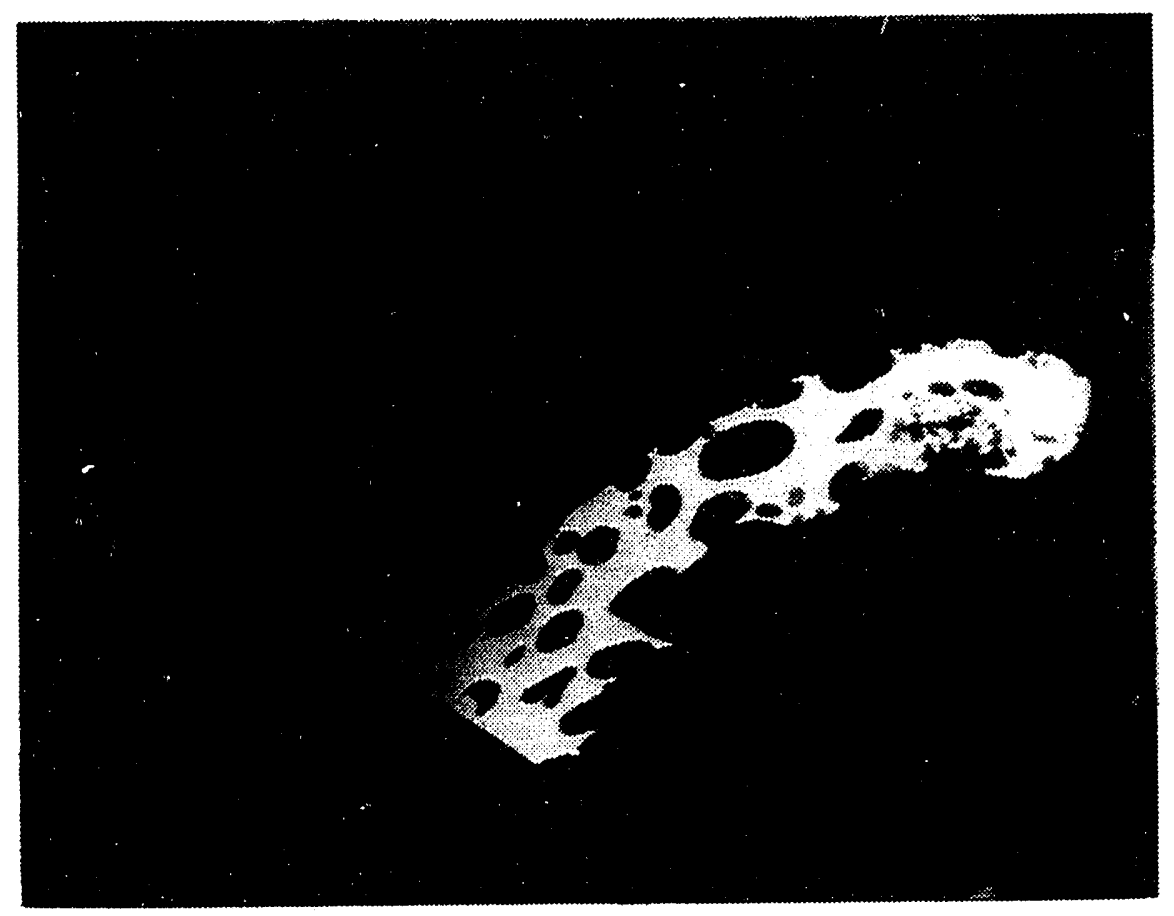

Figure C-2. Guide tube sample K-5-1 shown mounted and polished in the mount for metallography.

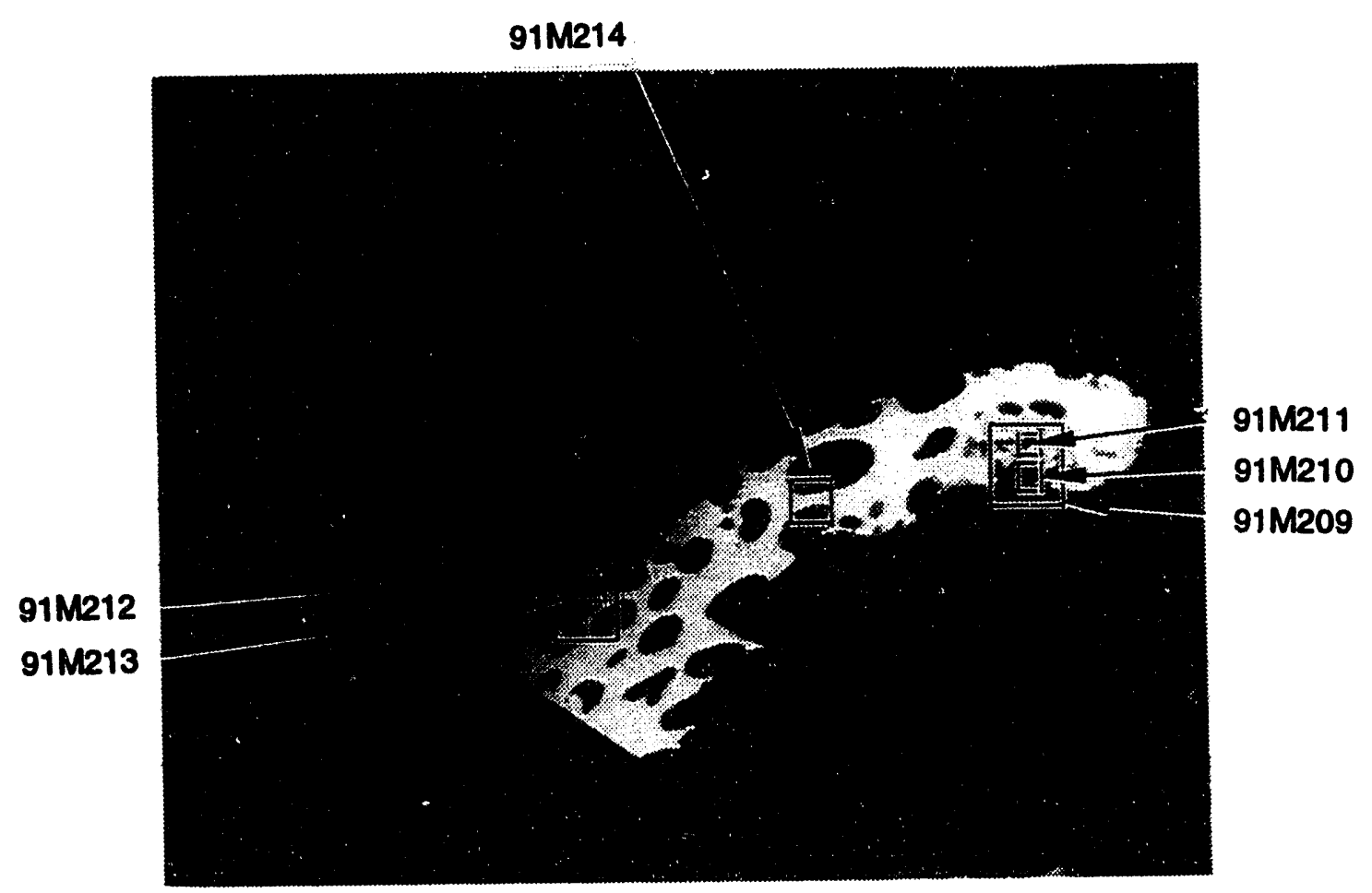

Figure C-3. Metallographic examination map showing ROIs of sample K-5-1 from the K-5 guide tube. 


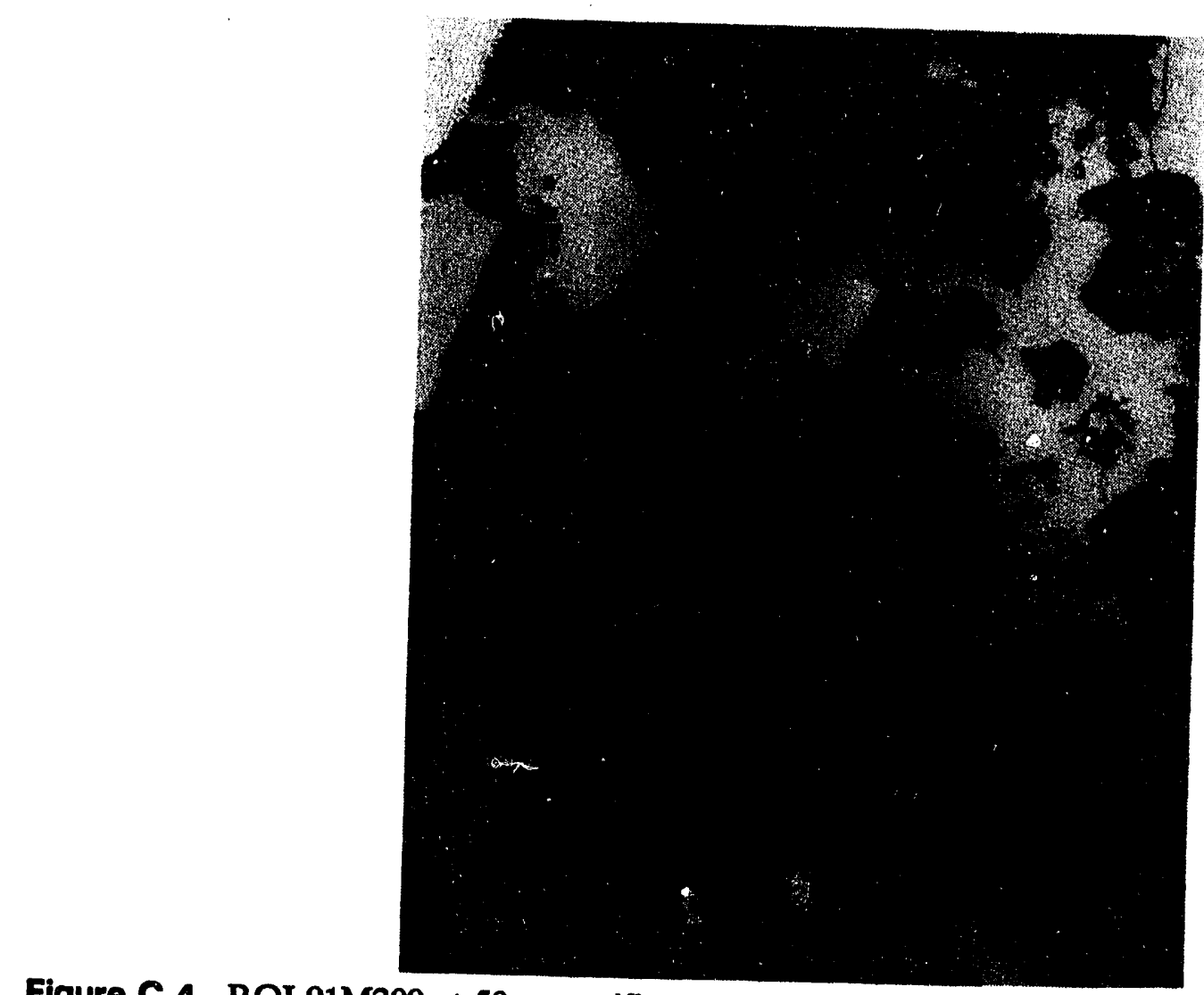

Figure C-4. ROI 91M209 at 50x magnification.

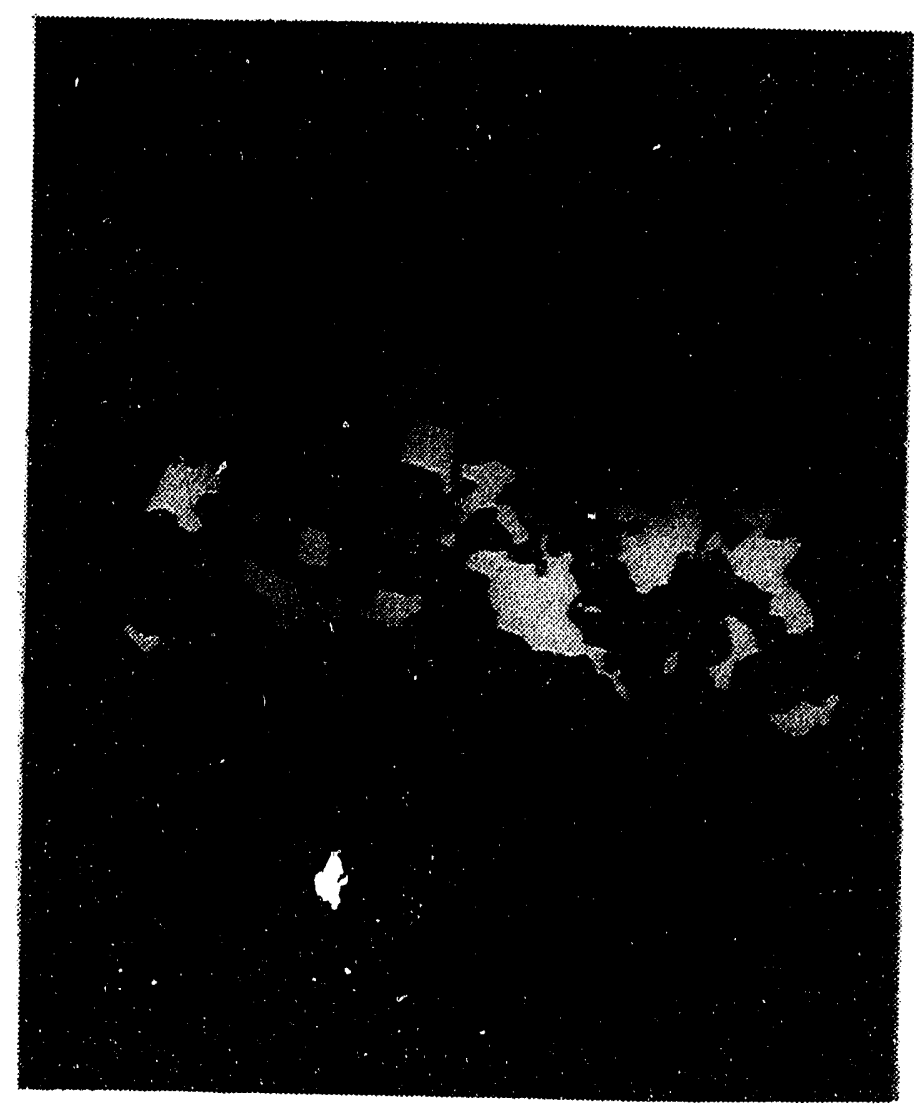

Figure C.5. ROI 91M210, showing 200x view of an isolated particle. 


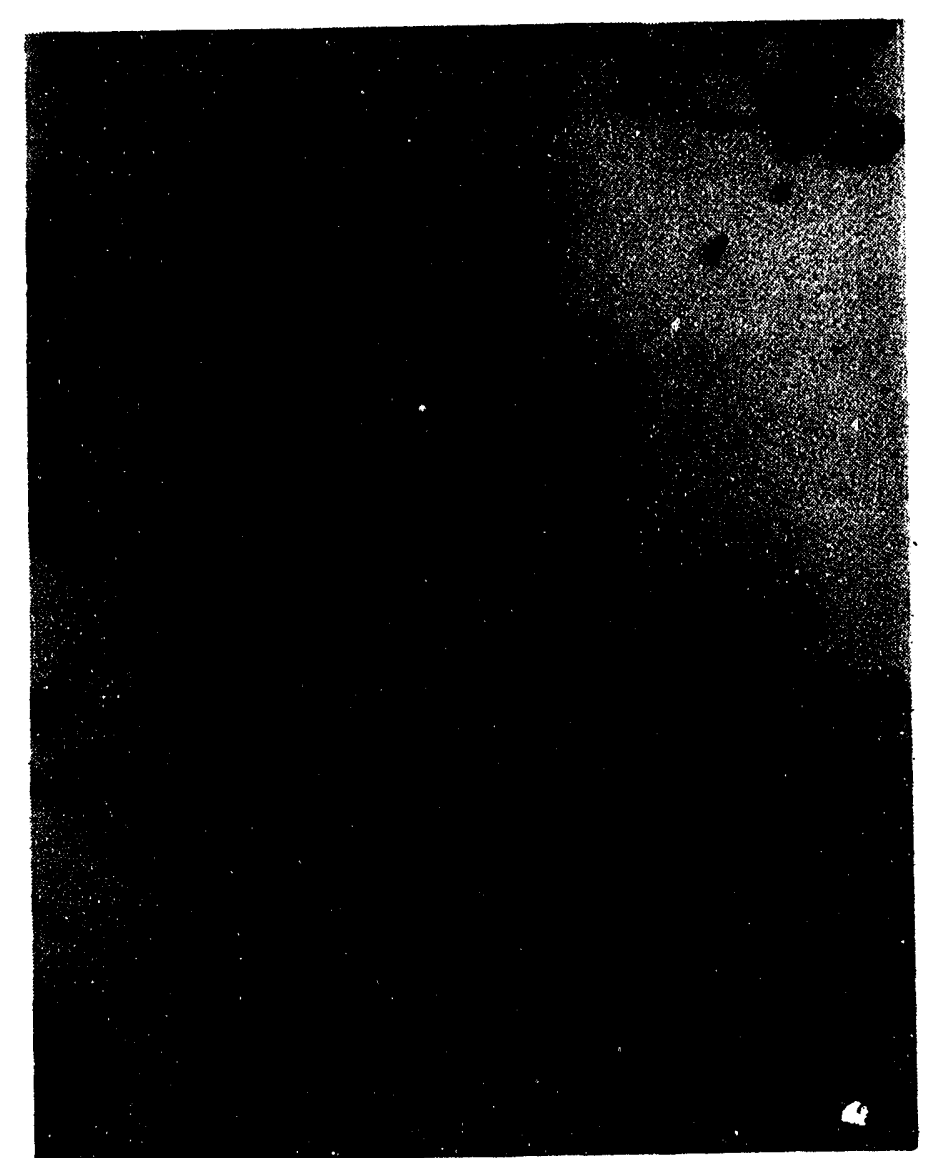

Figure C-6. ROI 91M211, showing a 200x view of a mottled structure.

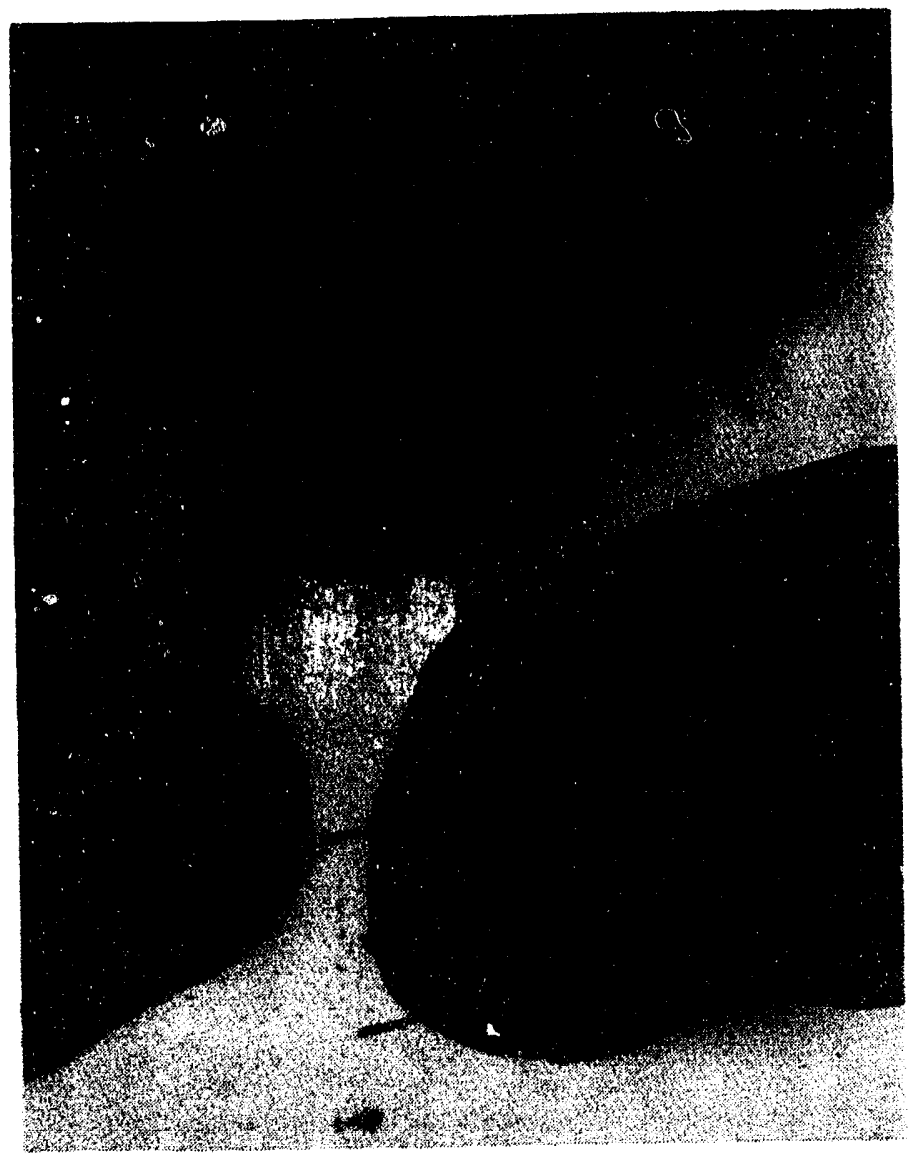

Figure C-7. ROI 91M212, showing porous K-5 material with attached melt. 


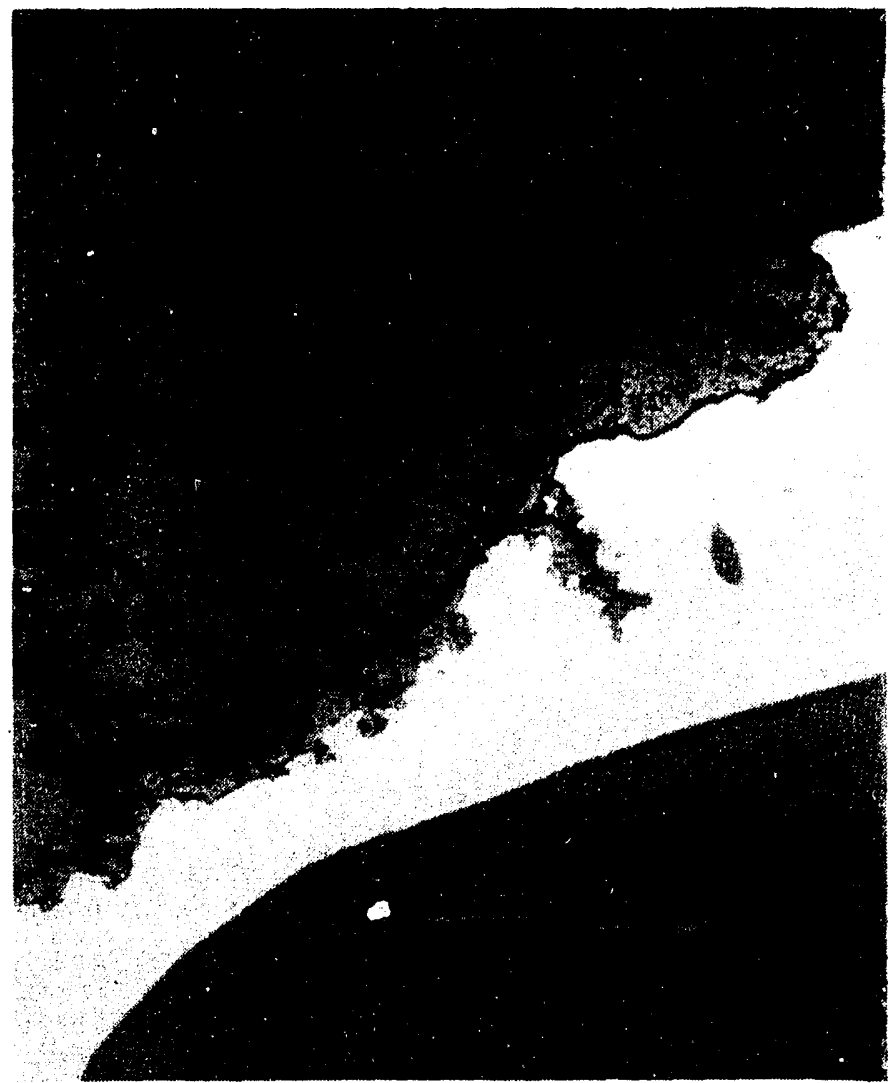

Figure C-8. ROI 91M213, displaying higher magnification view of fuel grains.

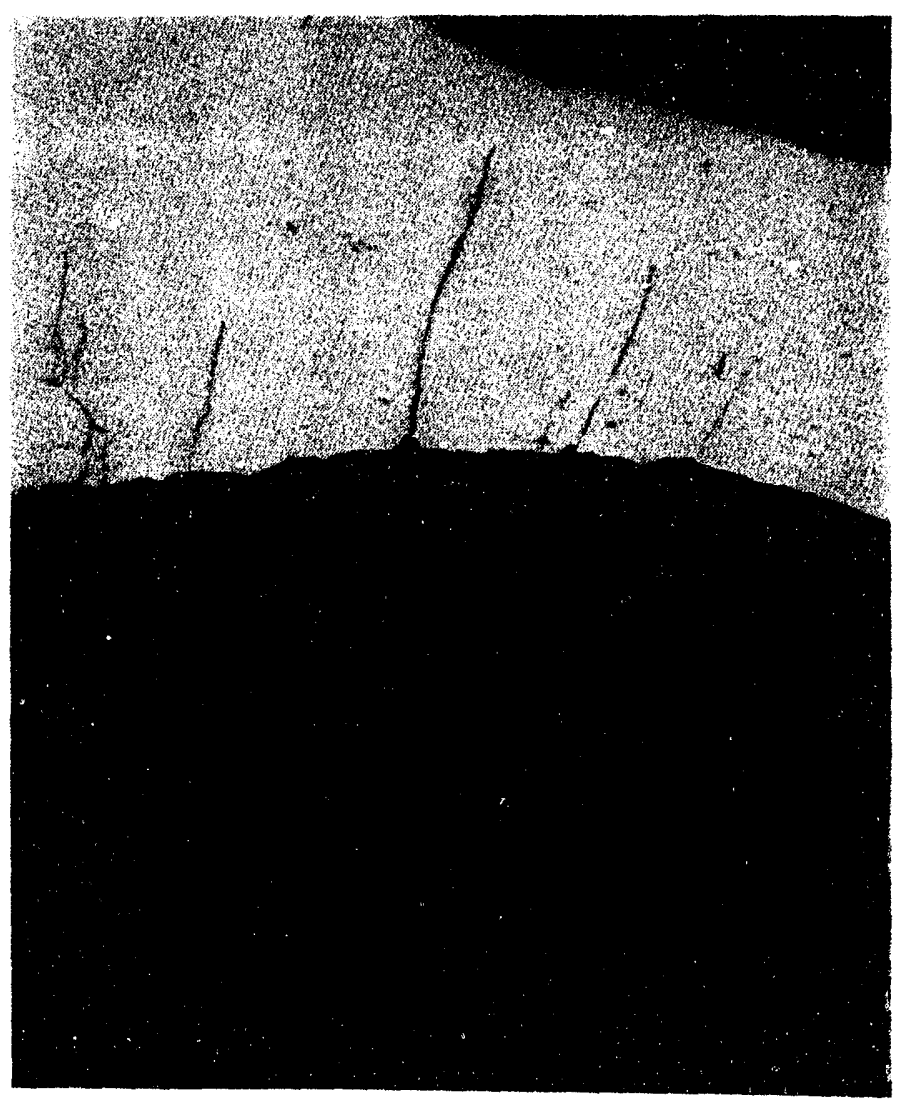

Figure C-9. ROI 91M214, showing evidence of cracking of the guide tube material. 


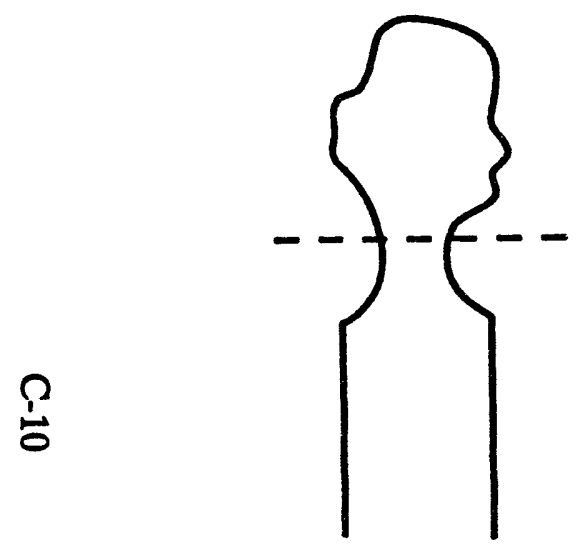

1st cut (side view)

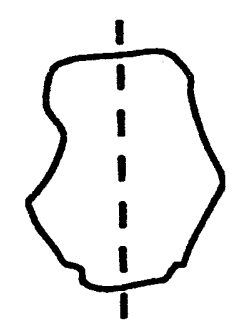

2nd cut (side vlew)

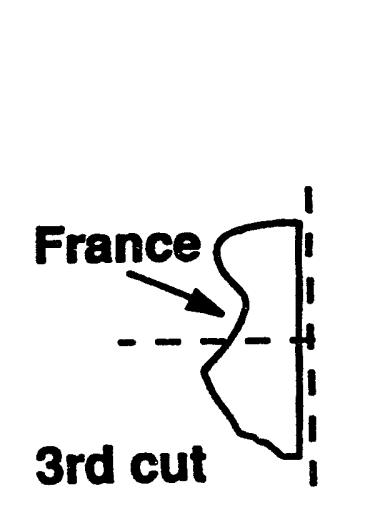

Figure C-10. Sectioning diagram of the R-7 nozzle with attached melt bulb.

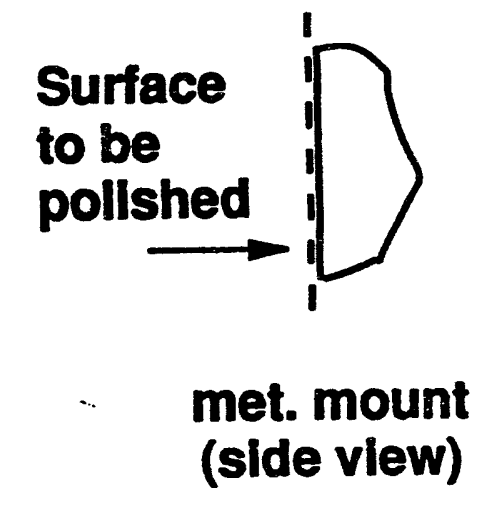




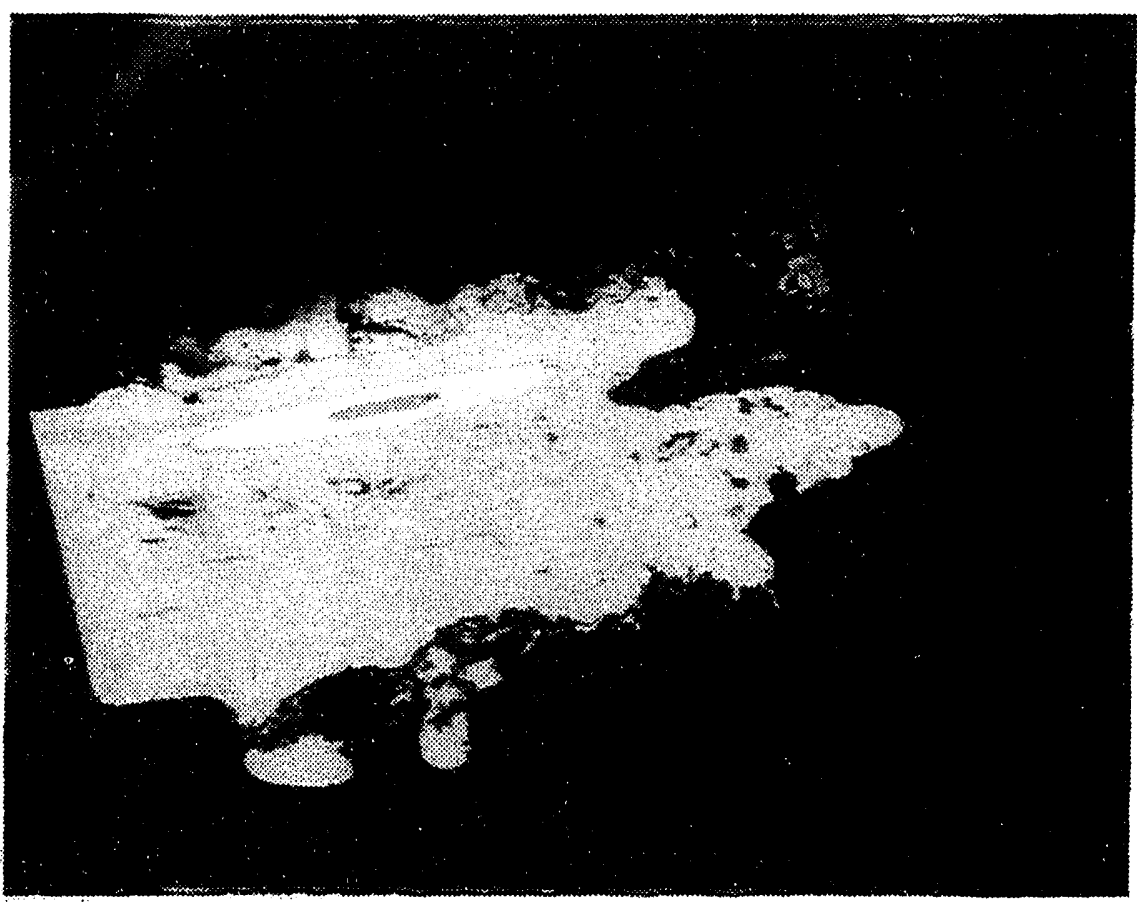

Figure C-11. Metallographic sample of R-7 nozzle melt bulb shown mounted and polished.

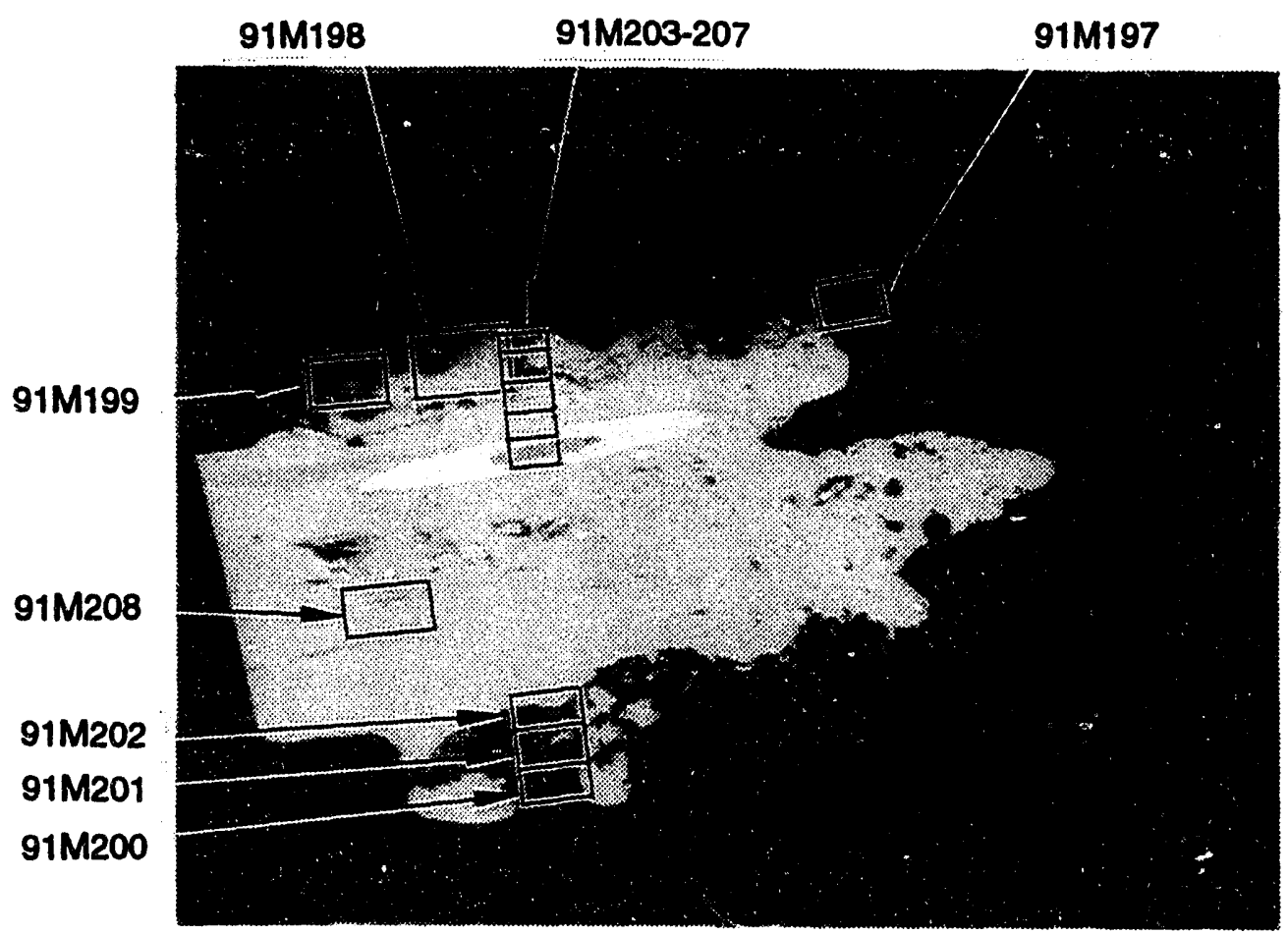

Figure C-12. Metallographic examination map showing ROIs of sample R-7-B. 


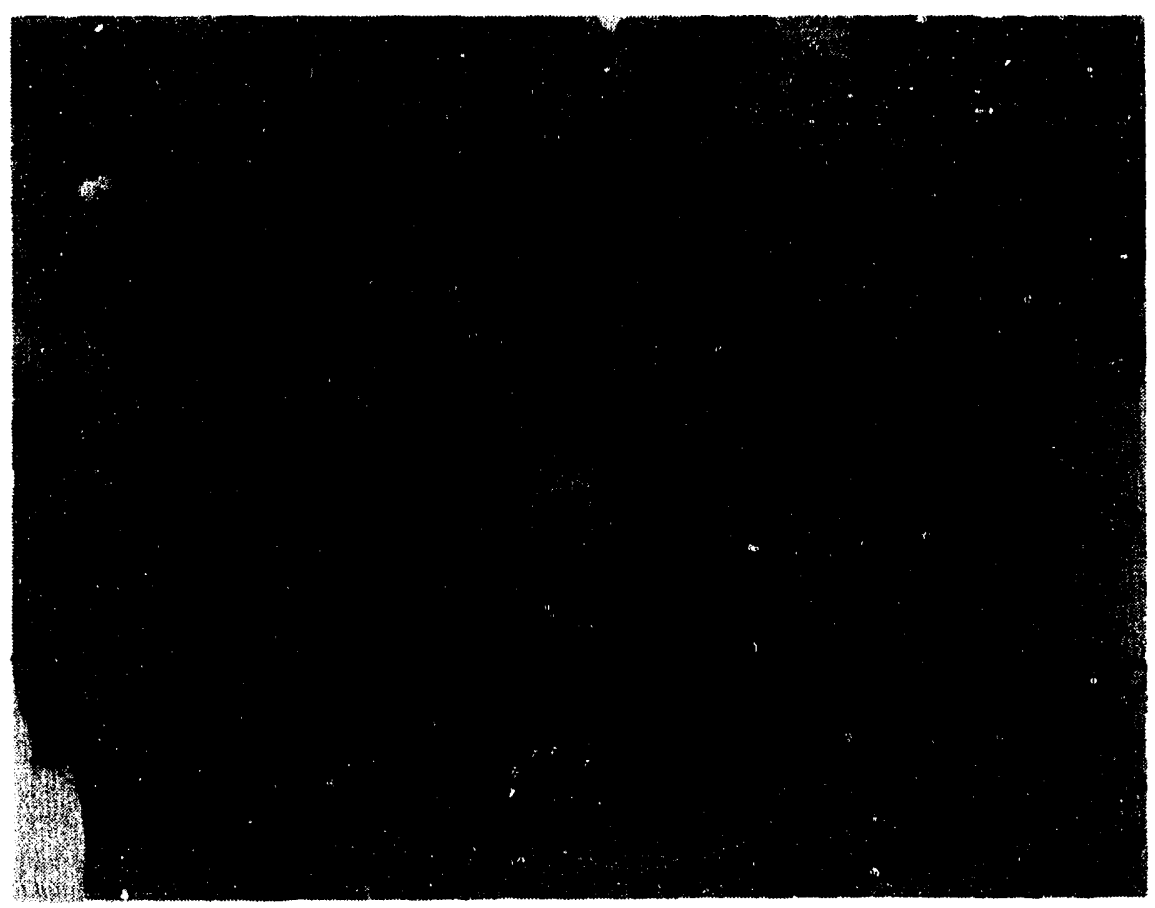

Figure C-13. ROI 91M197, showing apparent molten fuel.

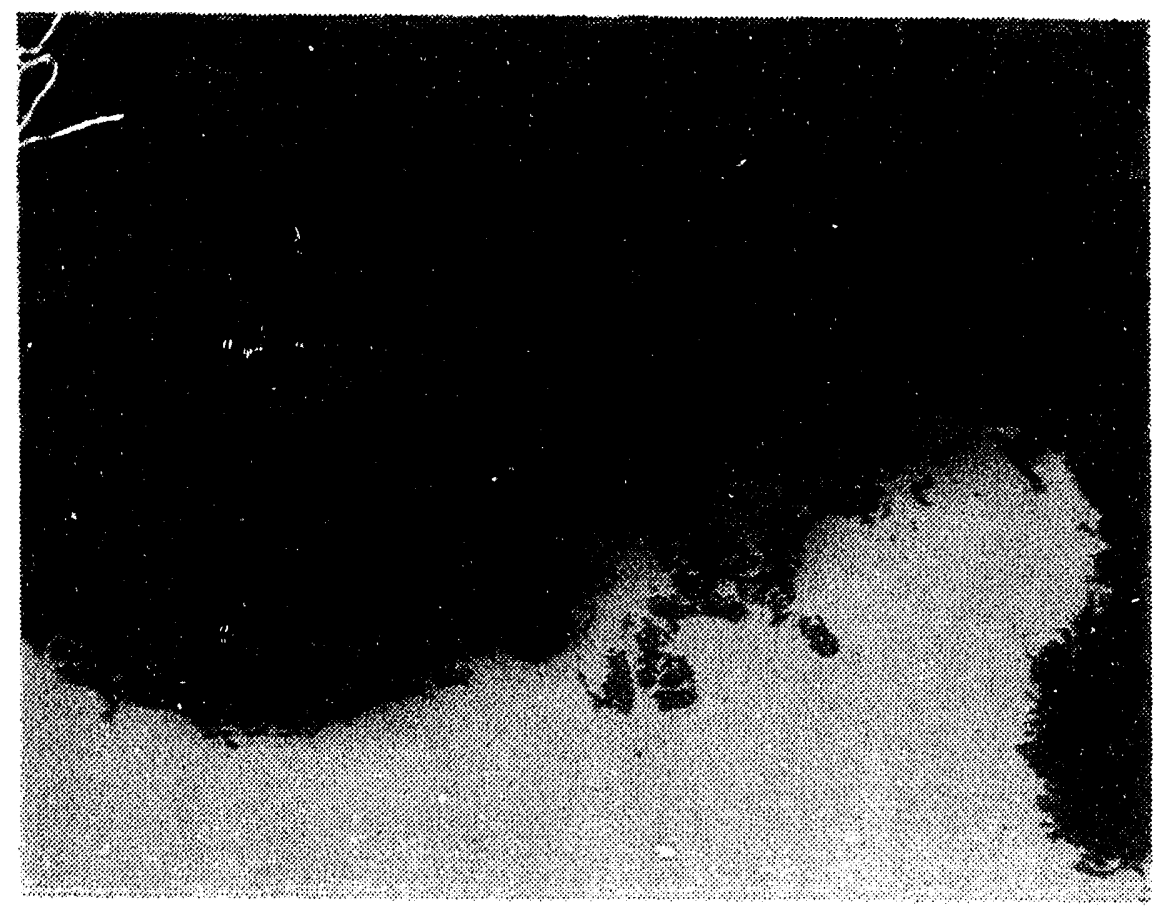

Figure C-14. Fuel adjacent to instrument leads at ROI 91M198. 


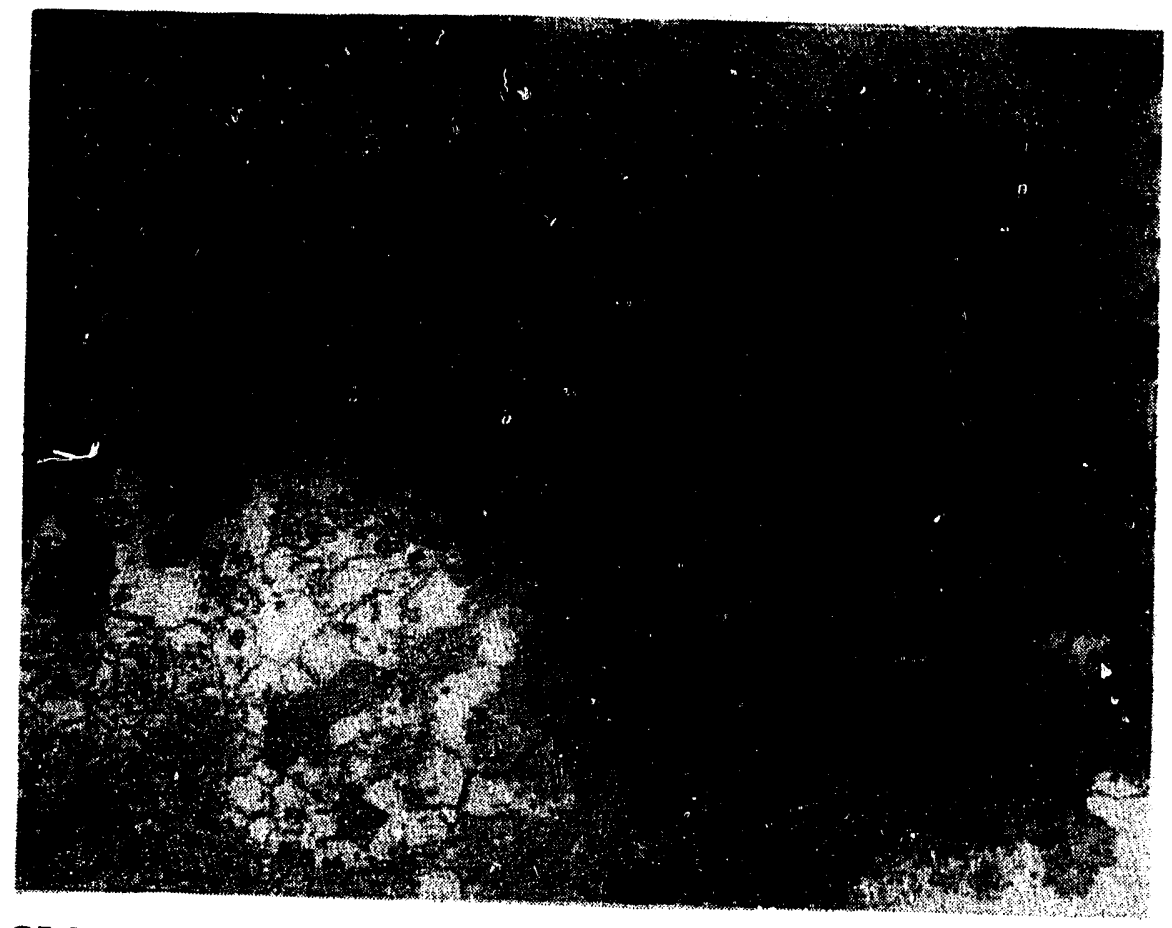

Figure C-15. ROI 91M199, showing 100x view of fuel and instrument leads.

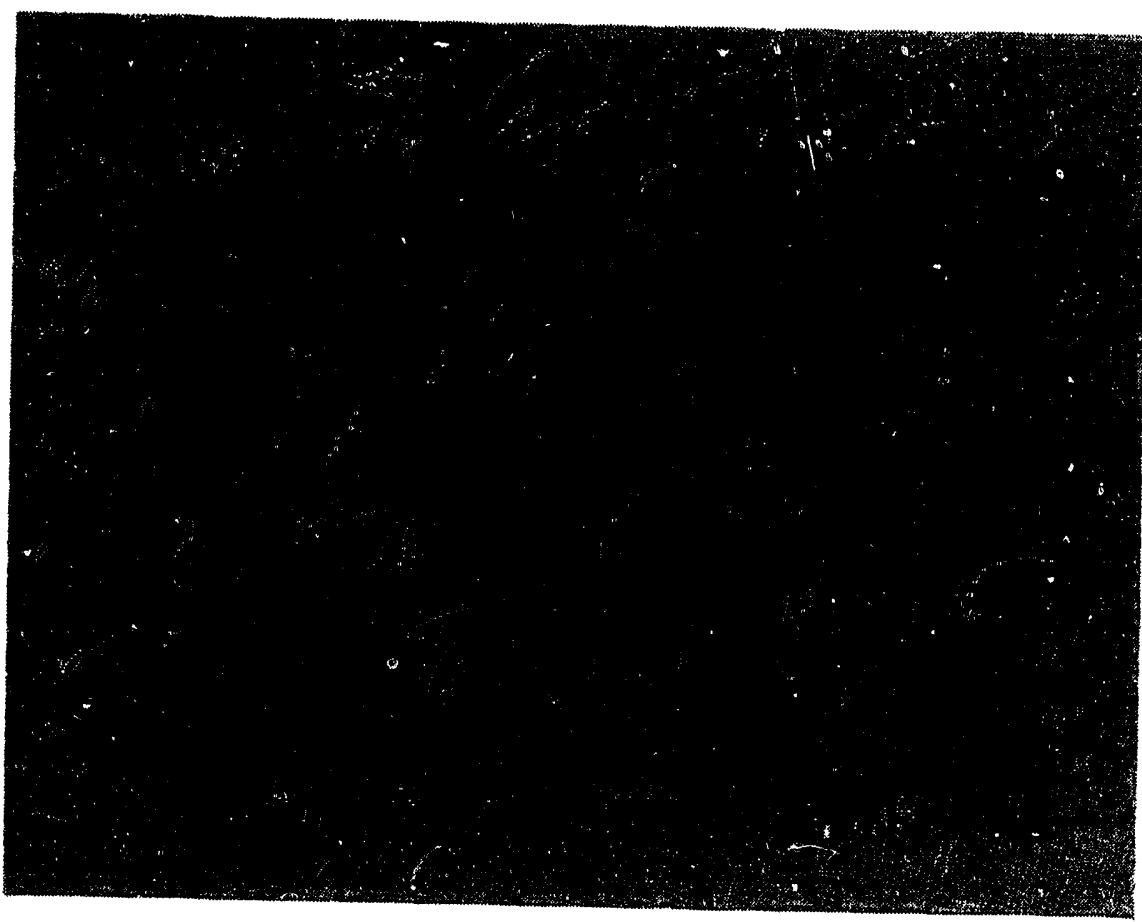

Figure C-16. ROI 91M208, showing material resembling braze metal. 


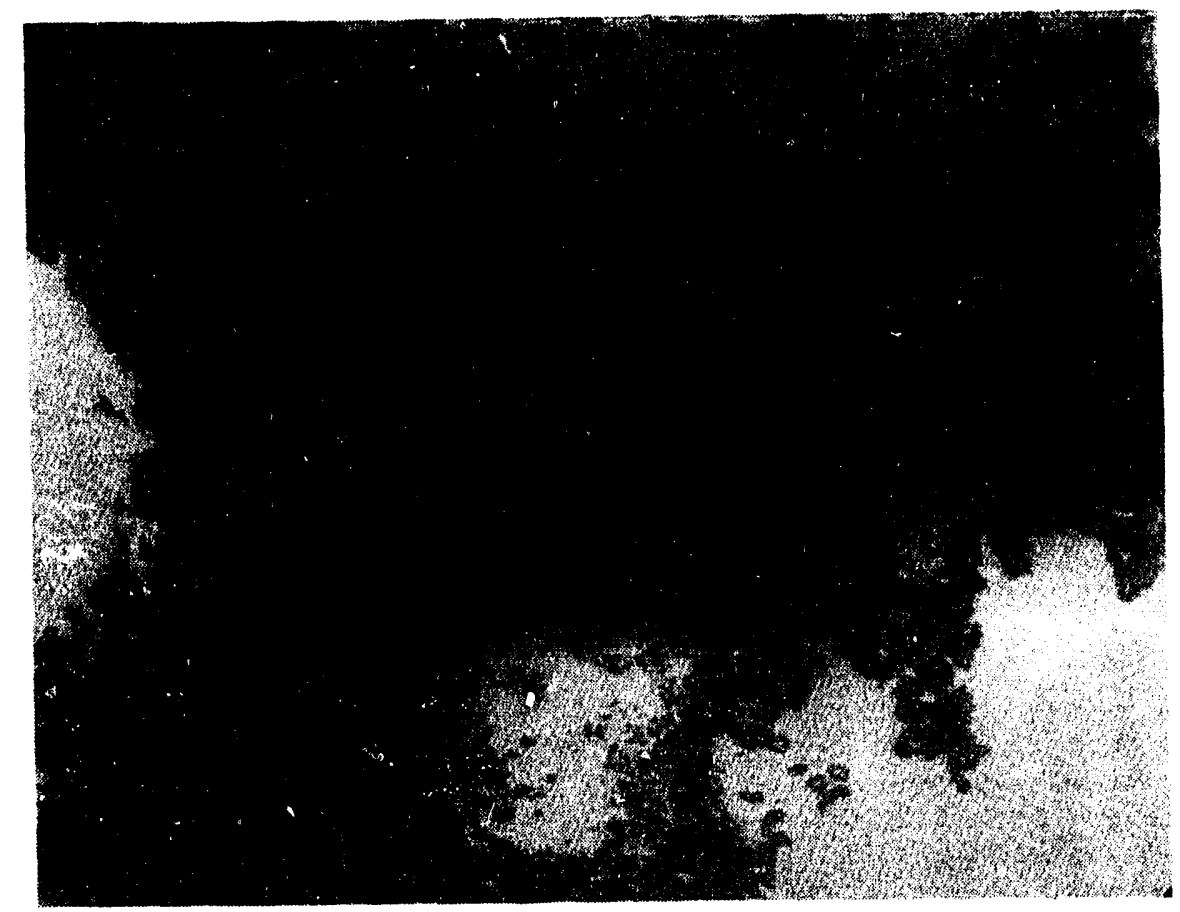

Figure C-17a. ROI 91M203 (view \#1 of a five-photo composite) (starting from edge of sample).

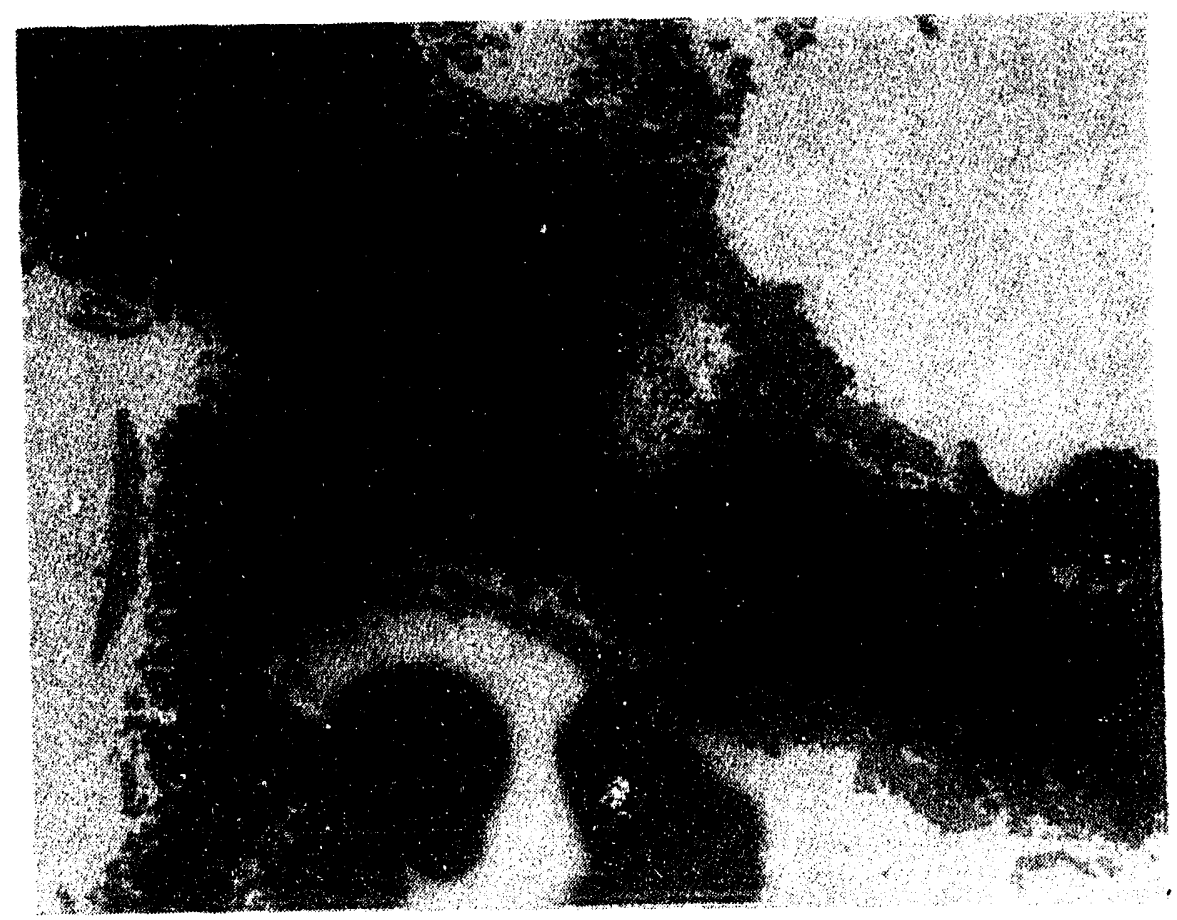

Figure C-17b. ROI 91M204 (view \#2 of a five-photo composite). 


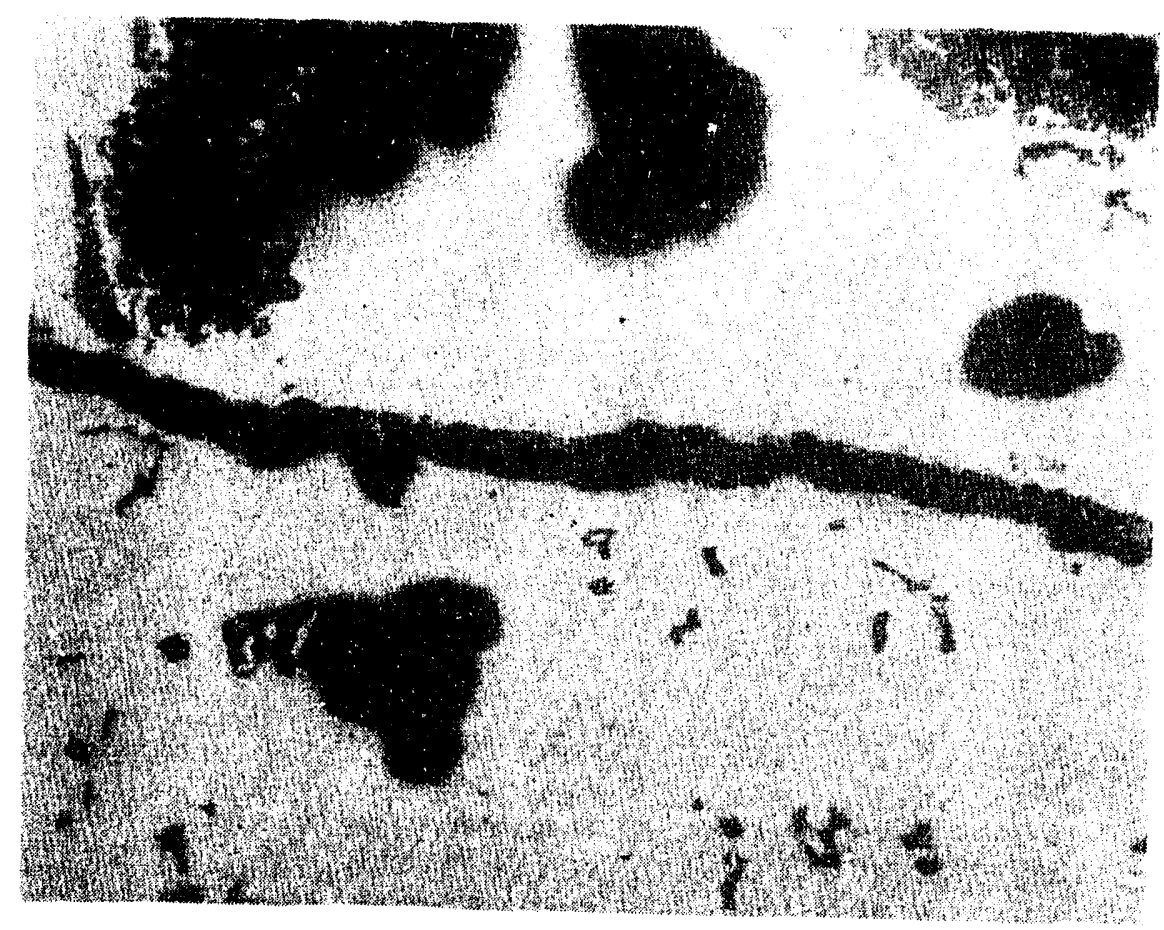

Figure C-17c. ROI 91M205 (view \#3 of a five-photo composite).

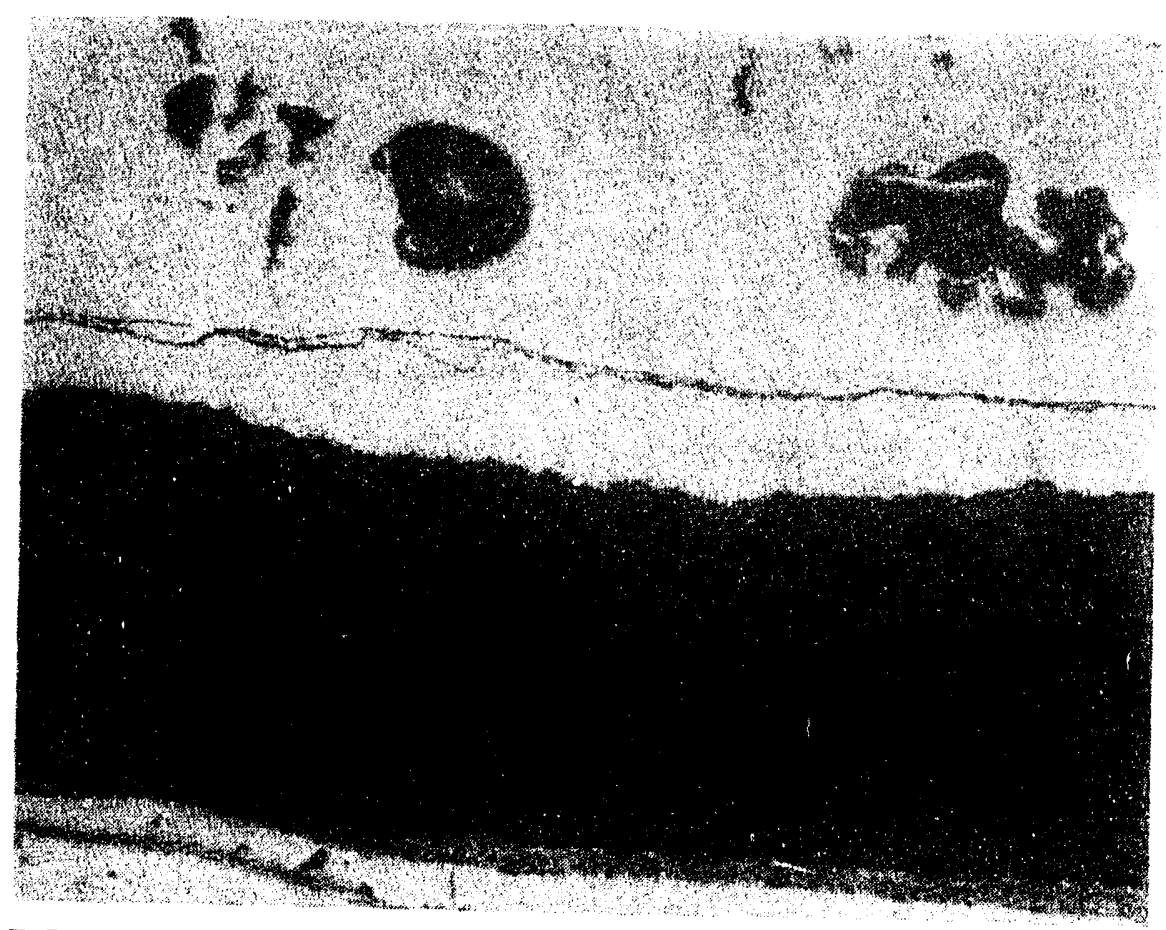

Figure C-17d. ROI 91M206 (view \#4 of a five-photo composite). 


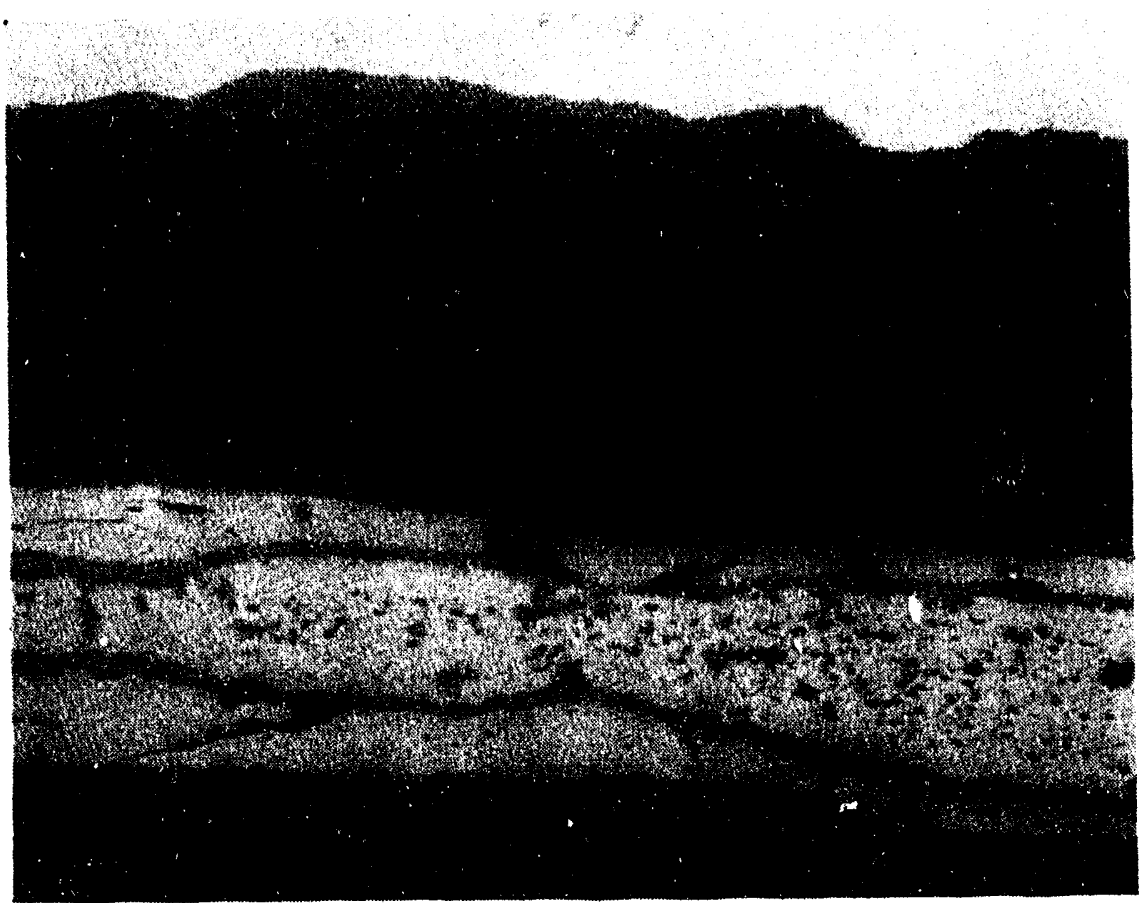

Figure C-17e. ROI 91M207 (view \#5 of a five-photo composite).

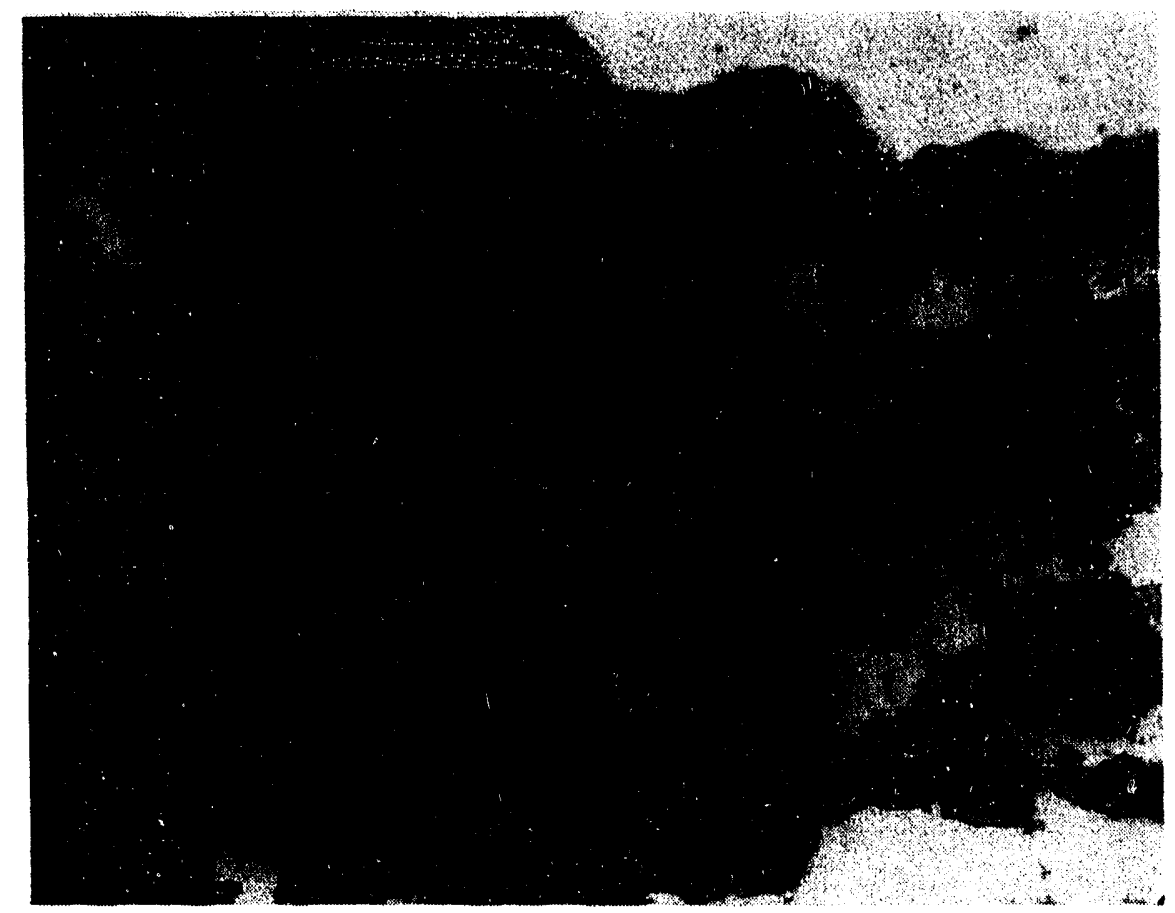

Figure C-18a. ROI 91M202 at 100x (view \#1 of a three-photo composite). 


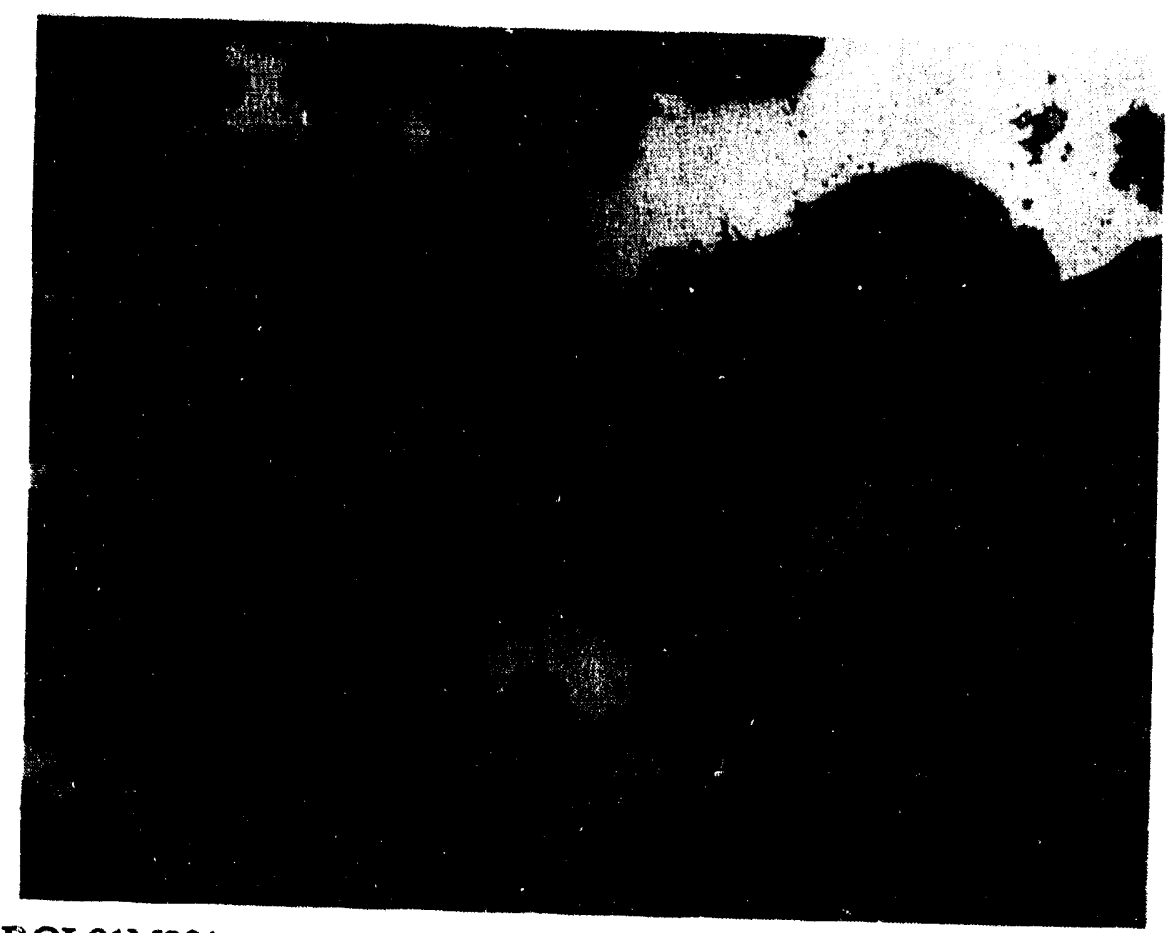

Figure C-18b. ROI 91M201 at 100x (view \#2 of a three-photo composite).

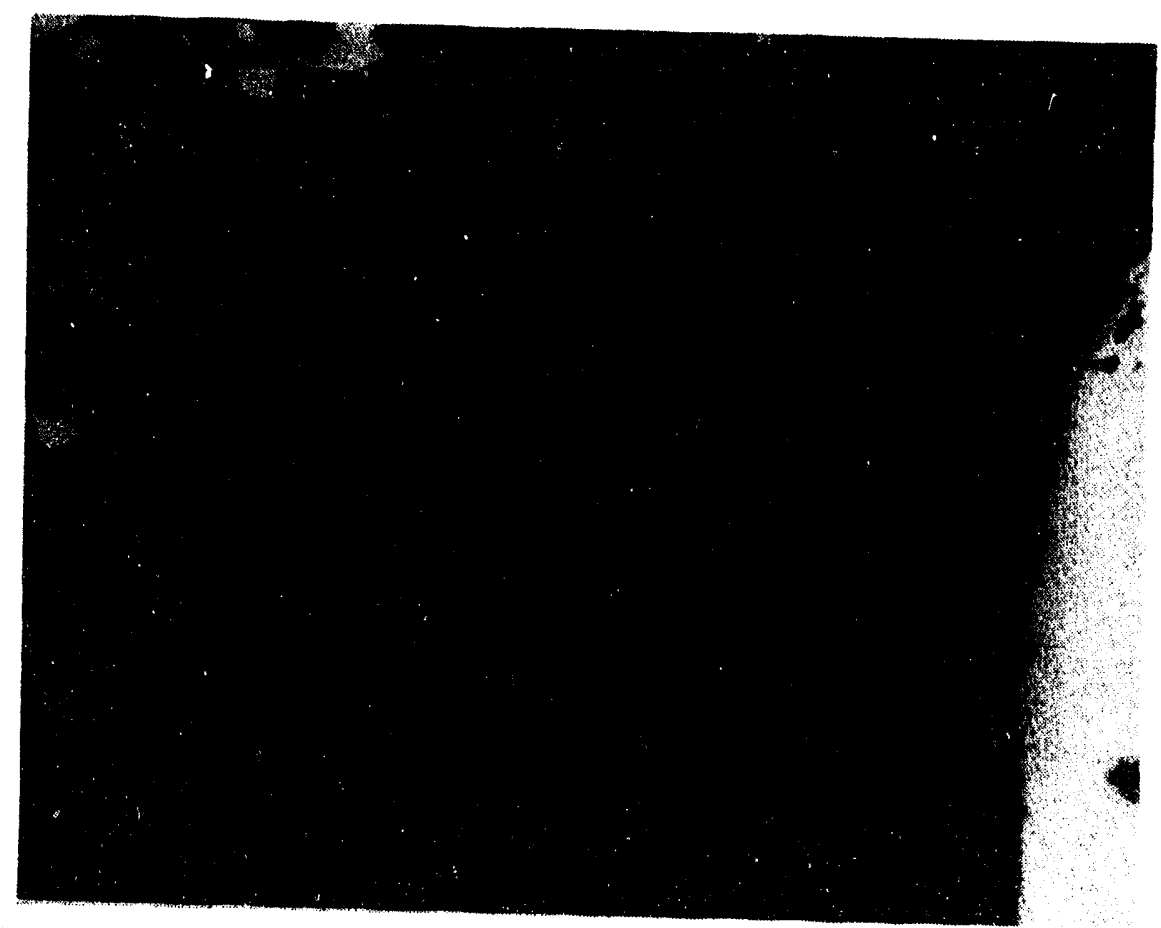

Figure C-18c. ROI $91 \mathrm{M} 200$ at $100 x$ (view \#3 of a three-photo composite). 
$\stackrel{?}{\infty}$
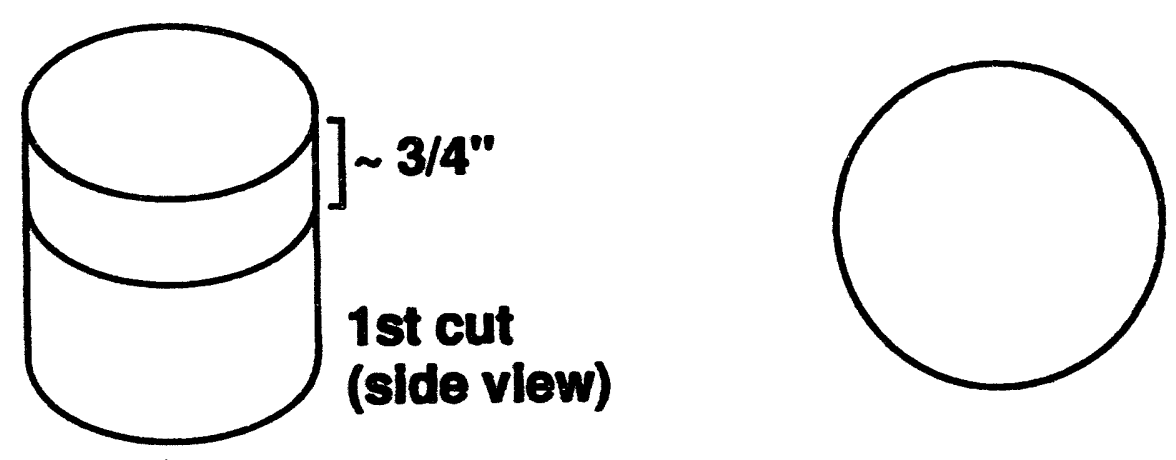

$$
\begin{aligned}
& \text { and cut } \\
& \text { (top view) }
\end{aligned}
$$
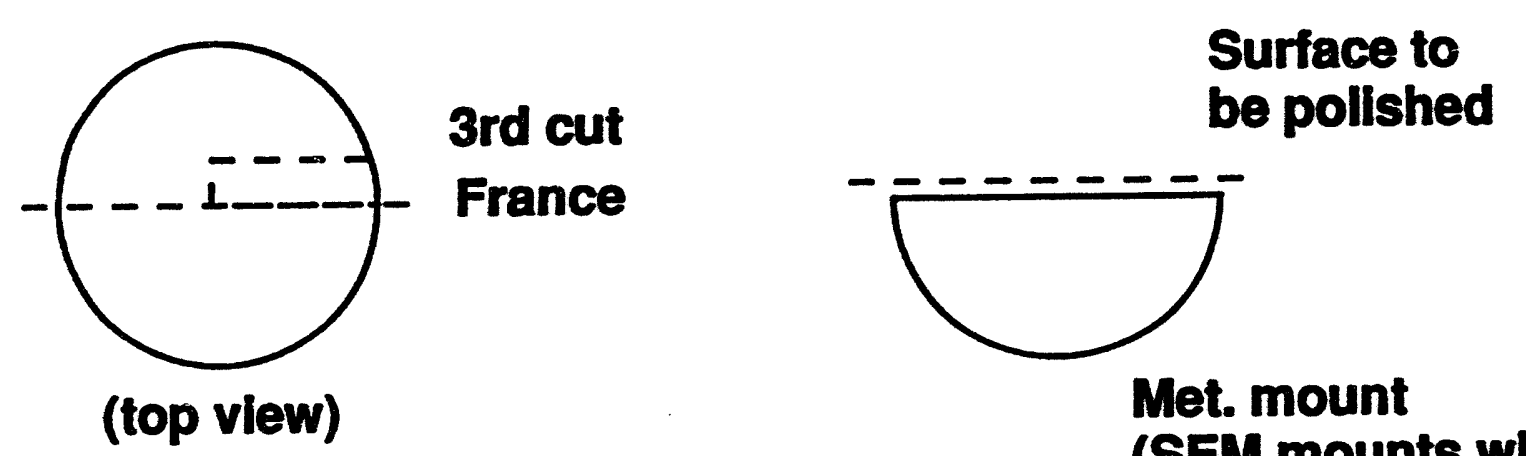

Met. mount (SEM mounts will be cut from this at a later date)

Figure C-19. Cutting diagram for the G-5 nozzle. 


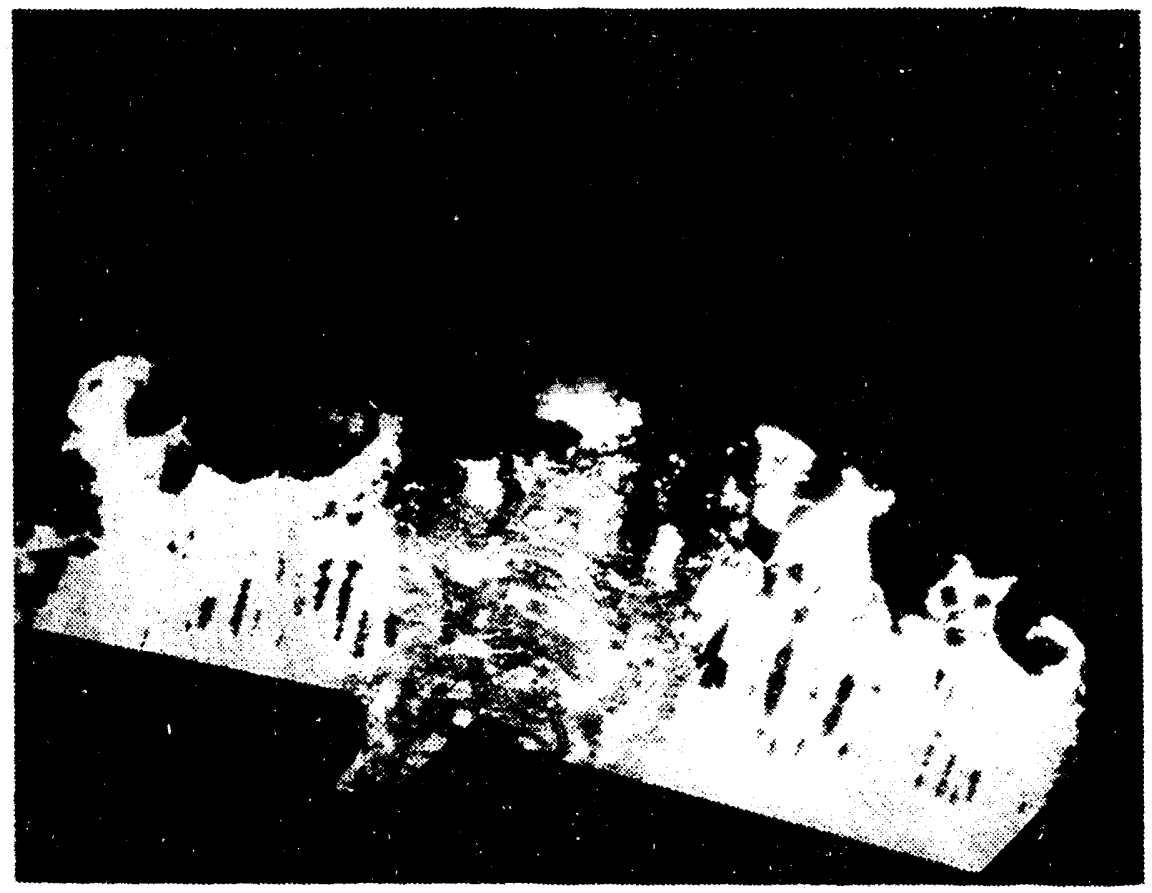

Figure C-20. The G-5 metallography sample mounted and polished for examination of the longitudinal face.

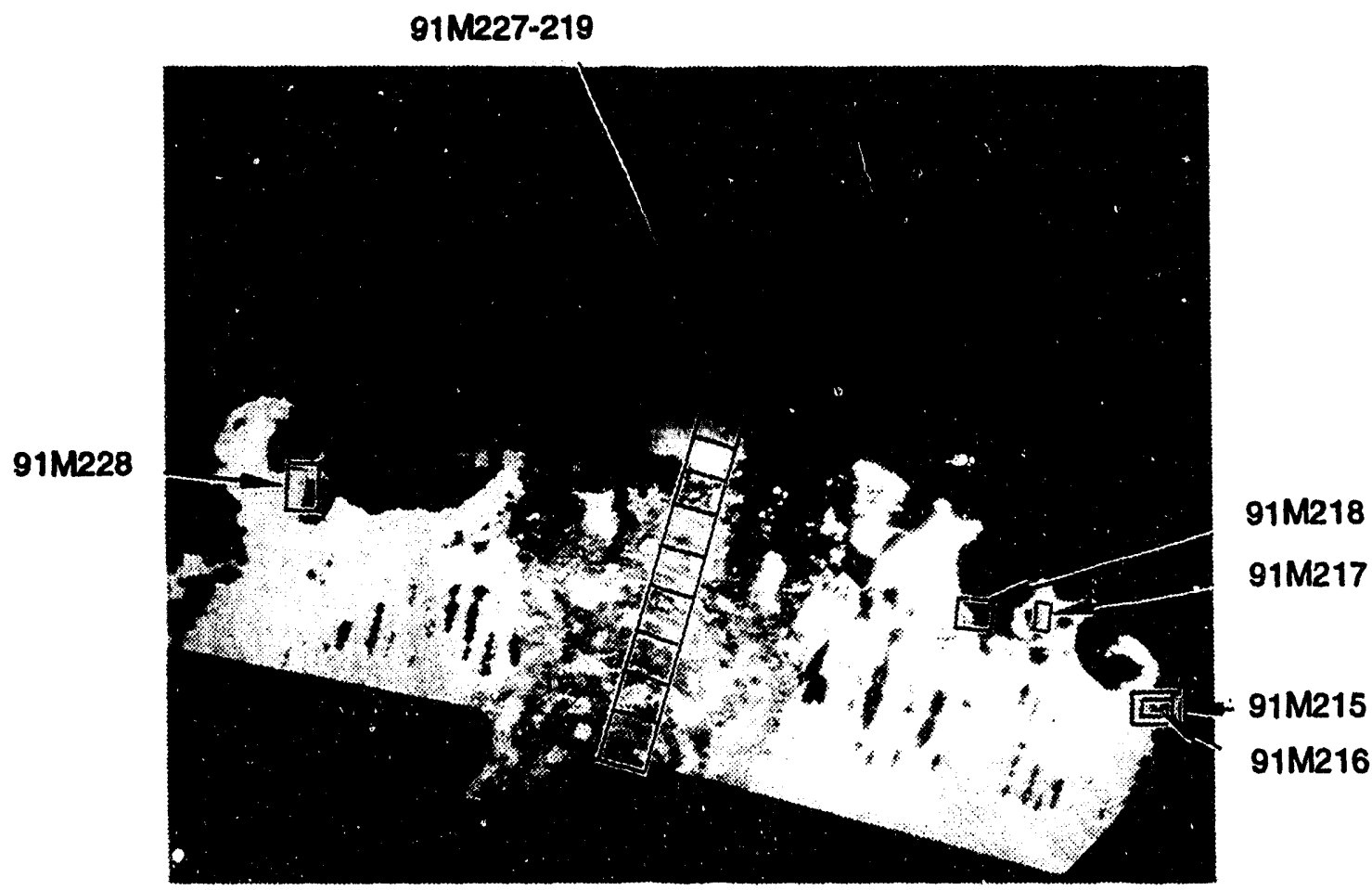

Figure C-21. Metallographic examination map showing ROIs of the G-5 nozzle. 


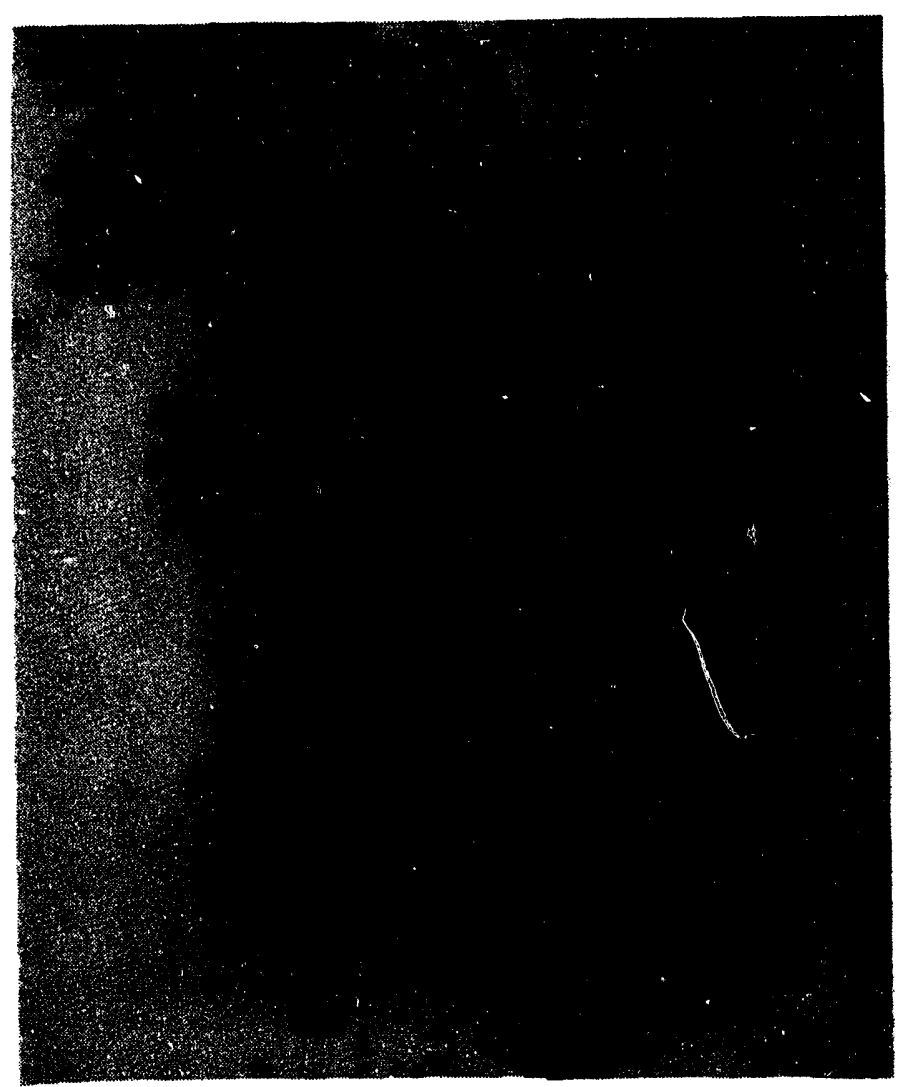

Figure C-22. 50x view of the melt at ROI 91M215.

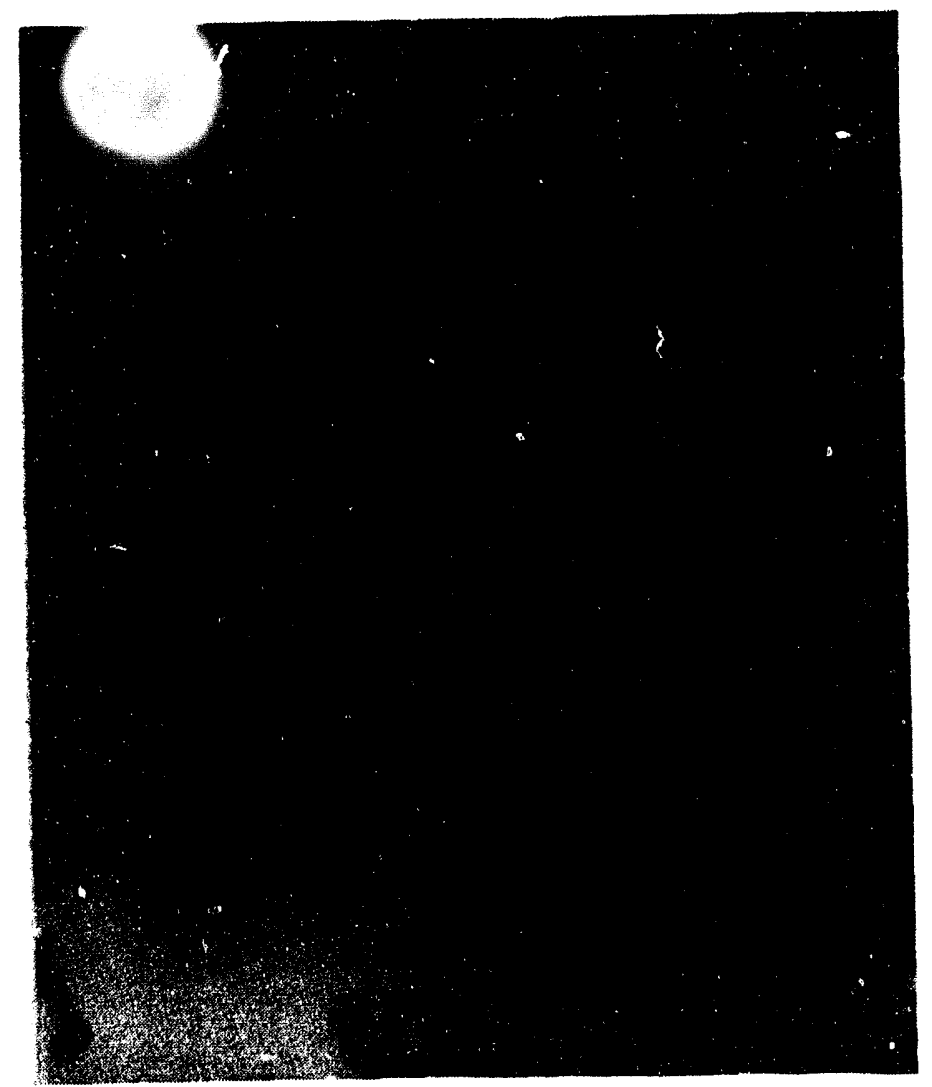

Figure C-23. Higher magnification (200x) view of ROI 91M215. 


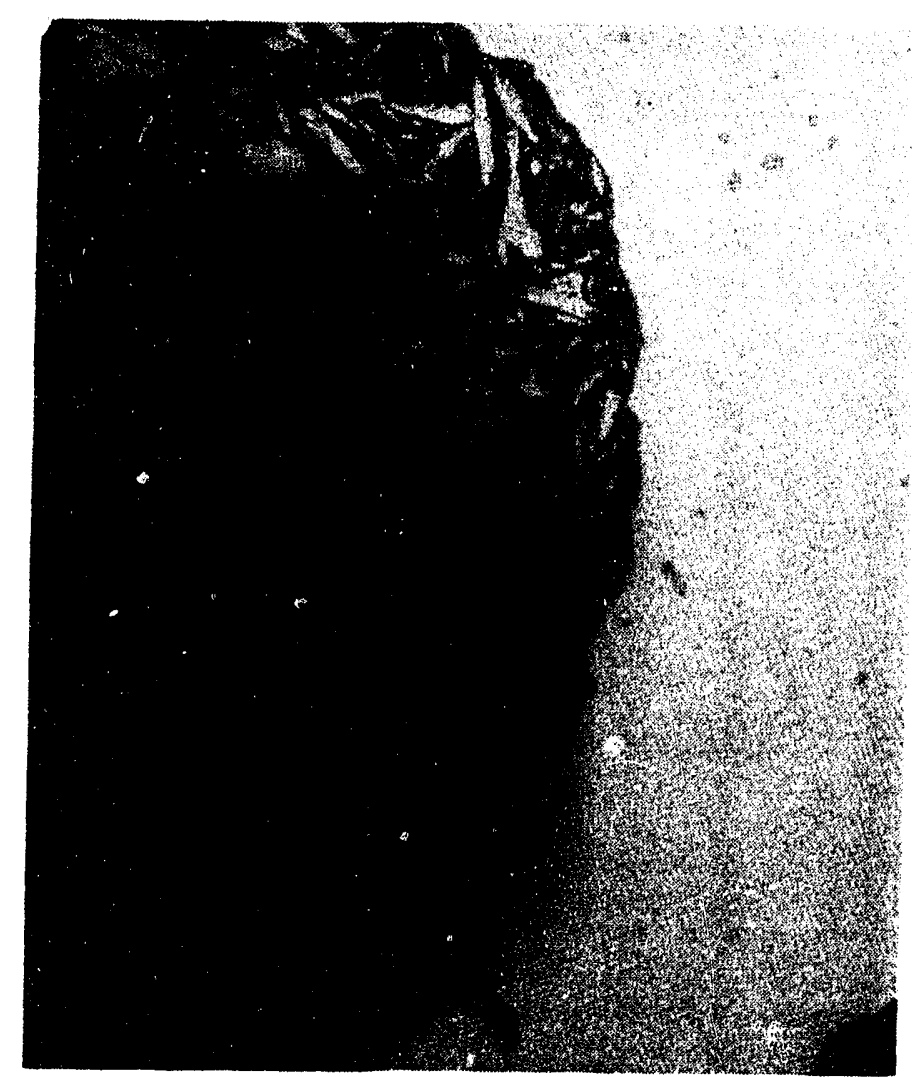

Figure C-24. ROI 91M217, showing debris inside hole (200x).

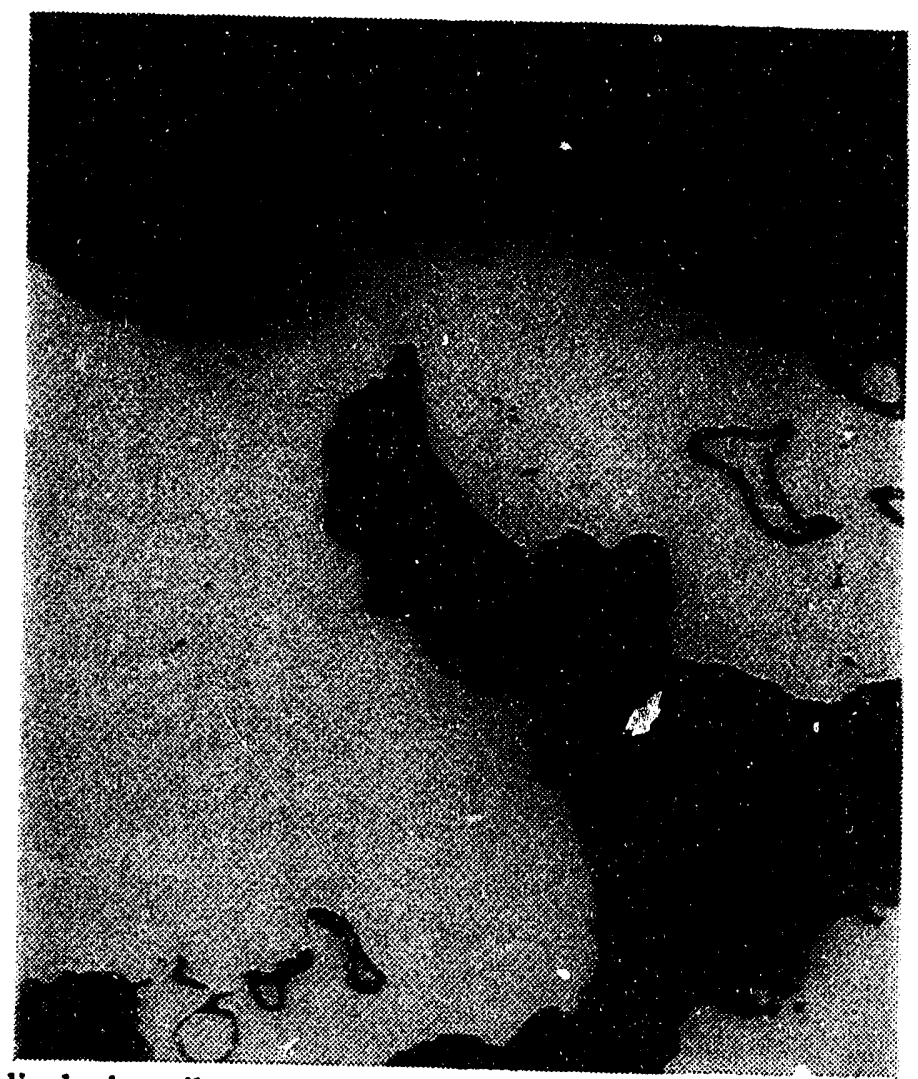

Figure C-25. 100x view displaying silver drops at ROI 91M218. 


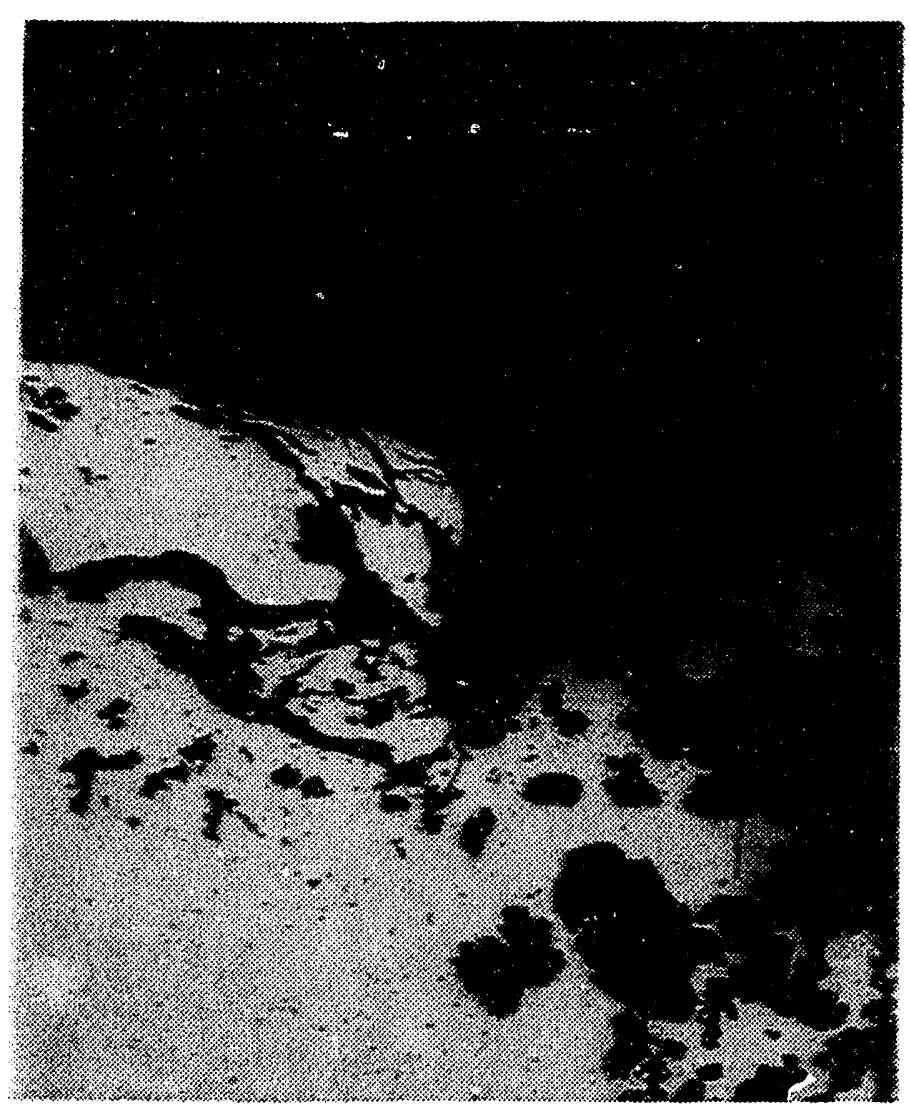

Figure C-26a. ROI 91M227 (view \#1 of a nine-photo composite) (proceeding from the top to the bottom).

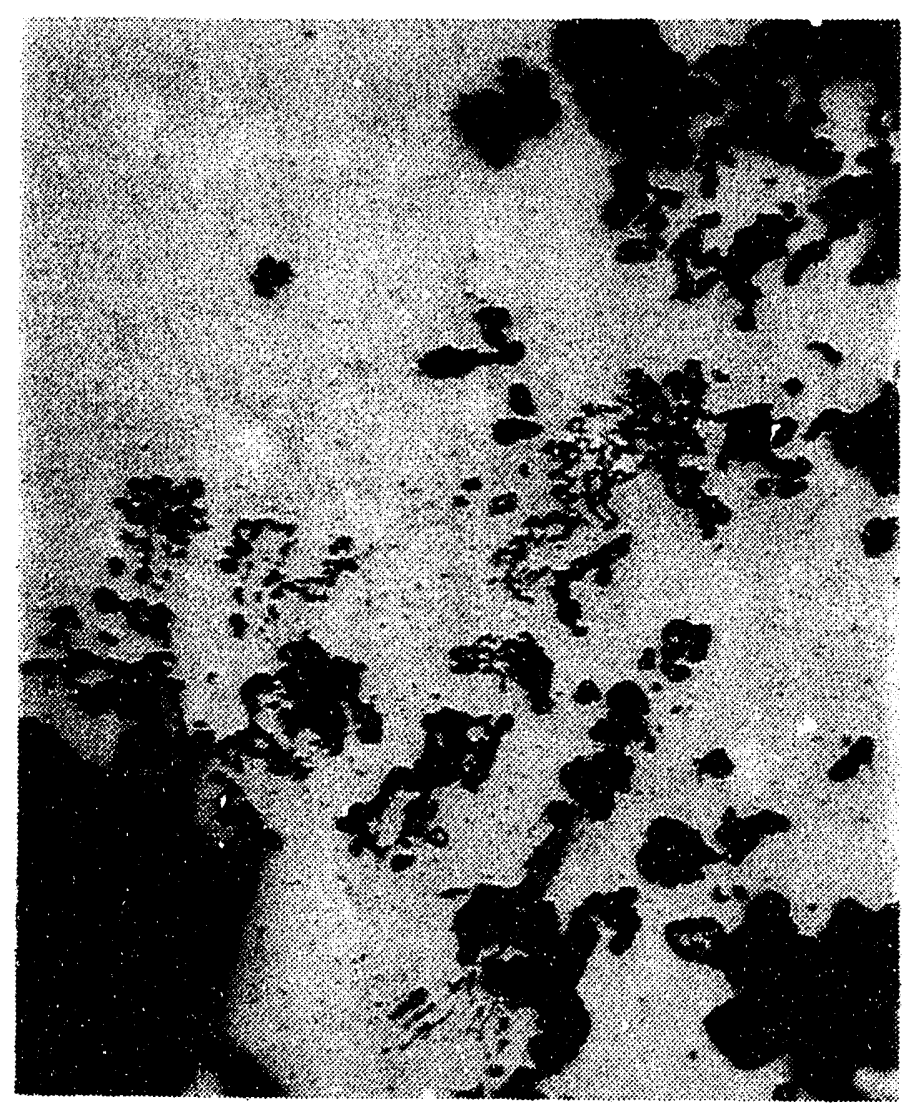

Figure C-26b. ROI 91M226 (view \#2 of a nine-photo composite). 


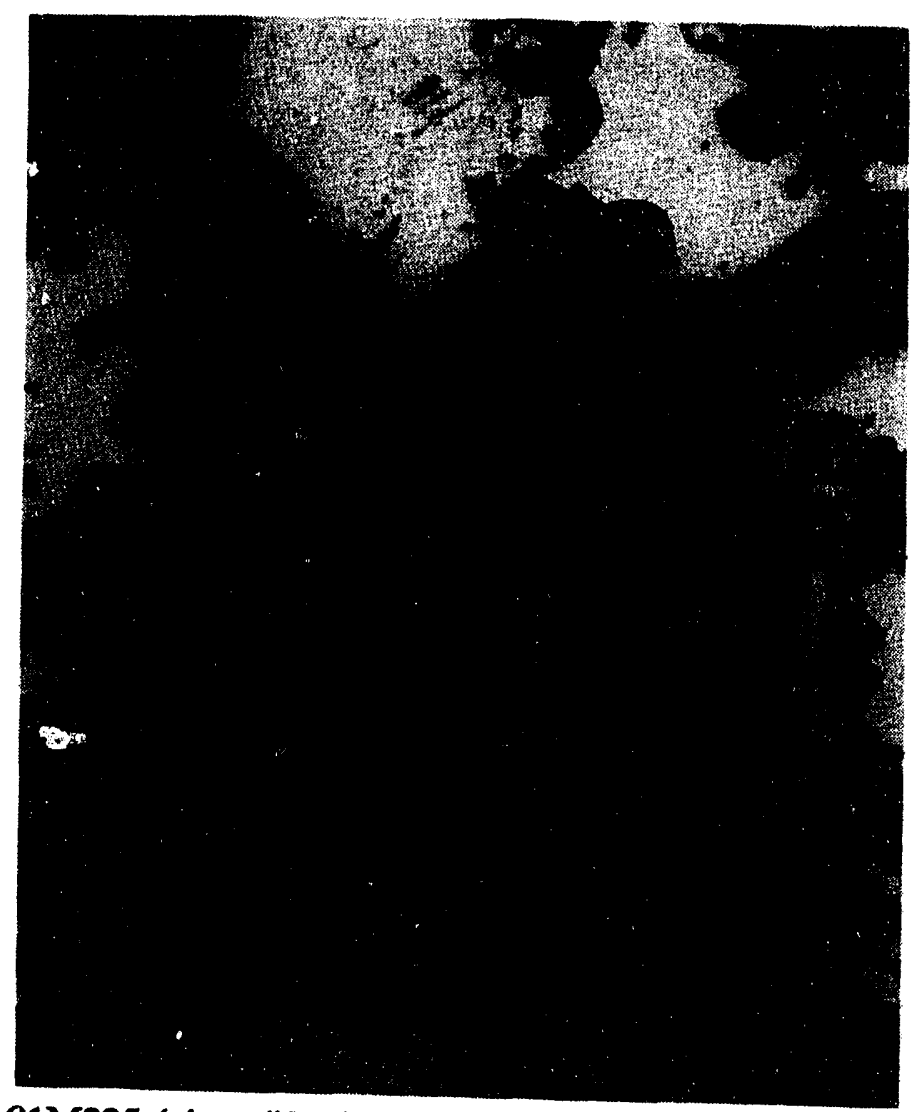

Figure C-26c. ROI 91M225 (view \#3 of a nine-photo composite).

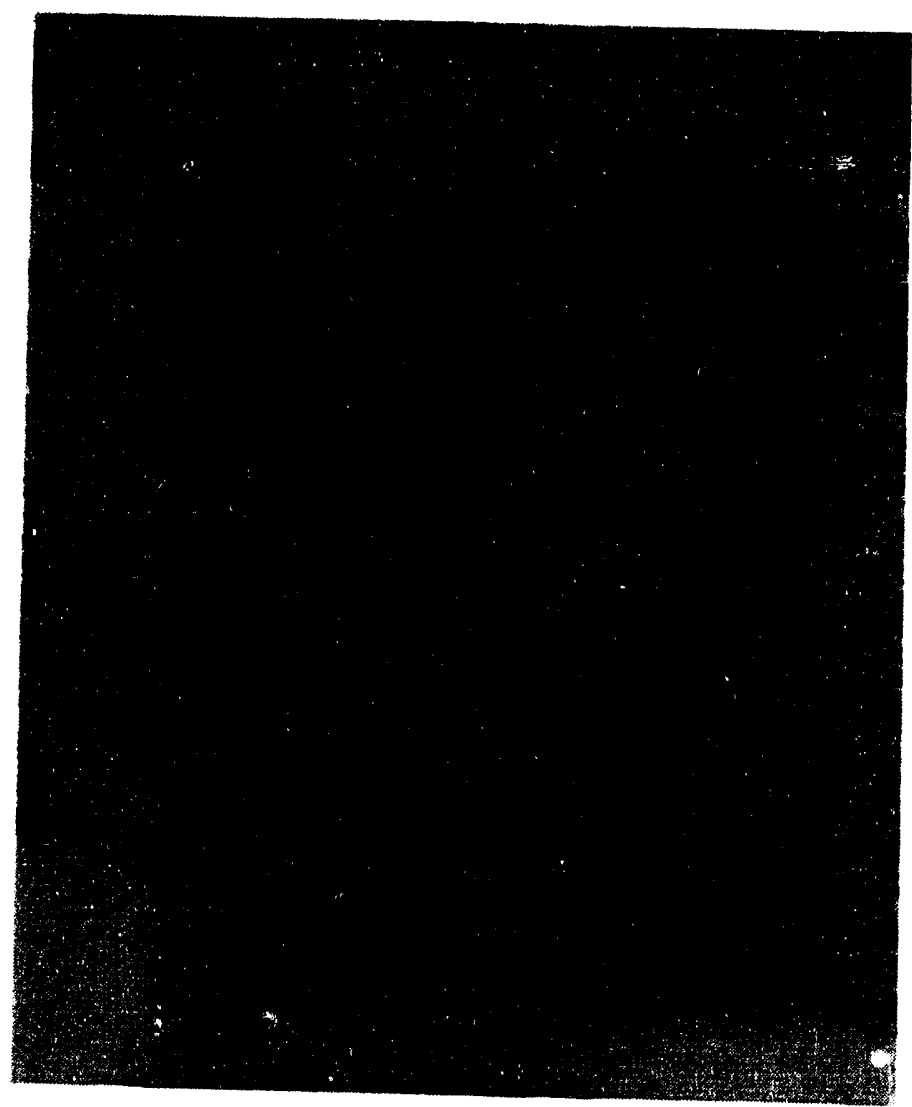

Figure C-26d. ROI 91M224 (view \#4 of a nine-photo composite). 


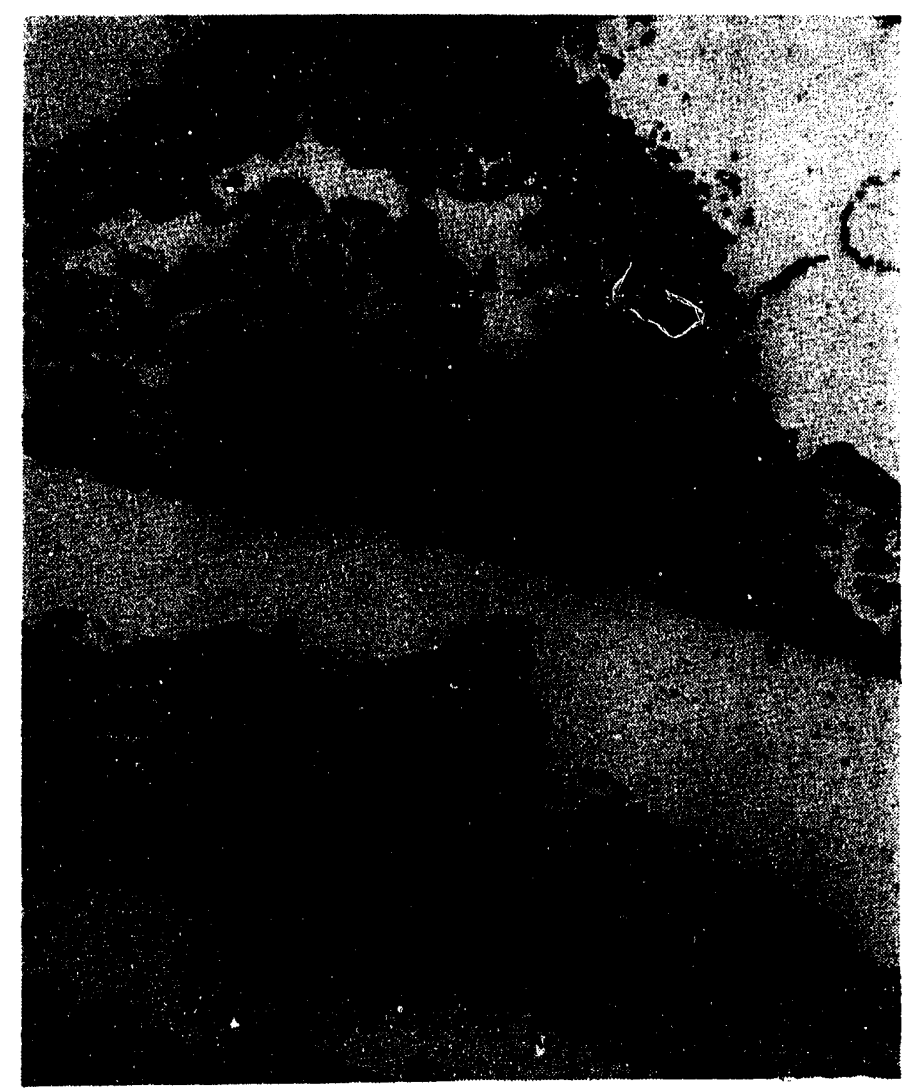

Figure C-26e. ROI 91M223 (view \#5 of a nine-photo composite).

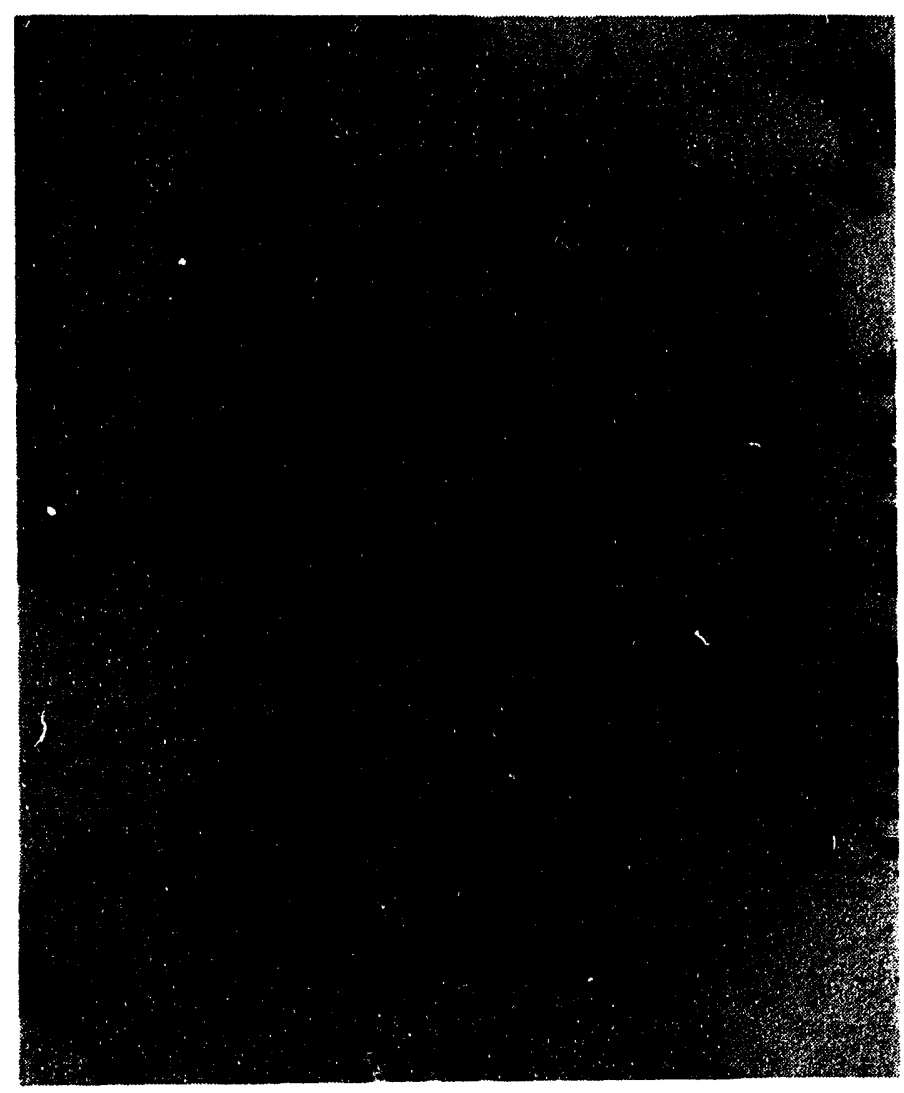

Figure C-26f. ROI 91M222 (view \#6 of a nine-photo composite). 


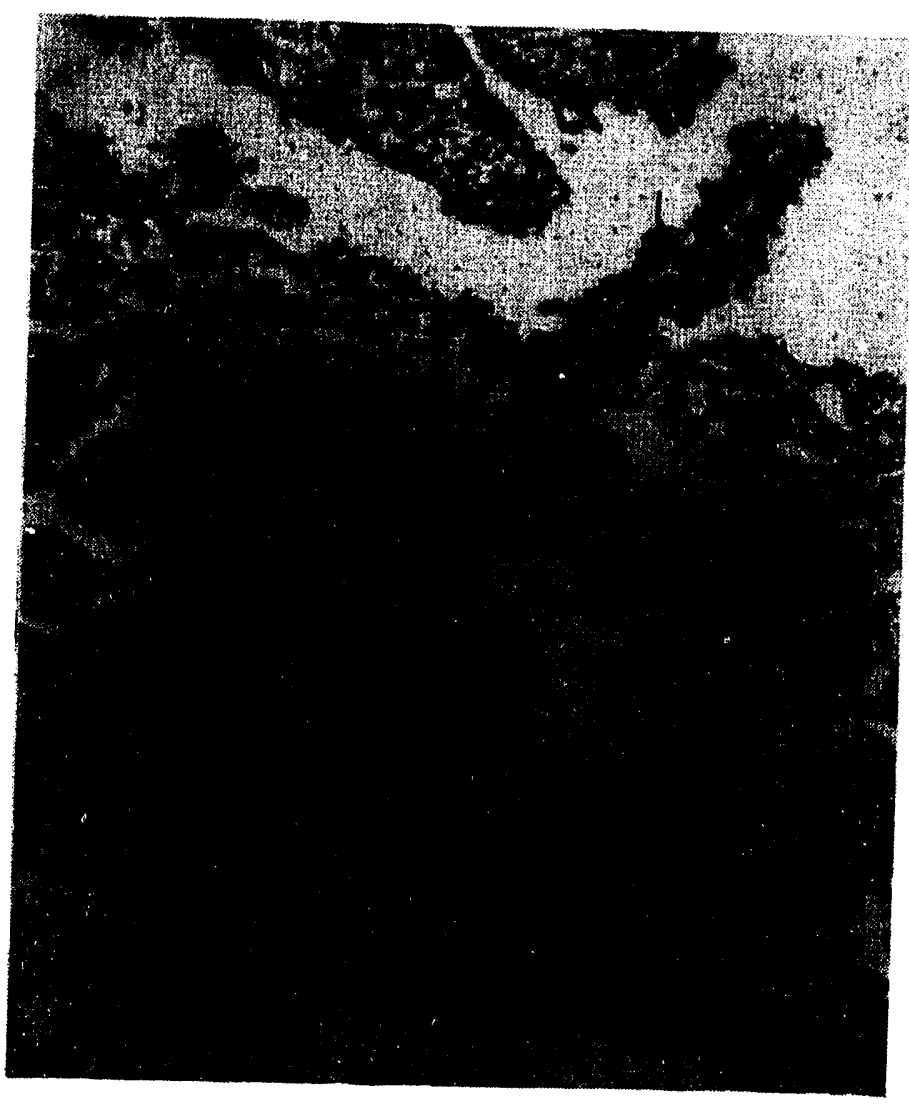

Figure C-26g. ROI 91M221 (view \#7 of a nine-photo composite).

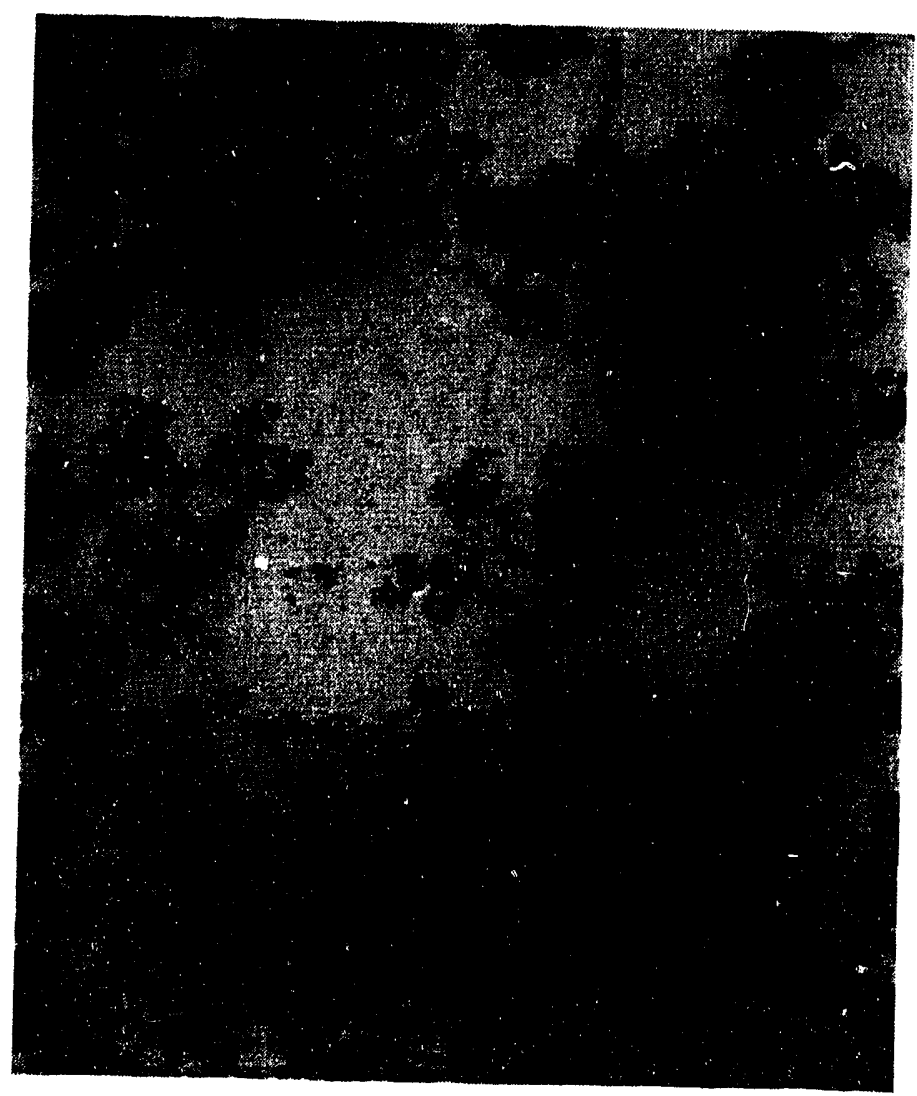

Figure C-26h. ROI 91M220 (view \#8 of a nine-photo composite). 


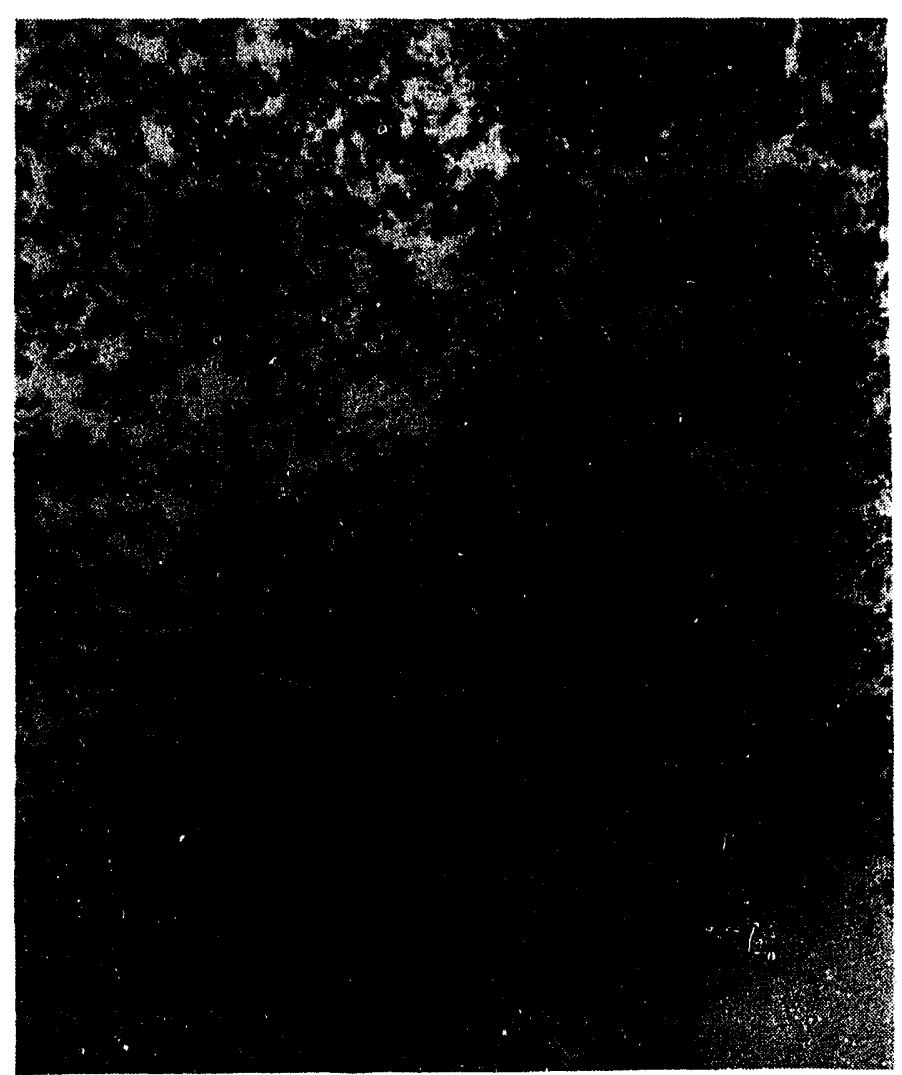

Figure C-26i. ROI 91M219 (view \#9 of a nine-photo composite).

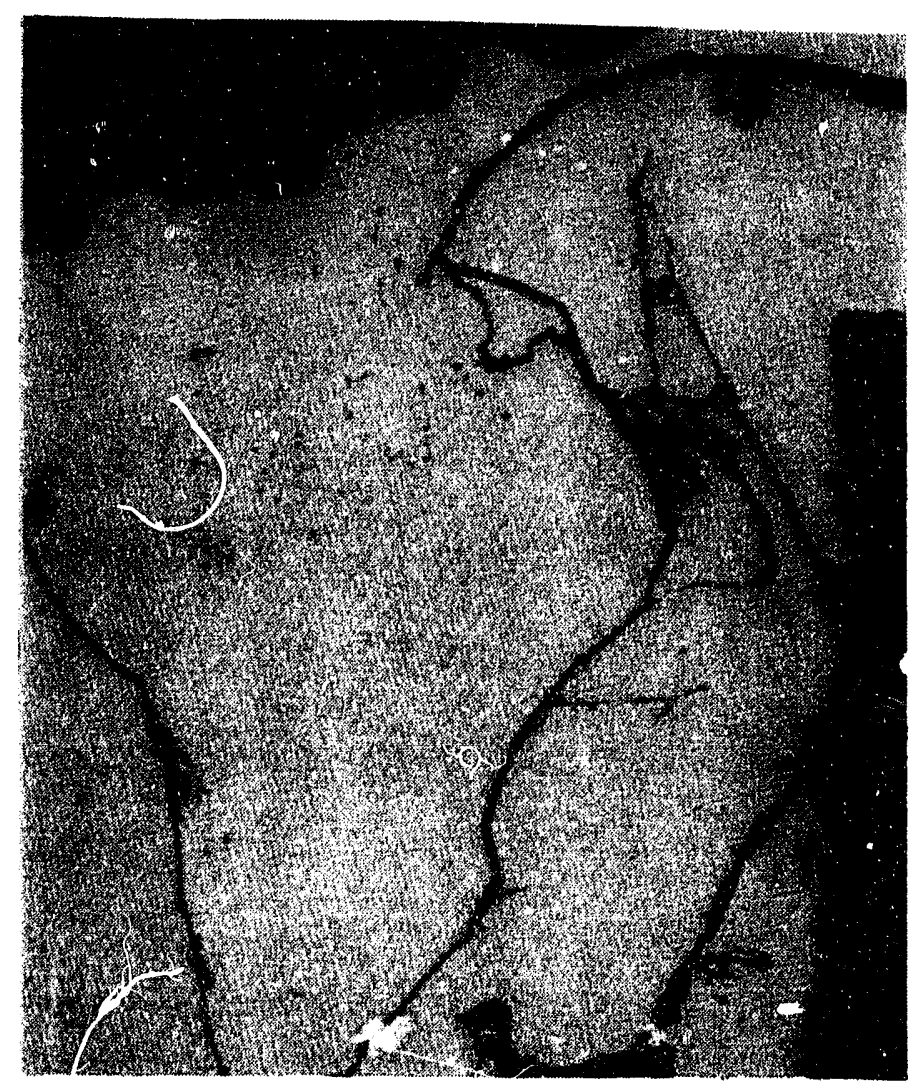

Figure C-27. RCI 91M228, exhibiting material cracking. 


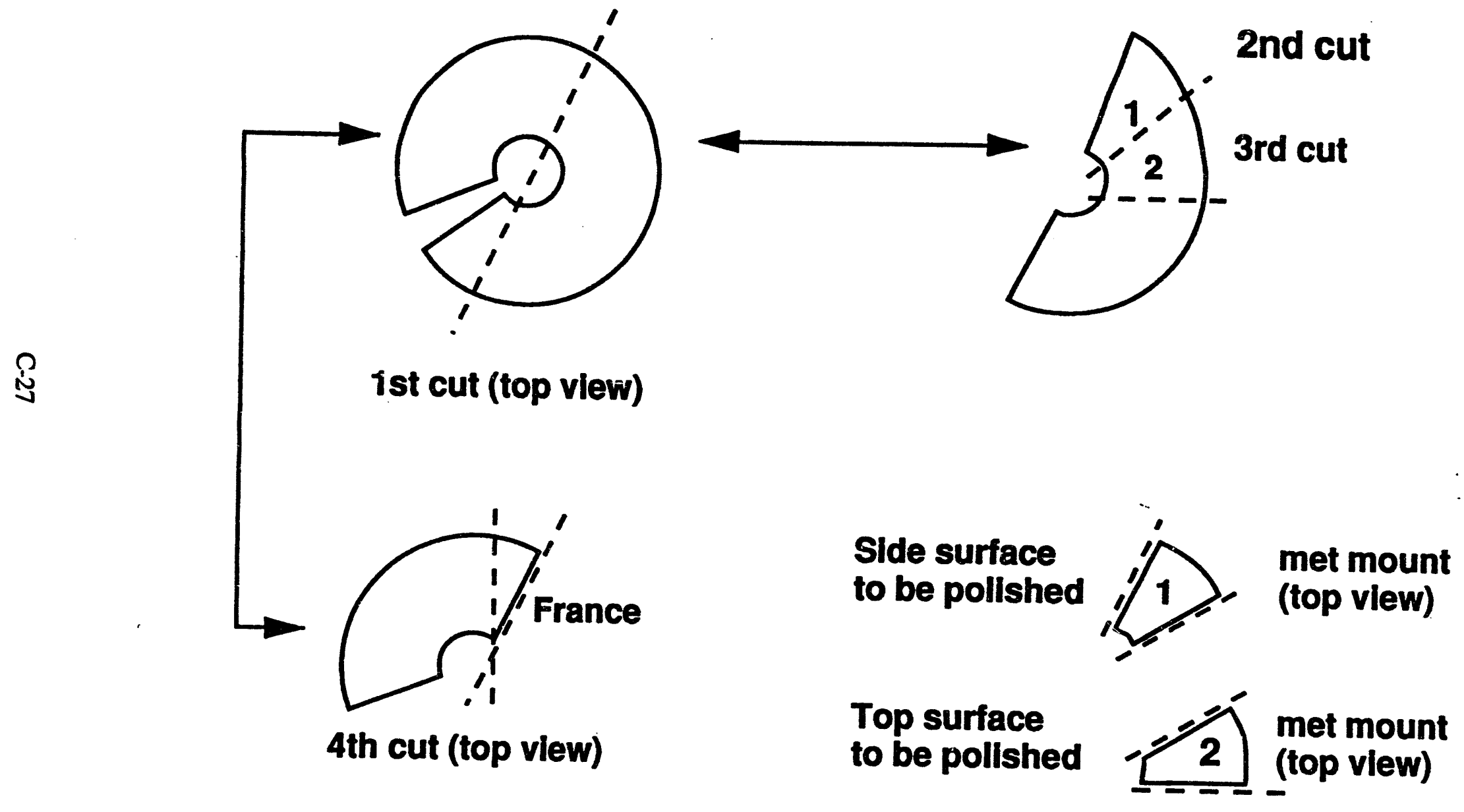

Figure C-28. Sectioning procedure for the E-7 nozzle. 


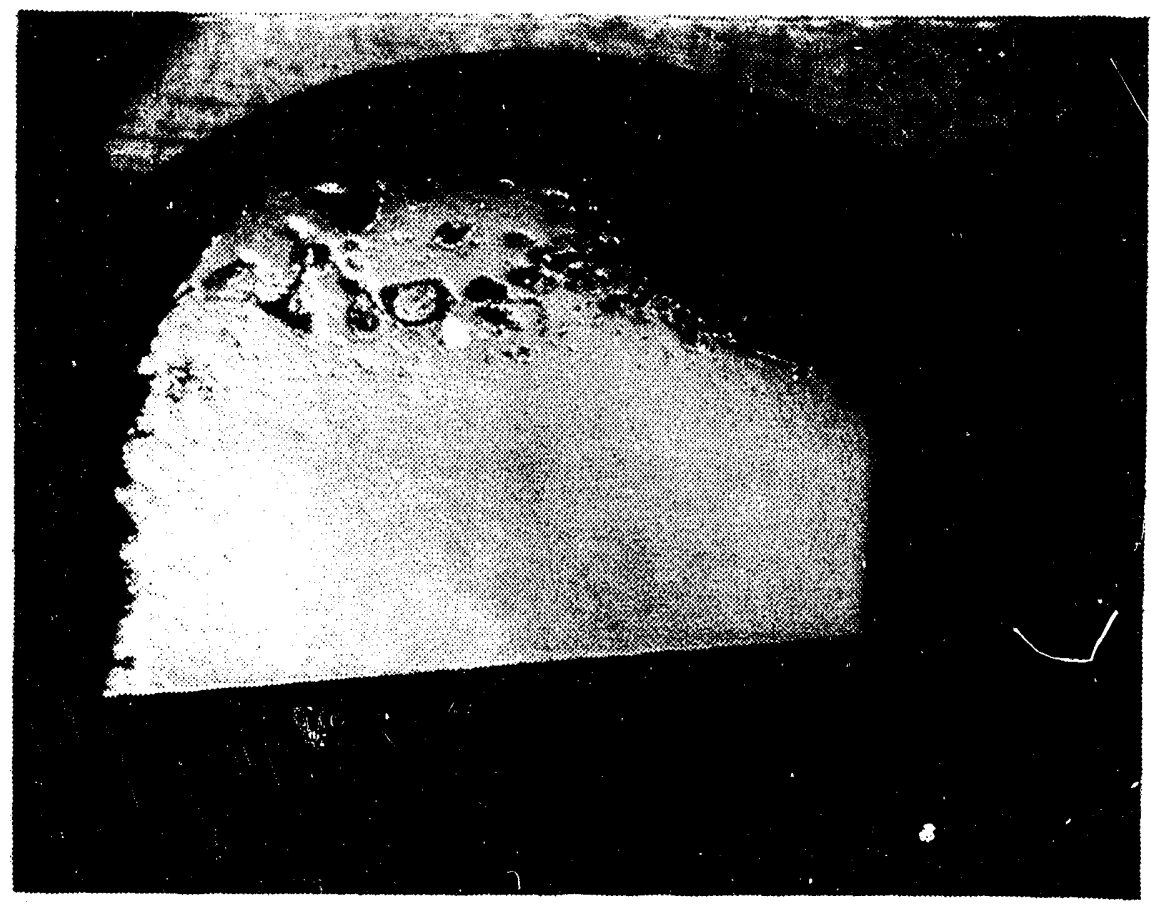

Figure C-29. Metallographic sample E-7-1, showing the side face.

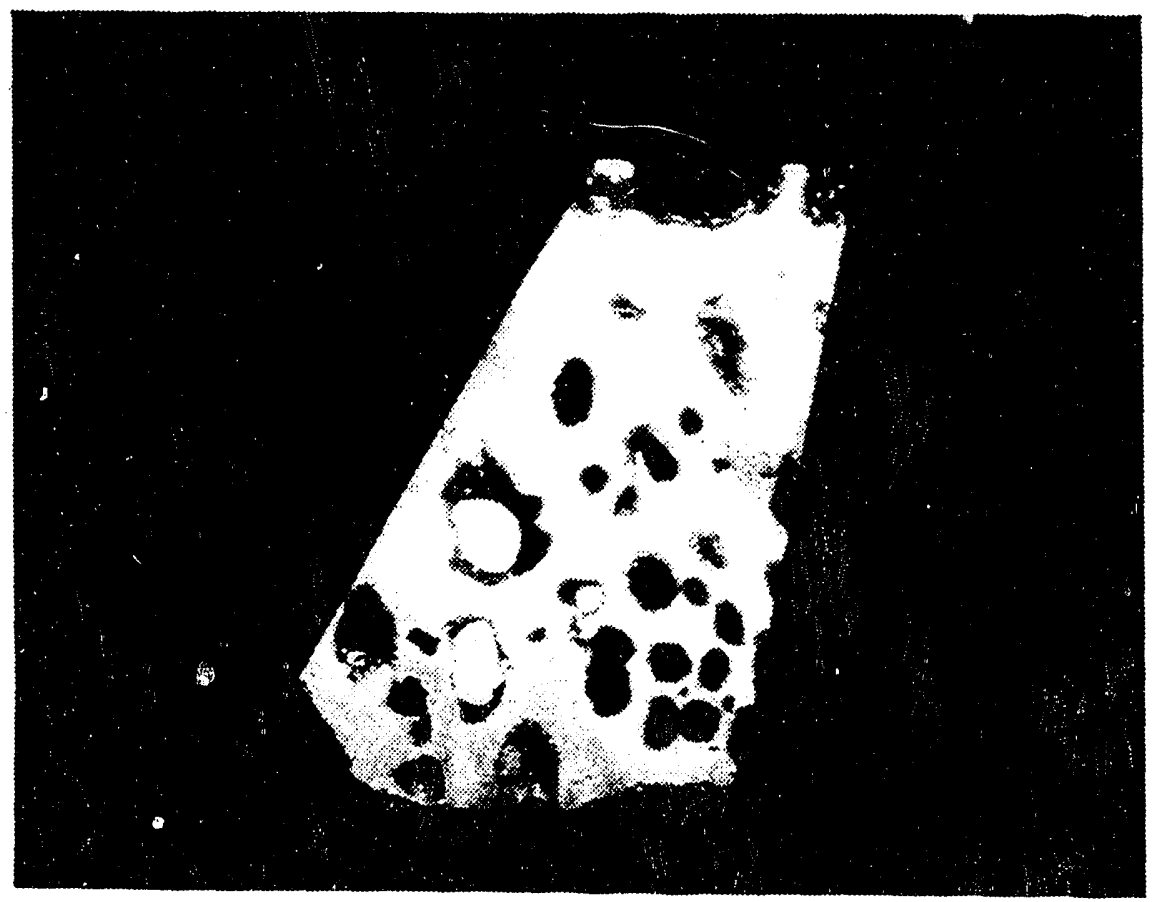

Figure C-30. Metallographic sample E-7-2, featuring the top surface. 


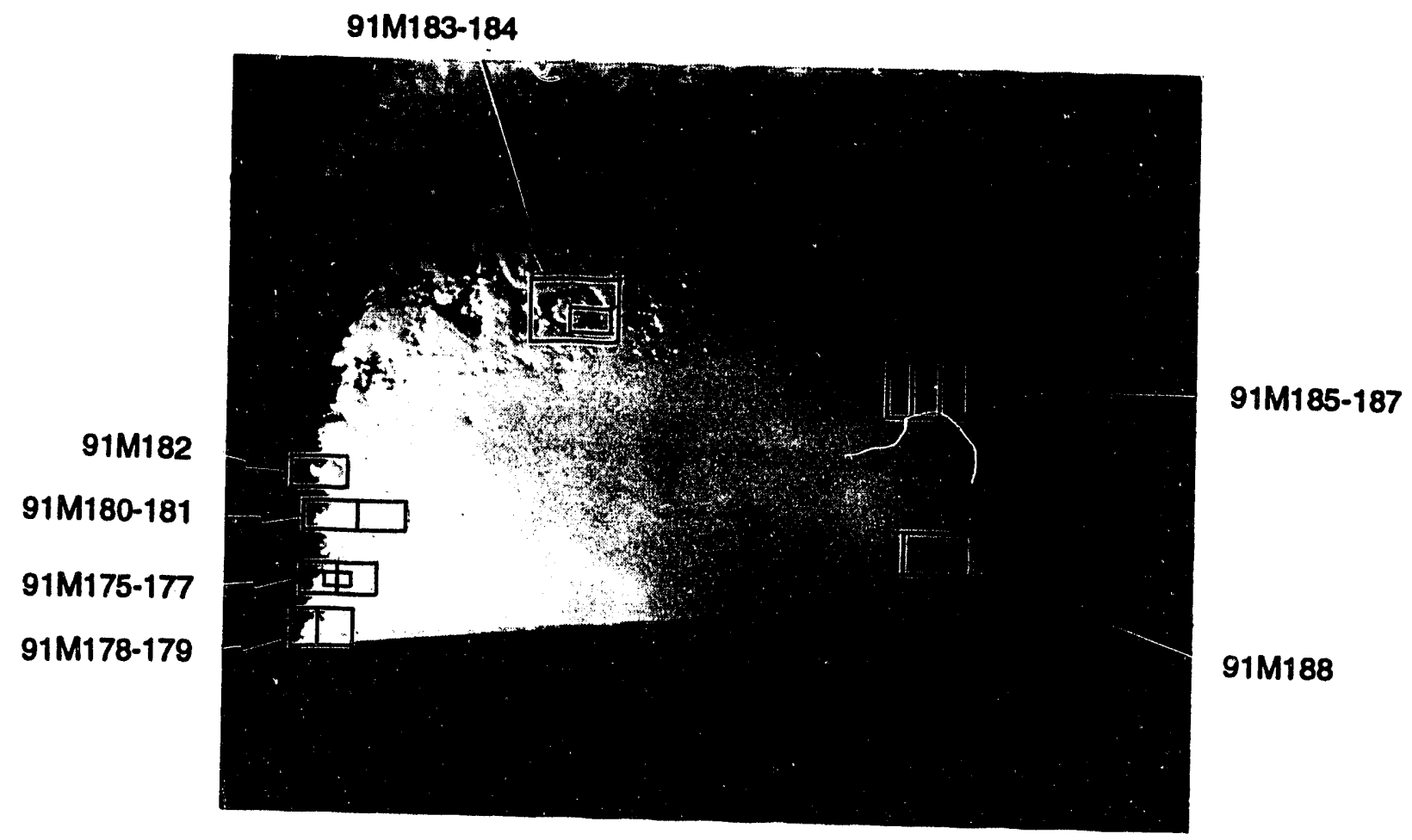

Figure C-31. Metallographic examination map showing ROIs of sample E-7-1. 


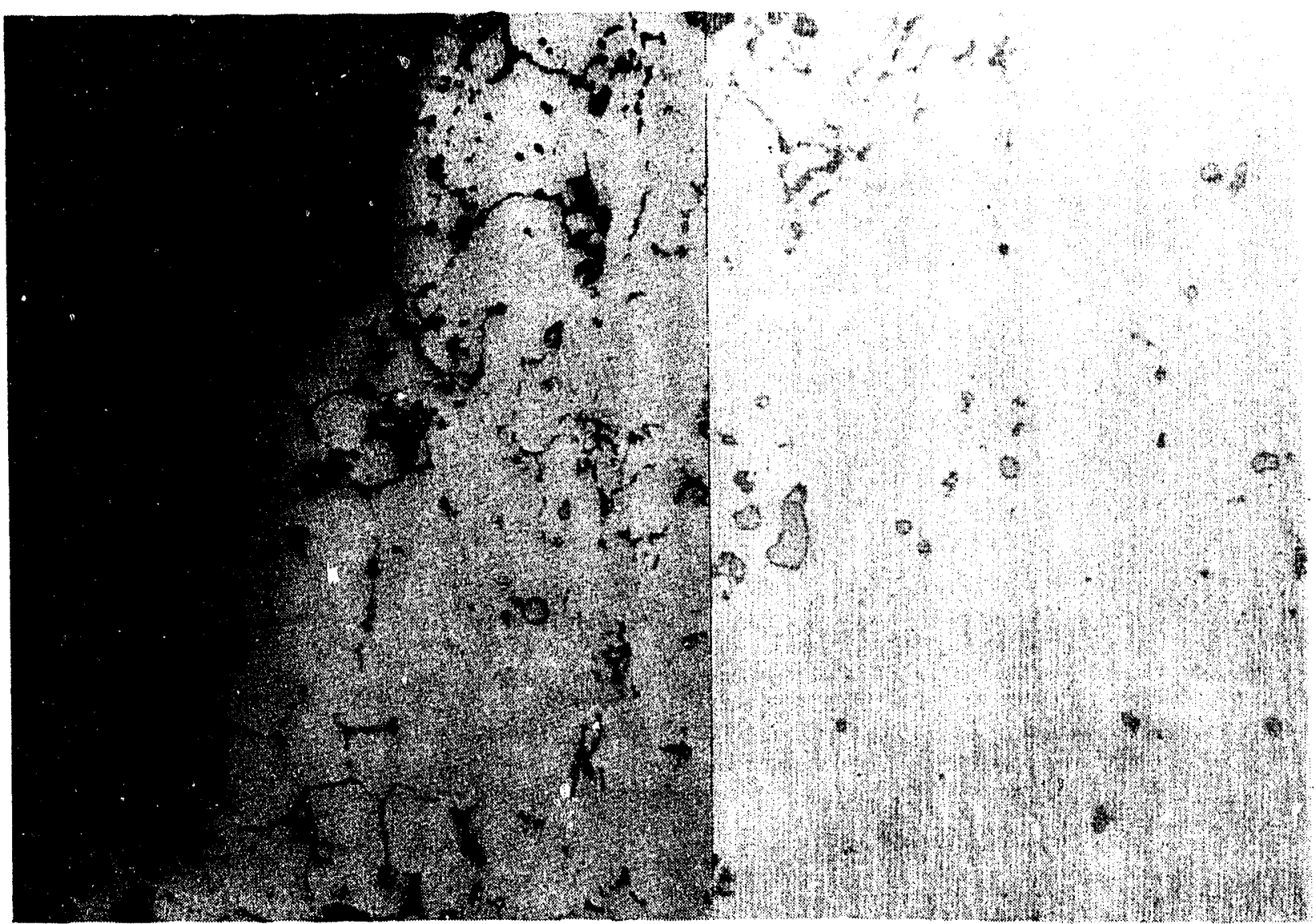

Figure C-32. ROIs 91M175 and 91M176, showing possible cracking (two-photo composite).

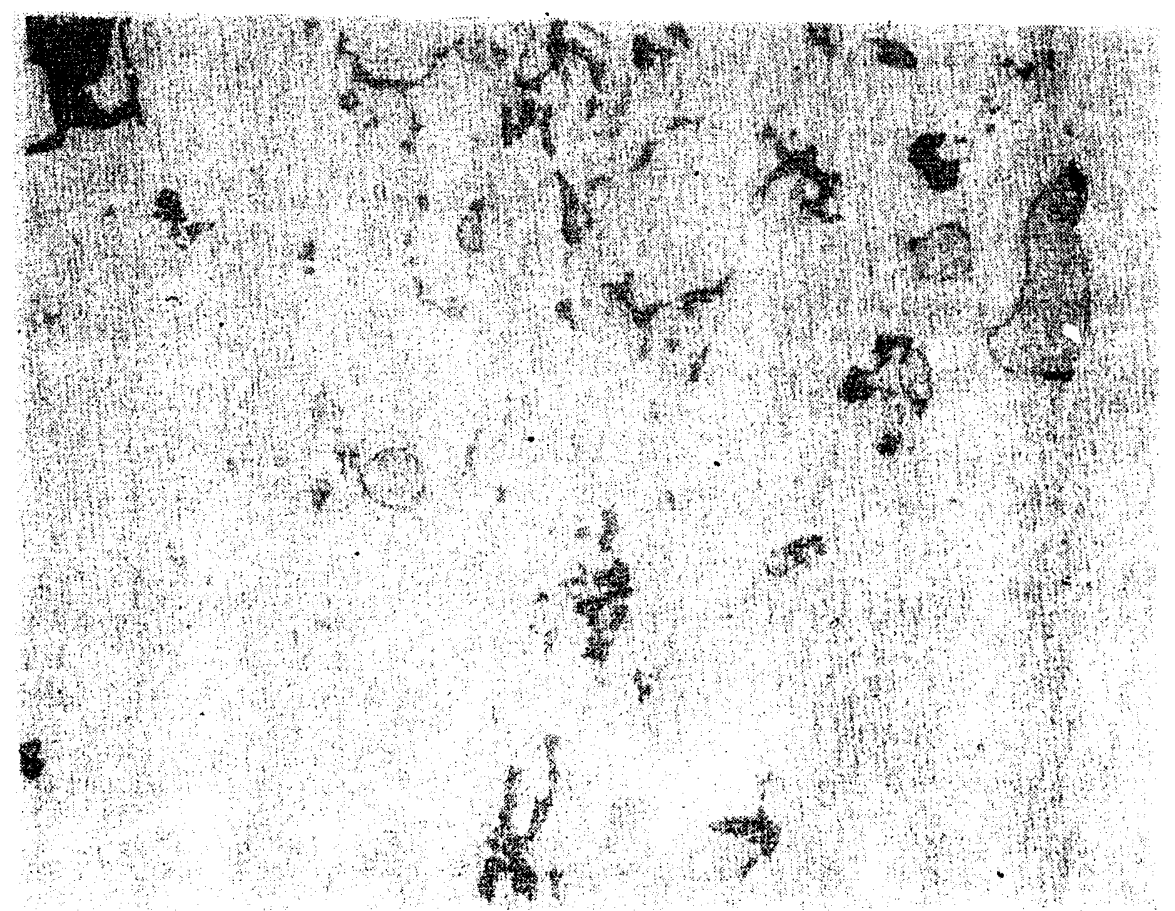

Figure C-33. ROI 91M177, showing higher magniīication (200x) view of possible cracking. 


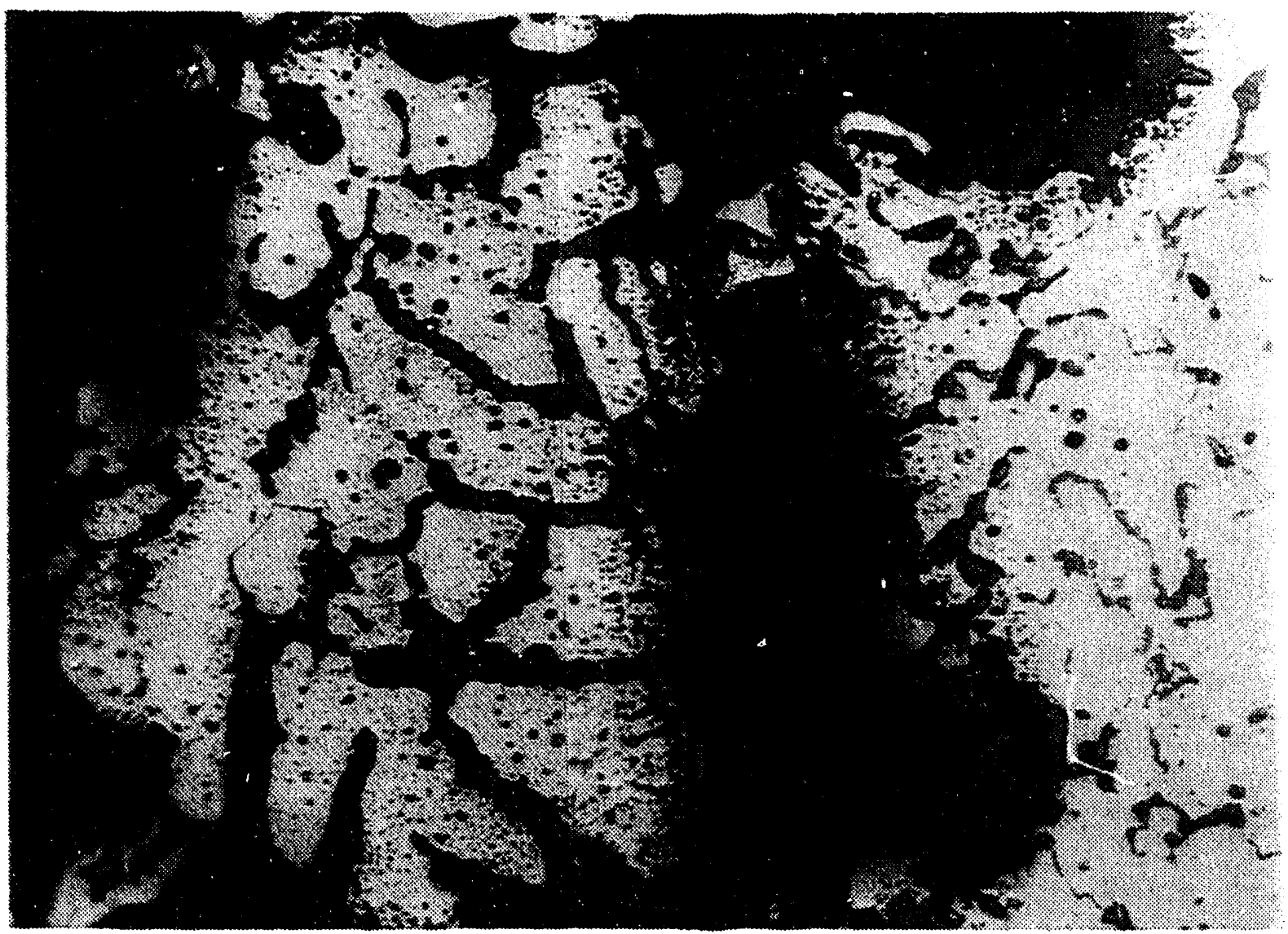

Figure C-34. ROIs $91 \mathrm{M} 178$ and 91M179, exhibiting fuel melt interaction (two-photo composite).

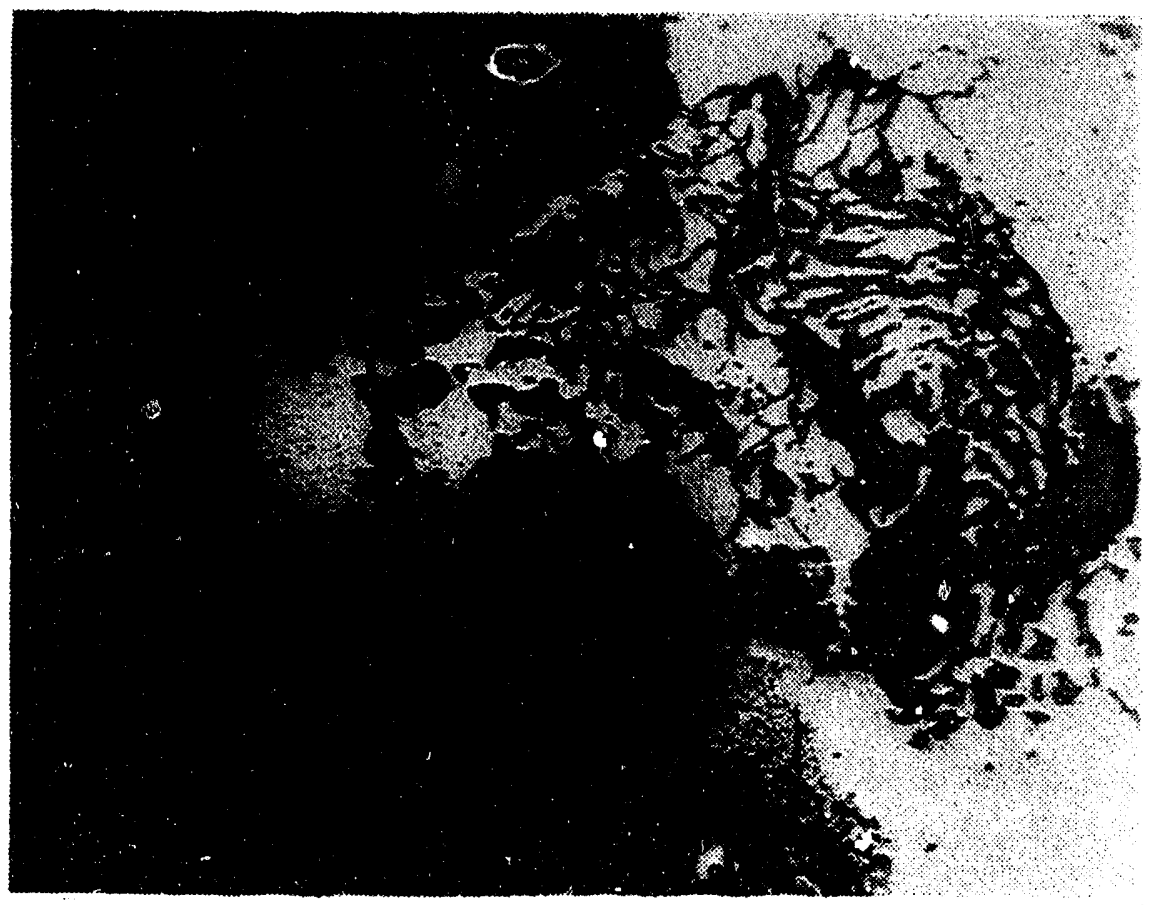

Figure C-35. ROI 91M182, showing indication of fluid melt interaction. 


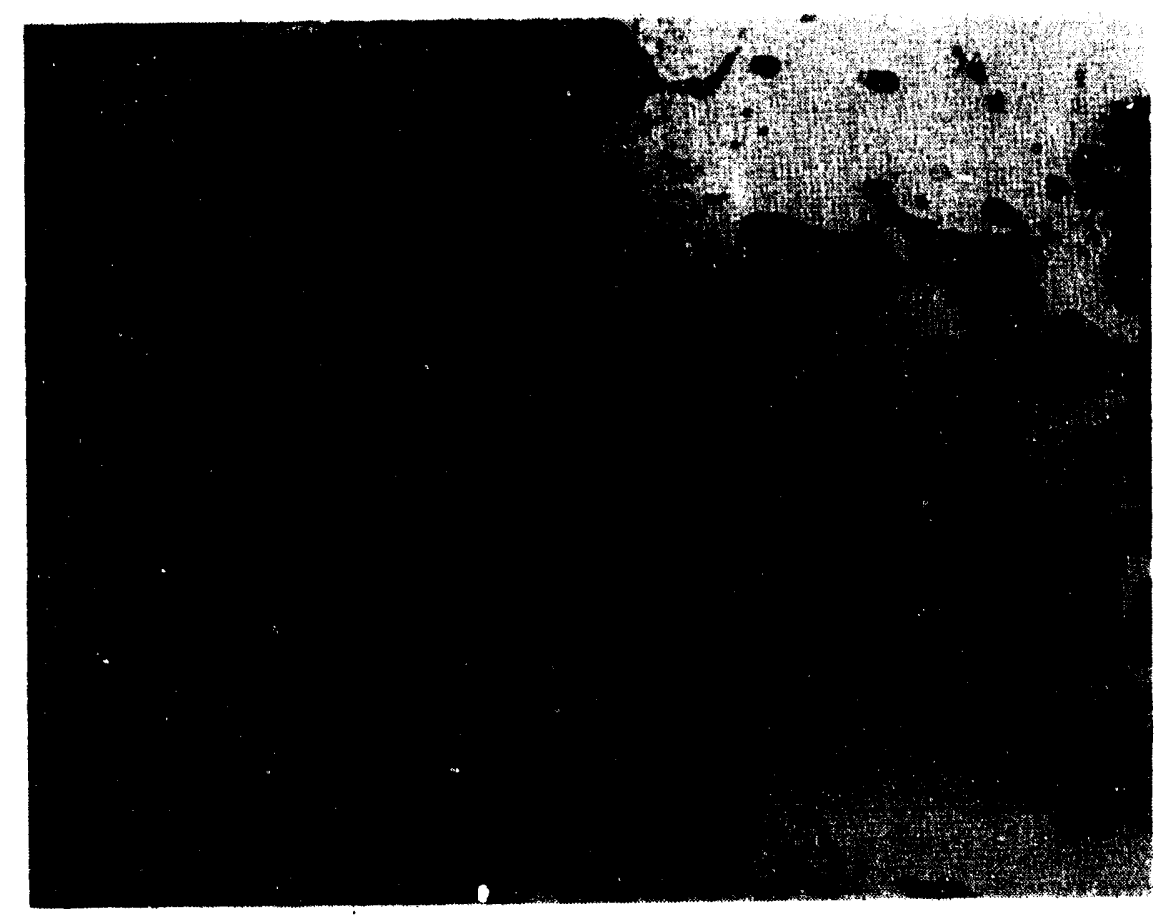

Flgure C-36a. ROI 91M180, exhibiting interspersed fuel (view \#1 of a two-photo composite).

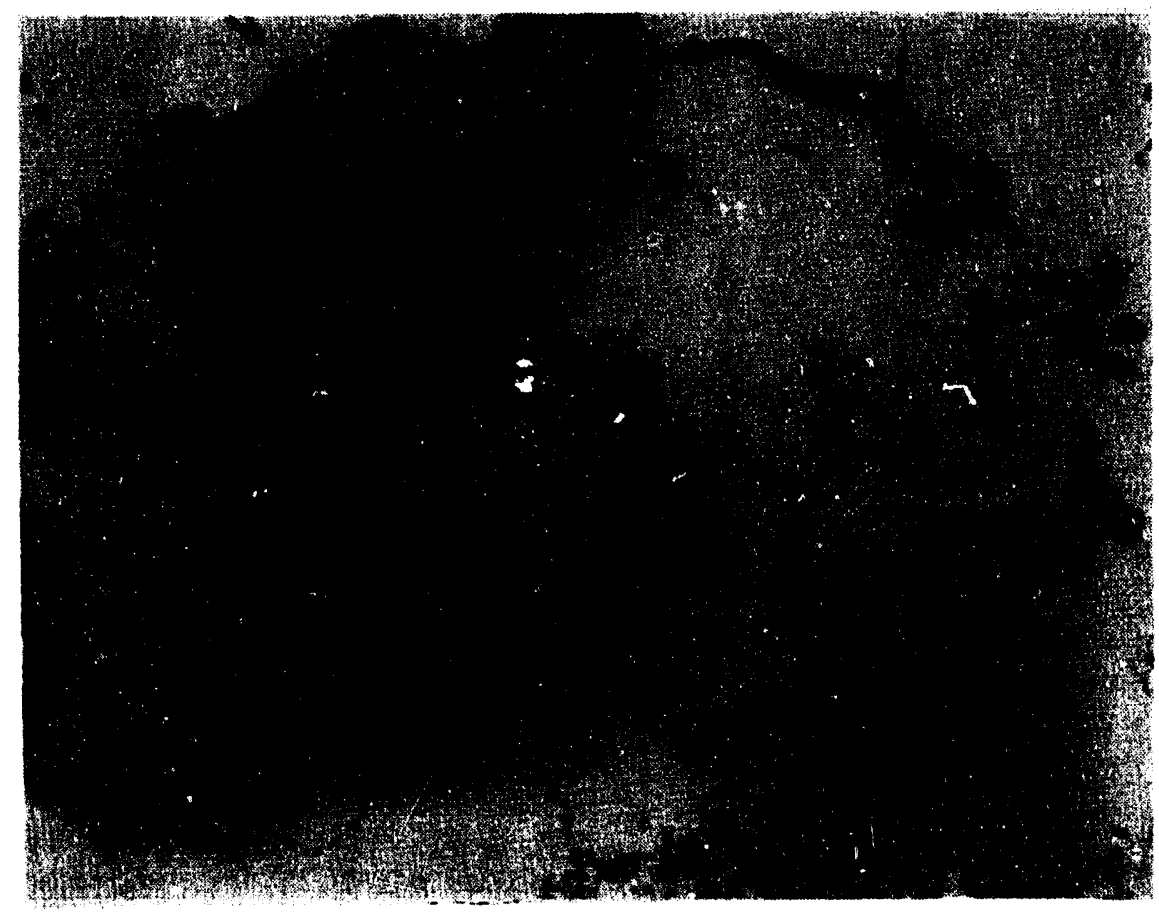

Figure C-36b. ROI 91M181, exhibiting interspersed fuel (view \#2 of a two-photo composite). 


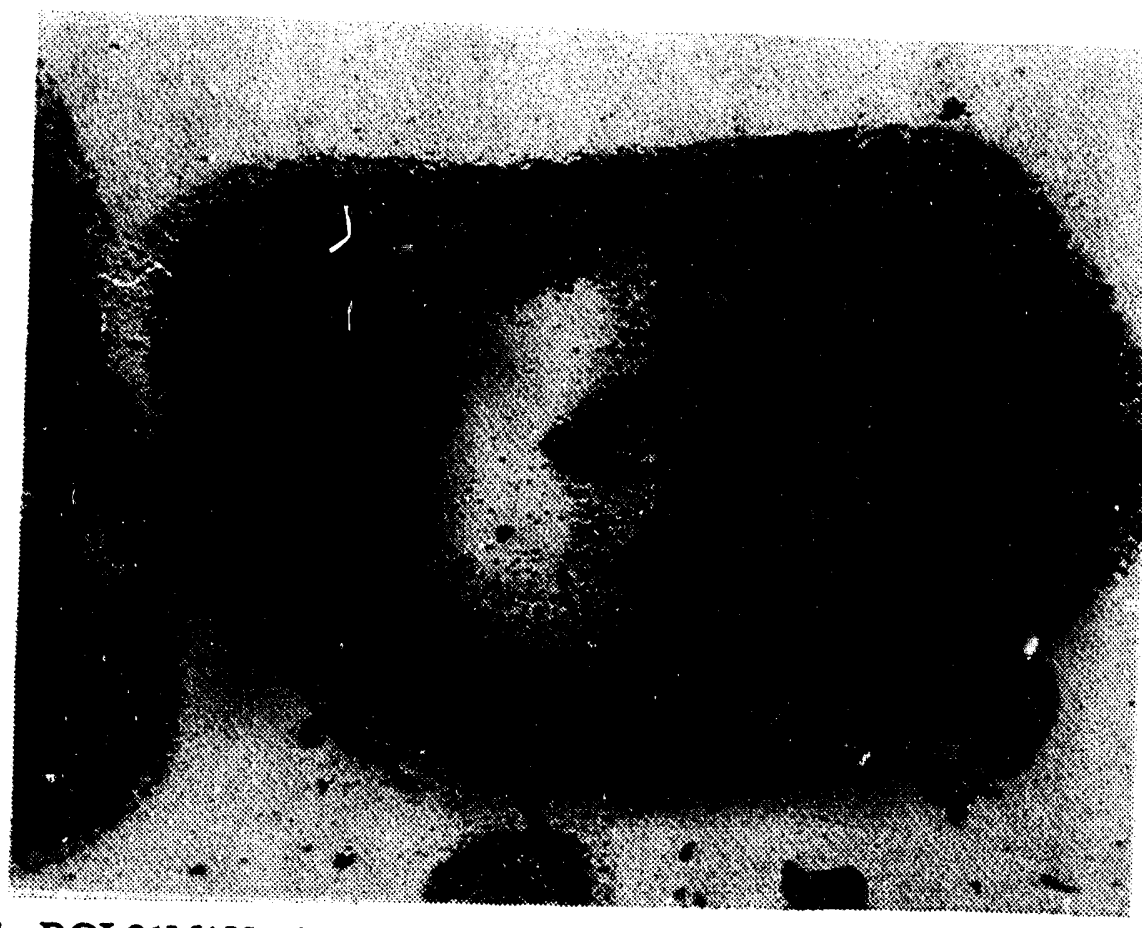

Figure C-37. ROI 91M183, showing macro view of spheroid material in hole.

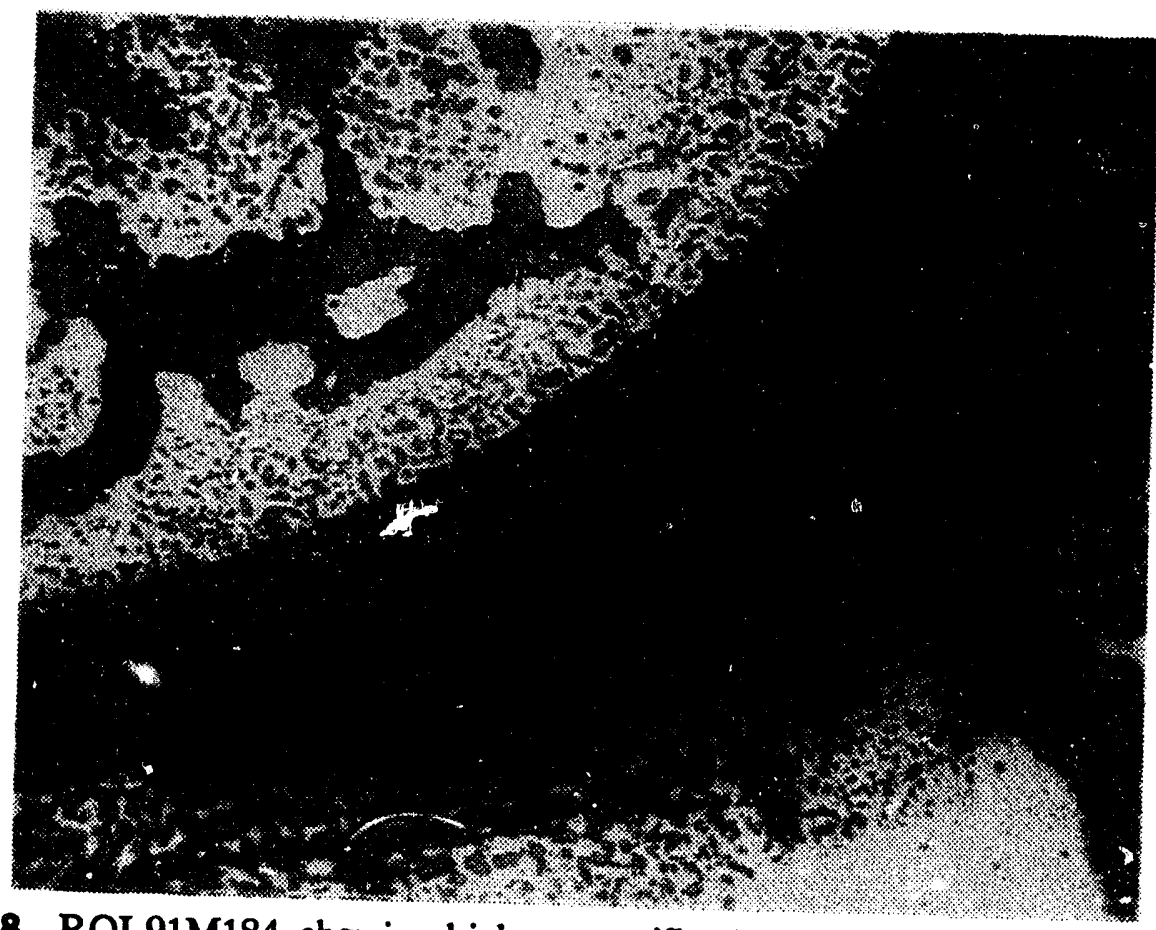

Figure C-38. ROI 91M184, showing higher magnification (200x) of hole. 


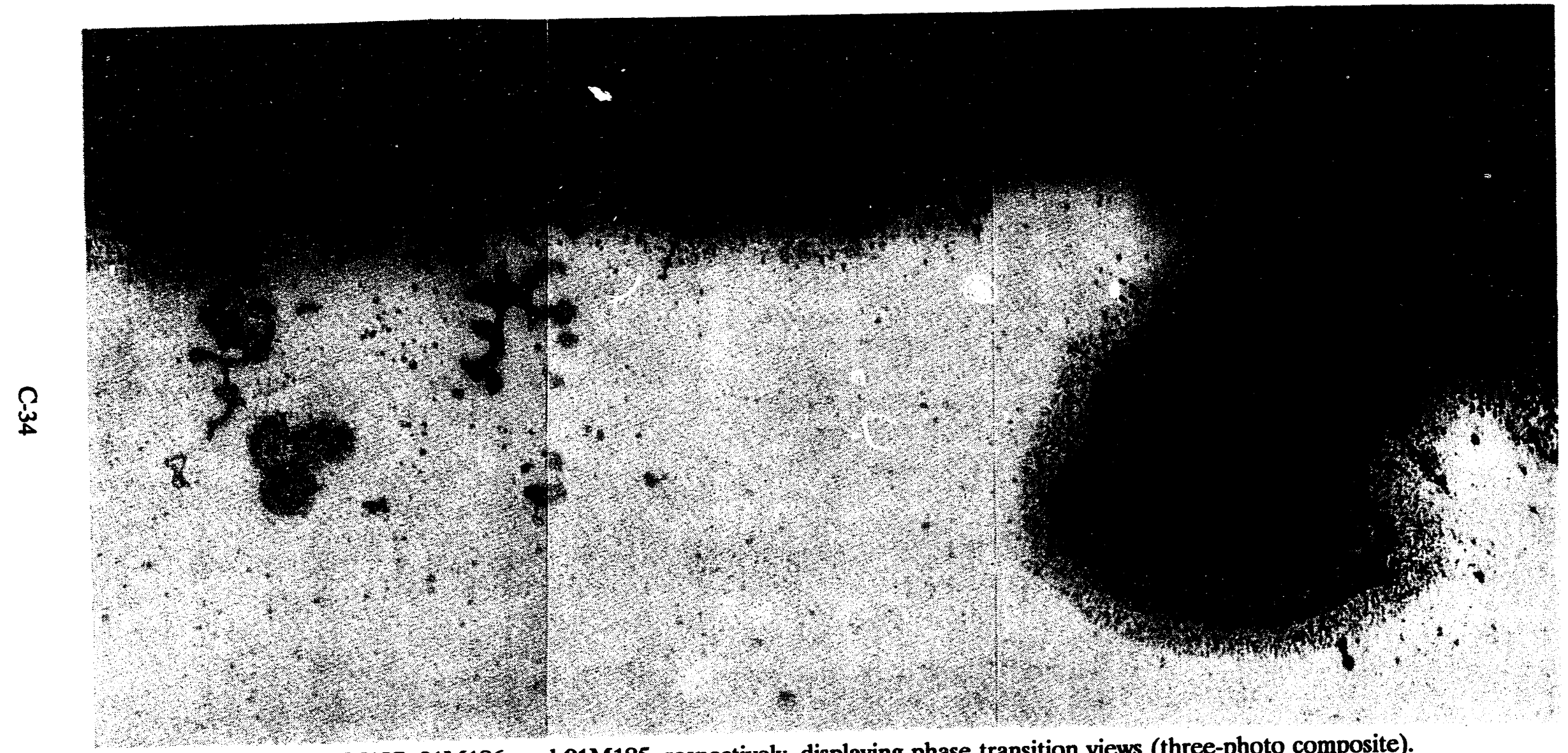

Figure C-39. ROIs 91M187, 91M186, and 91M185, respectively, displaying phase transition views (three-photo composite). 


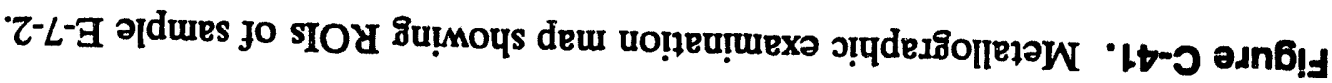

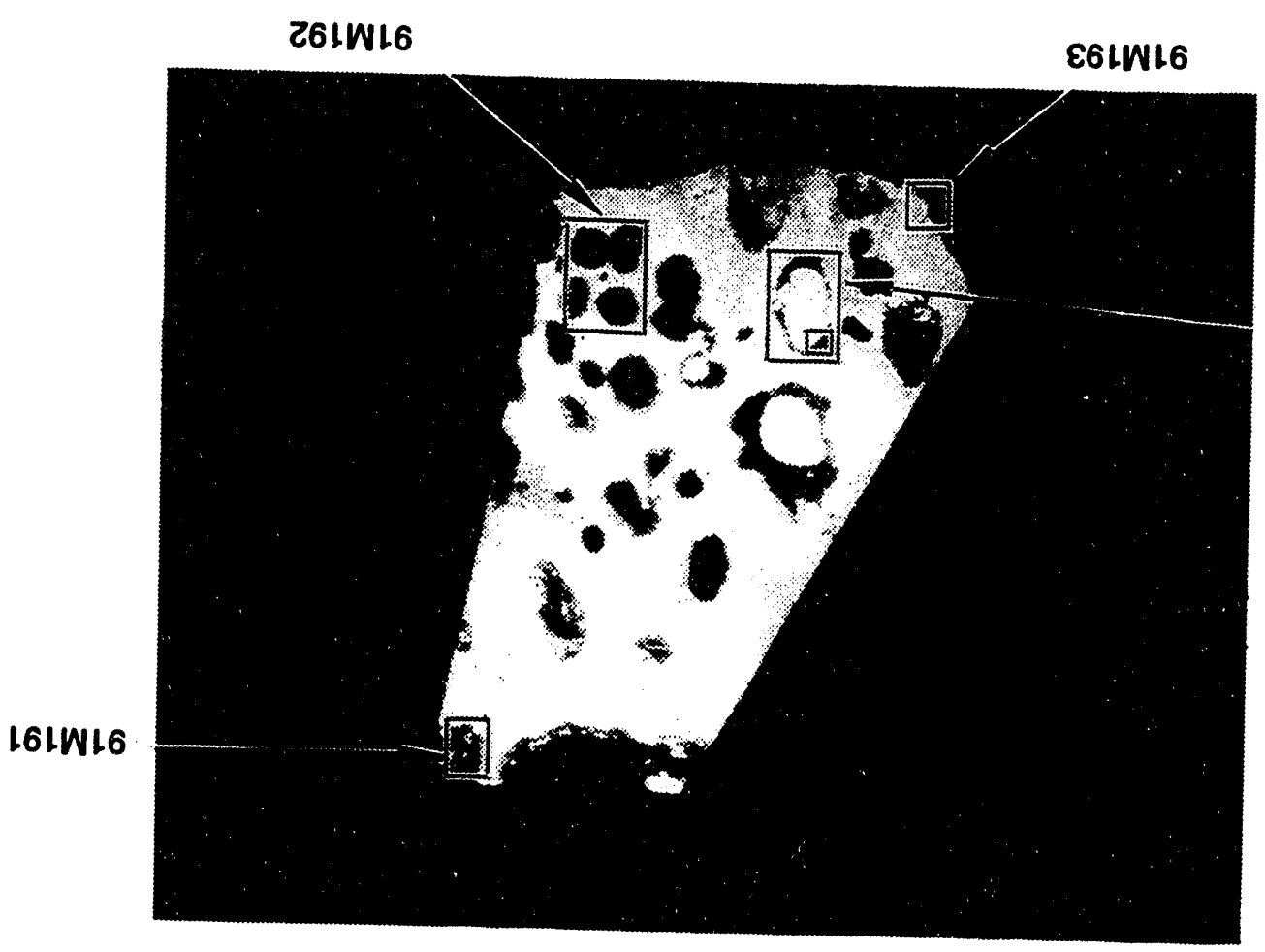

06L-68LWL6

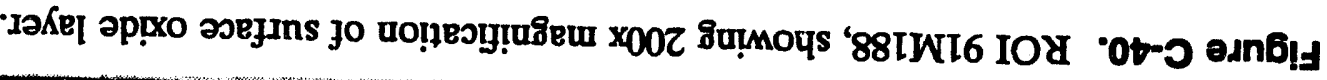

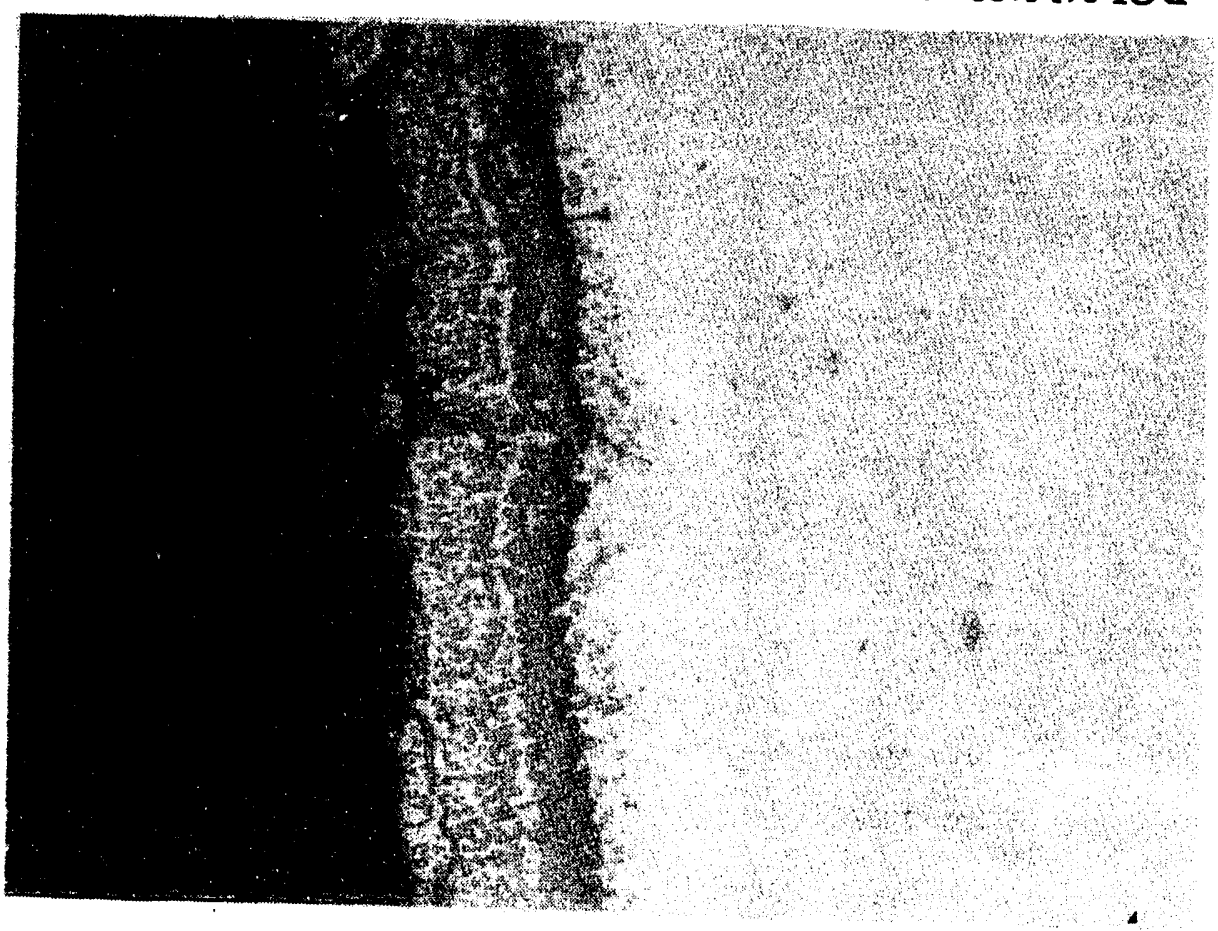




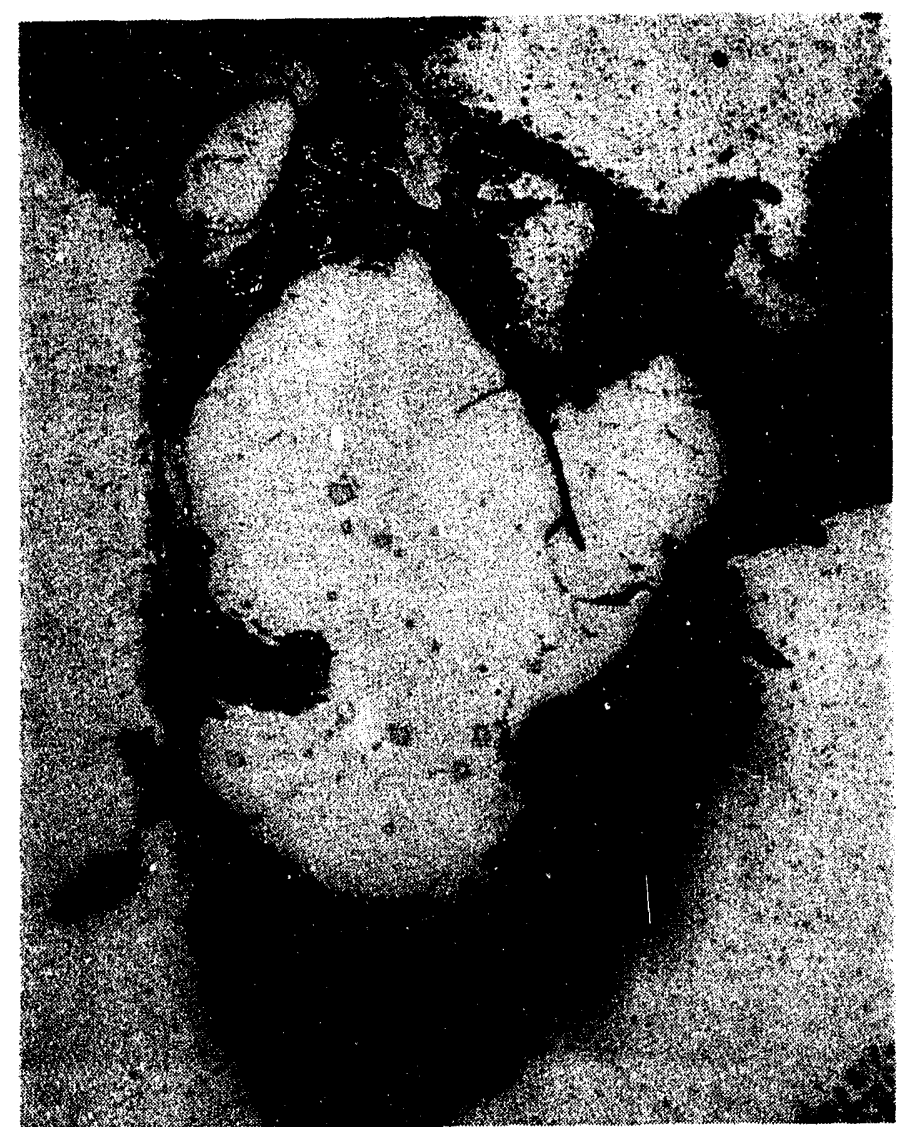

Figure C-42. ROI 91M189, showing pore material at 50x.

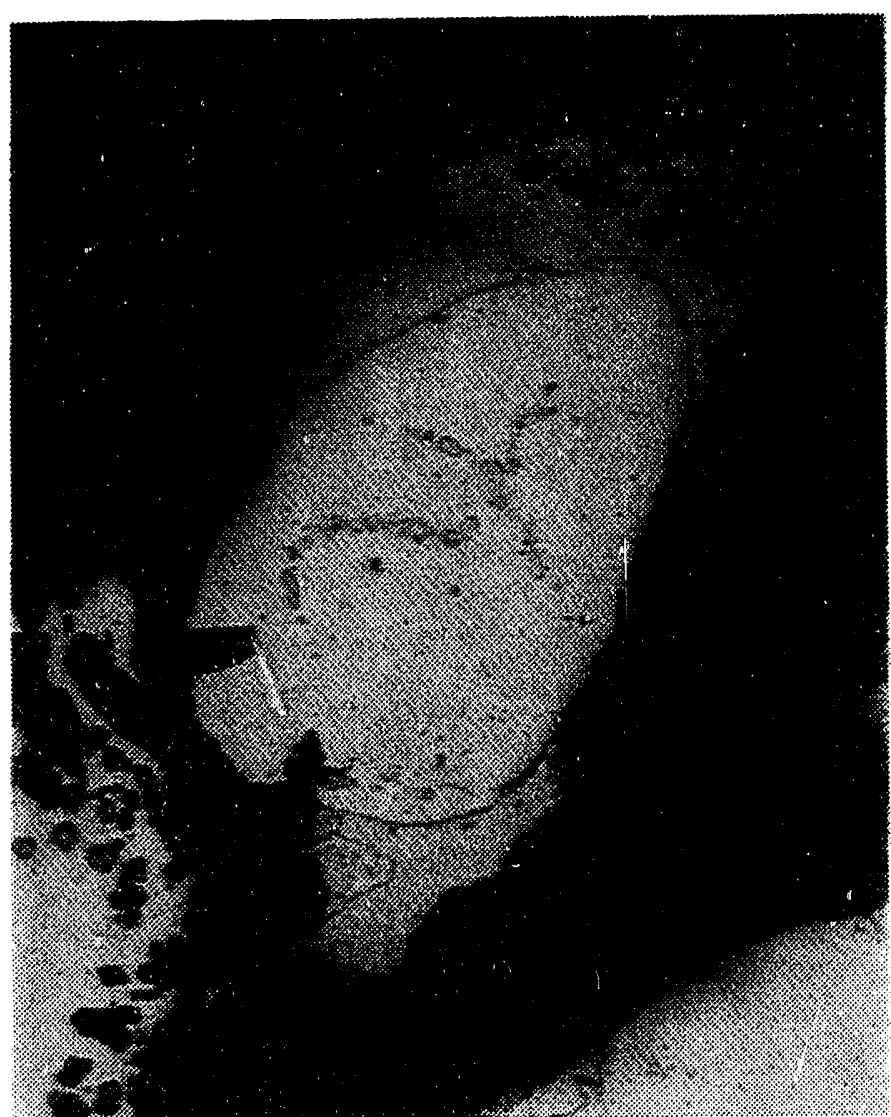

Figure C-43. ROI 91M190, showing higher magnification of top-left corner of Figure C-42. 


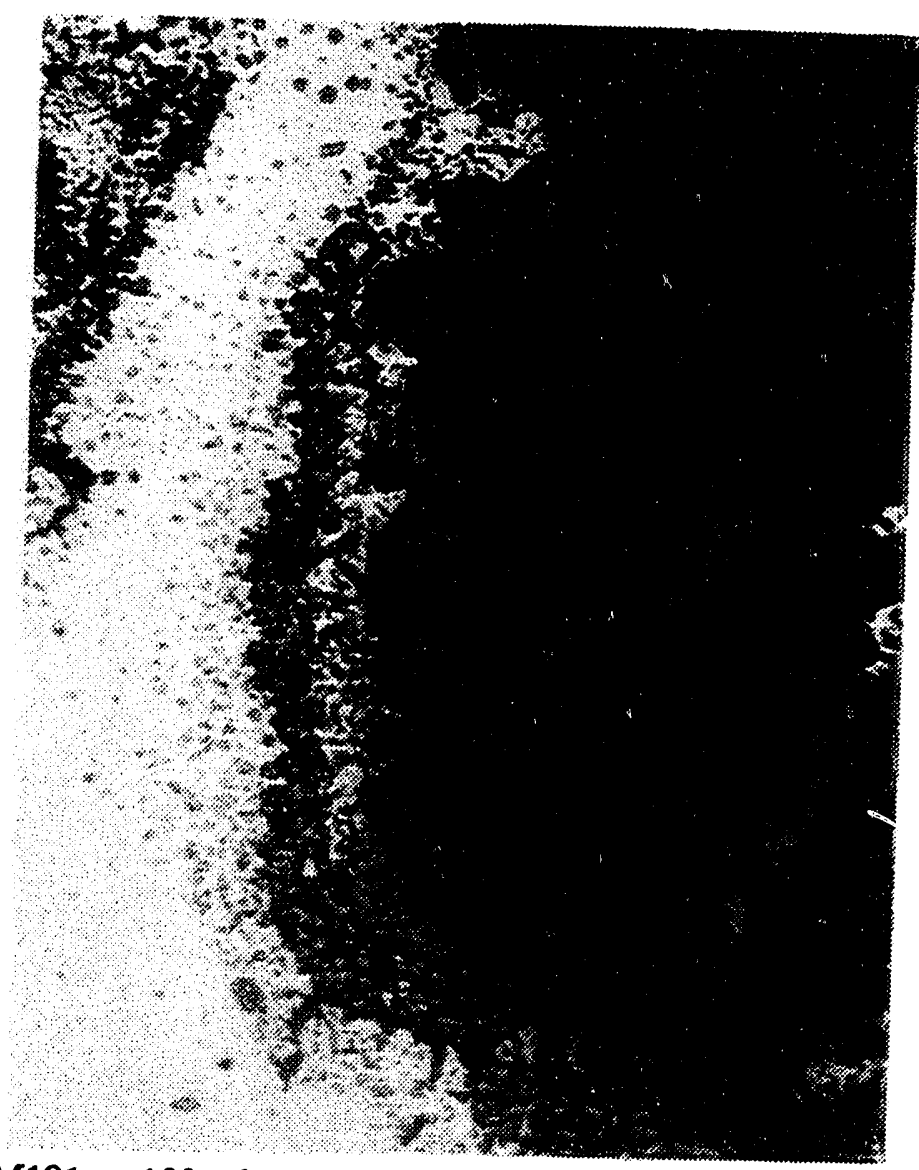

Figure C-44. ROI 91M191 at 100x showing phase interface.

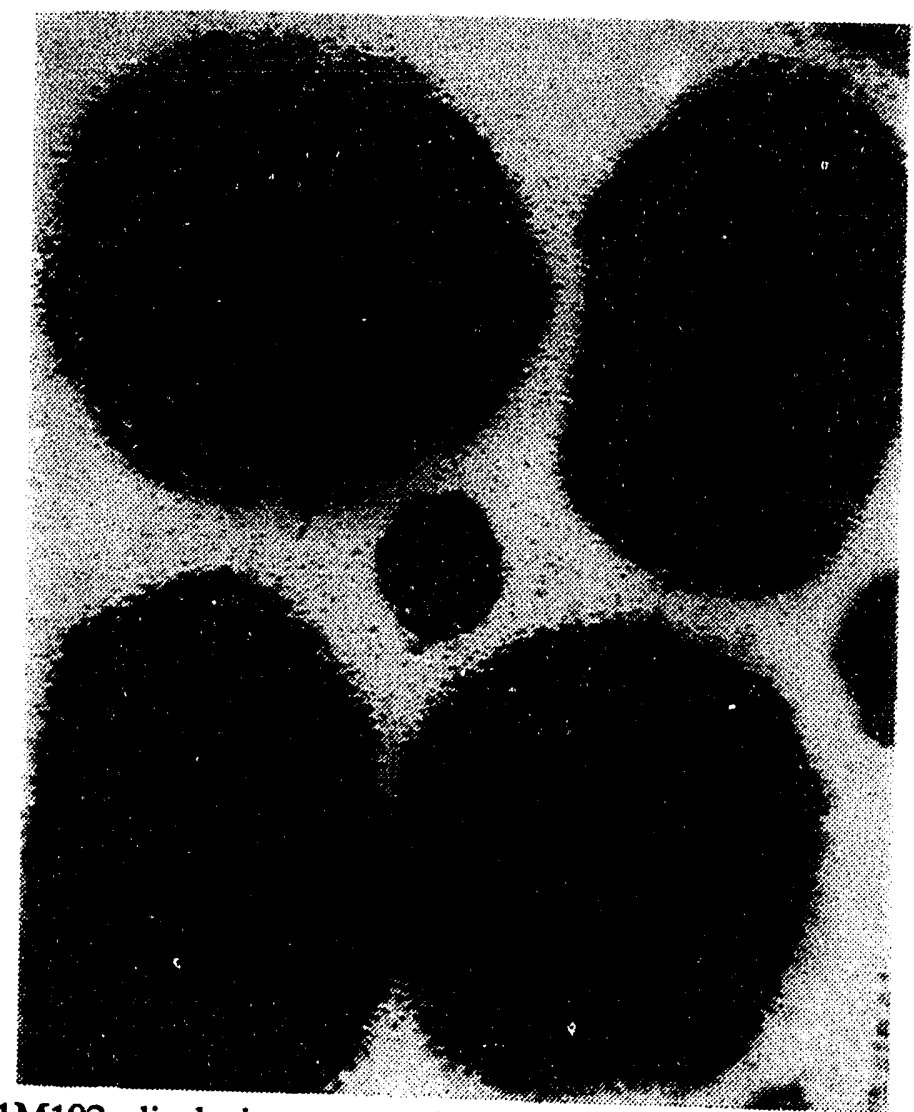

Figure C-45. ROI 91M192, displaying macro view of typical sample porosity. 


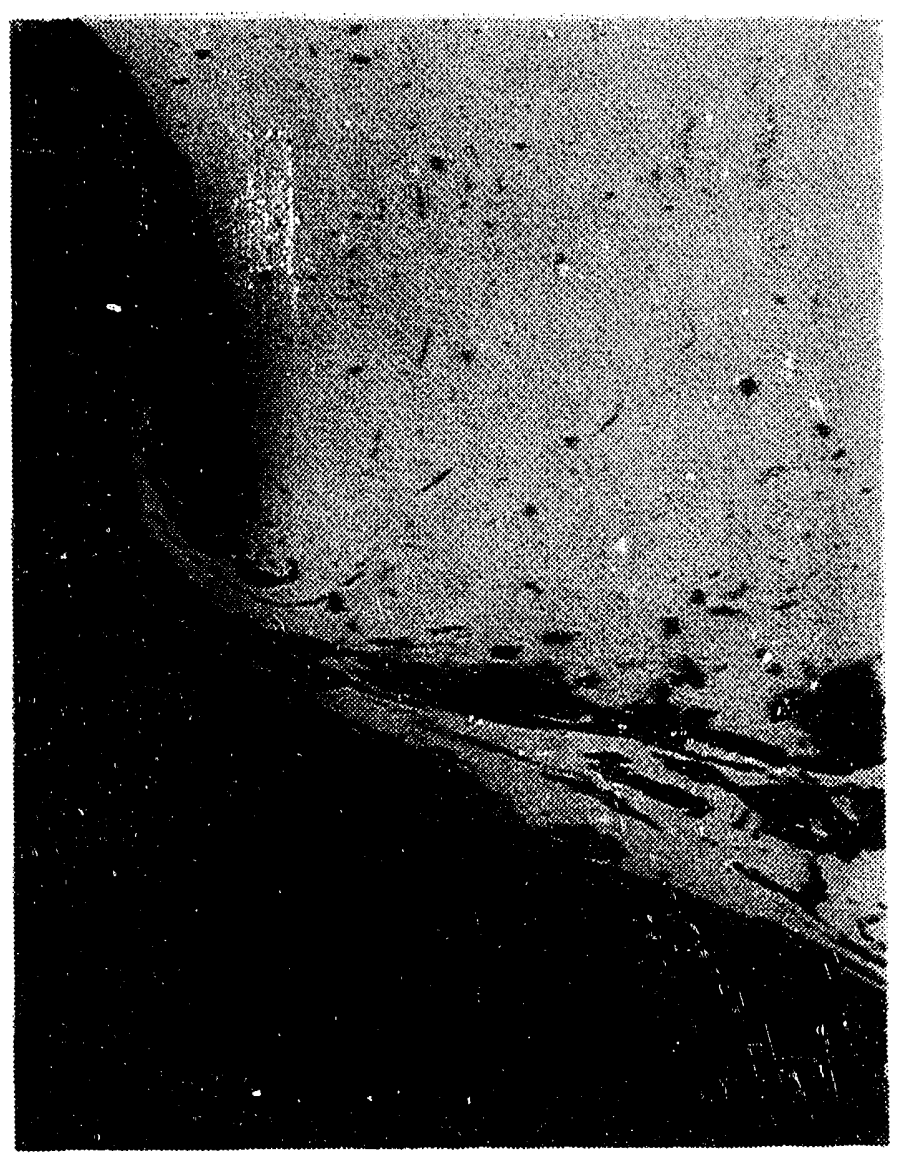

Figure C-46. ROI 91M193 at 200x, showing distinctive interface. 


\section{Appendix D}

\section{SEM and WDX Examination Results}




\section{Appendix D}

\section{SEM and WDX Examination Results}

Samples of surface debris were removed from several nozzles (i.e., M-10, E-7, R-7, and G-5) and were examined using SEM and WDX techniques. Only representative results from the R-7 and E-7 samples are shown. Figure D-1 shows a cross section of the bulb removed from R-7, and Figure D-2 shows a backscattered electron (BSE) image of the same surface. As indicated in the BSE image, there are two primary phases present: a uranium phase (the light colored region), which is adjacent to the instrument string (the darker material). Figure D-3 is an expanded view of the interface between the fuel and the structural material, and D-4 is the BSE image of the interface. Examination of the $U$ dot map (Figure D-5) indicates that the high $Z$ (atomic number) phase on the right is primarily a $(\mathrm{U}, \mathrm{Zr}) \mathrm{O}_{2}$ matrix. In contrast, Figure $\mathrm{D}-6$ shows that $\mathrm{Zr}$ is evenly distributed throughout the matrix in both phases and suggests that the $U$ and $\mathrm{Zr}$ did not relocate as $(\mathrm{U}, \mathrm{Zr}) \mathrm{O}_{2}$ or that some phase separation has occurred. Figures D-7 through D-9 show the dot maps for $\mathrm{Cr}, \mathrm{Mn}$, and $\mathrm{Fe}$, respectively. These dot maps suggest that the $\mathrm{Cr}$ was concentrated in the $\mathrm{Zr}$ phase and that iron oxides were present in both the $\mathrm{Zr}$ and $\mathrm{U}$ phases.

In contrast to the apparent composition discussed in the previous paragraph, a second location of R-7 is shown in Figure D-10. This is a magnified view of the bottom edge of Figure D-1 and shows the area around an instrument string. Figure D-11 shows the BSE image and indicates the presence of fuel material around the outer edge of the instrument string. Figures D-12 through D-16 indicate that this phase is composed of $\mathrm{U}, \mathrm{Fe}, \mathrm{Cr}, \mathrm{Mn}$, and Ni. However, as shown in Figure D-17, there is little or no apparent $\mathrm{Zr}$ present. These dot maps suggest that uranium phases are being formed with elements other than $\mathrm{Zr}$ and that, consequently, some low temperature eutectics are being formed.

Figure D-18 shows a BSE compositional image of a pore in sample E-7, as shown in Figures C-29 and C-30 in Appendix C. The BSE image indicates the presence of high Z material at the interface of the pore. Figures D-19 through D-20 show expanded views of the high Z material. Figure D-22 shows a Fe dot map, which indicates that these particles are Fe that has penetrated into the surface of E-7. In addition, Figure D-23 shows the presence of some Cd. The presence of $\mathrm{Cd}$ suggests that this material did not reach high temperatures or the highly volatile $\mathrm{Cd}$ would have been released from the melt. The dot map shown in Figure D-24 indicates that, in addition to the standard constituents of inconel, $\mathrm{Zr}$ was also present and had penetrated into the surface of sample E-7. Figure D-25 is a Cr dot map of sample E-7. 


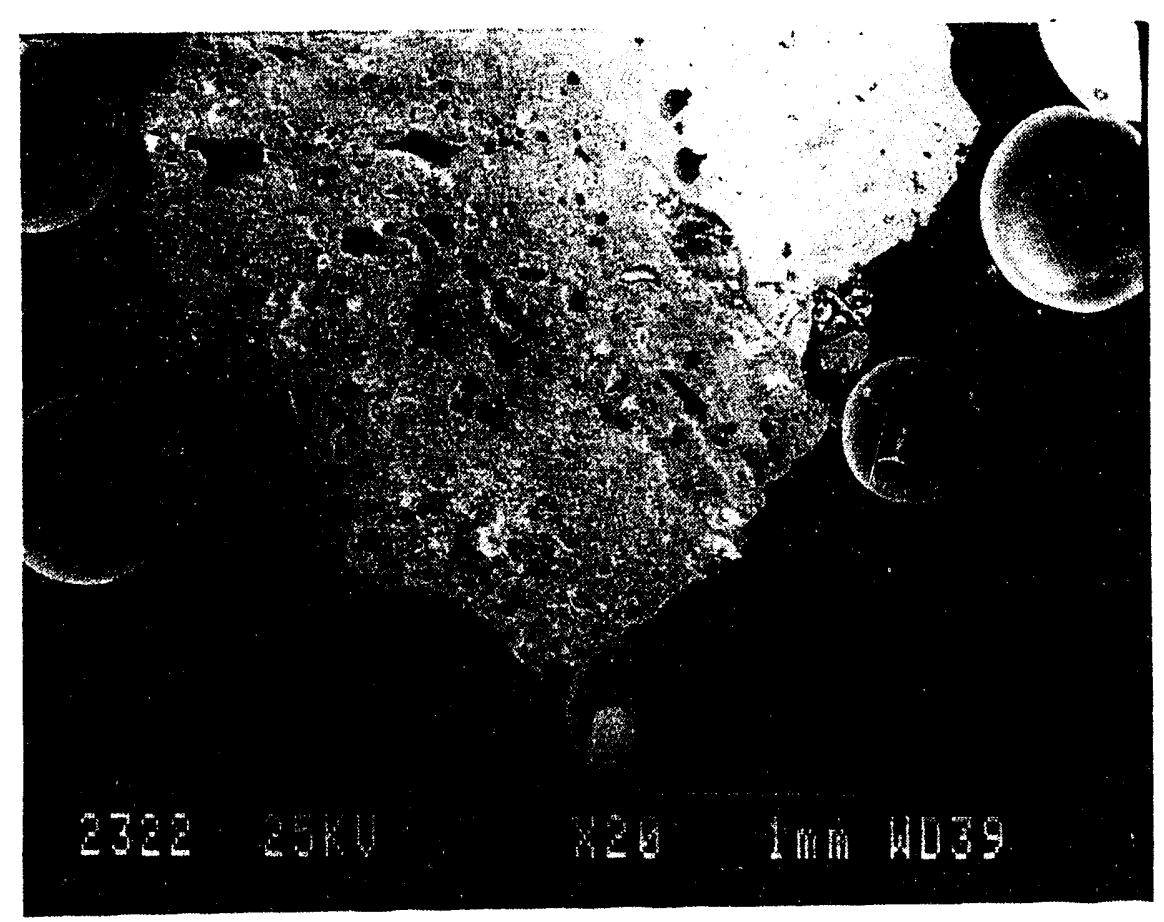

Figure D-1. R-7 Nozzle cross section at 1,000 micron.

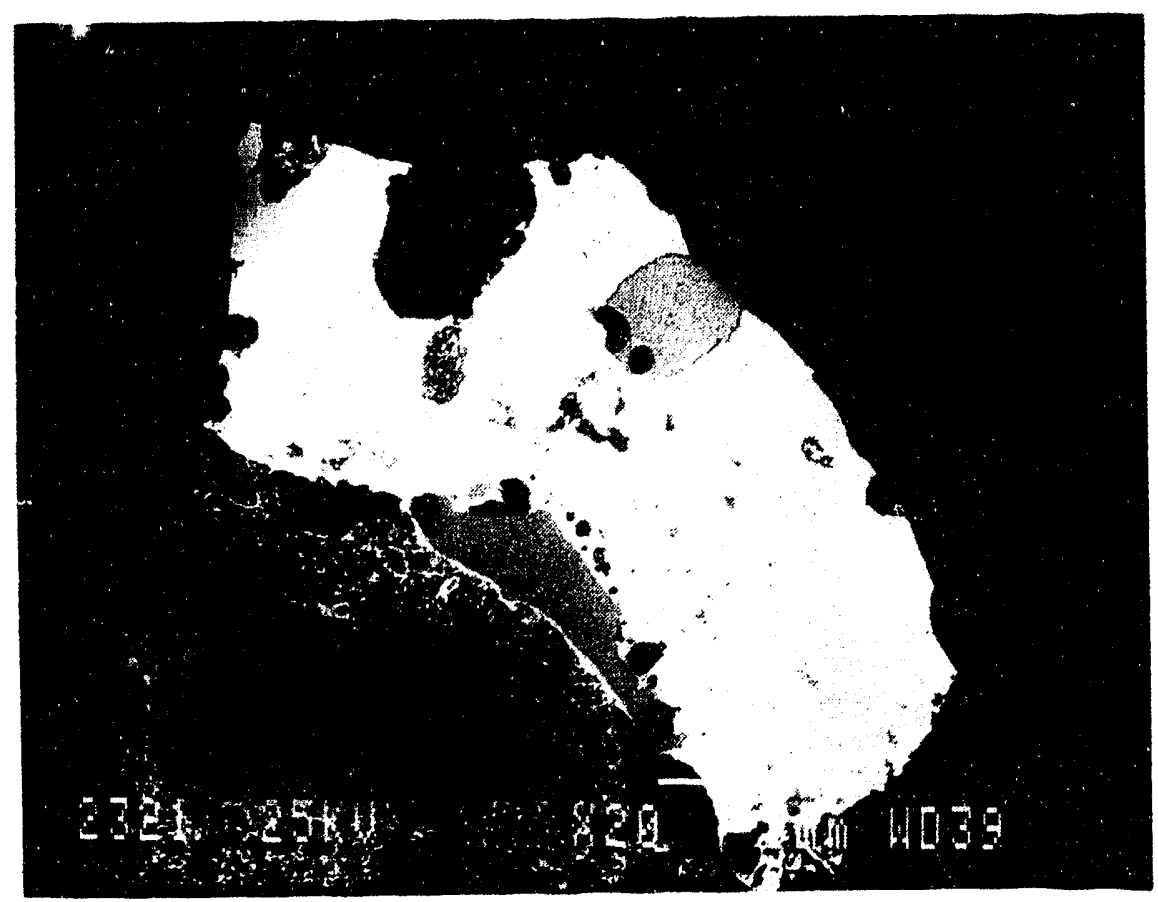

Figure D-2. BSE photograph of R-7. 


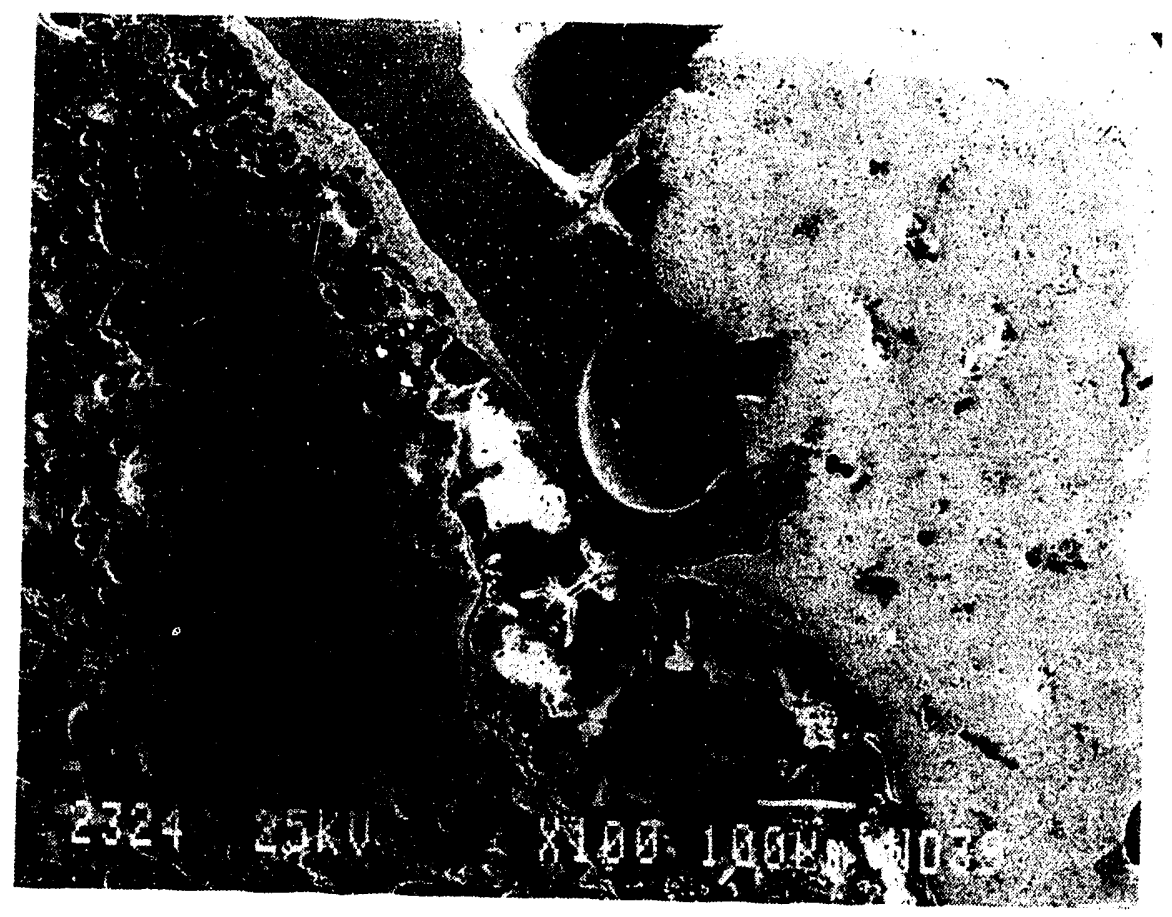

Figure D-3. R-7 Uranium and structural material interface (100x).

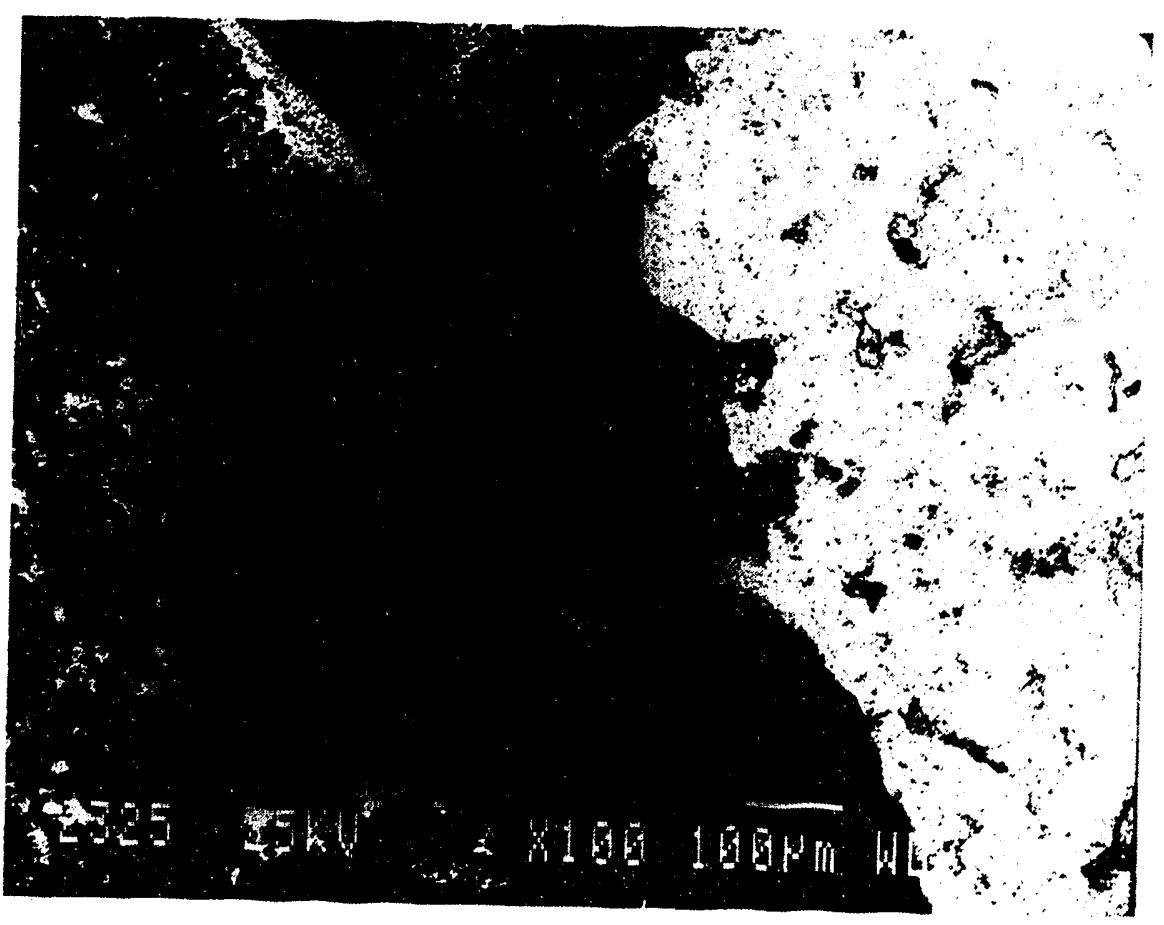

Figure D-4. Compositional photo of $U$ and structural material interface $(100 x)$. 


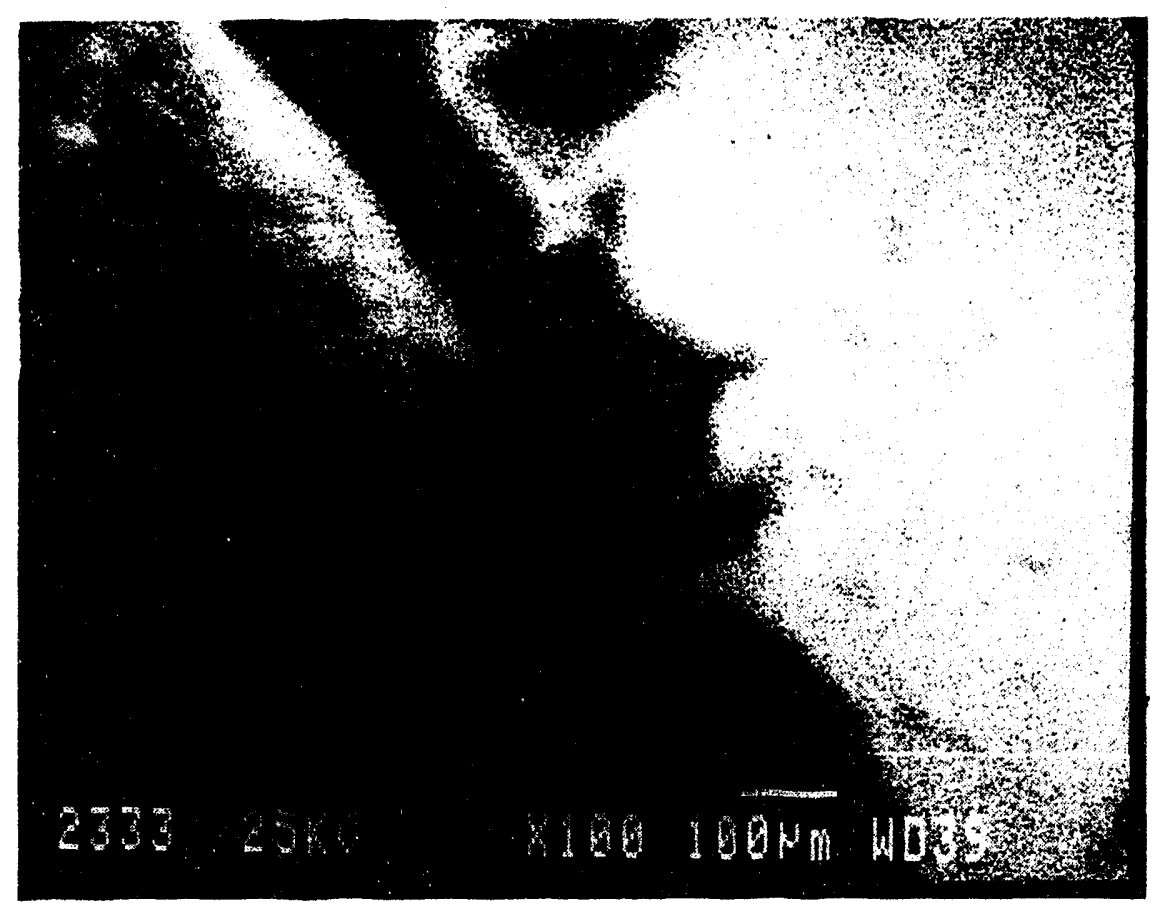

Figure D-5. R-7 dot map of U.

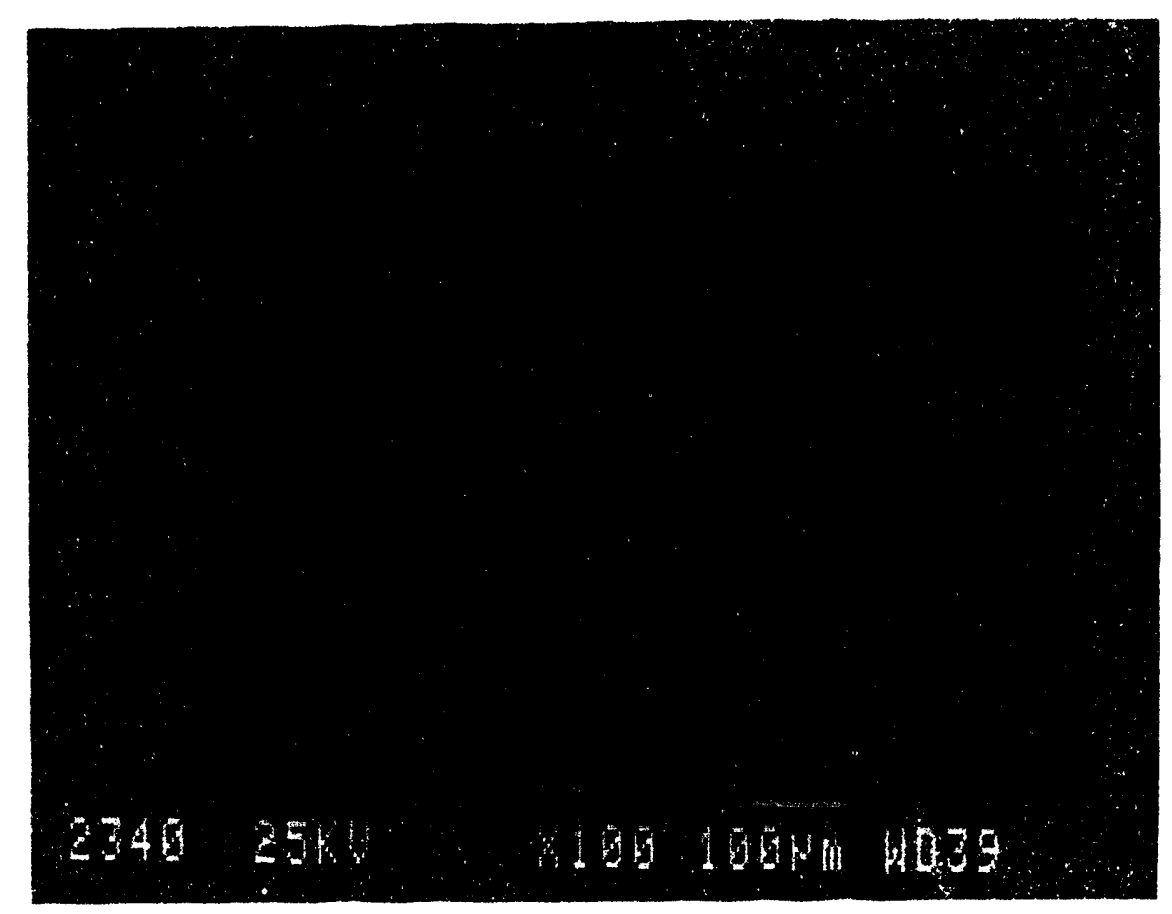

Figure D-6. R-7 dot map of Zr. 


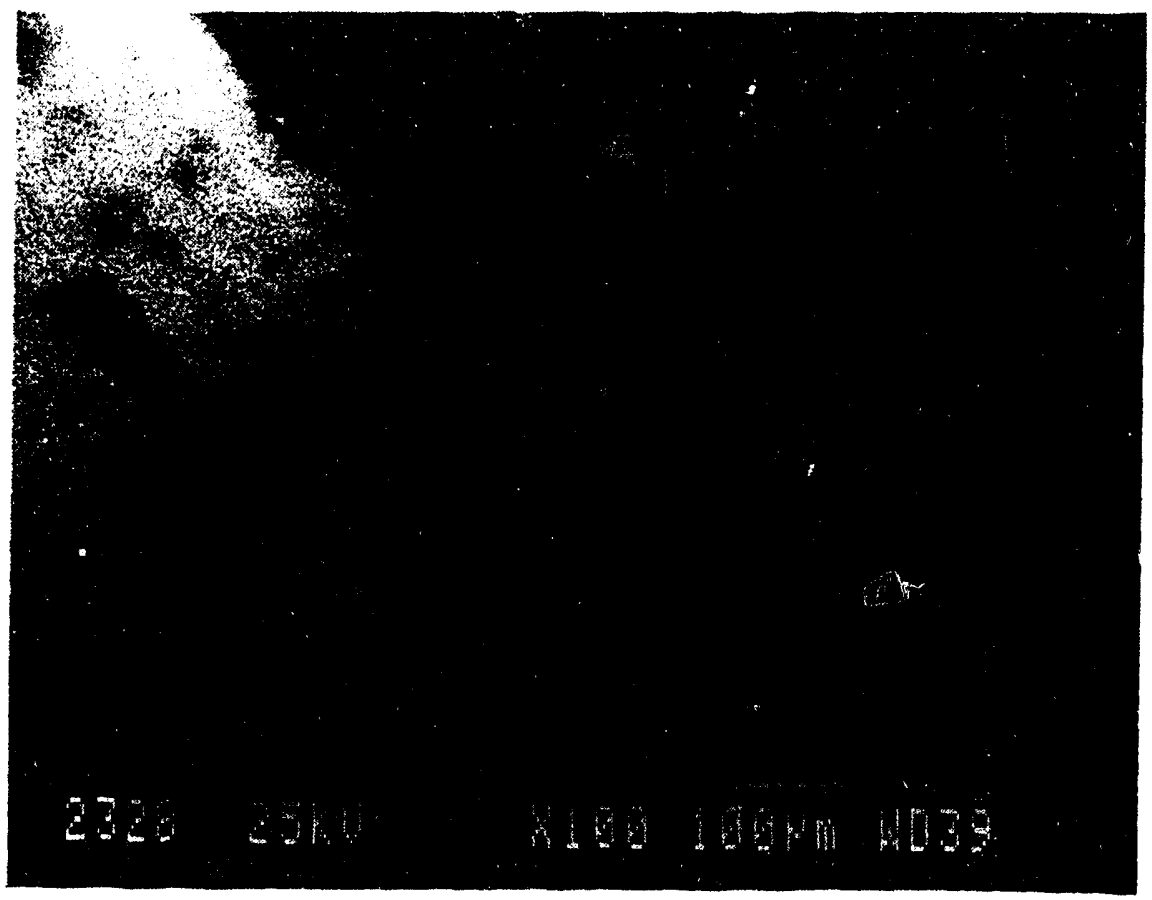

Figure D-7. R-7 dot map of Cr.

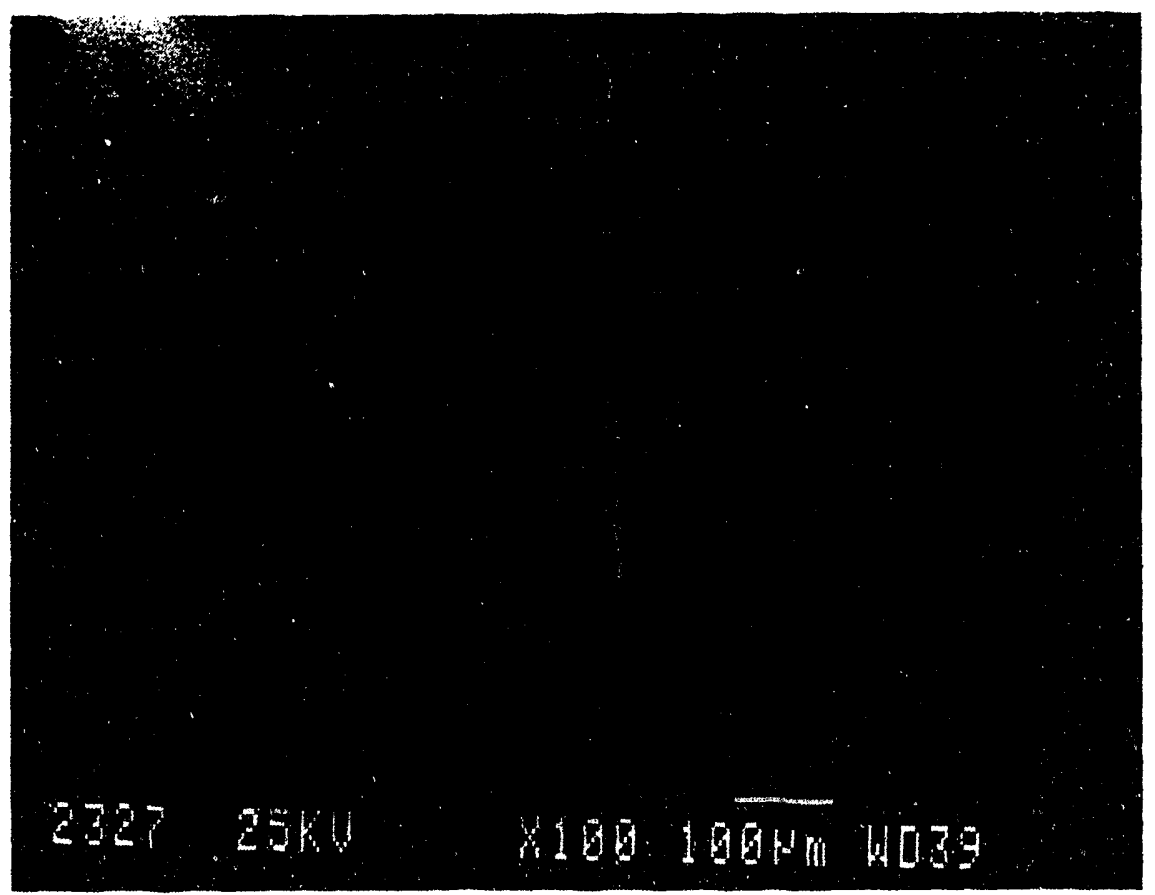

Figure D-8. R-7 dot map of Mn.

D-7 


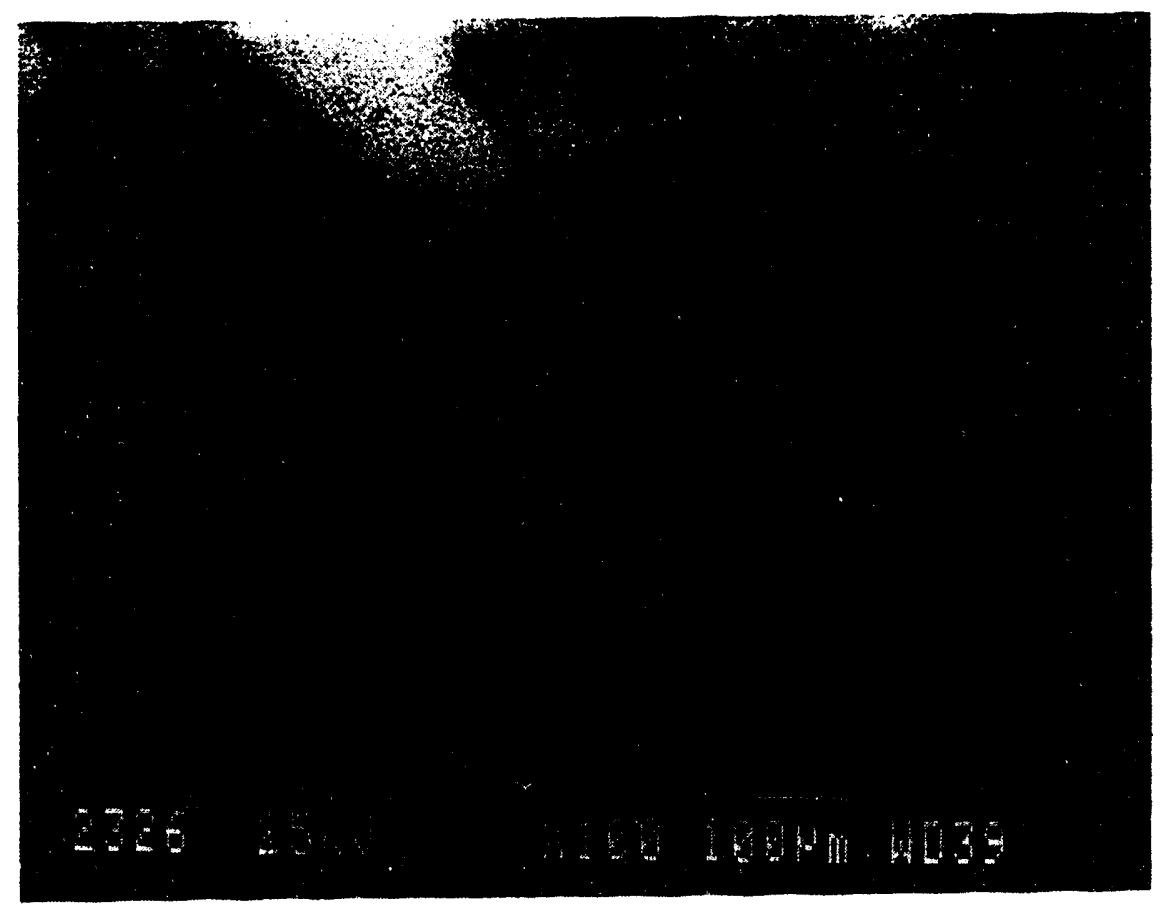

Figure D-9. R-7 dot map of Fe.

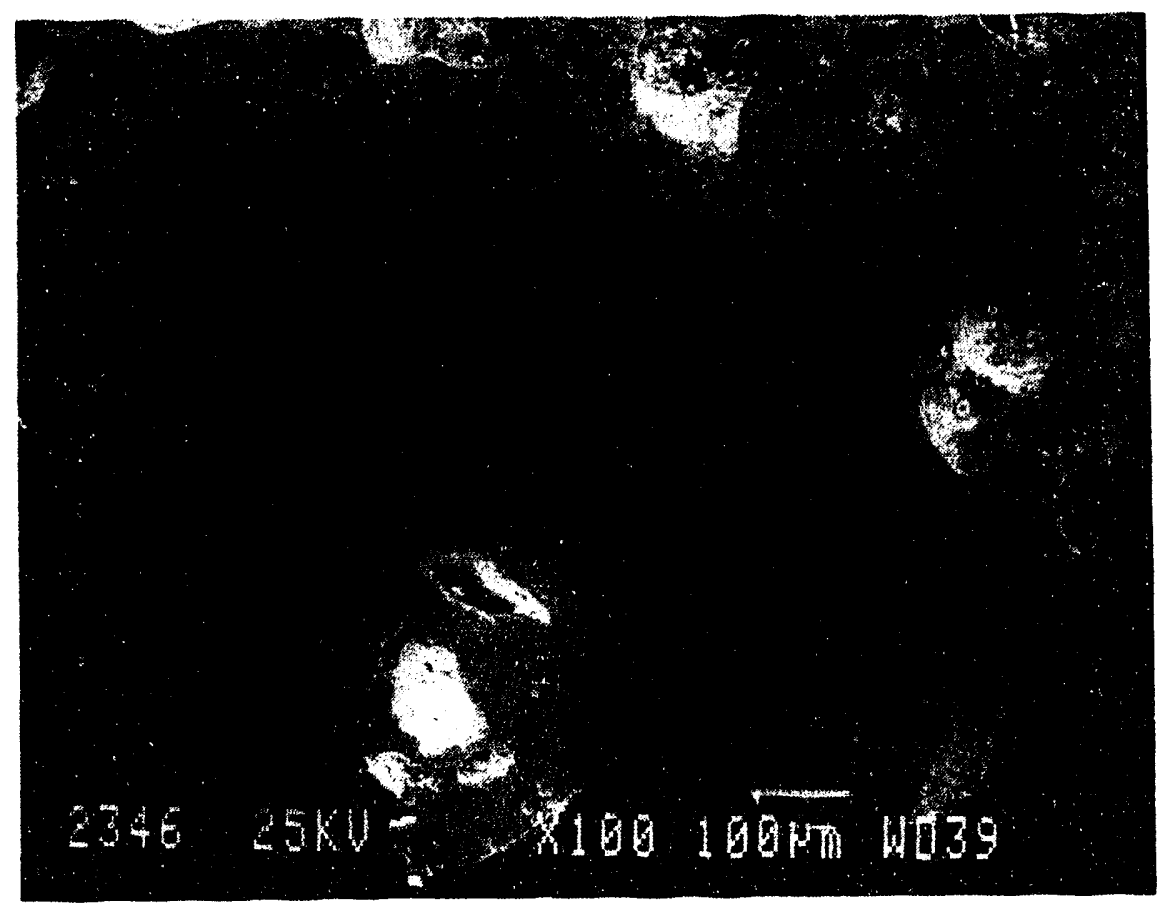

Figure D-10. R-7 instrument string interface. 


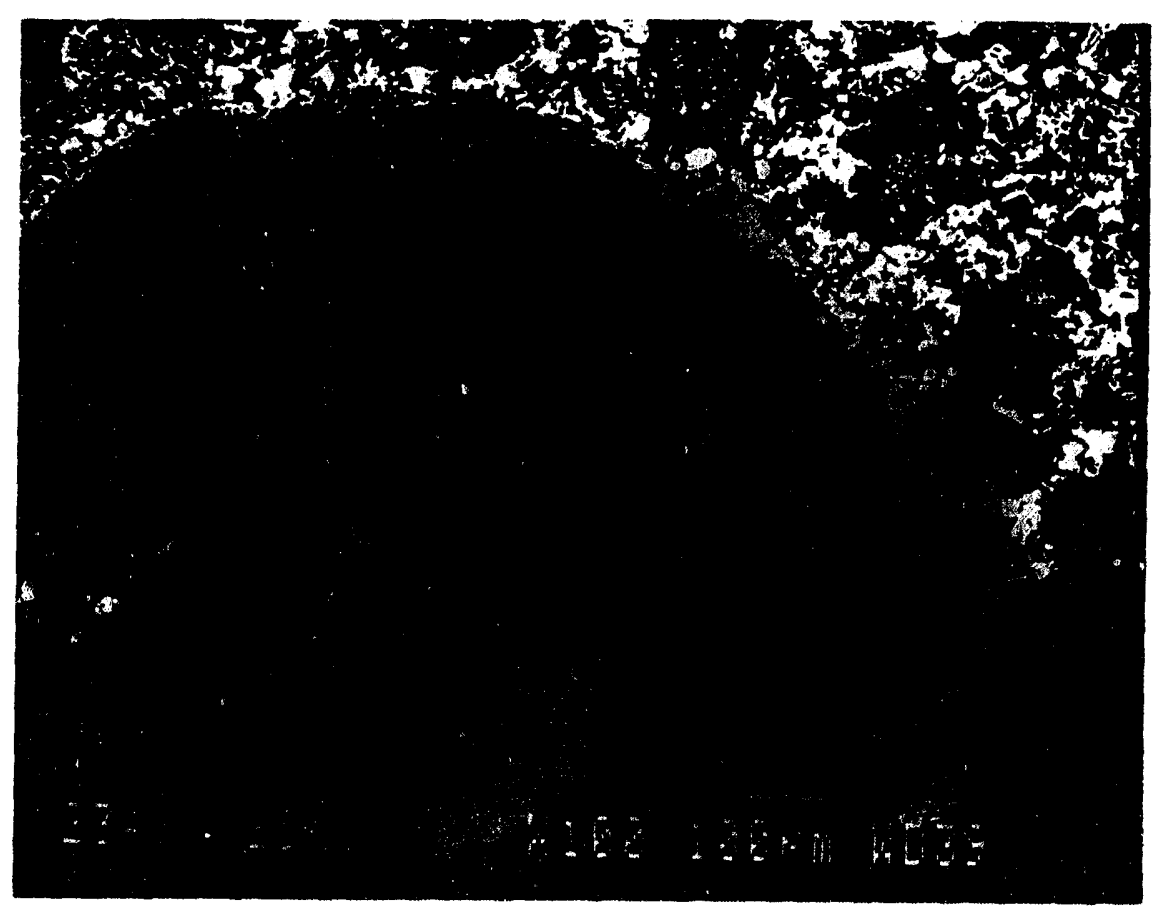

Figure D-11. R-7 instrument string compositional photomicrograph.

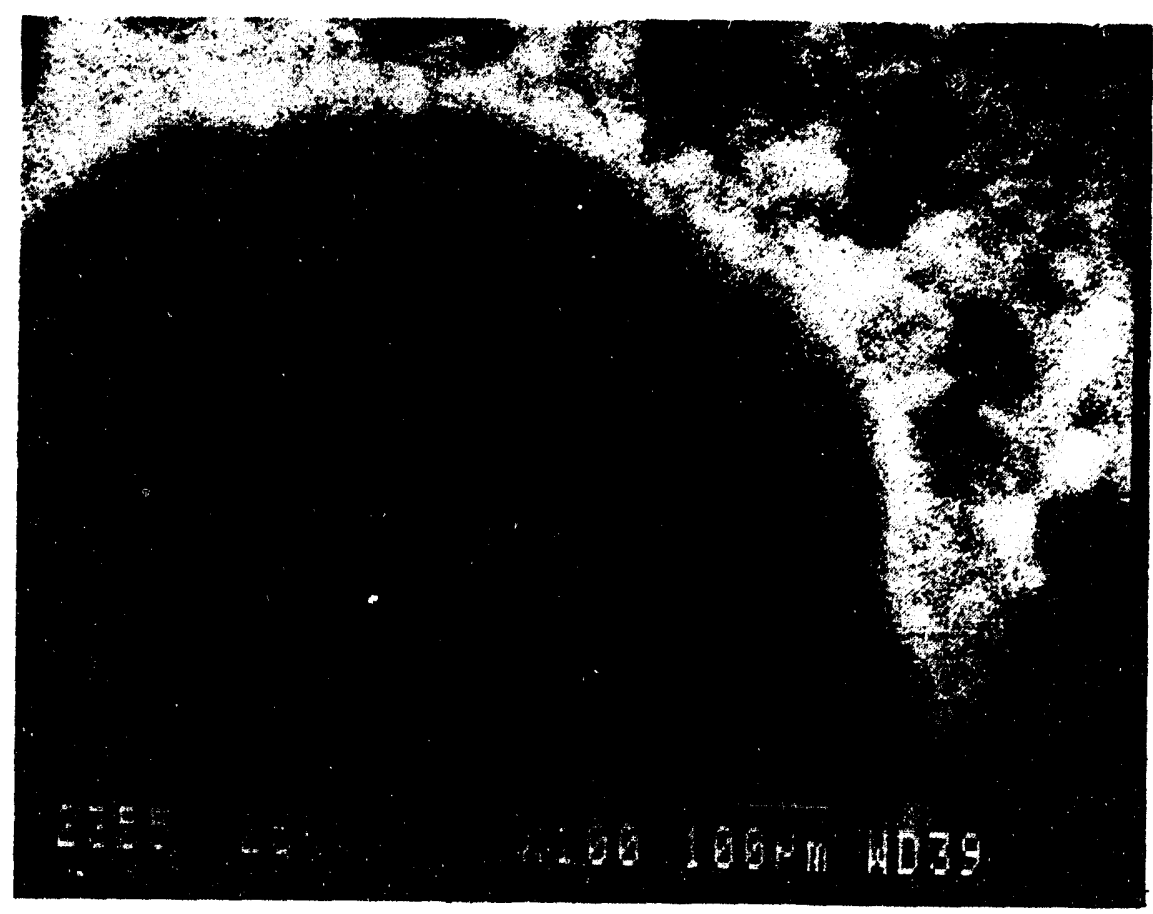

Figure D-12. R-7 instrument string dot map of $U$. 


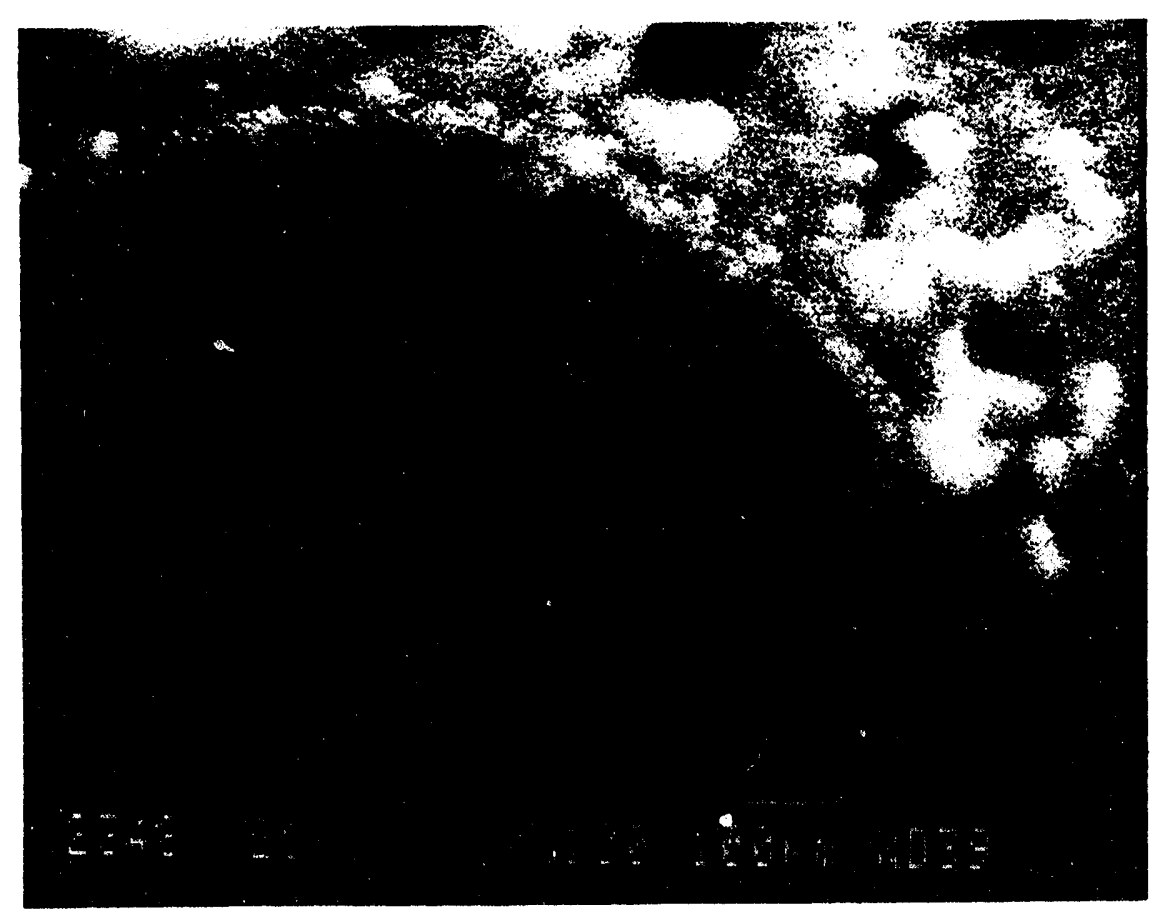

Figure D-13. $R-7$ instrument string dot map of Fe.

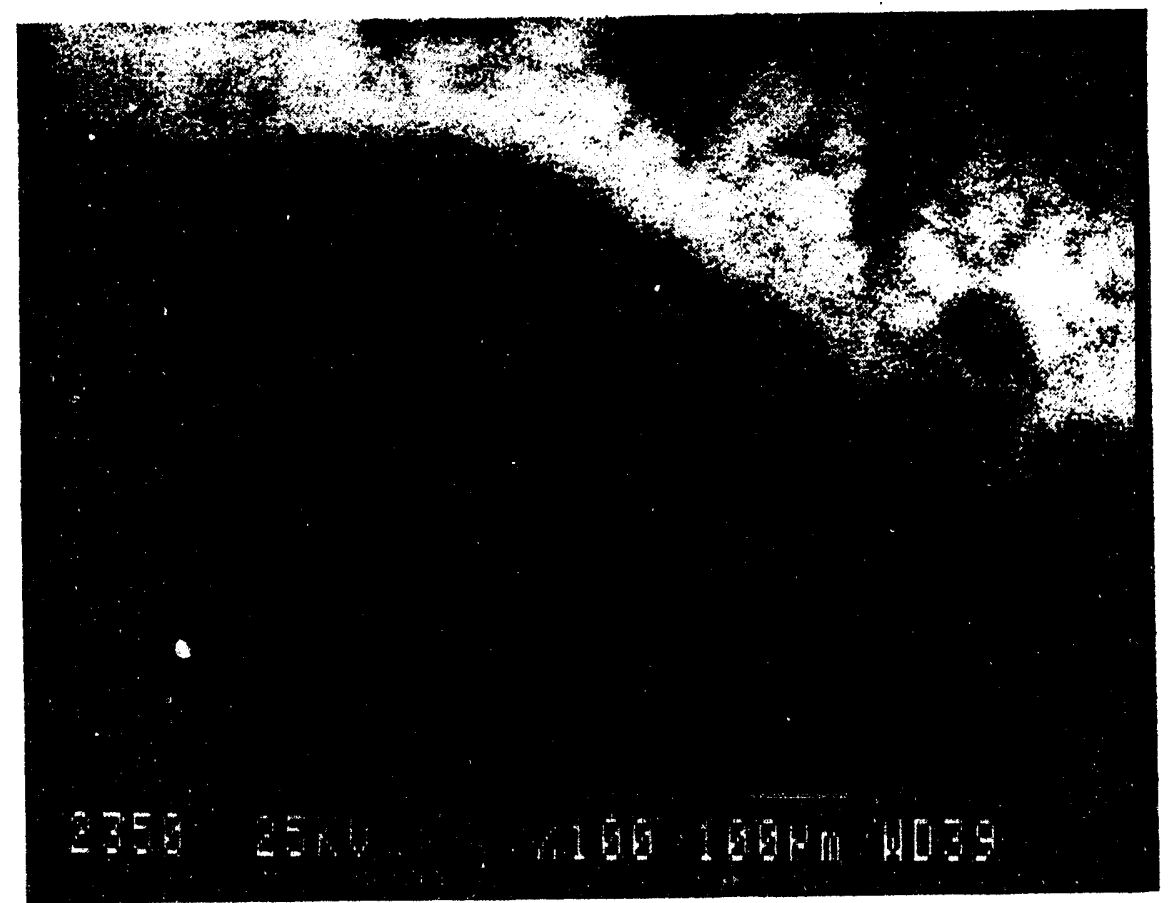

Figure D-14. R-7 instrument string dot map of Cr. 


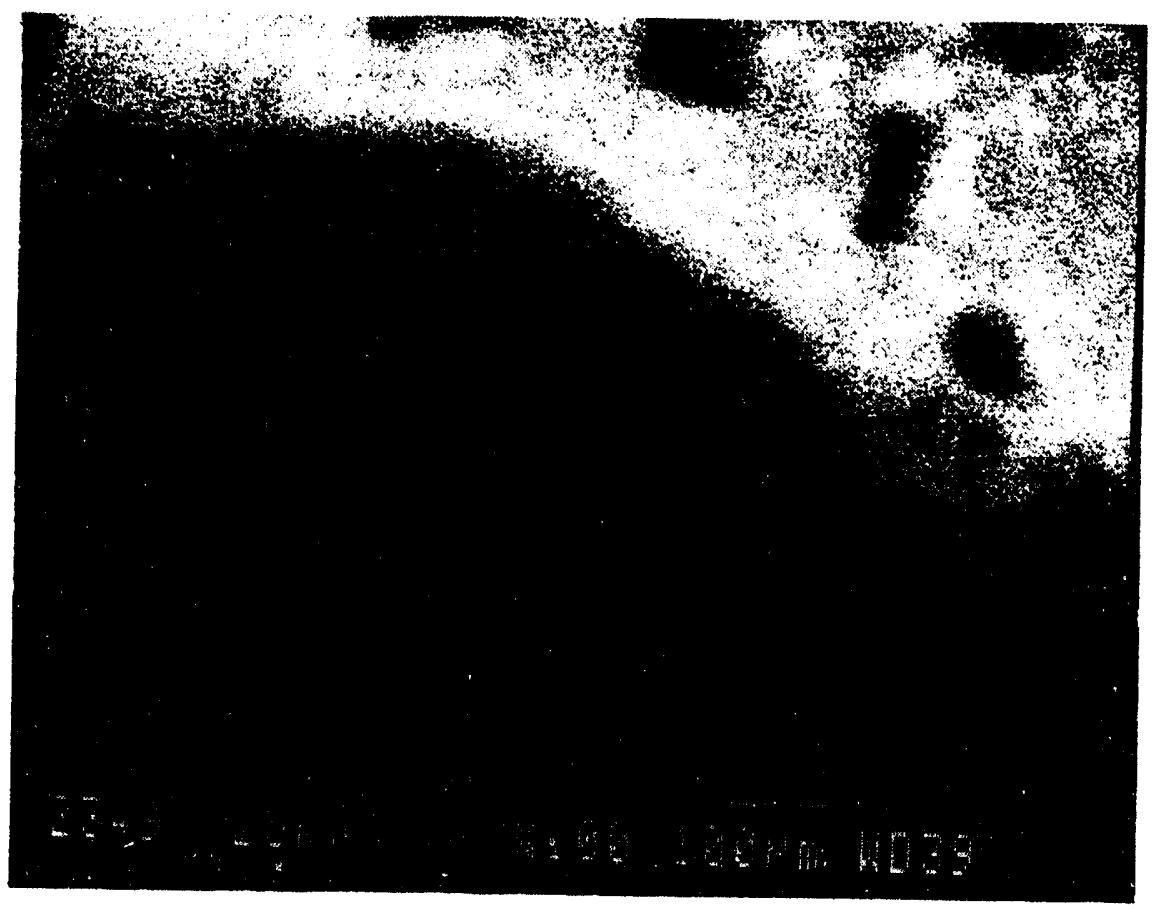

Figure D-15. R-7 instrument string dot map of Mn.

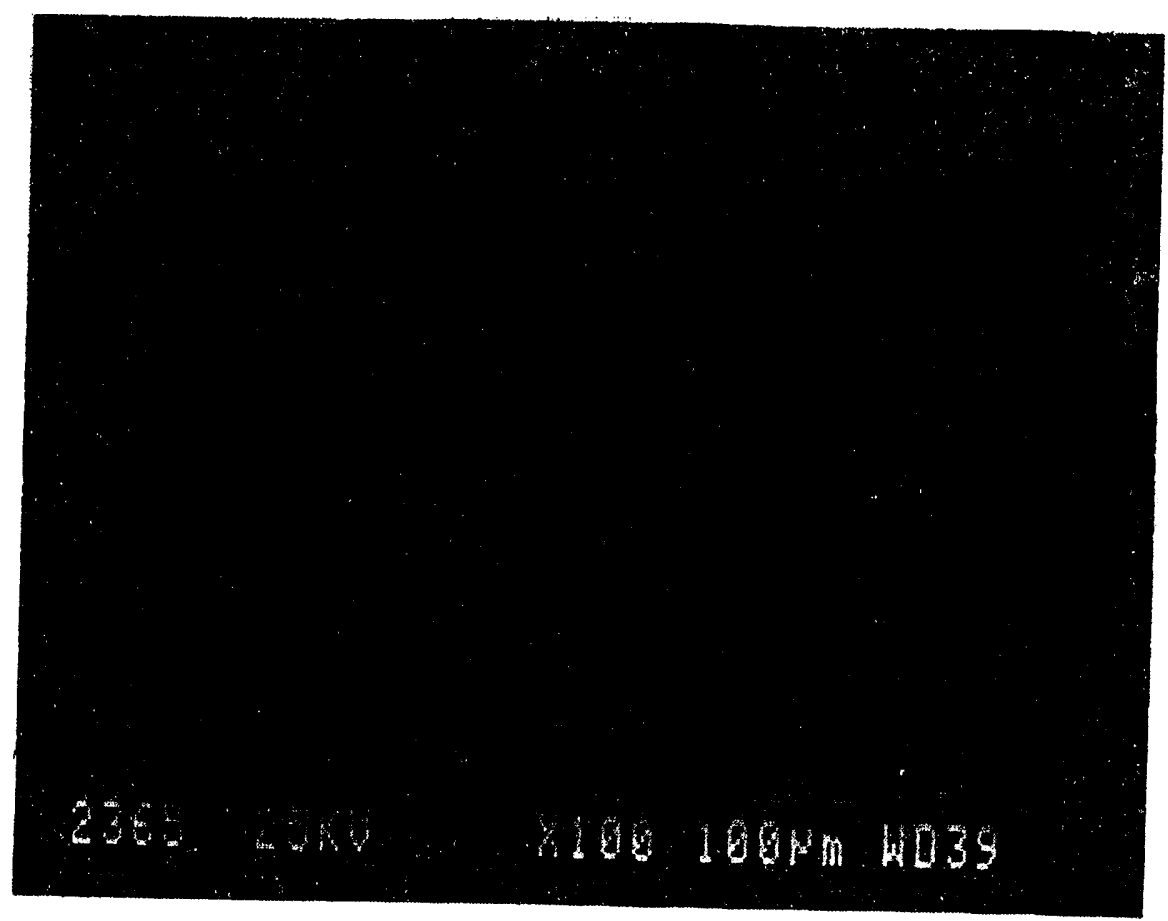

Figure D-16. R-7 instrument string dot map of Ni. 


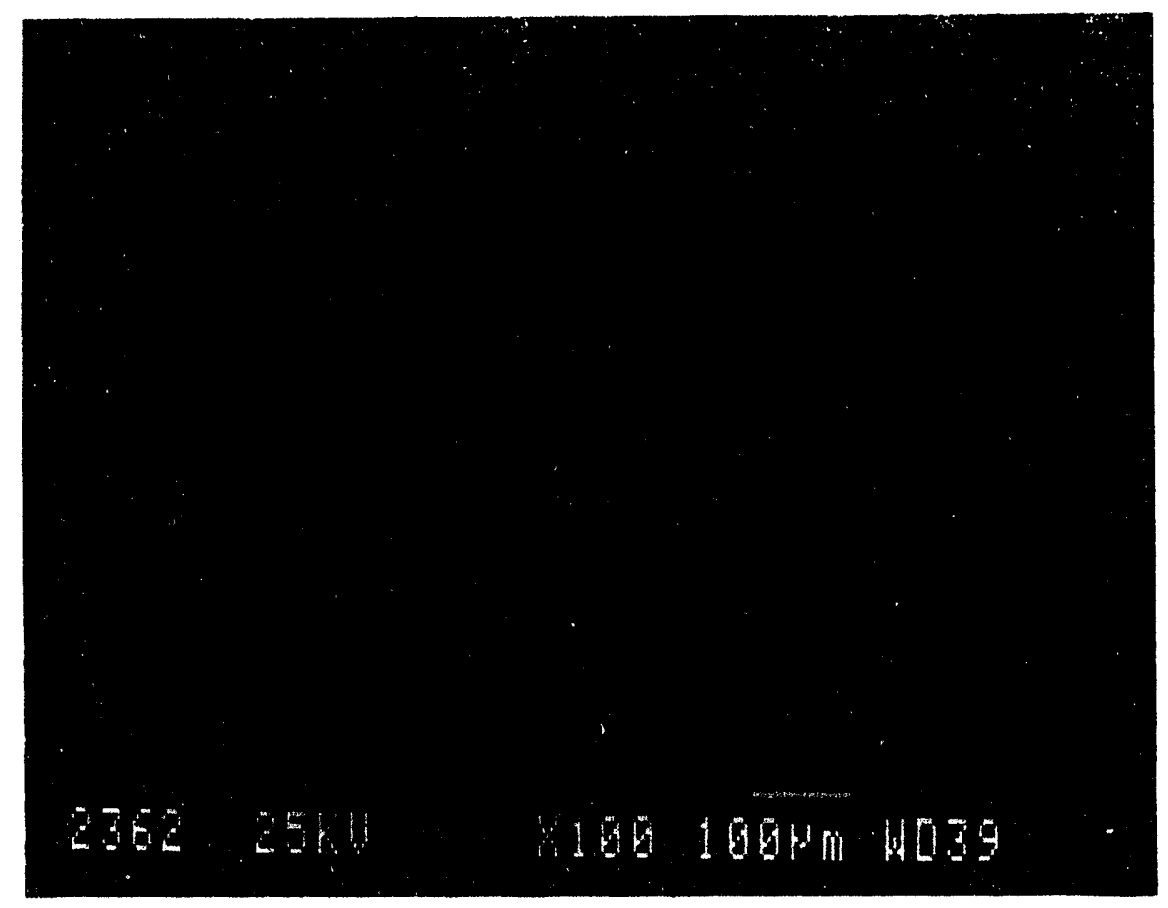

Figure D-17. $\mathrm{R}-7$ instrument string dot map of $\mathrm{Zr}$.

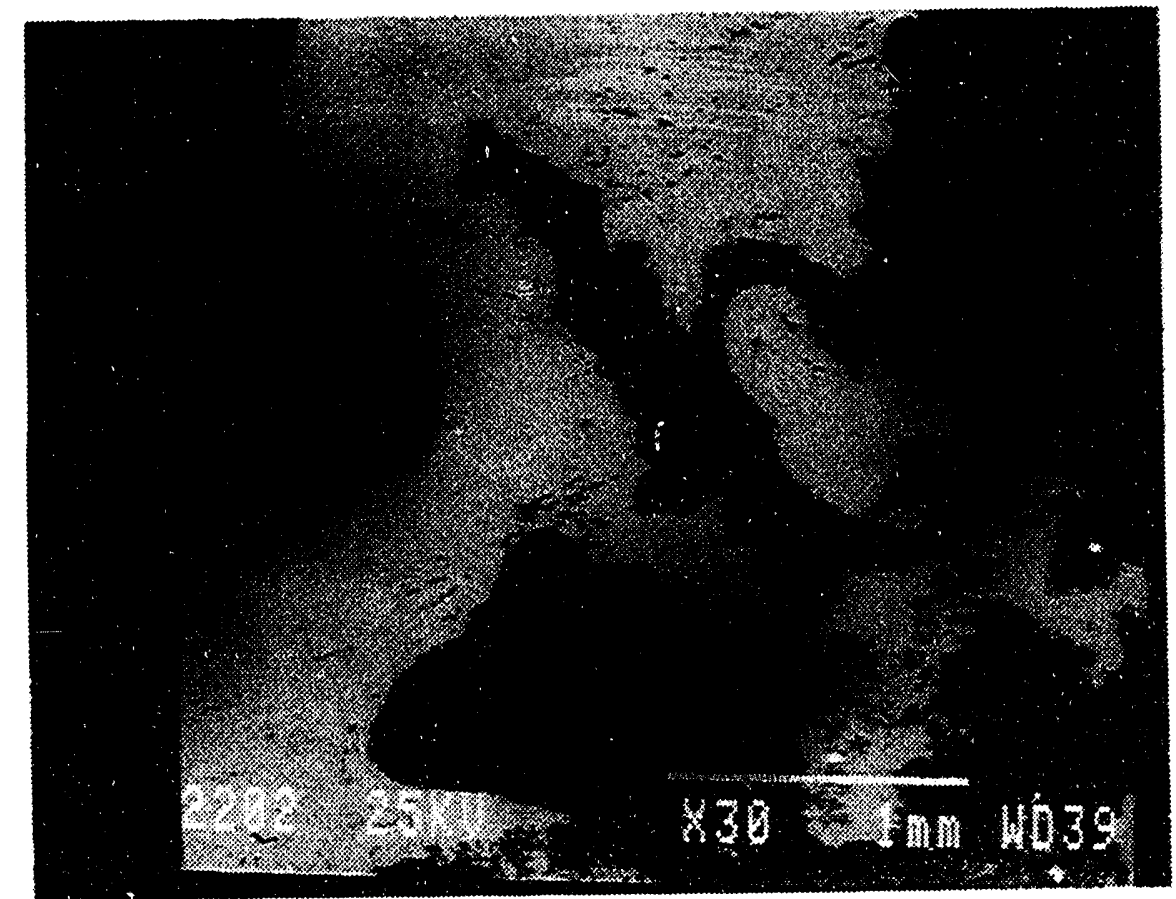

Figure D-18. E-7 cross section compositional (30x). 


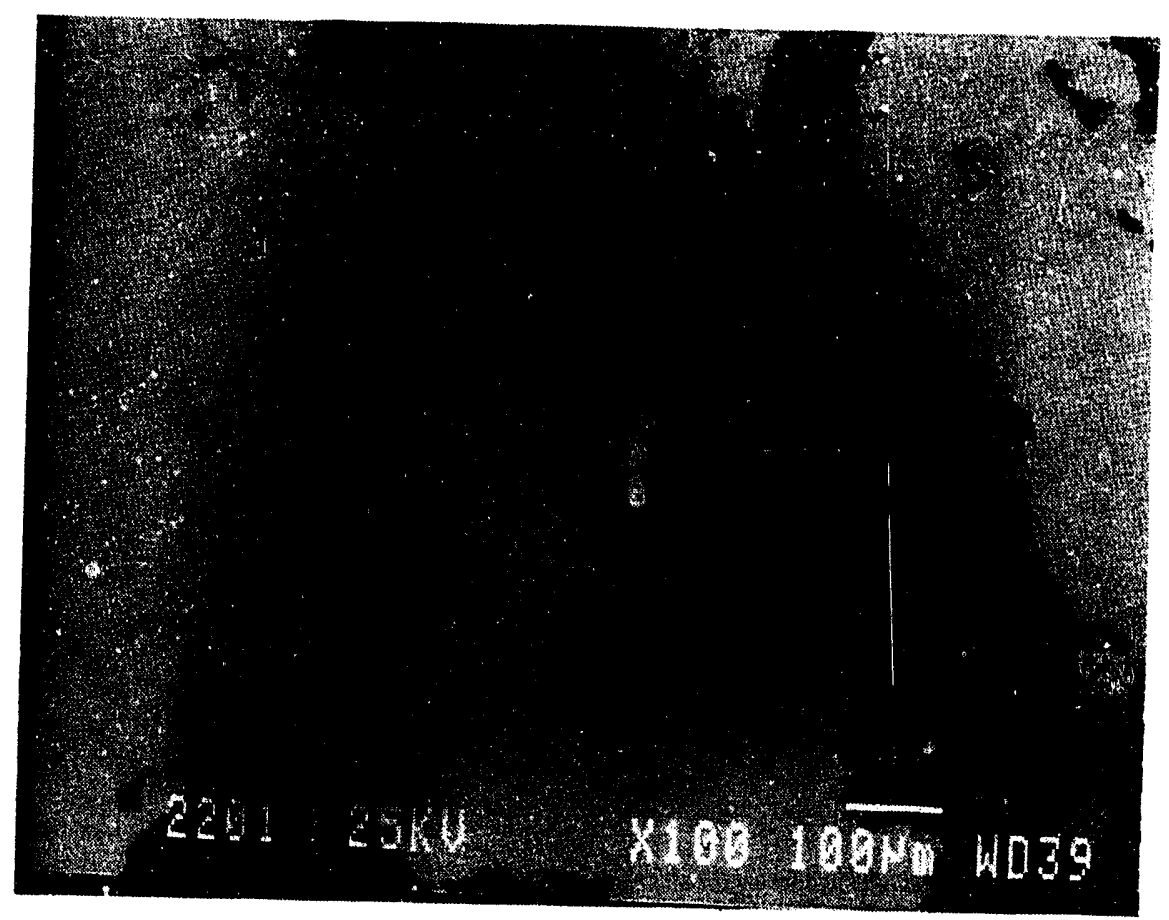

Figure D-19. E-7 cross section compositional (100x).

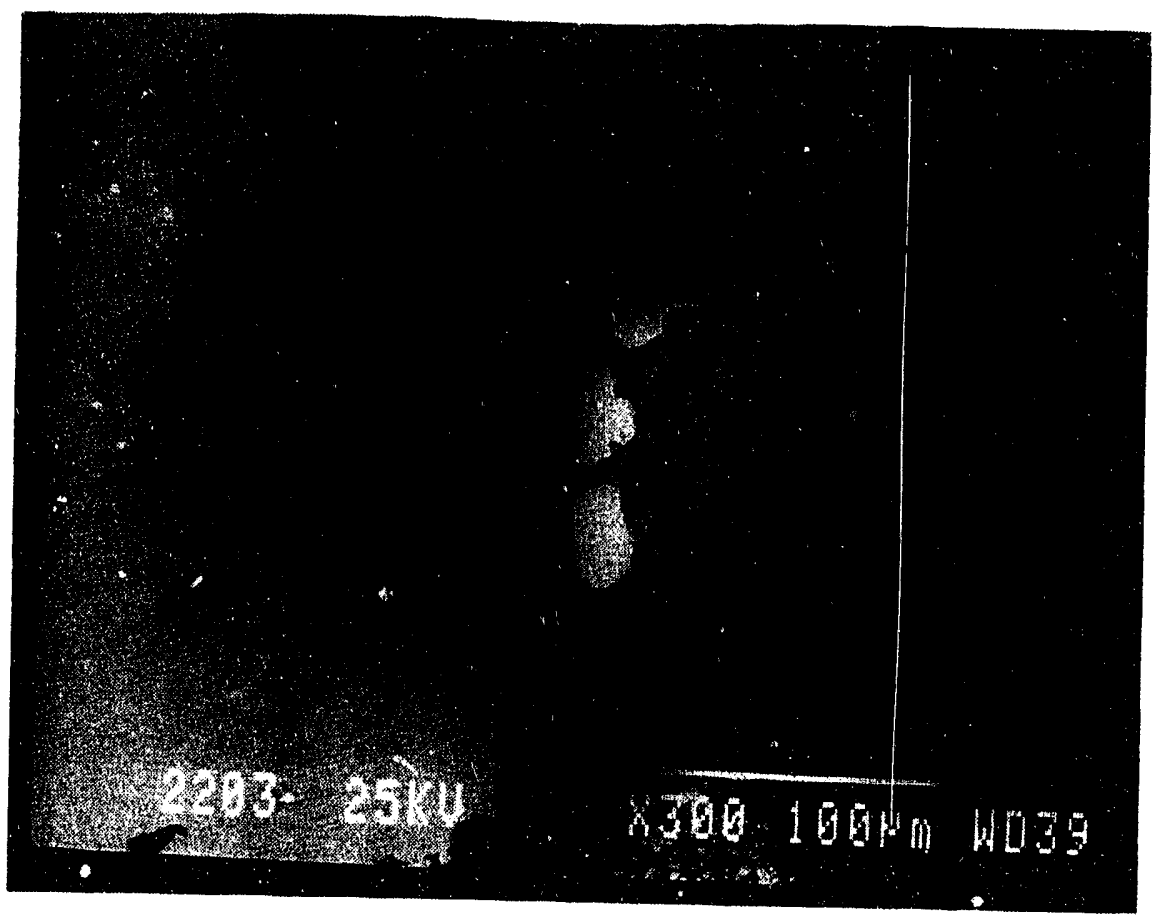

Figure D-20. E-7 cross section compositional (300x). 


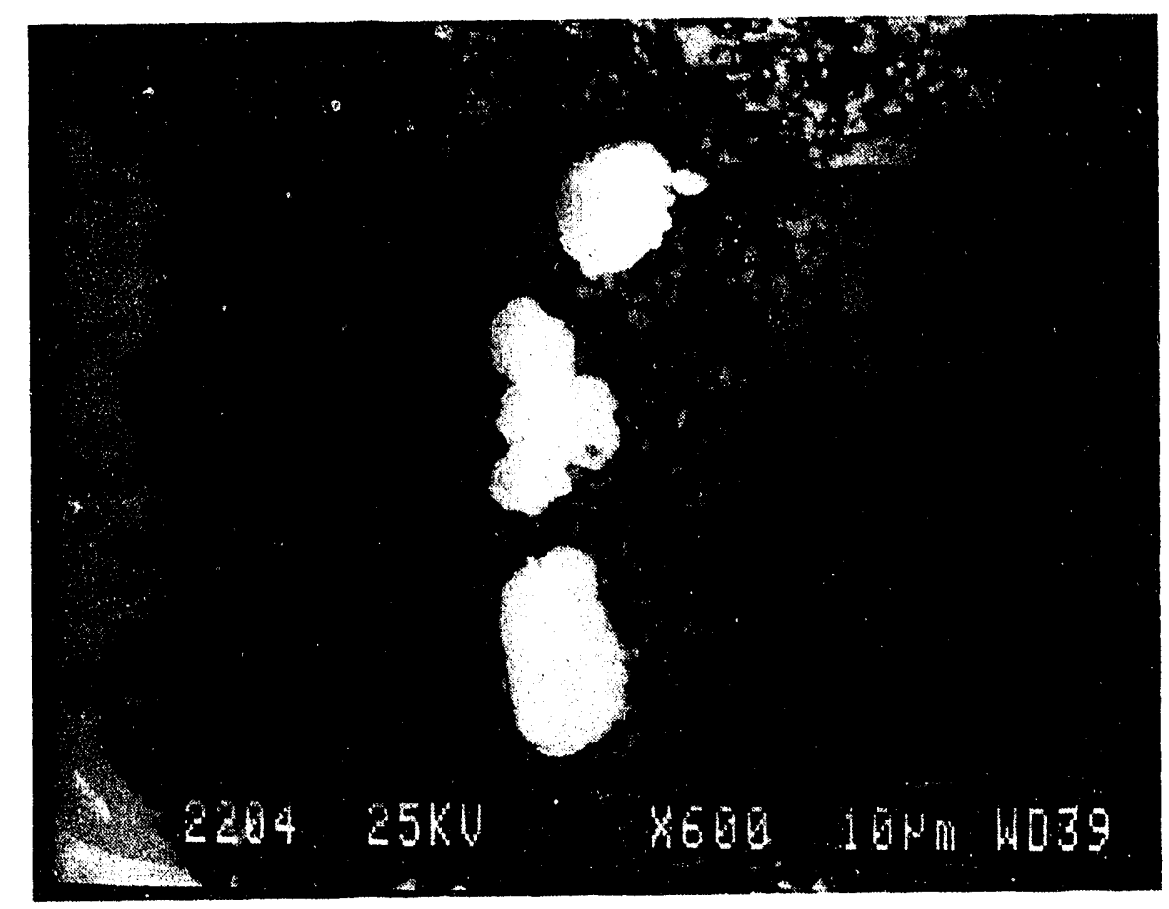

Figure D-21. E-7 cross section compositional (600x).

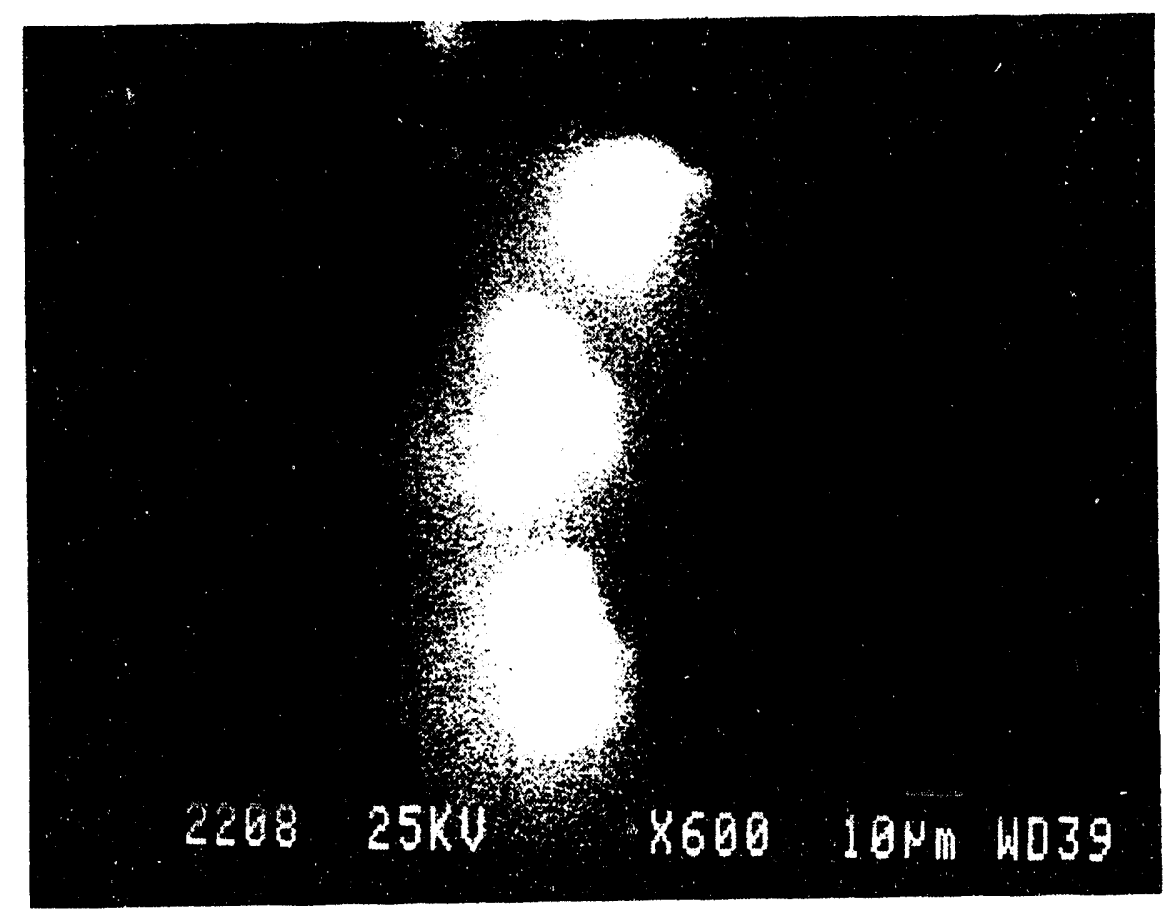

Figure D-22. E-7 dot map of Ag. 

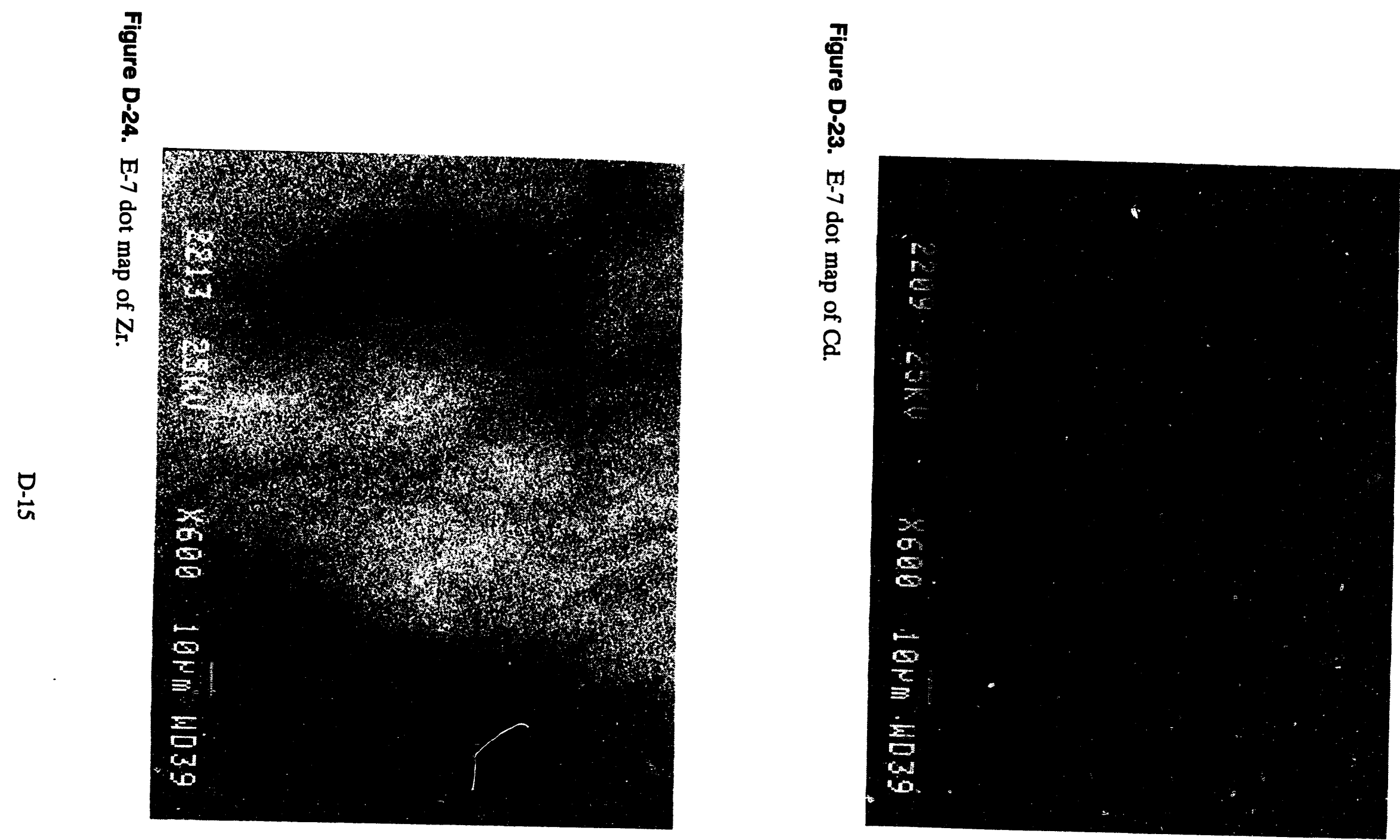


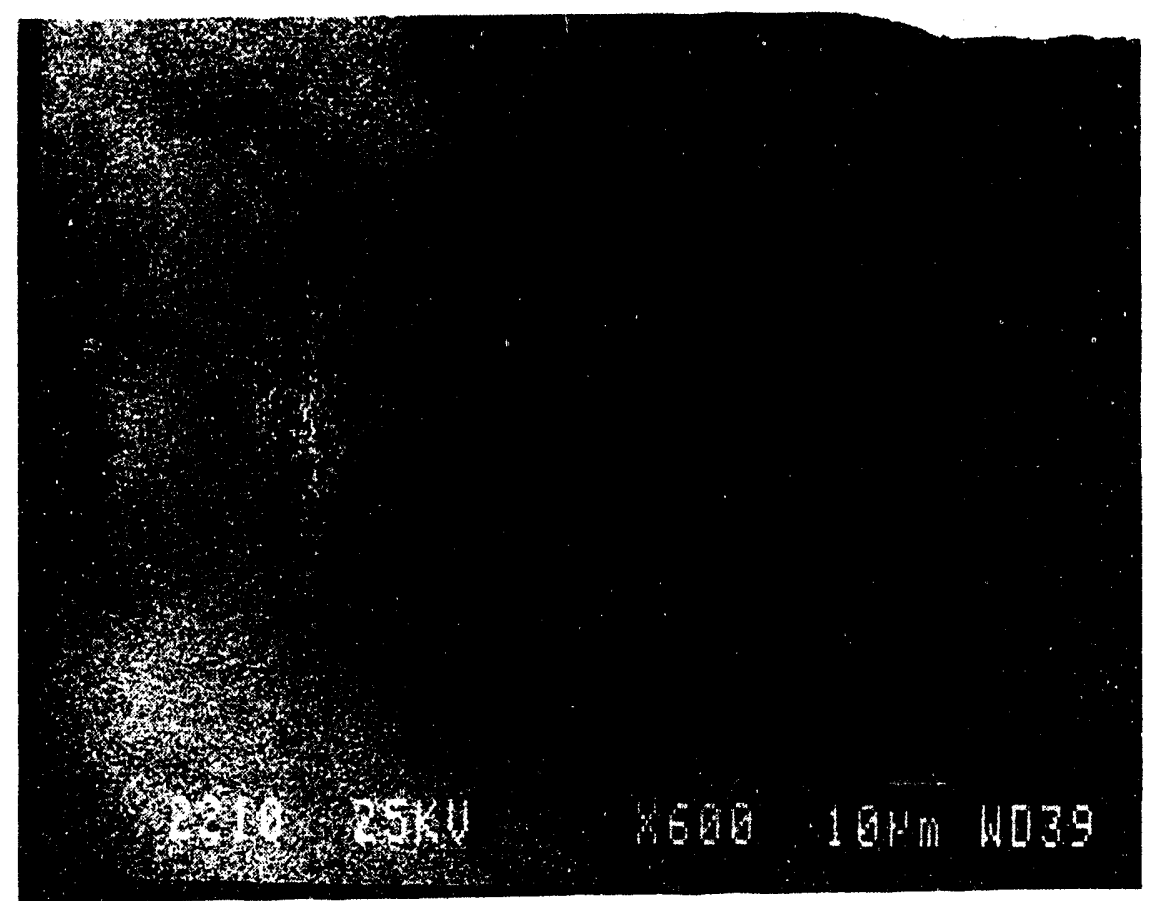

Figure D-25. E-7 dot map of Cr. 


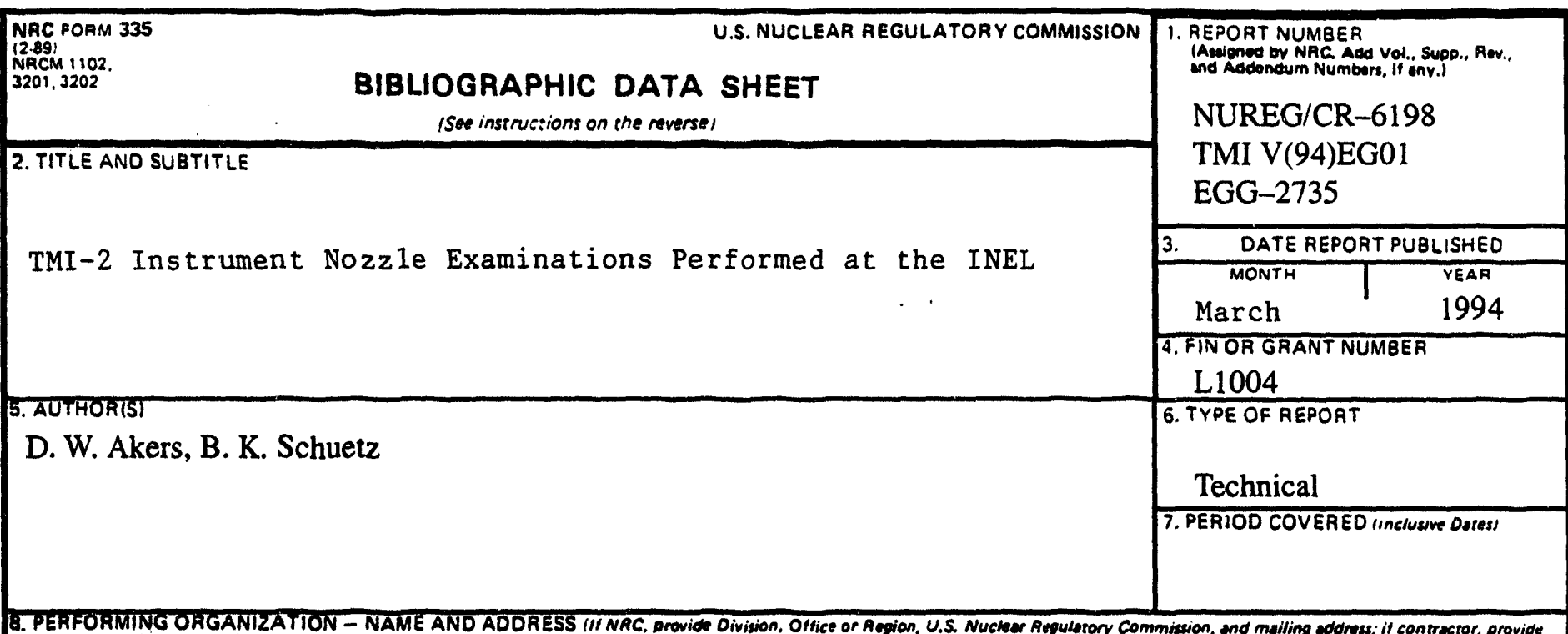

name and matiling codoreas)

EG\&G Idaho, Inc.

Idaho Falls, ID 83415

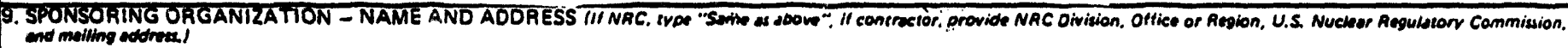

Division of Engineering

Office of Nuclear Regulatory Research

U.S. Nuclear Regulatory Commission

Washington, D.C. 20555-0001

10. SUPPLEMENTARY NOTES

\section{ABSTRACT 1200 words or reas}

As part of the Three Mile Island Unit 2 (TMI-2) Vessel Investigation Project, under the auspices of the Organization for Economic Cooperation and Development, examinations were performed at the Idaho National Engineering Laboratory on eight nozzles and one guide tube from the TMI-2 reactor vessel. This document describes the examination methodology, summarizes the examination results, and presents interpretations of the results as they relate to the damage to the reactor vessel and to the development of a core relocation scenario. Not all examinations originally proposed as part of this program were completed due to facility problems at the INEL. Consequently, only the results of completed aspects of the examination program are presented.

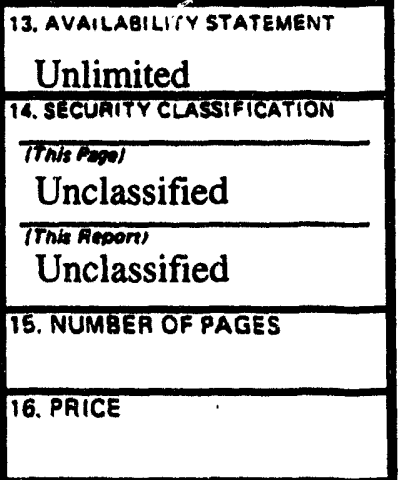



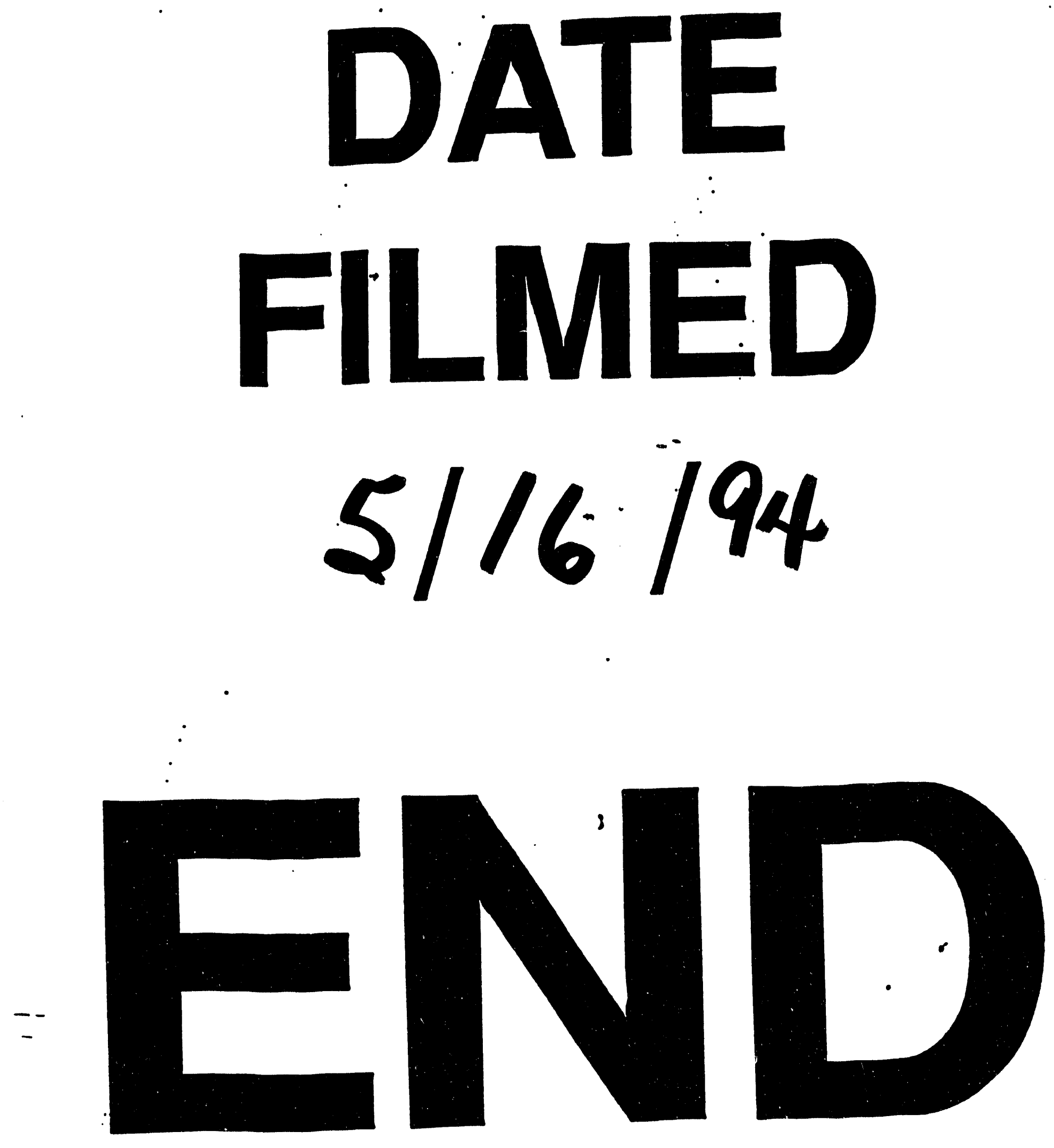
